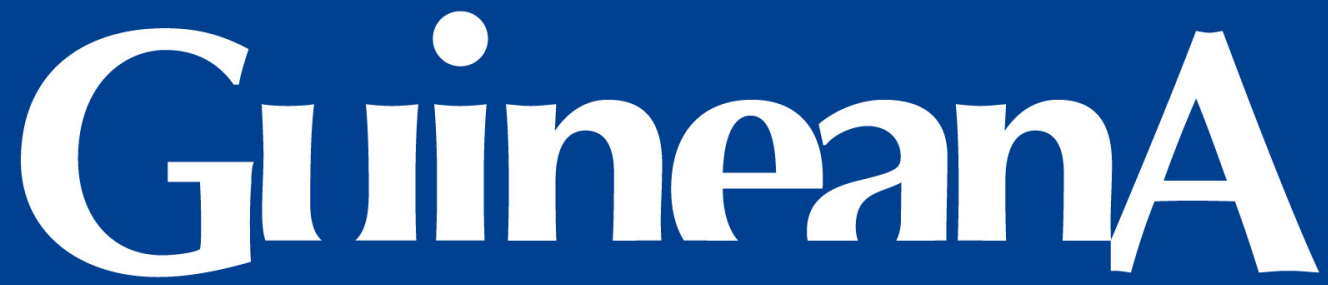

\title{
Vol. 22 - 2017
}

Micobiota de la ZEC Gándaras de Budiño (Pontevedra, N.O. Península Ibérica).

Oscar Requejo \& Marisa Castro

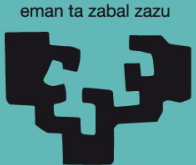

Universidad Euskal Herriko del País Vasco Unibertsitatea 


\section{GuineanA}

\section{Micobiota de la ZEC Gándaras de Budiño (Pontevedra, N.O. Península Ibérica)}

Oscar Requejo \& Marisa Castro

Leioa, 2017

DOI: $10.1387 /$ guineana.20427 


\section{RESUMEN}

Requejo O. ${ }^{1}$ \& Castro M.L. ${ }^{2}$ 2017. Micobiota de la ZEC Gándaras de Budiño (Pontevedra, N.O. Península Ibérica). Guineana 22:1-216.

${ }^{1}$ Grupo Micológico Gallego. San Xurxo, A Laxe 12b, 36470, Salceda de Caseleas. E-mail: oscarequejo@hotmail.com

${ }^{2}$ Facultad de Biología. Campus Lagoas-Marcosende, 36310-Vigo.

E-mail: 1castro@uvigo.es

La Zona de Especial Conservación (ZEC) Gándaras de Budiño está situada en el suroeste de la provincia de Pontevedra (Galicia, Península Ibérica). A pesar de las agresiones sufridas a lo largo de la historia, aún se conservan zonas muy representativas de esta con fauna y flora propia de estos lugares y poco frecuente en el resto del N.O. peninsular.

Ocupa una extensión de aproximadamente 800 ha, en las que destacan un amplio complejo de humedales, conformados por turberas, brañas, bosques aluviales y lagunas, así como brezales atlánticos, bosques de ribera y amplias extensiones más secas, constituidas básicamente por bosques mixtos de robles y pinos. En este espacio se realiza un estudio micológico con recolecciones periódicas durante 4 años, de las cuales resulta un catálogo con 359 taxa, con una aportación al catálogo gallego de 62 especies.

Entre ellas destaca Chaetotyphula actinipes, que se menciona por primera vez para Europa, además de Arnium olerum, Byssosphaeria schiedermayeriana, Conocybe brachypodii, Cordyceps polyarthra, Hemimycena angustispora, Inocybe salicis, Laccaria impolita, Mollisia olivascens, Mycena atrovinosa, Mycena mucor, Oligoporus alni, Russula sphagnophila y Trichoderma piluliferum, no mencionados anteriormente para la Península Ibérica.

Desde el punto de vista de la estrategia trófica destacan las especies entomapatógenas: Beauveria bassiana, Cordyceps polyarthra, Gibellula pulchra, Isaria farinosa y Torrubiella arachnophila. De las restantes 125 son micorrícicas, 211 son saprotróficas y 38 necrotróficas, en ambos casos, mayoritariamente lignícolas, justificado porque las $3 / 4$ partes del material ha sido recolectado en formaciones arbóreas de Alnus glutinosa y Salix atrocinerea.

Además, se analiza la autoecología de las especies, los patrones de fructificación y su aportación corológica, tanto ibérica como mundial.

Palabras clave: micobiota, Ascomycota, Basidiomycota, humedales, turberas, bosques hidrófilos, Galicia, Península Ibérica. 


\section{ABSTRACT}

Requejo O. \& Castro M.L. 2017. Mycobiota of the SAC Gándaras de Budiño (Pontevedra, NW. Iberian Peninsula). Guineana 22:1-216.

The Special Area of Conservation (SAC) Gándaras de Budiño is located in the southwest of the province of Pontevedra (Galicia, Iberian Peninsula). In spite of the aggressions suffered throughout the history, still very representative zones of this one are conserved with fauna and flora own of these places and infrequent in the rest of NW Iberian Peninsula.

It occupies an area of approximately 800 ha, which includes a large complex of wetlands (bogs, braves, alluvial forest and lagoons) as well as atlantics heaths, riverbank forest and more dry areas, consisting basically of mixed oak and pine forests.

In this space, a mycological study is carried out with periodic collections for 4 years, resulting in a catalog with 359 taxa, with a contribution to the Galician catalog of 62 species.

Among them is Chaetotyphula actinipes, which is mentioned for the first time in Europe, in addition to Arnium olerum, Byssosphaeria schiedermayeriana, Conocybe brachypodii, Cordyceps polyarthra, Hemimycena angustispora, Inocybe salicis, Laccaria impolita, Mollisia olivascens, Mycena atrovinosa, Mycena mucor, Oligoporus alni, Russula sphagnophila and Trichoderma piluliferum, not mentioned above for the Iberian Peninsula

From the point of view of the trophic strategy the entomopathogenic species stand out: Beauveria bassiana, Cordyceps polyarthra, Gibellula pulchra, Isaria farinosa, and Torrubiella arachnophila. Of the remaining 125 are mycorrhizal, 211 are saprotrophic and 38 necrotrophic, in both cases, mostly lignicolous, justified because $3 / 4$ parts of the material has been collected in tree formations of Alnus glutinosa and Salix atrocinerea.

In addition, we analyze the autoecology of the species, the fruiting patterns and the chorological contribution, both Iberian and worldwide.

Key words: mycobiota, Ascomycota, Basidiomycota, wetlands, peatlands, alluvial forest, Galicia, Iberian Peninsula. 


\section{ÍNDICE}

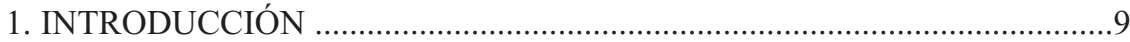

2. DESCRIPCIÓN DE LA ZONA DE ESTUDIO .........................................13

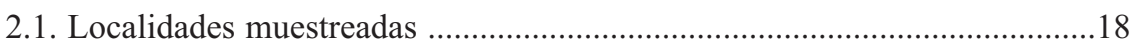

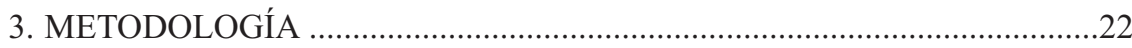

3.1. Recolección y conservación de colecciones ................................................22

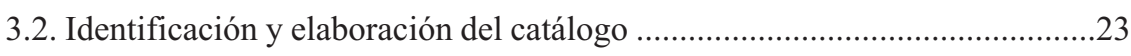

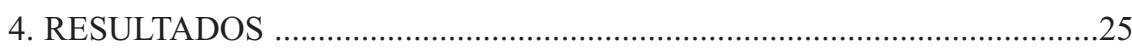

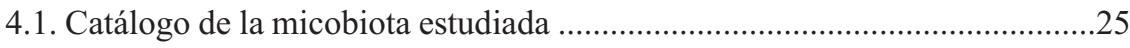

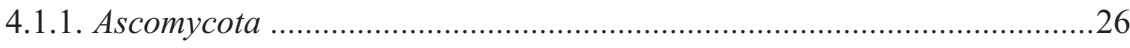

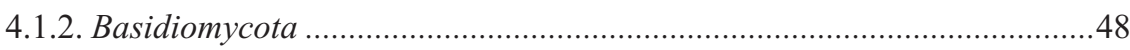

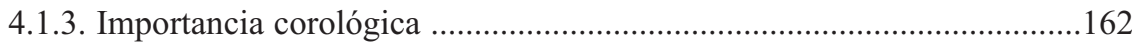

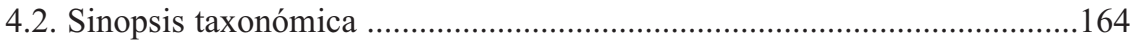

4.2.1. Ubicación taxonómica de los géneros del phyllum Ascomycota catalogados en las Gándaras de Budiño .164

4.2.2.Ubicación taxonómica de los géneros del phyllum Basidiomycota

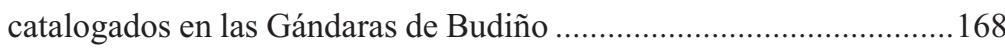

5. AUTOECOLOGÍA, FENOLOGÍA Y MICOCENOSIS................................177

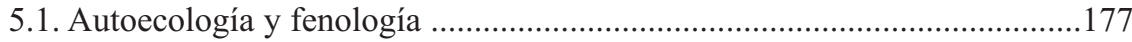

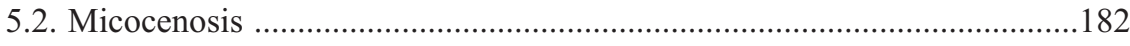

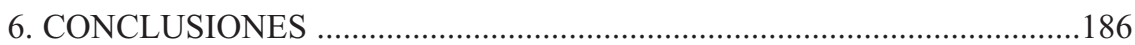

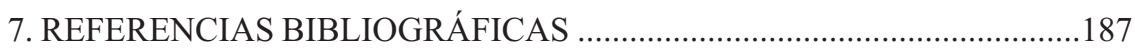

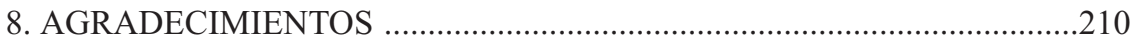

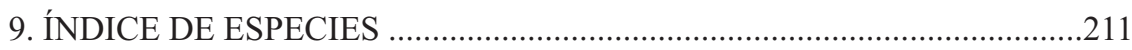


Introducción

\section{INTRODUCCIÓN}

Los humedales ocupan entre el $4-6 \%$ de la superficie de la tierra (Hernández 2010) y se diferencian varios tipos según el aporte de agua, la localización o el tipo de vegetación existente, con lo que una definición única de humedal resulta difícil. Según el Convenio de Ramsar "en los humedales se incluye una amplia variedad de hábitat tales como pantanos, turberas, llanuras de inundación, ríos y lagos, y áreas costeras tales como marismas, manglares y praderas de pastos marinos, pero también arrecifes de coral y otras áreas marinas cuya profundidad en marea baja no exceda de seis metros, así como humedales artificiales tales como estanques de tratamiento de aguas residuales y embalses". $\mathrm{Su}$ importancia radica en que pueden ser considerados los medios más productivos del planeta, ya que representan una permanente fuente de agua y asocian una elevada, variada y altamente especializada biodiversidad.

Históricamente los humedales se han destruido por acciones antropogénicas, tales como extracción de turba para combustible en los siglos XVIII y XIX, por supersticiones asociadas como la existencia de ciudades sumergidas en ellos, o por considerarse zonas insalubres, verdaderos criaderos de mosquitos portadores de numerosas enfermedades. Esta forma de pensar ha sido la responsable del desecado y relleno para intentar erradicar la malaria a principios del siglo XX (Moreau 1992). Además, la aparición de maquinaria para labores agrícolas, silvicultura intensiva ha facilitado el acceso a ellos y, llegados a este punto, el aumento demográfico también ha actuado en contra de estos medios.

A mediados del siglo $\mathrm{XX}$, naturalistas e investigadores identificaron estos ambientes como fuente de vida y riqueza natural, y alertaron sobre el peligro que corrían si no se protegían (Favre 1948). Galicia es la región con más humedales registrados de la Península Ibérica (Gómez-Orellana et al. 2014), por ello no sorprende que desde 1900 se haya intentado conocer, defender y aprovechar esa riqueza (García-Bobadilla Prósper et al. 2002). Y, ante la fragilidad de estos hábitats y el acoso demográfico sobre ellos, en el último cuarto del siglo XX se desarrollan acciones internacionales que intentan protegerlos.

En 1971 se celebró en Ramsar (Irán) la Convención relativa a los Humedales de Importancia Internacional especialmente como Hábitat de Aves Acuáticas, que actualmente se conoce como Convención sobre los Humedales o Convención de Ramsar, y, en 1992 se crea la Directiva relativa a la conservación de los hábitats naturales y de la fauna y flora silvestres (Directiva Hábitat) con sus figuras de protección: Zonas Especiales de Conservación (ZECs) y Zonas de Especial Protección para las Aves (ZEPAs), que forman una red de lugares protegidos a través de Natura 2000 (Red Natura 2000). 
Esta protección conlleva mayor información a la población, lo que permite sean espacios más valorados en la actualidad y que la población empiece a conocer sus beneficios como lugares de almacenamiento y depuración de agua, estabilización y control de la erosión, recarga/descarga de acuíferos, acúmulo de nutrientes, etc... (Secretaría de la Convención de Ramsar 2006). Son una de las más importantes reservas de carbono del mundo, lo que los convierte en fundamentales en la lucha contra la aceleración del cambio climático (GómezOrellana et al. 2014) y, en condiciones ecológicas tan características se desarrolla una biodiversidad diferente, tanto faunística como florística, en consecuencia, también micológica, ya que las especies de hongos dependen de la vegetación circundante (Arnolds 2007).

Como organismos heterótrofos que son, los hongos dependen de su entorno para obtener la materia orgánica necesaria para su desarrollo. Algunos animales consiguen realizar su aporte orgánico, pero son especialmente las plantas las que lo hacen, ya sea entre los hongos saprotróficos (hojarasca, ramillas o troncos procedentes de árboles muertos) como los biotróficos (mutualistas micorrícicos y parásitos). Este proceso de aprovechamiento orgánico se lleva a cabo tanto por micromicetos, hongos que no producen cuerpos fructíferos visibles a simple vista, como por macromicetos, los que tienen capacidad para formar setas, es decir ascomas y basidiomas aparentes.

Conocer y analizar la mayor cantidad de datos sobre su biodiversidad en los diversos hábitats es de vital importancia, por ello, el estudio de los macromicetos, gestores naturales del medio natural debido, en buena medida, a sus tipos de nutrición: biotrófica o saprotrófica, ayudan en la regulación y reciclaje de restos orgánicos y fomentan/ayudan a continuar el ciclo biológico de otros seres vivos (Favre 1948), aunque resulte muy difícil evaluar la actividad biológica específica por micotopo (Baldrian et al. 2013).

En Galicia, las zonas húmedas han sido ampliamente caracterizadas (García-Bobadilla Prósper et al. 2002) y estudiadas desde el punto de vista faunístico y florístico (Silva-Pando et al. 1987, Cordero Rivera 2007, PérezBilbao \& Garrido 2009, Romero Pedreira 2015, entre otros). Sin embargo, a pesar de que se trata de medios que permanecen húmedos la mayor parte del año, ricos en materia orgánica de procedencia leñosa y briofítica (Sphagnum) y en los que la única limitación ecológica para la producción de macromicetos son las bajas temperaturas invernales, sólo se encuentran menciones a macromicetos de humedales de forma aislada e incluidas en trabajos de carácter general (Rodríguez-Vázquez \& Castro 2016). La única mención específica a estos medios es el trabajo de Romero-Pedreira \& Sahuquillo-Balbuena (2007) referido a tres hongos de turberas: Mitrula paludosa Fr.: Fr., Galerina hypnorum (Schrank: Fr.) Kühner y Omphalina sp. 
Debido a la acción antrópica en estos medios se han provocado fuertes alteraciones que dejan paso a zonas, más o menos permanentemente, desecadas, pero en las que se conserva flora arbórea de humedales como Salix atrocinerea o Alnus glutinosa, entre los que van incorporándose otras especies de lugares más secos como Quercus robur y Pinus pinaster, con su cortejo micológico asociado. Además, en estos lugares se pueden observar brañas totalmente desecadas por colmatación y posterior floración del Pinus pinaster sobre ellas, en las que se van implantando matorrales, más o menos higrófilos con capas freáticas próximas a la superficie durante el período invernal. Todo ello contribuye a que la diversidad fúngica sea elevada (Pinna et al. 2010).

Los espacios menos antropizados conservan su capa freática más alta y la humedad es persistente durante casi todo el año. La vegetación puede presentar comunidades vegetales con estrato arbóreo o solamente herbáceo.

En el primer caso, saucedas, alisedas, choperas o ripisilvas, permiten observar macromicetos específicos de este tipo de árboles, como Hebeloma salicicola, Inocybe salicis o Lactarius aspideus, e incluso pueden encontrarse con mayor frecuencia ciertas especies "exóticas" como Chaetotyphula actinipes o Trichoderma piluliferum.

En el segundo grupo de comunidades se encuentran prados, brezales higroturbosos y turberas en sentido estricto, espacios en los que abundan briófitos del género Sphagnum y diversas gramíneas y juncáceas propias de estos medios, y lagunas. La micobiota de estas zonas es altamente específica, por ejemplo, en ellas pueden observarse Cortinarius chrysolitus, Hypholoma elongatum, Laccaria pumila, Laccaria tortilis, Mycena mucor y Rickenella mellea, entre otros.

Las primeras visitas realizadas a los humedales de la ZEC Gándaras de Budiño respondieron, e incluso superaron, las expectativas micológicas previstas (Requejo 2010, 2011b, 2012, Requejo \& Blanco-Dios 2012, Requejo \& Castro 2015a, 2015b). Su aporte al catálogo gallego hizo que nos planteáramos continuar el trabajo de forma sistematizada a lo largo del año y posiblemente durante los siguientes, con el fin de conseguir un catálogo lo más completo posible, ya que, en Galicia, la observación de las fructificaciones fúngicas alcanza el 80-85\% de su totalidad después de muestrear mensualmente, al menos durante 5 años, una determinada zona (Freire 1982).

Como principal objetivo marcado al proyectar este trabajo se tomó la elaboración de un catálogo de macromicetos (Ascomycota y Basidiomycota) de la ZEC Gándaras de Budiño, analizando la importancia corológica de dichas 
especies. En segundo lugar, si fuera posible con los datos obtenidos y tras un análisis de los mismos intentar establecer patrones y ciclos de fructificación de las especies recolectadas, aplicables a la región atlántica más cálida de Galicia (Rodríguez-Guitián \& Ramil Rego 2008), para ver las posibles diferencias con el resto de la región. 


\section{DESCRIPCIÓN DE LA ZONA DE ESTUDIO}

En Galicia se denomina braña a una superficie que permanece todo el año con un elevado nivel freático, rica en Sphagnum y vegetación herbácea higrófila, en tanto que gándara se refiere a la presencia de brezales húmedos sobre suelo preferentemente arcilloso.

Las Gándaras de Budiño, ubicadas en la provincia de Pontevedra, ocupan unas 800 ha pertenecientes a los ayuntamientos de O Porriño, Tui y Salceda de Caselas. Están incluidas como «Lugar de Importancia Comunitaria» (LIC, DOCE L 387 de 29 de diciembre de 2004) en Red Natura 2000 y recientemente han sido declaradas «Zona de Especial Conservación» (ZEC, Decreto 37/2014, de 27 de marzo, ES1140011).

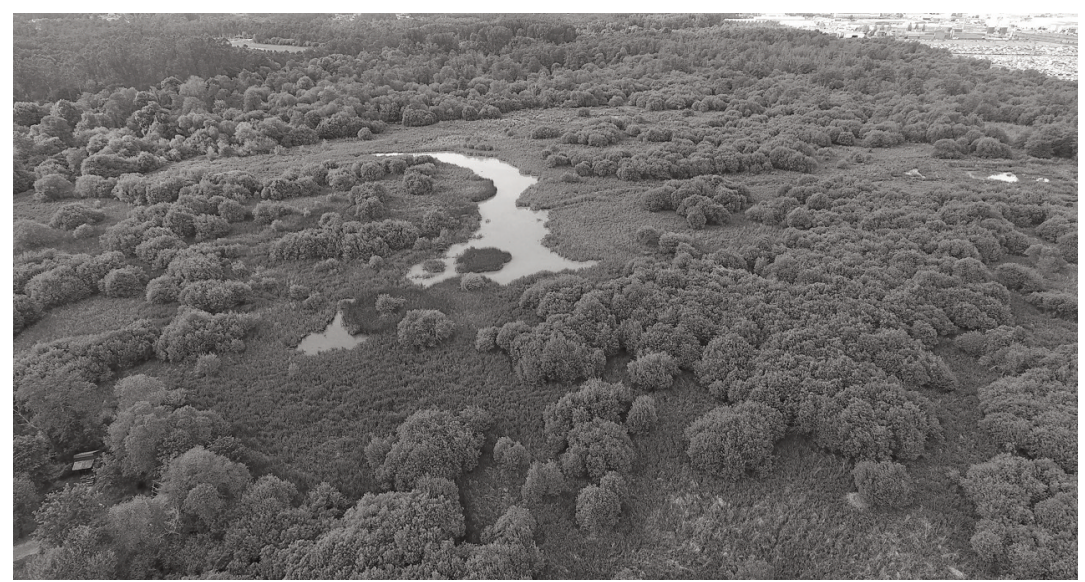

Fig. 1. Vista aérea de la Laguna de Orbenlle (O Porriño). Fotografía: Carlos Sanchidrián Gracía.

Esta zona húmeda se ha formado en la depresión generada por la cuenca del río Louro, que recibe agua procedente tanto de manantiales superficiales como profundos, además de la procedente de las zonas altas situadas en su entorno (Sierra do Galiñeiro y Faro de Budiño).

Aparece situada en una de las fallas que recorren Galicia de Norte a Sur, desde Baldaio (A Coruña) hasta Tui (Pontevedra), en la que se observan diversas fosas tectónicas consecutivas, rodeadas por laderas más o menos altas (Martínez Cortizas \& Pérez Alberti 1999) de gneis de riebeckita que conforman alturas como la citada sierra do Galiñeiro, con casi 500 millones de años, y por masas de granodioritas que constituyen las conocidas canteras de granito «rosa Porriño», originarias de hace unos 450 millones de años. Sin embargo, la topografía actual se calcula que fue configurada durante la era Terciaria, cuando se ha formado el 
valle del río Louro (Silva-Pando et al. 1987).

La situación climática durante este período, húmedo y cálido, provocó la alteración de los granitos dando lugar a arcillas tipo caolinita. Simultáneamente, la vegetación dominante se ha ido carbonizando de forma más o menos completa, lo que se manifiesta en la presencia de lignitos, a veces mal carbonizados, junto con la presencia de ciertas cantidades de arena y grava presentes en las lagunas procedentes del cercano río Miño (Silva-Pando et al. 1987).

Esta orografía circundante y el suelo arcilloso son, en parte, responsables de la sucesiva pérdida de características ombrotróficas en una buena parte de la zona, aunque conserva ambientes húmedos de forma permanente (brañas) y lagunas o charcas grandes, más o menos extensas, entre las que destaca la laguna de Budiño. De hecho, estas gándaras se consideran uno de los humedales permanentes del NW Ibérico (García-Bobadilla Prósper et al. 2002).

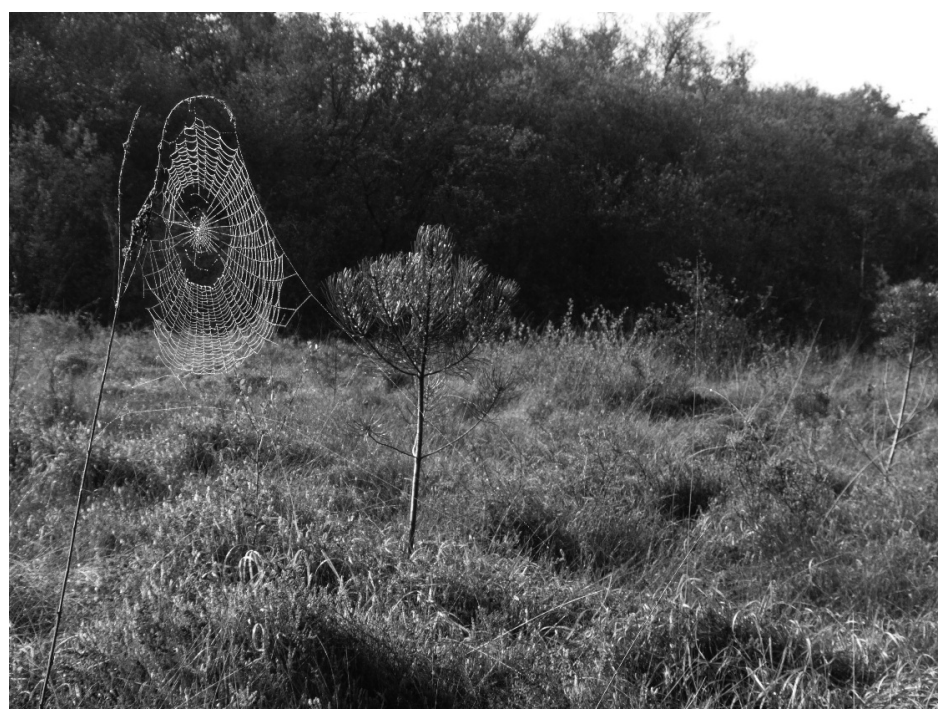

Fig. 2. Braña (Rego da Lama, Ponte Carneiro, Salceda de Caselas).

Se cree que, probablemente debido al interés cinegético de la zona, estas gándaras fueron importantes desde el Paleolítico como asentamientos humanos (28.000-20.000 años uno de los yacimientos), lo que ha contribuido a que conservaran cierto equilibrio ecológico hasta mediados del siglo XX, período en el que, como en muchos otros humedales Ibéricos, se han efectuado drenajes y transformaciones de la vegetación, bien por considerarse zonas insalubres o para obtener suelos fértiles que pudieran dedicarse a la agricultura. 
Además, dos vías de comunicación, el ferrocarril Vigo-Monforte y la carretera N-550 primero, y la A-55 después, que comunica Valença do Minho (Portugal) y las Rías Baixas cruzan la zona de Norte a Sur y abren camino para nuevos usos del terreno.

Por otra parte, en los años 60 la expansión de la comarca viguesa conlleva la construcción en esta zona dos polígonos industriales, que además de la destrucción de una buena parte de las Gándaras soporta un importante aporte de materiales contaminantes en sus lagunas y riachuelos. Pese a todas estas agresiones sus aguas todavía se encuentran en condiciones ecológicas aceptables (Pérez-Bilbao \& Garrido 2009).

Con estos preámbulos es fácil deducir que la zona de brañas, gándaras y lagunas ha reducido mucho su extensión en los últimos años, probablemente la superficie colmatada o en trance de colmatación no alcance las 100 ha, pero mantiene una gran riqueza ecológica, lo que ha conducido a que en 2014 haya sido declarada «Zona de Especial Conservación». De hecho, se consideran representados varios hábitats de interés comunitario (Directiva 92/43/CEE de Conservación de Hábitats Naturales, de Fauna y de Flora Silvestres) encuadrados en los apartados: hábitats de agua dulce (Camacho 2009a, 2009b), turberas altas, bajas y áreas pantanosas (Martínez Cortizas 2009a, 2009b) y brezales y matorrales de zona templada (Ojeda 2009).

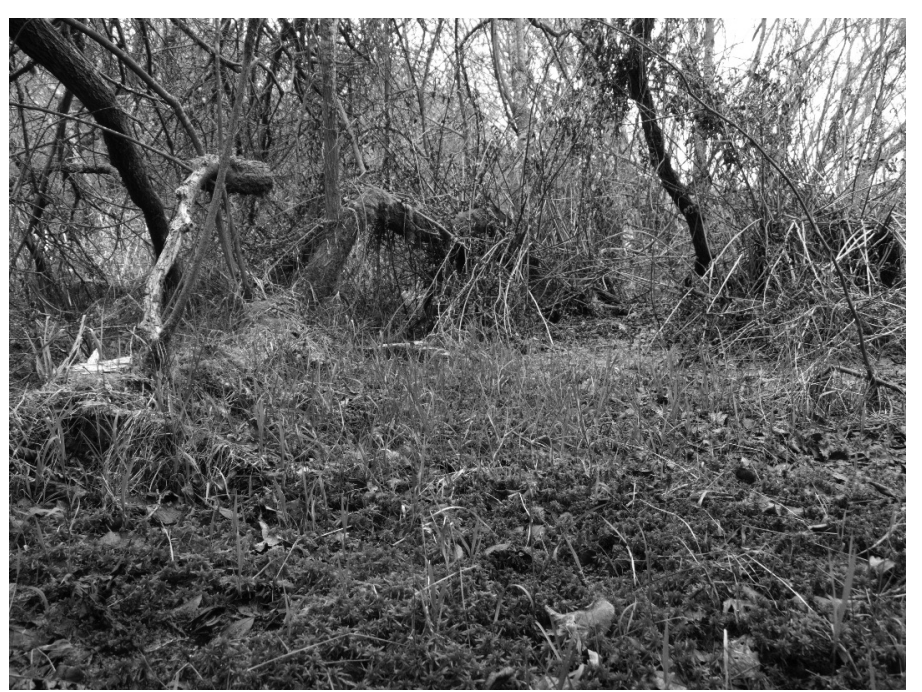

Fig. 3. Esfagnal en sauceda higrófila (observatorio ornitológico, laguna de Orbenlle, O Porriño). 
Biogeográficamente las Gándaras de Budiño se encuadran en la región Eurosiberiana, dentro del subsector Miñense de la provincia Astur-Galaica (Izco \& Sánchez 1995) o del subsector Rías Baixas de la provincia Atlántica Europea, según la revisión fitogeográfica realizada para Galicia por Rodríguez Guitián \& Ramil-Rego (2008).

Esta zona debió de verse fuertemente afectada por los cambios climáticos del Cuaternario, glaciación-interglaciación, lo que podría justificar la aparición de flora paleártica relicta, semejante a la que puede ser observada en los Pirineos a 2000 m, como Eriophorum angustifolium Honck., Arnica montana L., Nymphaea alba L., Potamogeton natans L., o Alisma plantago-aquatica L. (Silva-Pando et al. 1987).

La diversidad de hábitats, heterogénea y a la vez afectada por un factor común como es el agua, se observan situaciones interesantes desde el punto de vista micológico. Destacan como biotopos bien conservados diversas zonas de fraga con robles (Quercus robur L.) y laurel (Laurus nobilis L.). En estos bosques predominan macromicetos micorrícicos de los géneros Amanita, Boletus en sentido amplio y Russula.

Son importantes los bosques de ribera, inundables durante todo o parte del año, bastante bien conservados como el de Ponte das Febres (Tui) y las formaciones casi puras, de sauces (Salix atrocinerea Brot. y S. salviifolia Brot.) con sotobosque rico en esfagnos en lo que se recolectaron especies micorrícicas poco frecuentes en otros medios como Entoloma rhodocylix o Lactarius aspideus, y alisos (Alnus glutinosa (L.) Gaertn) como las de la aliseda de Albelos y los bosques aluviales de Ponte Carneiro, en los que habitan especies micorrícicas como Cortinarius saturninus, Inocybe praetervisa o Laccaria tortilis y saprofitas exclusiva de de aliso como Cyathicula amenti, sobre viejos pseudoestróbilos.

En estas comunidades, inundadas buena parte del año, el sotobosque (turba), apenas se reduce a comunidades de Sphagnum, con alguna que otra planta hidrófila, se pueden observar gran cantidad de ramas y hojas caídas, por ello la mayor parte de las fructificaciones se centran sobre troncos musgosos de árboles o en la periferia, más seca, de estos bosques, en los que está bien representado el género Mycena. En el suelo se observan pequeños hongos humícolas, inmediatamente antes de las inundaciones como Scutellinia cejpii, Hygrocybe miniata, Hypholoma ericaeoides, etc.

También aparecen algunos macromicetos parásitos, reguladores naturales de estas poblaciones degradadas, por ejemplo, sobre la especie arbórea más abundante, Alnus glutinosa, se observan numerosos carpóforos de Xanthoporia radiata. Otras especies parásitas, aparentemente menos agresivas como las del género Ganoderma, producen carpóforos que persisten a lo largo del año, y 
durante varios años, sobre los sauces. Cuando uno de estos ejemplares atacado por él, pierde una rama o parte del tronco, el hongo sigue viviendo como saprotróficos facultativo.

Desde la perspectiva micológica, también manifiestan cierto interés las formaciones arbóreas mixtas, en las que además del roble, aparecen pinos (Pinus pinaster) y eucaliptos (Eucalyptus globulus) con sotobosque de brezos (Erica umbellata, E. cinerea, E. tetralix, E. ciliaris, Daboecia cantabrica subsp. cantabrica, Calluna vulgaris, tojos (Ulex sp.pl.) entre los que destaca Ulex micranthus, y cierta proliferación del helecho común (Pteridium aquilinum subsp. aquilinum), que favorecen la aparición de especies exclusiva de estas especies arbóreas como Descolea maculata, Chroogomphus rutilus o Elaphomyces granulatus.

Entre las superficies inundables durante la mayor parte del año destacan matorrales higrófilos como los de la laguna de Budiño, Rego da Lama y Arroio, con importantes poblaciones de Genista ancistrocarpa Spach. y Ulex micranthus Lange (García 2016), entre otras retamas como Cytisus striatus (Hill.) Rothm. y Genista berberidea Lange y, algunas turberas como las de la laguna de Cerquido y la de Albelos con gran proliferación de esfagnos y helecho real (Osmunda regalis L.). Estas formaciones vegetales interesantes desde el punto de vista florístico, probablemente por inundarse durante largos períodos presentan escasa micetación, aunque puede resultar extremamente interesante como Nidularia deformis, Laccaria pumila, Cortinarius chrysolitus, Rickenella mellea o Hypholoma elongatum.

Tanto en turberas como en brañas se encuentran muchos menos macromicetos micorrícicos, a pesar de que trabajos filogenéticos y evolutivos concluyen que el 92\% de las familias revisadas establecen micorrizas (Wang \& Qiu 2006), incluso las de plantas más primitivas como musgos, hepáticas, helechos y gimnospermas.

En espacios donde escasea el oxígeno en el suelo, las especies vegetales tienen más dificultad para conseguir alimento, por lo que necesitan de agentes externos que les ayuden a sobrevivir, por ello forman asociaciones con hongos de otro tipo como las micorrizas ericoides, propias de géneros como Erica y Calluna frecuentes en estos ambientes, pero que no llegan a producir carpóforos, por lo tanto pasan inadvertidas al ojo del micólogo de campo.

Todavía se observan zonas permanentemente encharcadas en las que destaca una variada flora acuática como Utricularia australis R. Br., Scirpus lacustris L., Phragmites australis (Cav.) Trin. ex Steud., Iris pseudacorus L., etc., con islas turbosas ricas en Sphagnum sp. pl., que acompañan poblaciones de Drosera intermedia Hayne., Drosera rotundifolia L. y Rhynchospora alba (L.) Vahl. "A priori" estas zonas encharcadas o extremadamente húmedas parecen 
propicias para la aparición de macromicetos descomponedores (saprotróficos) y, de hecho, son muy abundantes los micelios, aunque no siempre se pueden observar carpóforos, a excepción de ascomicetos y basidiomicetos lignícolas, muchos de ellos persistentes durante todo el año, como las diversas especies del género Stereum, Hypoxylon o Lachnum. Sin embargo, como las turberas son una zona propicia para los insectos y arácnidos se observan macromicetos zoopatógenos como Beauveria bassiana, Cordyceps polyarthra, Gibellula pulchra, etc.

A pesar de la existencia de condiciones peculiares para la fructificación y estudio de macromicetos apenas se han publicado trabajos referidos a su micobiota (López-Prada \& Castro 1996, Fernández-Martínez \& Castro 1998, Requejo 2010, 2011, Requejo \& Parada-Miniño 2011, Requejo \& Blanco-Dios 2012) y, más recientemente trabajos relacionados con grupos taxonómicos concretos, como ascomicetos (Requejo \& Castro 2015a) o agaricales (Requejo \& Castro 2015b). Todos ellos han permitido poner de manifiesto el elevado interés de la micobiota presente en la ZEC Gándaras de Budiño.

Para este estudio se seleccionaron las zonas que se describen brevemente a continuación, en las que están representados varios hábitats de interés comunitario: turberas, bosque de ribera, matorrales higroturbosos, etc. La flora ha sido identificada usando floras locales (Silva-Pando \& al. 1987, García 2016) y otras más generales como Flora Ibérica (Castroviejo 1986-2012).

\subsection{Localidades muestreadas (Fig. 4):}

1. Barreras de Centeáns, O Porriño (29TNG3007): Antigua explotación minera de arcillas y barros, en la que, tras el cese de su actividad, quedaron varias lagunas que, poco a poco, se fueron naturalizando. En su entorno se pueden observar turberas de cobertura, bosques hidrófilos (saucedas y alisedas inundables) y formaciones de Pinus pinaster. Un poco más alejado aparece un bosque mixto con Quercus robur con Eucalyptus globulus y Acacia melanoxylon.

2. Observatorios ornicológicos, O Porriño (29TNG3061): Podría considerarse el centro neurálgico de las Gándaras de Budiño ya que en él se construyeron la mayoría de las infraestructuras relacionadas con la ZEC y es la mayor laguna de la zona. En su periferia se observan diversas turberas y brañas, encargadas del filtrado de agua al río Louro. Como zona adaptada para esparcimiento de los visitantes presenta varios abedules (Betula alba) intercalados con la vegetación existente.

En las riberas del arroyo se observa un importante bosque formado por Salix atrocinerea, Alnus glutinosa, Fraxinus excelsior y Laurus nobilis y, a 
ambos lados del cauce se encuentran bosques aluviales (saucedas y alisedas inundables) y pequeños robledales (fragas) con Quercus robur, que también se inundan en ciertas épocas del año. Al alejarse progresivamente de las franjas más húmedas comienzan a aparecer formaciones arbóreas mixtas con Eucalyptus globulus, Pinus pinaster, plantados entre los robles existentes.

3. Barrera «A Granxa» Sur, O Porriño (29TNG3153): Esta zona formaba parte de la turbera do «Arroio», pero ha quedado aislada tras la construcción de la vía férrea, autovía y polígono industrial. Tiene una laguna naturalizada (observatorio ornitológico), rodeada por vegetación leñosa riparia, principalmente Salix atrocinerea. La antigua turbera ha sido colonizada por Pinus pinaster con sotobosque formado por vegetación higrófila (Carex sp., Gentiana pneumonante) y matorrales húmedos de Erica ciliaris y E. tetralix.

4. Os Eidos, O Porriño (29TNG3022): En este lugar, a ambas orillas del río Louro, aparecen bosques formados por Salix atrocinerea, Alnus glutinosa, Fraxinus excelsior, Sambucus nigra y Laurus nobilis, bastante bien conservados, aunque en los últimos años comenzaron a proliferar Acacia melanoxylon y Robinia pseudoacacia. A medida que se alejan de la ribera dejan paso a prados o a saucedas y alisedas inundables. También pueden observarse pequeñas choperas (Populus nigra), bosquetes más o menos puros de Quercus robur, a veces con Eucalyptus globulus y Pinus pinaster, intercalados.

5. Desembocadura del río Becerreira, Salceda de Caselas (29TNG3019): El río Becerreira (o río Tinto), aporta las aguas procedentes de la sierra del Faro de Budiño al río Louro. A lo largo del cauce aparecen bosques de galería, formados por Salix atrocinerea, Alnus glutinosa, Fraxinus excelsior, Sambucus nigra y Laurus nobilis. En su margen norte predominan formaciones mixtas de Eucalyptus globulus y Quercus robur, que a medida que se aproximan a la desembocadura del Louro se transforman en bosques hidrófilos (saucedas y alisedas inundables) con pequeñas turberas. El margen sur limita con la aliseda de Albelos.

6. Aliseda de Albelos, Tui (29TNG3019): Es un extenso bosque higrófilo donde predomina Alnus glutinosa, aunque también existe una sauceda casi pura de Salix atrocinerea, que se inunda tanto por las crecidas del río Becerreira como durante los períodos de lluvia. En el sotobosque escasea la vegetación herbácea y arbustiva. 
7. Turberas de Albelos, Tui (29TNG3036): Se trata de un sistema de turberas bastante bien conservado, rodeadas por prados que son drenados mediante canales (sangras) en las cabeceras, y por bosques higrófilos con grandes ejemplares de Salix atrocinerea, pertenecientes a las tierras agrícolas abandonadas. En la zona más alta existen formaciones mixtas de Quercus robur con Eucalyptus globulus, Pinus pinaster e importantes comunidades de Erica australis.

8. Lugar de Albelos, Tui (29TNG3043): Es un espacio formado por praderas intercaladas con terrenos agrícolas. La construcción de infraestructuras para facilitar el acceso a las zonas agrícolas detiene el movimiento natural de las aguas, causando el encharcamiento de algunas zonas en las que se instalan bosquetes de Salix atrocinerea.

Próximas a las riberas del río Louro existen choperas (Populus nigra) y bosques de ribera formados por Salix atrocinerea, Alnus glutinosa y Fraxinus excelsior. Y, en las zonas más altas, alejadas del río, aparecen formaciones de Quercus robur con Eucalyptus globulus y Pinus pinaster, así como una pequeña población de Platanus orientalis var. acerifolia.

9. Ponte Carneiro, Salceda de Caselas (29TNG3164): Este espacio está situado al este de la vía del ferrocarril Vigo-Monforte y la autovía A-55, por lo que no ha sido incluida en la ZEC, a pesar de contar con los mismos hábitats protegidos y elevado interés micológico.

En este espacio se juntan los ríos Meixía y Becerreira, por ello se observan turberas bien conservadas, bosques hidrófilos (saucedas y alisedas inundables), brezales húmedos atlánticos de zonas templadas con Erica ciliaris y Erica tetralix, en los que aparece Genista ancistrocarpa y un bosque ripario bien conservado con Alnus glutinosa, Laurus nobilis y Fraxinus excelsior.

Como en el punto anterior, las zonas más elevadas presentan robledales de Quercus robur, en los que comienzan a proliferar especies forestales como Robinia pseudoacacia.

10. Ponte das Febres, Tui (29TNG2996): Esta zona de estudio cuenta con gran valor etnológico, ya que en él hay un puente de época medieval y una placa y cruceiro de piedra dedicado a San Telmo, patrón de Tui, ya que según cuenta la leyenda, allí enfermo de muerte. Coincide el río San Simón, poco antes de unirse al río Louro, lo que nos deja importantes y bien conservados bosques de ribera tanto a orillas de un rio como del otro. Paralelo al rio San Simón está el camino de Santiago, en forma de un ancho sendero de tierra bastante transitado y que separa el rio y su bosque ripario de los prados que en épocas lluviosas se 
encharcan. Muchos de estos prados aún están trabajados como pastos, los que cesaron su actividad se convierten en saucedas que también se inundan en épocas lluviosas. Entre los prados se alternan plantaciones de Populus nigra.

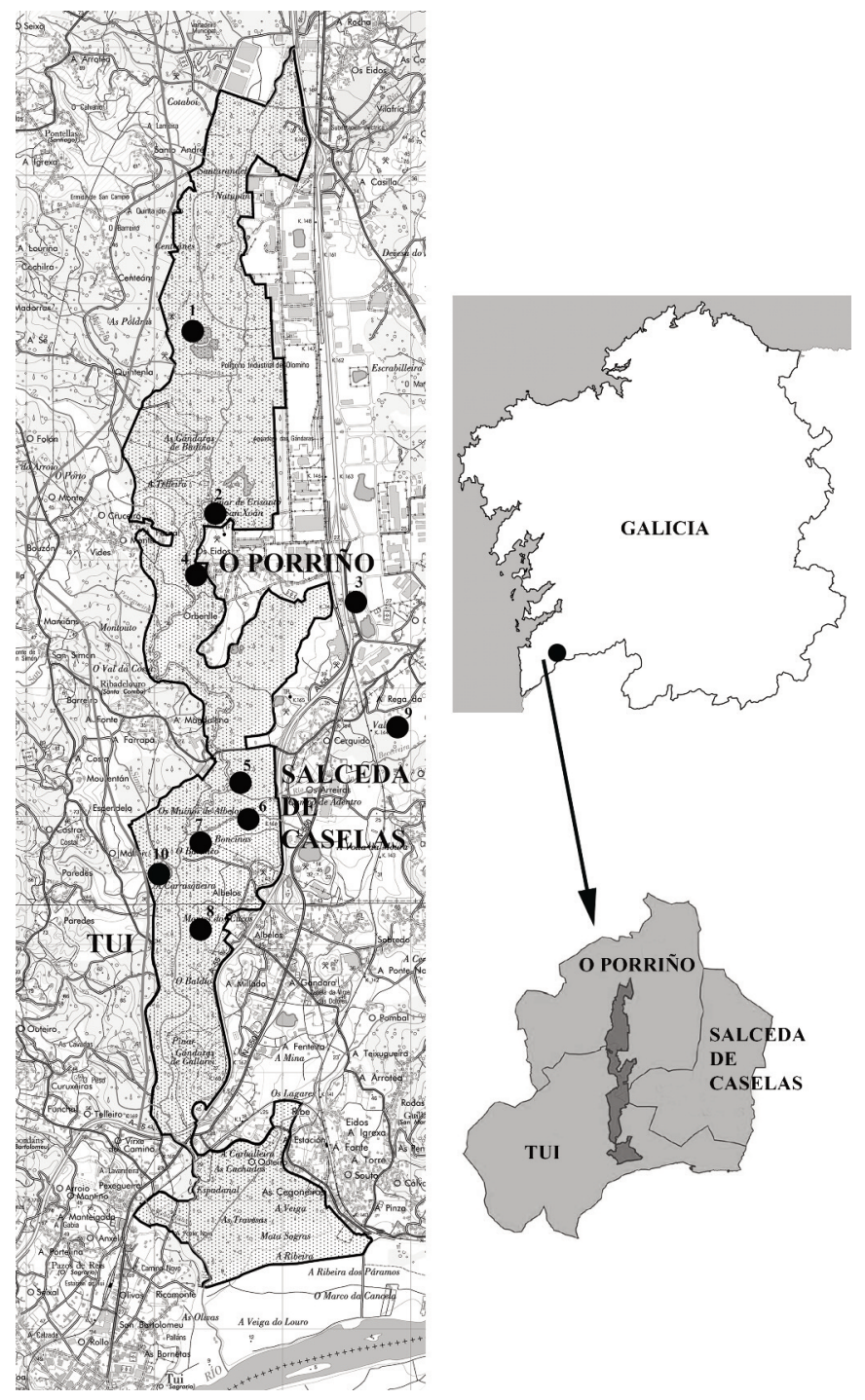

Fig. 4. Zonas de muestreo (Izquierda) y ubicación de la ZEC en Galicia (Derecha). 


\section{METODOLOGÍA}

La metodología empleada para la realización de este trabajo fue la habitual para desarrollar estudios de la micobiota de una zona escasamente prospectada. Se realizó en primer lugar una recopilación bibliográfica referente a la zona para analizar tanto los elementos de la micobiota previamente publicados como la distribución de micotopos interesantes para la prospección, fenología de las especies vegetales que, en mayor o menor medida, sirven de substrato a la micobiota, climatología, etc.

A la vista de la prospección previa se seleccionaron las 10 localidades en las que los micohábitats se encontraban en mejor estado de conservación y a los que era posible el acceso. Se diseñó el posible calendario de muestreo (una vez por mes), pendiente de cualquier modificación en función de las condiciones climatológicas del momento.

\subsection{Recolección y conservación de colecciones}

Se realizaron salidas entre 2012 y 2016, intentando cumplir el calendario diseñado, en todas las zonas de trabajo, pertenecientes a los 3 ayuntamientos sobre los que se asientan las Gándaras de Budiño, y procurando que los hábitats granxa figuraran entre los de interés comunitario (Directiva 92/43/CEE de Conservación de Hábitats Naturales, de Fauna y de Flora Silvestres). Debido a la fragilidad de estos hábitats, las prospecciones se efectuaron de forma meticulosa y metódica, pero respetando al máximo el medio e intentando no dañar el entorno.

El material fúngico ha sido extraído mediante la ayuda de una navaja, separando cuidadosamente, durante el transporte, las colecciones por especies para evitar la contaminación de las muestras, bien en conos de papel o envases rígidos. Asimismo, se fotografió el mayor número posible de los taxones recolectados, tanto a tamaño natural como aumentando algunas partes del carpóforo mediante lentes de aproximación. Se utilizaron cámaras Sony Alpha 57, con objetivo Tamron $180 \mathrm{~mm} \mathrm{f/3.5,} \mathrm{y} \mathrm{Panasonic} \mathrm{Lumix} \mathrm{FZ38,} \mathrm{a} \mathrm{la} \mathrm{que} \mathrm{se} \mathrm{le}$ acoplaba una lente de aproximación Raynox 250 para ejemplares muy pequeños, todo ello con trípode. Las fotografías han sido un importante apoyo adicional, por no decir imprescindible, en el trabajo de laboratorio, pues sirve como apoyo gráfico a las notas tomadas en campo y permite confirmar aspectos como colores, sustratos, humedad del suelo etc...

Junto a las colecciones recolectadas se tomaron notas de la vegetación circundante, substrato (siempre que fue posible), tamaño, color, morfología, caracteres organolépticos y cualquier otro dato, más o menos fugaz, que resultara necesario para la determinación. 
La primera aproximación a la identificación de material se hizo en estado fresco, por ello en épocas de copiosas recolecciones, al tener que hacer varios ciclos de secado, los carpóforos se guardaron en neveras a una temperatura de entre 2 y $5{ }^{\circ} \mathrm{C}$ con el fin de evitar procesos de putrefacción y gelificación de estructuras.

Posteriormente, las colecciones se secaron mediante convector de aire caliente procurando no exceder los $40^{\circ} \mathrm{C}$, para poder ser utilizados en posteriores estudios moleculares. Una vez secas y pre-identificadas, las exsiccata se guardaron en sobres a los que se les asignaba un número de micoteca LOU-Fungi (Centro de Investigaciones Forestales y Ambientales de Lourizán, Pontevedra), junto con los datos referidos a la recolecta: provincia, ayuntamiento, localidad, hábitat, fecha de recolección y legit.

\subsection{Identificación y elaboración del catálogo}

El proceso de identificación se llevó a cabo en el laboratorio, ya que además del pormenorizado análisis morfológico con un microscopio estereoscópico (Nikon SMZ-1), era imprescindible el estudio de las estructuras microscópicas. Este trabajo se realizó principalmente con microscopios Leitz Laborlux S, Nikon Eclipse E600, Nikon Optiphot-2, en fase clara, en contraste de fases $\mathrm{x} 400$ y x1000 y con objetivos Nomanski para 1.000 aumentos.

Los cortes histológicos en material seco se hicieron a mano alzada con ayuda del microscopio estereoscópico, y las muestras se prepararon en agua destilada, o para una mejor interpretación de las mismas, se usaron los reactivos habituales (Charbonnel 1995, 2004), entre los que cabe destacar hidróxido potásico $(\mathrm{KOH})$ al $5 \%$ y $10 \%$; rojo-congo en solución amoniacal; reactivo Melzer para observar reacciones amiloides o dextrinoides; azul de algodón para la reacción cianófila, sulfato férrico al 10\% y amoníaco en solución acuosa al $10 \%$.

El análisis de estructuras ha sido el habitual para cada uno de los grupos taxonómicos estudiado (Basso 2005, 2012): pelis, elementos del himenio como, cistidios, paráfisis, basidios, ascos y esporas. Para calcular los valores de las esporas se han medio no menos de 20.

Con los datos registrados para cada colección se ha procedido a la identificación. La primera aproximación siempre se ha realizado a partir de obras generales como Bas \& al. (1988, 1990, 1995, 1999), Basso (1999), Berniccia (2005), Berniccia \& Gorjón (2010), Breitenbach \& Kränzlin (1984, 1986, 1991, 1995, 2000), Candusso \& Lanzoni (1990); Candusso (1997); Corner (1950); Dennis (1981); Kränzlin (2005); Ladurner \& Simonini (2003); Muñoz (2005); Neville \& Poumarat (2004); Noordeloos (1992, 2004, 2011); Noordeloos \& al. (2001, 2005); Parra Sánchez (2013); Riva (1988); Robich (2003) y Sarnari (1998, 2005), Beker (2016), entre otros, aunque para la identificación de la mayor parte de los taxones 
fue imprescindible el uso de referencias específicas, tanto bibliográficas como webgráficas, relacionadas con taxonomía, corología y distribución. Éstas se mencionan en las observaciones de las diferentes especies del catálogo. Estos mismos trabajos, así como las Bases Corológicas de Flora Micológica Ibérica (Bueno \& Illana 2004, Calonge 1996, Cardoso \& Melo 1992, Castro et al. 1997, Daniëls 2003, Dueñas 1997, 2001, Esteve-Raventós 1999, Illana \& Blanco 2001, Llistosella Vidal 2008, Pando 1996, 2001, Pando et al. 1990, 1999, Parra 2003, Salcedo et al. 2004, Tellería 1992, 1993 y Tellería et al. 1991) fueron empleados para el análisis corológico de los taxones recolectados.

El sistema taxonómico seguido y la nomenclatura son los propuestos en la obra de Cannon \& Kirk (2007) y en las bases de datos Index Fungorum (online) y Mycobank (online), respectivamente. En caso de discordancia entre ambas bases de datos hemos optado por la primera, debido a que referencia mayoritariamente material europeo.

Los datos de las recolecciones se incluyeron en una hoja Excell (paquete Microsoft Office), lo que ha permitido archivar y ordenar los registros para el posterior análisis taxonómico y ecológico de los mismos. 


\section{RESULTADOS}

Los trabajos de catalogación son imprescindibles de cara a futuros proyectos relacionados con la protección y conservación de poblaciones fúngicas, así como con la gestión forestal y la sustentabilidad del recurso micológico, tanto en áreas protegidas como en aquellas utilizadas por la comunidad rural y/o industrial sin estar asociadas a figuras de protección (Palm \& Chapela 1997, Shiva \& Verma 2002).

En este trabajo se presenta un catálogo de 359 taxones, de los cuales 52 pertenecen al phyllum Ascomycota (14,5\%) distribuidos en 20 familias y 9 órdenes y 307 a Basidiomycota (85,5\%) clasificados en 130 géneros, 57 familias y 12 órdenes, es decir, alrededor de 6 veces más basidiomicetos que ascomicetos.

\subsection{Catálogo de la micobiota estudiada}

Para facilitar la localización de las especies, en el catálogo se han dispuesto por orden alfabético separados por clases, Ascomycota y Basidiomycota, considerando el nombre actual según la última actualización realizada por Index Fungorum (en línea, consultada 13/12/2016), salvo excepciones de nomenclatura más actualizada y debidamente justificada en las publicaciones correspondientes.

Cada taxon incluye además del protólogo nomenclatural, algún sinónimo si se trata de un nombre utilizado con frecuencia en la Península Ibérica o si ha sido modificado recientemente. A continuación, figura el material estudiado indicando ayuntamiento, localidad, nombre local del punto de recolección, UTM, altitud, hábitat, fecha, legit y número de la micoteca LOUFungi (Centro de Investigaciones Forestales y Ambientales de Lourizán, Pontevedra) en el que se ha depositado.

Si se trata de un taxon poco conocido o conflictivo a la hora de identificarlo se han añadido unas breves observaciones que explican sus características y justifican la identificación..

Por último, se incluyen comentarios sobre la ecología de la especie en base a anotaciones realizadas durante la recolección y también sobre su corología, no sólo para la Península Ibérica, ya que para todos los taxones se han consultado las bases de datos de GBIF (en línea), además de la bibliografía ibérica disponible, que se mencionan en cada una de las especies, así como las Bases de Datos del proyecto Flora Mycologica Ibérica (Pando et al. en línea y Hernández-Crespo en línea). 


\subsubsection{Ascomycota}

Adelphella babingtonii (Sacc.) Pfister, Matočec \& I. Kudatsan, Mycologia Montenegrina 11: 7-17 (2009) [2008]

$\equiv$ Pachyella babingtonii (Sacc.) Boud., Hist. Class. Discom. Eur. (Paris): 51 (1907)

Material estudiado: O Porriño, Budiño, 29TNG3061, $22 \mathrm{~m}$, sobre tronco de Salix atrocinerea en descomposición dentro de la turbera, 17/03/2012, O. Requejo, LOUFungi 19770.

Observaciones: apotecios pulvinados o disciformes, de color pardo rojizo, más claros en la zona de inserción con el sustrato, de tamaño inferior a 10 $\mathrm{mm}$ de diámetro. Ascosporas lisas de (17,4) -19,6-21,8 x (10,4) -11,7-13 $\mu \mathrm{m}(\mathrm{Q}=$ $1,7)$.

Las características macro y microscópicas corresponden con las aportadas por Dennis (1981), Breitenbach \& Kränzlin (1984) y Medari (2006); sin embargo, la superficie externa, aunque conserva tonalidades pardas es más clara que la zona fértil.

Esta especie se incluía en el género Pachyella, pero en base a caracteres histoquímicos y citológicos (Pfister et al. 2009) ha sido segregada al género Adelphella.

Ecología y distribución: recolectada sobre tronco caído de Salix atrocinerea en avanzado proceso de descomposición y que durante ciertas épocas del año acaba semi sumergido. Se ha observado durante varios años en el mismo tronco, sin embargo, no es una especie común en la zona de estudio, a pesar de que el hábitat es propicio (Dennis 1981).

En general se trata de una especie poco frecuente (Calvo-Pérez en línea), georreferenciada para el continente americano, Nueva Zelanda y Europa occidental (GBIF en línea, $\mathrm{n}^{0}$ 2595016). Citada recientemente para el N.O. Ibérico por Pérez-Butrón et al. (2011), Marcote et al. (2011) y Castillo \& Guillén (en línea).

Aleuria aurantia (Pers.) Fuckel, Jb. nassau. Ver. Naturk. 23-24: 325 (1870) [1869-1870]

Material estudiado: O Porriño, Budiño, Orbenlle, observatorio ornitológico, 29TNG3061, 22 m, sobre tierra removida próxima a una charca, 07/12/2013, O. Requejo, LOU-Fungi 19763.

Ecología y distribución: se recolectó en zona arenosa próxima a una balsa de decantación donde había realizado un pequeño destierre. 
Ampliamente citada en el Hemisferio Norte; así como en América del Sur, Australia y Nueva Zelanda (GBIF en línea, nº 5258678). También en el N.O. Ibérico (Soliño et al. 2000).

Annulohypoxylon stygium (Lév.) Y.M. Ju, J.D. Rogers \& H.M. Hsieh, Mycologia 97 (4): 861 (2005)

$\equiv$ Hypoxylon stygium (Lév.) Sacc., Syll. fung. (Abellini) 1: 379 (1882)

Material estudiado: O Porriño, Budiño, Orbenlle, observatorio ornitológico, 29TNG3061, $22 \mathrm{~m}$, sobre ramas sin identificar, posiblemente de Alnus glutinosa, 30/4/2014, O. Requejo, LOU-Fungi 19771.

Observaciones: esta especie es fácilmente identificable por su aspecto almohadillado y textura semejante al carbón, con ostíolos papilados y una aureola o anillo en la base. Presenta ascos de hasta $180 \times 8 \mu \mathrm{m}$, no amiloides y ascosporas elipsoides, de 8-8,7 x 3,2-3,7 $\mu \mathrm{m}$, con surco germinativo. Al aplicar $\mathrm{KOH}(10 \%)$ sobre el estroma adquiere color azul verdoso.

En base a caracteres morfológicos y al análisis de $\beta$-tubulina y secuencias del gen $\alpha$-actina, (Hsieh et al. 2005) se propuso crear el género Annulohypoxylon para incluir los taxa de la sección Annulata del género Hypoxylon.

De esta especie se han descrito dos variedades: Annulohypoxylon stygium (Lév.) Y.M. Ju, J.D. Rogers \& H.M. Hsieh var. stygium y A. stygium var. annulatum (Rehm.) Y.M. Ju, J.D. Rogers \& H.M. Hsieh, que son considerados sinónimos por Ju \& Rogers (2013), a pesar de que presentan anillos periostiolares y estromas químicamente distintos. Sin embargo, Makornwattana et al. (2013) mediante estudios moleculares defienden que se trata de dos especies bien diferenciadas.

Ecología y distribución: el material estudiado se recolectó sobre una rama caída en bosque de Alnus glutinosa y Quercus robur. Fructificaba directamente sobre la madera levantando la corteza. Fue observado, sin recolectar exsiccata, en varios puntos más de la zona de estudio, siempre como saprotrófico en ramas caídas. Parece ser un taxon común en la zona de estudio.

No se conoce su distribución mundial debido a la confusión entre las dos variedades (Miller 1961) y no aparece georreferenciada en GBIF (en línea). En la Península Ibérica existe una mención de A. stygium var. annulatum para Asturias (Rubio-Domínguez en línea). No lo conocemos citado para Galicia. 
Arnium olerum (Fr.) N. Lundq. \& J.C. Krug, Symb. bot. upsal. 20 (1): 212 (1972)

Material estudiado: O Porriño, Budiño, Orbenlle, Os Eidos, 29TNG3022, 30 m, sobre tallo de Brassica oleracea var. viridis, 15/01/2015, O. Requejo, LOU-Fungi 20618.

Observaciones: en el material estudiado apenas se observaron restos de tomento en el peritecio. Las medidas esporales de 42-50 x $(17,5) 20-25(27,5) \mu \mathrm{m}$ y el hábitat descartan que pueda tratarse de Arnium tomentosum (Speg.) N. Lundq. \& J.C. Krug (Krug \& Cain 1972). Sin embargo, estudios moleculares recientes (Kruys et al. 2014) sugieren que podría tratarse de la misma especie, aunque que no han podido confirmarlo debido a la escasez de material revisado.

Ecología y distribución: recolectado sobre su sustrato habitual (Krug \& Cain 1972), tallos de Brassica oleracea var. viridis, procedentes de un cultivo y tiradas en el medio de una sauceda inundable, por tanto, esta especie no se podría considerar como característica de las zonas muestreadas.

Taxón georreferenciado de Canadá, Noruega, Francia, Alemania, Finlandia, Reino Unido, Dinamarca y Australia (GBIF en línea, nº 108339572). No se encontraron citas para la Península Ibérica.

Ascocoryne sarcoides (Jacq.) J.W. Groves \& D.E. Wilson, Taxón 16 (1): 40 (1967)

Material estudiado: O Porriño, Budiño, Orbenlle, Os Eidos, 29TNG3022, 30 m, sobre tronco de Pinus pinaster con musgo, 29/11/2014, O. Requejo, LOU-Fungi 19834. Salceda de Caselas, Cerquido, Ponte Carneiro 29TNG3164, 35 m, sobre ramas de Salix atrocinerea, 25/01/2015, O. Requejo, LOU-Fungi 19926.

Ecología y distribución: común sobre ramas caídas de todo tipo de árboles, las recolecciones de las Gándaras no difieren de las consultadas en la bibliografía (Dennis 1981, Breitenbach \& Kränzlin 1984), ni en hábitat ni en época.

Común en Europa, también referenciada de los continentes americano y austral (GBIF en línea, $\mathrm{n}^{\circ}$ 2584352). Conocida de las cuatro provincias gallegas (Rodríguez-Vázquez \& Castro 2016).

Beauveria bassiana (Bals.-Criv.) Vuill., Bull. Soc. bot. Fr. 12: 40 (1912)

Material estudiado: Salceda de Caselas, Cerquido, Ponte Carneiro, 29TNG3164, 35 m, sobre Tipula sp, 01/12/2015, O. Requejo, LOU-Fungi 20540.

Ecología y distribución: a pesar de la cantidad de insectos avistados durante los muestreos, este patógeno, solo ha sido observado en una ocasión y 
sobre un díptero, sin embargo, en el resto de citas gallegas fructificó sobre coleópteros (Requejo, 2012, De la Peña, 2016).

Conocida de los 5 continentes, aunque no frecuente (GBIF en línea, $\mathrm{n}^{\circ}$ 2560612). Seguro que es una especie más común de lo que refleja la bibliografía, dado que se utiliza como controlador biológico de plagas (Santamaría et al., 1998). Para Galicia solo se conoce de Pontevedra (Requejo, 2012, De la Peña, 2016).

Bisporella citrina (Batsch) Korf \& S.E. Carp., Mycotaxon 1 (1): 58 (1974)

Material estudiado: O Porriño, Budiño, Orbenlle, observatorio ornitológico, 29TNG3061, 22 m, sobre restos de bellotas, 03/11/2013, O. Requejo, LOU-Fungi 19759.

Ecología y distribución: se observó repetidas veces, sin recolectar exsiccata, sobre restos de bellotas, incluso sobre madera de Quercus robur. Abundante a finales de otoño e invierno en los bosques de frondosas de la zona.

Común en Europa (Breitenbach \& Kränzlin 1984), también en el N.O. Ibérico (Rodríguez-Vázquez \& Castro 2016). Ampliamente citada de Europa y la costa oriental norteamericana, aunque también se conoce de Australia y Nueva Zelanda (GBIF en línea, $\mathrm{n}^{\circ}$ 2584306).

Byssosphaeria schiedermayeriana (Fuckel) M.E. Barr, Mycotaxon 20 (1): 34 (1984)

Material estudiado: Salceda de Caselas, Cerquido, Ponte Carneiro 29TNG3164, 35 m, sobre rama sin identificar, 27/12/2014, J.Á. Gándara \& O. Requejo, LOU-Fungi 19993.

Observaciones: ascocarpos globosos de color negro con la periferia del ostíolo de color pardo amarillento. Ascosporas fusiformes de 30-35 (42) x 4,3-7,5 $\mu \mathrm{m}$ con un notable septo central.

Ecología y distribución: fructifican numerosos ascomas agrupados sobre una rama sin corteza, asentada sobre turba, en bosque aluvial de Quercus robur, Alnus glutinosa y Salix atrocinerea. Muy rara en la zona de estudio.

Parece tratarse de una especie extendida preferentemente por el Hemisferio Sur, aunque está también mencionada de Alemania (GBIF en línea, ${ }^{\circ}$ 108293142). No la conocemos de la Península Ibérica.

Ciboria viridifusca (Fuckel) Höhn., in Weese, Mitt. bot. Inst. tech. Hochsch. Wien 3 (3): 101 (1926)

Material estudiado: O Porriño, Budiño, Orbenlle, observatorio ornitológico, 29TNG3061, 22 m, sobre amentos femeninos de Alnus glutinosa, 28/03/2011, O. Requejo, LOU-Fungi 19735. 
Ecología y distribución: recolectado sobre su substrato habitual (Breitenbach \& Kränzlin, 1984), bajo Alnus glutinosa, al pie de la laguna.

Georreferenciada para el Centro Europa y Países Escandinavos (GBIF en línea, $n^{\circ}$ 2583074). En Galicia sólo se conoce de la provincia de Pontevedra (Requejo \& Parada Miniño 2011).

Cordyceps polyarthra Möller, Bot. Mitt. Trop. 9: 213 (1901)

=Isaria tenuipes Peck, Ann. Rep. N.Y. St. Mus. nat. Hist. 31: 44 (1878)

Material estudiado: Tui, Guillarei, turbera de Albelos, 29TNG3036, $20 \mathrm{~m}$, sobre oruga de insecto sin identificar, 07/09/2015, J. Valeiras y O. Requejo, LOU-Fungi 20258. O Porriño, Budiño, Orbenlle, observatorio ornitológico, 29TNG3061, $22 \mathrm{~m}$, sobre pupa sin identificar, 1/12/2015, O. Requejo, LOU-Fungi 20539.

Observaciones: encontrado en su forma imperfecta Isaria tenuipes Peck. Se diferencia de Isaria farinosa (Holmsk.) Fr. por tener conidios mucho mayores y curvados (Samson 1974).

Ecología y distribución: se recolectó en dos ocasiones, la colección LOU-Fungi 20258, fructificaba a finales de verano en el fondo de la turbera, donde apenas entra luz por la cobertura de Carex sp., inundada en gran parte del año. La otra recolección, LOU-Fungi 20539, emergía entre los musgos que recubrían el tronco de un Alnus glutinosa al pie de la turbera.

Muy raro, georreferenciado en pocas localidades, aunque parece extendido por Suecia, Norte y Sudamérica, Australia y Nueva Zelanda (GBIF en línea, $n^{\circ}$ 3451661). No conocemos citas para la Península Ibérica.

Cudoniella clavus (Alb. \& Schwein.) Dennis, Persoonia 3 (1): 73 (1964)

Material estudiado: Salceda de Caselas, Cerquido, Ponte Carneiro, 29TNG3164, $35 \mathrm{~m}$, sobre pequeñas ramas sin identificar, 15/04/2016, O. Requejo, LOU-Fungi 20620.

Ecología y distribución: recolectado sobre una pequeña rama caída en una sauceda inundable, con sotobosque recubierto de Sphagnum sp., común en época de inundaciones en los bosques aluviales de la zona de estudio.

Esta variedad está referenciada únicamente de Centroeuropa, Inglaterra e Irlanda (GBIF en línea, $\mathrm{n}^{\circ}$ 7073971). En Galicia ha sido mencionada para Caveiro (Pontedeume, A Coruña) por Merino Alcántara (en línea), también en Pontevedra y Lugo (Rodríguez-Vázquez \& Castro 2016). 
Cyathicula amenti (Batsch) Baral \& R. Galán, in Baral, Galán, Platas \& Tena, Mycosystema 32 (3): 420 (2013)

$\equiv$ Peziza amenti Batsch, Elench. fung., cont. prim. (Halle): 211 (1786)

$\equiv$ Pezizella amenti (Batsch) Dennis, Mycol. Pap. 62: 55 (1956)

Material estudiado: Tui, Guillarei, aliseda de Albelos, 29TNG3019, $20 \mathrm{~m}$, sobre amento femenino de Salix atrocinerea, 15/12/2016, O. Requejo, LOU-Fungi 20605.

Observaciones: Pequeños apotecios difíciles de diferenciar a simple vista de algunas especies de Pezizella o Hymenoscyphus, pero el sustrato particular y las ascosporas de 8-11 x 3,5-4 $\mu$ m permiten caracterizar el taxón.

Ecología y distribución: el sustrato y hábitat de la recolección es el habitual (Dennis 1981, Breitenbach \& Kränzlin 1984). Raro en la zona de estudio a pesar de ser un descomponedor específico de amentos femeninos de Salix, árbol muy común en las Gándaras de Budiño.

No existe ninguna localidad georreferenciada (GBIF en línea, $\mathrm{n}^{\circ}$ 8189913). Para la Península Ibérica apenas conocemos la mención de Picón (2004). No conocemos citas para Galicia.

Diatrypella quercina (Pers.) Cooke, J. Bot., London 4: 99 (1866)

Material estudiado: O Porriño, Budiño, Orbenlle, observatorio ornitológico, 29TNG3061, 22 m, sobre madera de Quercus robur, 10/2/2014, O. Requejo, LOU-Fungi 19756.

Observaciones: Se diferencia de otras especies del género por el hábitat y la curvatura de las ascosporas. Se trata de una especie frecuente sobre Quercus (Breitenbach \& Kränzlin 1984, Dennis 1981), también sobre castaño (Cobos Suárez 1989).

Ecología y distribución: recolectado como saprotrófico sobre ramas caídas de Quercus robur, en bosque mixto de frondosas.

Ampliamente georreferenciada para Europa, pero también es conocida de Estados Unidos y Australia (GBIF en línea, no 5254550). En el N.O. Ibérico ha sido citada en toda Galicia (Rodríguez-Vázquez \& Castro 2016).

Elaphomyces granulatus Fr., Syst. mycol. (Lundae) 3 (1): 58 (1829)

Material estudiado: O Porriño, Budiño, 29TNG3061, 22 m, zona mixta de Pinus pinaster y Quercus robur, 01/09/2014, O. Requejo, LOU-Fungi 19755. O Porriño, Pontellas, barreras de Centeáns, 29TNG3007, 20 m, bajo Pinus pinaster, 26/12/2014, O. Requejo, LOU-Fungi 20245. 
Ecología y distribución: se trata de un ascomiceto hipogeo, recolectado en bosque mixto de Pinus pinaster y Quercus robur, así como en plantación monoespécifica de Pinus pinaster, en ambos casos micorrizando con coníferas. La localización se efectuó devido a la presencia de ascocarpos de su parásito Tolypocladium ophioglossoides.

Frecuente, aunque difícilmente observable (Montecchi \& Sarasini 2000), ampliamente distribuido por Europa, incluida la Península Ibérica (Gómez-Reyes et al. 2012) y América (GBIF en línea, $n^{\circ}$ 2598370). También se ha observado en el N.O. Ibérico (Soliño et al. 2000).

Eutypella quaternata (Pers.) Rappaz, Mycol. Helvetica 2 (3): 500 (1987)

Material estudiado: Tui, Guillarei, turbera de Albelos, 29TNG3036, $20 \mathrm{~m}$, sobre rama de Populus nigra, 03/07/2015, Julio Valeiras \& O. Requejo, LOU-Fungi 20211.

Observaciones: recolectada en su forma imperfecta Quaternaria quaternata (Pers.) J. Schröt. (Index Fungorum, en línea).

Ecología y distribución: los ejemplares observados fructificaban en verano, emergiendo de la corteza de algunas ramas caídas de Populus nigra, en una zona que se inunda en épocas lluviosas.

La especie ha sido referenciada para el Norte de Península Ibérica, Centroeuropa, Países Escandinavos, Inglaterra, Irlanda, Nueva Zelanda, Nordeste del continente americano (GBIF en línea, $\mathrm{n}^{\circ}$ 2575237); sin embargo, no conocemos menciones exclusivas de la forma imperfecta. Ninguna de las dos ha sido mencionada anteriormente para Galicia.

Geopora tenuis (Fuckel) T. Schumach., Norw. Jl. Bot. 26(1): 56 (1979)

Material estudiado: O Porriño, Budiño, Orbenlle, observatorio ornitológico, 29TNG3061, $22 \mathrm{~m}$, en balsa de decantación sobre una pared de cemento recubierta de musgos, 15/032016, O. Requjeo, LOU-Fungi 20606.

Observaciones: apotecios pequeños. En la colección estudiada apenas superaban $10 \mathrm{~mm}$ de diámetro. Paráfisis septadas, al igual que los tricomas. Ascosporas de 20-24 x 10-12,5 $\mu \mathrm{m}$, a veces con 1-3 gútulas oleosas.

Semejante macroscópicamente a Geopora arenicola (Lév.) Kers, de la que se diferencia por el menor tamaño de apotecios y ascosporas y a Humaria hemisphaerica (F.H. Wigg.) Fuckel, pero esta tiene ascosporas verrucosas (Dennis 1981, Breitenbach \& Kränzlin 1984).

Ecología y distribución: se trata de un taxón que fructifica habitualmente bajo Salix, en suelos húmedos y arenosos. El material estudiado 
crecía semienterrado entre musgos y la arena acumulada por la erosión de una pared de cemento en una balsa de decantación, a veces anegada.

Escasamente georreferenciada, pero observada en Asia y Europa, incluida la Península Ibérica (GBIF en línea, no 5258622). No la conocemos citada de Galicia.

Gibellula pulchra Cavara [as 'pulcra'], Atti Ist. bot. R. Univ. Pavia, 2 Sér. 3: 347 (1894)

Material estudiado: Salceda de Caselas, Cerquido, Ponte Carneiro 29TNG3164, $35 \mathrm{~m}$, sobre aracnido sin identificar, en el envés de hoja de Alnus glutinosa, 02/10/2014, Roberto Requejo, LOU-Fungi 19798. O Porriño, Budiño, Orbenlle, observatorio ornitológico, 29TNG3061, 22 m, en el envés de una hoja de Salix atrocinerea, 1/12/2015, LOU-Fungi 20536.

Observaciones: este taxón parece corresponder con la forma conidial de Torrubiella aranicida Bound. (Palla Costa 2014), que se diferencia de Torrubiella arachnophila (J.R. Johnst.) Mains por los conidióforos más largos, de aspecto rugoso y ápice en vesícula.

Ecología y distribución: es común encontrar entomopatógenos en las Gándaras de Budiño. Todos los ejemplares recolectados fructificaban a finales de otoño, principios de invierno sobre arácnidos, en el envés de las hojas de especies arbóreas riparias.

Georreferenciada de los Países Escandinavos, Sur de África y Nueva Zelanda (GBIF en línea, $n^{\circ}$ 2560455). Escasamente citado en la Península Ibérica (Rubio-Domínguez en línea Moreno-Gámez en línea). No conocemos menciones para Galicia.

Helminthosphaeria clavariarum (Desm.) Fuckel, Jb. nassau. Ver. Naturk. 2324: 166 (1870) [1869-70]

Material estudiado: O Porriño, Budiño, Orbenlle, Os Eidos, 29TNG3022, 30 m, sobre Clavaria sp, 29/11/2014, O. Requejo, LOU-Fungi 19851. Salceda de Caselas, Cerquido, Ponte Carneiro 29TNG3164, 35 m, sobre clavariáceo, 27/12/2014, J.Á. Gándara, LOU-Fungi 19887. Salceda de Caselas, desembocadura del río Becerreira, 29TNG3019, 20 m, sobre clavariáceo, 26/09/2015, O. Requejo, LOU-Fungi 20278.

Observaciones: parásita de clavariáceos, sobre los que provoca ennegrecimiento y proliferación de pequeñas papilas de color negro. Ascosporas fusiformes de 10-15 x 6-7 $\mu \mathrm{m}$.

Ecología y distribución: frecuente en la zona de estudio sobre clavariáceos, especialmente en otoño cuando se combinan fuertes lluvias con elevadas temperaturas. 
Referenciada de Europa, incluida Península Ibérica (GBIF en línea, $\mathrm{n}^{\circ}$ 2572770). No conocemos referencias para Galicia.

Helvella atra J. König, in Olafsens \& Povelsens, Reisen ingien. Island, Append.: 20 (1770)

Material estudiado: Salceda de Caselas, Cerquido, Ponte Carneiro 29TNG3164, 35 m, bajo Quercus robur, 27/12/2014, J.Á. Gándara \& O. Requejo, LOU-Fungi 19897.

Ecología y distribución: fructificaba bajo Quercus robur, entre sus hojas caídas, en una zona afectada por la erosión causada por las crecidas del otoño.

Observada en el Hemisferio Norte, especialmente continente europeo (GBIF en línea, $n^{\circ}$ 2594709). En Galicia se conoce de las provincias litorales (Rodríguez-Vázquez \& Castro 2016).

Helvella lacunosa Afzel., K. Vetensk-Acad. Nya Handl. 4: 304 (1783)

Material estudiado: Salceda de Caselas, Cerquido, Ponte Carneiro 29TNG3164, 35 m, bajo Alnus glutinosa, 02/10/2014, O. Requejo, LOU-Fungi 19805.

Ecología y distribución: es una especie muy cosmopolita (Dennis 1981, Breitenbach \& Kränzlin 1984) y de amplia estacionalidad, aunque la fructificación del material estudiado no presentaba ninguna particularidad en ese aspecto.

Probablemente la especie más común del género en Europa. Extendida por el Hemisferio Norte (GBIF en línea, $\mathrm{n}^{\circ}$ 2594765). Muy común en Galicia (Soliño et al. 2000).

Helvella macropus (Pers.) P. Karst., Bidr. Känn. Finl. Nat. Folk 19: 37 (1871)

Material estudiado: O Porriño, Budiño, Orbenlle, observatorio ornitológico, 29TNG3061, 22 m, entre hojarasca de Quercus robur, Alnus glutinosa y Salix atrocinerea, 21/3/2013, LOU-Fungi 19762. Tui, Guillarei, aliseda de Albelos, 29TNG3019, 20 m, bajo Salix atrocinerea, 22/12/2015, O. Requejo, LOU-Fungi 20572. Tui, Guillarei, Albelos, 29TNG3043, 13 m, 26/12/2015, LOU-Fungi 20564.

Ecología y distribución: especie común, tanto bajo coníferas como caducifolios (Dennis 1981), la colección LOU-Fungi 20572 se recolectó en una zona inundable.

Ampliamente extendida por el Hemisferio Norte (GBIF en línea, $\mathrm{n}^{\circ}$ 2594776), mencionada para Galicia en las provincias de A Coruña, Lugo y Pontevedra (Soliño et al. 2000). 


\section{Hymenoscyphus herbarum (Pers.) Dennis, Persoonia 3 (1): 77 (1964).}

Material estudiado: O Porriño, Budiño, Orbenlle, observatorio ornitológico, 29TNG3061, 22 m, en turbera, sobre restos de planta herbácea, 30/4/2014, O. Requejo, LOU-Fungi 19764.

Ecología y distribución: recolectado sobre planta herbácea y turba, durante la época en la que baja el nivel del agua.

Parece tratarse de una especie común en Europa (Dennis, 1981); georreferenciada en Europa occidental y Australia (GBIF en línea, $n^{\circ} 2582384$ ). En la Península Ibérica se conoce de Andalucía (Moreno-Arroyo 2004); Navarra (García-Bona 2000) y Asturias (Rubio-Domínguez et al. 2006). No lo conocemos citado para Galicia.

Hypomyces aurantius (Pers.) Fuckel, Jb. nassau. Ver. Naturk. 23-24 : 183 (1870) [1869-70]

Material estudiado: Salceda de Caselas, desembocadura del río Becerreira, 29TNG3019, 20 m, sobre corticiáceo en rama de Quercus robur, 12/09/2015, O. Requejo, LOU-Fungi 20261.

Ecología y distribución: parece ser parasito de hongos, más comúnmente sobre poliporales (Breitenbach \& Kränzlin 1984). En esta ocasión fructificaba sobre un corticiáceo que no se ha conseguido identificar. Raro en la zona de estudio, a pesar de que es relativamente fácil ver los hospedantes durante todo el año.

Escasas referencias mundiales, a excepción de Centroeuropa, Noruega y Suecia (GBIF en línea, $n^{\circ}$ 2561856). También escasa para en la Península Ibérica, donde las citas se centran en la zona norte (Cortés et Montón 2004, RubioDomínguez 2005, Picón 2004, Fernández-Vicente \& Undagoitia 2009), con alguna mención en la isla de La Palma (Iglesias et al. 2011). En Galicia sólo ha sido mencionado de la provincia de A Coruña (Marcote et al. 2011).

Hypoxylon fuscum (Pers.) Fr., Summa veg. Scand., Section Post. (Stockholm): 384 (1849)

Material estudiado: Salceda de Caselas, Cerquido, Ponte Carneiro 29TNG3164, $35 \mathrm{~m}$, sobre rama caída sin identificar, 21/01/2015, O. Requejo, LOU-Fungi 20005. Salceda de Caselas, desembocadura del río Becerreira, 29TNG3019, $20 \mathrm{~m}$, sobre rama de Quercus robur, 31/07/2015, J. Valeiras y O. Requejo, LOU-Fungi 20235. 
Ecología y distribución: los ejemplares estudiados se recolectaron sobre sus substratos habituales (Dennis 1981, Breitenbach \& Kränzlin 1984), rama caída de Alnus en la colección LOU-Fungi 20235 y rama caída de frondosa sin identificar, presumiblemente Alnus o Quercus, para LOU-Fungi 20005.

Ampliamente referenciado para Europa, pero también para Australia y América del Norte y del Sur (GBIF en línea, $\mathrm{n}^{\circ}$ 5254797). Para el territorio gallego se conoce de A Coruña, Lugo y Pontevedra (Rodríguez-Vázquez \& Castro 2016).

Hypoxylon howeanum Peck [as 'howeianum'], Ann. Rep. N.Y. St. Mus. 24: 98 (1872)

Material estudiado: Salceda de Caselas, desembocadura del río Becerreira, 29TNG3019, $20 \mathrm{~m}$, sobre rama en bosque de Alnus glutinosa y Quercus robur, 12/09/2015, LOU-Fungi 20262.

Ecología y distribución: se ha recolectado en bosque aluvial de Alnus glutinosa y Quercus robur, sobre un trozo de rama que no se pudo identificar, alojada sobre la turba.

Observado en Centroeuropa, Países Escandinavos y Japón (GBIF en línea, $n^{\circ}$ 5254707). En la Península Ibérica no parece un taxón muy extendido y con preferencias por el norte dado las citas encontradas (Pérez-Butrón et al. 2011, Rubio-Domínguez et al. 2006, Picón 2004, Cortés (2001), Fernández-Vicente \& Undargoitia 2009). Se conoce para Galicia, Pontevedra, desde la cita de Pérez Froiz (1996) y recientemente de la de A Coruña (Marcote et al. 2011).

Isaria farinosa (Holmsk.) Fr., Syst. mycol. (Lundae) 3 (2): 271 (1832).

$\equiv$ Paecilomyces farinosus (Holmsk.) A.H.S. Br. \& G. Sm., Trans. Br. mycol. Soc. 40(1): 50 (1957)

Material estudiado: O Porriño, Budiño, Orbenlle, observatorio ornitológico, 29TNG3061, $22 \mathrm{~m}$, en el hueco de un tronco de Salix atrocinerea sobre una pupa de insecto sin identificar, 07/12/2013, O. Requejo, LOU-Fungi 19768. Salceda de Caselas, Cerquido, 29TNG3164, $30 \mathrm{~m}$, sobre pupa de insecto sin identificar, 27/9/2014, O. Requejo, LOUFungi 19790.

Observaciones: este taxón fue erróneamente considerado forma anamorfa de Cordyceps militaris (L.) Fr., a pesar de que esta sinonimización había sido justificadamente rechazada por Petch (1936), al menos hasta que estudios moleculares demuestren lo contrario.

Ecología y distribución: es una especie común en la zona de estudio, la colección LOU-Fungi 19768, se encontró en plena turbera en el hueco del tronco de Salix atrocinerea. 
Se trata de una especie escasamente georreferenciada (GBIF en línea, $\mathrm{n}^{\circ}$ 5260125), con distribución mal conocida, en parte por la reiterada confusión con formas anamorfas de diversas especies del género Cordyceps (Petch 1936, Dennis 1981). Para Galicia aparece citada por Marcote \& Requejo (2012).

Lachnum tenuissimum (Quél.) Korf \& W.Y. Zhuang, Mycotaxon 22 (2): 501 (1985)

三Dasyscyphus tenuissimus (Kuntze) Dennis, Kew Bull. 17(2): 370 (1963)

Material estudiado: O Porriño, Budiño, Orbenlle, observatorio ornitológico, 29TNG3061, 22 m, sobre ramas caídas de Salix atrocinerea en la turbera, 20/7/2013, O. Requejo, LOU-Fungi 19766.

Observaciones: las ascosporas de la colección analizada son ligeramente más anchas $(7,5-8 \times 2 \mu \mathrm{m})$ que las indicadas por Breitenbach \& Kränzlin (1984); no obstante, el resto de caracteres como la ausencia de septos en las paráfisis y forma de los pelos del receptáculo la diferencian de especies con morfología y hábitat similares como L. virgineum (Batsch) P. Karst. o Dasyscyphella nivea (R. Hedw.) Raitv.

Ecología y distribución: recolectado fructificando en ramas caídas sobre turba, durante la época en que baja el nivel hídrico.

Ha sido ampliamente georreferenciada para Europa occidental y aparentemente sólo en dos localidades ibéricas: Alicante (GBIF en línea, $\mathrm{n}^{\circ}$ 2586081) y Asturias (Rubio-Domínguez et al. 2006). No la conocemos citada para Galicia.

Lachnum virgineum (Batsch) P. Karst., Bidr. Känn. Finl. Nat. Folk 19: 169 (1871)

Material estudiado: O Porriño, Budiño, Orbenlle, mirador ornitológico, 29TNG3061, 22 m, sobre ramas sin identificar, 04/05/2014, O. Requejo, LOU-Fungi 19767. O Porriño, Pontellas, barreras de Centeáns, 29TNG3007, 20 m, sobre ramilla de Salix atrocinerea, 15/06/2015, O. Requejo, LOU-Fungi 20210.

Ecología y distribución: posiblemente la especie más común sobre pequeñas ramas caídas en los humedales de la zona de estudio, durante las épocas en que baja el nivel del agua.

Georreferenciada tanto para Europa como América Central y del Norte, así como Nueva Zelanda (GBIF. en línea $n^{\circ}$ 2586107). En la Península Ibérica encontramos varias citas en la mitad norte (Moreno et al. 2004, RubioDomínguez et al. 2006, Picón 2005; Pérez-Butrón et al. 2011, Vidal 1998b, 
Ribes-Ripoll en línea). Para Galicia encontramos varias citas en A Coruña, Lugo y Pontevedra (Rodríguez-Vázquez \& Castro 2016, Marcote et al. 2011, Requejo 2012).

Lasiosphaeris hirsuta (Fr.) A.N. Mill. \& Huhndorf, Mycol. Res. 108 (1): 31 (2004)

Material estudiado: Salceda de Caselas, Cerquido, Ponte Carneiro, 29TNG3164, 35 m, sobre rama de Alnus glutinosa, 27/12/2014, O. Requejo, LOU-Fungi 20238.

Observaciones: Dennis (1981) le adjudica ascosporas de 55-65 $\mu \mathrm{m}$ de largo; sin embargo, en la colección estudiada las encontramos hasta $67 \mu \mathrm{m}$, coincidiendo con Ribes-Ripoll (en línea), que indica hasta $70 \mu \mathrm{m}$ y por Merdari (2006) hasta 72.

Ecología y distribución: recolectado en bosque aluvial, en zonas de inundación, especie rara en la zona de estudio.

Conocida de Europa, así como Norte y Centroamérica (GBIF en línea, $n^{\circ}$ 2572904), pocos registros para la Península Ibérica (Ribes-Ripoll en línea, Rubio-Domínguez et al. 2006, Picón 2004, Fernández-Vicente \& Undagoitia 2009). Para Galicia se encontró una reciente cita de Pontevedra (De la Peña 2016).

Leotia lubrica (Scop.) Pers., Comm. fung. clav. (Lipsiae): 31 (1797)

Material estudiado: O Porriño, Budiño, Orbenlle, Os Eidos, 29TNG3022, $30 \mathrm{~m}$, bajo Quercus robur y Pinus pinaster en muro con musgos, 30/11/2014, O. Requejo, LOUFungi 19843. Salceda de Caselas, Cerquido, Ponte Carneiro 29TNG3164, 35 m, bajo Quercus robur, 27/12/2014, J.Á. Gándara \& O. Requejo, LOU-Fungi 19888.

Ecología y distribución: frecuente en todas las zonas húmedas de Galicia (Rodríguez-Vázquez \& Castro 2016). En Las Gándaras crece en bosque mixto de Quercus robur y Pinus pinaster, algo más alejado y elevado que los humedales.

Taxón ampliamente distribuido por el Hemisferio Norte, Australia y Nueva Zelanda (GBIF en línea, $n^{\circ} 2577646$ ).

Mollisia olivascens (Feltgen) Le Gal \& F. Mangenot, Revue Mycol. 23: 54 (1958)

= Haglundia perelegans Haglund ex Nannf., Nova Acta R. Soc. Scient. upsal., Ser. 48 (2): 108 (1932)

Material estudiado: O Porriño, Budiño, Orbenlle, observatorio ornitológico, 29TNG3061, 22 m, sobre madera de Alnus glutinosa, 10/05/2015, C. Ayres, LOU-Fungi 20203. 
Observaciones: ascosporas de 8-10 x 1,5-2 $\mu \mathrm{m}$, ligeramente más grandes que las indicadas por Dennis (1981), no obstante, Le Gal \& Mangenot (1960) dejan patente la variabilidad en el tamaño esporal. Reacción con $\mathrm{KOH}$ amarillo fuerte.

Ecología y distribución: fructificaba sobre madera muy degradada de Alnus glutinosa que se encontraba en zona de turba constantemente húmeda. Es un taxón raro en la zona de estudio, ya que no hubo más observaciones para este mismo hábitat ni otros similares.

Georreferenciada de Centro Europa, Países Escandinavos e Inglaterra (GBIF en línea, $\mathrm{n}^{\circ}$ 2585094). No se encontraron referencias bibliográficas para la Península Ibérica.

Nemania aenea (Nitschke) Pouzar, Česká Mykol. 39 (3): 129 (1985)

三 Hypoxylon aeneum Nitschke, Pyrenomyc. Germ. 1: 47 (1867)

= Nemania aenea var. aureolutea (L.E. Petrini \& J.D. Rogers) Y.M. Ju \& J.D. Rogers, Nova Hedwigia 74(1-2): 84 (2002)

= Nemania aenea var. macrospora (J.H. Mill.) Y.M. Ju \& J.D. Rogers, Nova Hedwigia 74(1-2): 85 (2002)

Material estudiado: Salceda de Caselas, desembocadura del río Becerreira, 29TNG3019, $20 \mathrm{~m}$, sobre madera en bosque de Quercus robur y Alnus glutinosa, 12/09/2015, O. Requejo, LOU-Fungi 20264.

Observaciones: el material estudiado presenta ascosporas de 17-20(22) x 5-7,5 $\mu \mathrm{m}$, con la hendidura germinativa apenas visible y fuerte reacción amiloide en el opérculo de las ascas. Este tamaño sobrepasa los valores indicados por Fournier \& Magni (en línea), pero es semejante al indicado por Rubio (en línea) para N. aenea var. aureolutea (L.E. Petrini \& J.D. Rogers) Y.M. Ju \& J.D. Rogers, aunque descartamos que se trate de esta variedad por la fuerte reacción amiloide que muestra la colección estudiada. Sin embargo, la hendidura germinativa apenas visible, junto con las medidas de las ascosporas indican que puede tratarse de N. aenea var. macrospora (J.H. Mill.) Y.M. Ju \& J.D. Rogers.

Ecología y distribución: recolectado en bosque de ribera, bajo Quercus robur y Alnus glutinosa, en zona muy húmeda y sombría sobre madera muy deteriorada que no se consiguió identificar.

De la especie tipo no se conoce con precisión su distribución mundial; pero ha sido observada en Noruega, Dinamarca, Estonia, Alemania, Suiza, Península Ibérica, Portugal, Canadá y Estados Unidos (GBIF en línea, $n^{\circ} 82955$ ). No conocemos citas para Galicia para ninguna de las variedades. 
Ombrophila violacea (Hedw.) Fr., Summa veg. Scand., Section Post. (Stockholm): 357 (1849).

Material estudiado: O Porriño, Budiño, Orbenlle, observatorio ornitológico, 29TNG3061, 22 m, Sobre tocón de Populus nigra, 28/2/2009, O. Requejo, LOU-Fungi 19765.

Ecología y distribución: parece ser una especie sin preferencia específica por el sustrato, pudiendo fructificar tanto sobre madera, como en la recolección efectuada en Las Gándaras, como sobre hojas (Dennis, 1981) o plantas herbáceas y leñosas (Marcote et al. 2011).

Especie poco frecuente (Dennis, 1981), georreferenciada con mayor frecuencia en los países occidentales de Europa (GBIF en línea, $\left.n^{\circ} 2582019\right)$. En el N.O. Ibérico ha sido publicada por Rubio-Domínguez et al. (2005), Requejo (2010), Marcote et al. (2011) y Blanco-Dios (2014).

Paxina queletii (Bres.) Stangl., Ber. naturhist. Augsburg 16: 114 (1963)

$\equiv$ Helvella queletii Bres., Fung. trident. 1 (3): 39 (1882)

Material estudiado: O Porriño, Budiño, Orbenlle, observatorio ornitológico, 29TNG3061, 22 m, bajo Quercus robur y Salix atrocinerea, 21/3/2013, O. Requejo, LOUFungi 19760. Ibídem, bajo Alnus glutinosa y Quercus robur, 04/5/2014, O. Requejo, LOU-Fungi 19787.

Observaciones: se trata de una especie fácil de diferenciar por el estipe acostillado que soporta un único receptáculo en forma de copa (Breitenbach \& Kränzlin, 1984). Landerós \& Guzmán-Dávalos (2012) han considerado esta especie como sinónima de Helvella solitaria P. Karst.; sin embargo, esta propuesta no es asimilada en Mycobank (en línea) e Index Fungorum (en línea).

Ecología y distribución: En la zona de estudio es muy común en primavera, entre las hojas caídas en bosques de frondosas, incluso en zonas inundables.

Observada en el Hemisferio Norte, Europa central y Países Escandinavos (GBIF en línea, $n^{\circ}$ 2594699). Citada en el N.O. Ibérico desde Pérez Froiz (1996).

Peroneutypa scoparia (Schwein.) Carmarán \& A.I. Romero, in Carmarán, Romero \& Giussani, Fungal Diversity Res. Ser. 23: 84 (2006)

Material estudiado: Tui, Guillarei, Albelos, 29TNG3043, 13 m, sobre madera sin identificar, 22/12/2015, O. Requejo, LOU-Fungi 20551. 
Ecología y distribución: recolectada en bosque de ribera sobre madera sin identificar, aunque las especies arbóreas presentes eran Quercus robur, Alnus glutinosa y Salix atrocinerea. Es una especie poco común en la zona de estudio.

Georreferenciada para Francia, Italia, Centroeuropa, Islas Británica, Suecia, Canadá, Nueva Zelanda y Centroamérica (GBIF en línea, $\mathrm{n}^{\circ} 2575318$ como Eutypella). En la Península Ibérica es muy poco conocida, apenas se encontraron citas (Rubio-Domínguez et al. 2006, Picón 2004, Cortés 2009). En Galicia se ha recolectado en A Coruña (Marcote et al. 2011) y Pontevedra (Requejo Martínez 2010).

Peziza domiciliana Cooke, Gard. Chron., N.S. 8: [1] (1877)

Material estudiado: Salceda de Caselas, Cerquido, Ponte Carneiro, 29TNG3164, 35 m, directamente sobre barro, 02/10/2014, O. Requejo, LOU-Fungi 20247.

Observaciones: especie con ascosporas ligeramente punteadas a microscopio óptico (inmersión), de 18-20 x $10 \mathrm{~mm}$, paráfisis cilíndricas, septadas y ligeramente ensanchadas en el ápice. Es semejante a Peziza repanda Wahlenb. y P. varia (Hedw.) Alb. \& Schwein., pero ambas presentan ascosporas totalmente lisas y más cortas, no sobrepasan las $16 \mathrm{~mm}$ de longitud (Medardi 2006).

Ecología y distribución: se ha recolectado fructificando en un camino en el que se había formado un barrizal con arcillas (caolín) y algún escombro procedente de obras que, en épocas lluviosas, permanece inundado. La zona estaba abovedada por Salix atrocinerea.

No se conoce su distribución mundial con precisión (GBIF en línea), en buena medida por la dificultad de identificarla sólo por caracteres macroscópicos. En la Península Ibérica se puede considerar como una especie rara (RubioDomínguez et al. 2006). Para Galicia ha sido mencionado para A Coruña (Bellot \& Casaseca 1960, Marcote et al. 2011) y Pontevedra (Castro et al. 1997).

Peziza succosa Berk., Ann. Mag. nat. Hist., Ser. 1 6: 358 (1841)

Material estudiado: Tui, Guillarei, aliseda de Albelos, 29TNG3019, 20 m, bajo Salix atrocinerea y Alnus glutinosa, 22/12/2015, O. Requejo, LOU-Fungi 20619.

Ecología y distribución: esta especie fructificaba en una aliseda con el sotobosque turboso y desnudo, apenas recubierto por musgos y restos de los árboles, el nivel de humedad era muy alto.

Ampliamente extendida por el Hemisferio Norte, también mencionada de Sudamérica y Australia (GBIF en línea, $n^{\circ}$ 5259214). En Galicia sólo ha sido citada en la provincia de A Coruña (Pérez Froiz, 1996). 
Pezizella alniella (Nyl.) Dennis, Mycol. Pap. 62: 56 (1956)

Material estudiado: O Porriño, Budiño, Orbenlle, observatorio ornitológico, 29TNG3061, 22 m, sobre amentos femeninos de Alnus glutinosa, 28/03/2011, O. Requejo, LOU-Fungi 19740. Salceda de Caselas, Cerquido, Ponte Carneiro 29TNG3164, 35 m, sobre amentos femeninos de Alnus glutinosa, 25/01/2015, O. Requejo, LOU-Fungi 19932.

Ecología y distribución: todas las recolecciones fueron efectuadas sobre su sustrato habitual (Dennis 1981, Breitenbach \& Kränzlin 1984), es una especie común en comunidades de alisos.

Ampliamente georreferenciada en Europa occidental. También mencionada de Nueva Zelanda y Canadá (GIBF en línea ${ }^{\circ}$ 5357165). Para Galicia sólo ha sido observada en la localidad de estudio (Requejo \& Parada Miniño 2011).

Propolis farinosa (Pers.) Fr., Summa veg. Scand., Section Post. (Stockholm): 372 (1849)

= Propolis versicolor $($ Fr.) Fr., Summa veg. Scand., Sectio Post. (Stockholm): 372 (1849)

Material estudiado: O Porriño, Budiño, Orbenlle, Os Eidos, 29TNG3022, 30 m, sobre madera de Acacia melanoxylon, 21/3/2013, O. Requejo, LOU-Fungi 19757.

Ecología y distribución: es uno de los pocos macromicetos que, de alguna forma encontramos asociados a esta fabácea alóctona. No parece ser una especie muy exigente en cuanto al sustrato (Dennis 1981, Breitenbach \& Kränzlin 1984).

Se trata de una taxón georreferenciado en el Hemisferio Norte, especialmente en el continente europeo, incluidas las Islas Británicas e Islandia. También en Canadá, Estados Unidos y México (GBIF nº 2579078). En Península Ibérica ha sido mencionada por Rocabruna (1999), LLamas \& Terrón (2003) y Siquier et al. (2009). No la conocemos citada de Galicia.

Pyrenopeziza revincta (P.Karst.) Gremmen, Fungus, Wageningen 28: 42 (1958) $\equiv$ Mollisia revincta (P. Karst.) Rehm, in Winter, Rabenh. Krypt.-Fl., Edn 2 (Leipzig) 1.3(lief. 55): 1264 (1896)

Material estudiado: O Porriño, Budiño, Orbenlle, observatorio ornitológico, 29TNG3061, 22 m, sobre tallo de Typha latifolia, 07/9/2013, O. Requejo, LOU-Fungi 19758.

Ecología y distribución: crecía saprotrófica sobre tallo de Typha latifolia muerto y completamente embebido por el agua de la laguna. 
Georreferenciada únicamente en los países nórdicos (GBIF en línea, ${ }^{\circ}$ 2583887). En la Península Ibérica es un taxón poco conocido con escasas citas (Rubio-Domínguez et al. 2006, Picón 2004). En Galicia ha sido mencionada de Pontevedra (De la Peña 2016).

Rosellinia mammiformis (Pers.) Ces. \& De Not., Commentario della Società Crittogamologica Italiana 1 (4): 227 (1863)

三 Hypoxylon mammiforme (Pers.) Berk. [as 'mammaeforme'], Grevillea 4(30): 52 (1875)

Material estudiado: Salceda de Caselas, desembocadura del río Becerreira, 29TNG3019, 20 m, sobre rama sin identificar, 31/07/2015, J. Valeiras, LOU-Fungi 20236.

Ecología y distribución: especie recolectada en bosque ripario formado por Quercus robur, Alnus glutinosa y Salix atrocinerea, en zona donde el agua arrastró y acumuló ramas caídas, por lo que no se pudo concretar a que especie arbórea pertenecía el substrato. Parece ser un ascomiceto común sobre ramas de caducifolio (Dennis 1981).

Georreferenciada de Centroeuropa, Islas Británica, países nórdicos, Islas Canarias y Nueva Zelanda (GBIF en línea, $n^{\circ}$ 2576677). En la Península Ibérica parece preferir el norte, la encontramos en el País Vasco (Picón 2004), Cantabria (Pérez-Butrón et al. 2011) y Asturias (Rubio Domínguez et al. 2005). En Galicia mencionada para A Coruña (Pérez Froiz 1998) y Pontevedra (Requejo 2012, De la Peña 2016).

Rutstroemia firma (Pers.) P.Karst., Bidr. Känn. Finl. Nat. Folk 19: 108 (1871).

Material estudiado: O Porriño, Budiño, 29TNG3061, $22 \mathrm{~m}$, sobre pequeñas ramas de Alnus glutinosa, 22/4/2014, O. Requejo, LOU-Fungi 19773. Salceda de Caselas, Cerquido, Ponte Carneiro 29TNG3164, 35 m, sobre ramas caídas de Salix atrocinerea, 25/01/2015, O. Requejo, LOU-Fungi 19927.

Ecología y distribución: común en la zona de estudio, creciendo saprotrófico sobre ramas de caducifolio caídas. Parece tratarse de un taxón frecuente (Dennis 1981) y está ampliamente georreferenciada en los países occidentales de Europa (GBIF en línea, $\mathrm{n}^{\circ}$ 2580410). En Galicia aparece ampliamente citada (Rodríguez-Vázquez \& Castro 2016).

Scutellinia cejpii (Velen.) Svrček, Česká Mykol. 25(2): 83 (1971)

Material estudiado: O Porriño, Budiño, Orbenlle, Os Eidos, 29TNG3022, 30 m, bajo Salix atrocinerea sobre turba y madera, 07/12/2013, O. Requejo, LOU-Fungi 20626.

Observaciones: esporas de 20-23,5 $\mu \mathrm{m}$, oblongo elipsoidales, con ornamentación verrucosa. Parafisis con ápices ensanchados hasta $8 \mu \mathrm{m}$. Los pelos 
marginales que llegan hasta casi $500 \mu \mathrm{m}$, con base bifurcada y paredes anchas, con 1-4 septos son aspectos característicos de la especie (Jeannerot 2010).

Ecología y distribución: fructificaba bajo Salix atrocinerea, sobre turba y restos leñosos acumulados por el arrastre del agua en época de crecidas.

Georreferenciada principalmente en el norte de Europa, Islas Británicas y la parte más oriental de Rusia, pero también conocido, aunque en menor medida en Canadá y Corea del norte (GBIF en línea, $n^{\circ}$ 2593906). Parece no ser un taxón muy común en la Península Ibérica (Rubio-Domínguez et al. 2006, Suárez \& Suárez Gracia 2012), ya conocido en Pontevedra (Rodríguez-Vázquez \& Castro 2016).

Scutellinia scutellata (L.) Lambotte, Mém. Soc. roy. Sci. Liège, Série 2 14: 299 (1887)

Material estudiado: O Porriño, Budiño, 29TNG3061, $22 \mathrm{~m}$, sobre madera sin identificar, 21/3/2013, O. Requejo, LOU-Fungi 19772. Ibídem, sobre restos de ramas de Salix atrocinerea y turba, 05/4/2014, O. Requejo, LOU-Fungi 19788.

Ecología y distribución: el material estudiado se recolectó sobre su sustrato habitual, madera (Dennis 1981, Breitenbach \& Kränzlin 1984). Especie muy común en primavera en todas las zonas húmedas de la zona de estudio.

Ampliamente georreferenciado en el Hemisferio Norte, pero también en América del Sur, Australia y Nueva Zelanda (GBIF en línea, no 2593897). En el N.O. Ibérico aparece ampliamente mencionada (Rodríguez-Vázquez \& Castro 2016).

Tarzetta catinus (Holmsk.) Korf \& J.K. Rogers, Phytologia 21 (4): 206 (1971)

Material estudiado: O Porriño, Pontellas, barreras de Centeáns, 29TNG3007, 20 $\mathrm{m}$, bajo Salix atrocinerea, entre turba, 05/03/2015, O. Requejo, LOU-Fungi 20004. Tui, Guillarei, aliseda de Albelos, 29TNG3019, 20 m, bajo Salix atrocinerea y Alnus glutinosa, 22/12/2015, O. Requejo, LOU-Fungi 20567.

Observaciones: en la revisión de la colección LOU-Fungi 20004 se observan ascosporas unigutuladas en el centro, carácter no indicado en la descripción dada por Dennis (1981), el resto de los caracteres son coincidentes con los observados por este autor.

Ecología y distribución: es una especie común en los bosques aluviales de Las Gándaras, fructifica directamente sobre suelo turboso.

No se georreferencia a nivel mundial, pero se indica su presencia en Dinamarca, Suecia, Noruega, Bélgica, Alemania, Italia, Península Ibérica, etc. (GBIF en línea, $\mathrm{n}^{\circ}$ 79469). En Galicia se ha observado en Lugo, Ourense y Pontevedra (Rodríguez-Vázquez \& Castro 2016). 
Tolypocladium ophioglossoides (J.F. Gmel) Quandt, Kepler \& Spatafora in Quandt, Kepler, Gams et al., IMA Fungus 5: 127 (2014)

三Cordyceps ophioglossoides (J.F.Gmel.) Fr., Hand. Erk. Nutzb. Häufig. Vork. Gew. 3: 347 (1818)

$\equiv$ Elaphocordyceps ophioglossoides (Ehrh.) G.H. Sung, J.M.Sung \& Spatafora, in Sung, Hywel-Jones, Sung, Luangsa-ard, Shrestha \& Spatafora, Stud. Mycol. 57 : 37 (2007)

Material estudiado: O Porriño, Budiño, Orbenlle, observatorio ornitológico, 29TNG3061, 22 m, sobre Elaphomyces granulatus, 13/8/2014, O. Requejo, LOU-Fungi 19769.

Observaciones: este taxón incluido antiguamente en el género Cordyceps, en base a estudios filogenéticos se ha incluido en el género creado recientemente (Sung et al. 2007).

Ecología y distribución: el ejemplar citado se encontró en bosque mixto de Pinus pinaster y Quercus robur, parasitando ascocarpos de Elaphomyces granulatus. También se ha observado parasitando Elaphomyces en la colección LOU-Fungi 20245, pero no se ha conservado dicha exsiccata al estar muy degradado el material. Todas las observaciones se realizaron alejadas de zonas húmedas.

Se conoce en el Hemisferio Norte, donde algunos autores la indican como rara (Dennis, 1981), mientras que otros la consideran común (Gerhardt et al. 2000). Parece ser muy frecuente en Suecia (GBIF en línea, $n^{\circ}$ 2564386). En el N.O. Ibérico no es frecuente, aunque está ampliamente extendido (RodríguezVázquez \& Castro 2016).

Torrubiella arachnophila (J.R. Johnst.) Mains, Mycologia 42 (2): 316 (1950) 三 Cordyceps arachnophila J.R. Johnst., Bull. Porto Rico Insula Exp.Stn. 10: 23 (1915)

Material estudiado: Tui, Guillarei, turbera de Albelos, 29TNG3036, $20 \mathrm{~m}$, sobre arácnido en el envés de una hoja, 07/08/2015, O. Requejo, LOU-Fungi 20256.

Observaciones: encontrado en forma anamorfa Gibellula leiopus (Vuill. ex Maubl.) Mains. Se diferencia de G. pulchra por tener los conidióforos no rugosos, de hasta $80 \mu \mathrm{m}$ y el ápice en cuña o semi peniciliado (Tzean et al. 1997).

Ecología y distribución: al igual que G. pulchra, esta especie se encontró parasitando una araña en el envés de una hoja.

Como Torrubiella se referencia sólo de Dinamarca, Holanda, Canadá y Nueva Zelanda (GBIF en línea, $n^{\circ}$ 3452062) y como Gibellula, de Suecia (GBIF en línea, $n^{\circ}$ 2560454). Para la Península Ibérica la encontramos citada como anamorfo en Asturias (Rubio-Domínguez en línea). No la conocemos de Galicia. 
Trichoderma piluliferum J. Webster \& Rifai, in Rifai, Mycol. Pap. 116: 16 (1969)

三Hypocrea pilulifera J. Webster \& Rifai, Trans. Br. mycol. Soc. 51 (3-4): 511 (1968)

Material estudiado: Tui, Guillarei, aliseda de Albelos, 29TNG3019, $20 \mathrm{~m}$, sobre ramas de diversas plantas y árboles, 23/12/2015, O. Requejo, LOU-Fungi 20591.

Observaciones: presenta estromas pulvinados de color amarillo pálido, con los ostiolos translúcidos en fresco, anaranjados al secar. Al rehidratar con $\mathrm{KOH}$ adquiere aspecto acuoso, pero sin cambios de coloración aparentes. Peritecios globosos, de 250-300 $\mu \mathrm{m}$, ostiolos que rondan las $100 \mu \mathrm{m}$ de largo. Ascosporas globosas a subglobosas, de 3-5 x 3-4 (5) $\mu \mathrm{m}$, verrucosas. Semejante a Hypocrea placentula Grove, que se diferencia por su estroma más pálido en $\mathrm{KOH}$ y ascosporas y peritecio más pequeños (Jaklitsch 2011).

En Index Fungorum (en línea) se indica como binomem actual al anamorfo Trichoderma piluliferum J. Webster \& Rifai (Rifai 1969) considerándolo como si se tratara de la forma teleomorfa, sin embargo, debe ser un error como se ha demostrado con otras especies del género (Bezerra et al. 2003, Lu et al. 2004, Druzhinina \& Kubicek 2005), por ello se prioriza Hypocrea.

Ecología y distribución: Webster \& Rifai (1968) y Lu et al. (2004) lo consideran asociado a abedules, aunque con apariciones ocasionales sobre Juncus. Los ejemplares estudiados se recogieron en una aliseda inundable, predominantemente sobre pequeñas ramas de Salix atrocinerea, Rubus sp. y otras pequeñas ramas de plantas herbáceas sin identificar, todas ellas secas, por lo que pensamos que su estrategia nutricional es saprotrófita. Muy abundante en la zona donde se localizó, no así en el resto de las zonas muestreadas.

Georreferenciada únicamente de Suecia (GBIF en línea, $n^{\circ}$ 2561454). No se encontraron referencias para la Península Ibérica.

Xylaria hypoxylon (L.) Grev., Fl. Edin.: 355 (1824)

Material estudiado: Salceda de Caselas, Cerquido, Ponte Carneiro 29TNG3164, 35 m, sobre rama de árbol sin identificar, 27/12/2014, J.Á. Gándara, LOU-Fungi 19892. Salceda de Caselas, desembocadura del río Becerrera, 29TNG3019, $20 \mathrm{~m}$, sobre restos leñosos, 10/11/2015, O. Requejo, LOU-Fungi 20515. Tui, Guillarei, Albelos, 29TNG3043, 13 m, 22/12/2015, sobre madera sin identificar, O. Requejo, LOU-Fungi 20552.

Ecología y distribución: especie muy común en toda la zona de estudio, siempre sobre restos leñosos muy degradados o recubiertos por musgos, lo que dificulta la identificación de los mismos. 
Taxón ampliamente georreferenciado por todo el planeta, especialmente en Europa occidental (GBIF en línea, $\mathrm{n}^{\circ}$ 5255147). Ampliamente distribuida por Galicia (Soliño et al. 2000).

Xylaria longipes Nitschke, Pyrenomyc. Germ. 1: 14 (1867)

Material estudiado: O Porriño, Budiño, Orbenlle, observatorio ornitológico, 29TNG3061, 22 m, sobre madera de Salix atrocinerea, 10/2/2014, O. Requejo, LOUFungi 19761. Tui, Guillarei, Albelos, 29TNG3043, 13 m, sobre madera sin identificar, 22/12/2015, O. Requejo, LOU-Fungi 20553.

Observaciones: se caracteriza por presentar un estipe bien definido, poseer ostíolos que sobresalen en la superficie, así como la tendencia de ésta a arrugarse y/o agrietarse (Dennis 1981). Es semejante macroscópicamente a $X$. polymorpha (Pers.) Grev., que se diferencia por los ascostromas más esbeltos y mucronados y las ascosporas de menor tamaño, que no sobrepasan $16 \mu \mathrm{m}$ de longitud frente a las $29 \mu \mathrm{m}$ de $X$. polymorpha.

Ecología y distribución: no es tan común como $X$. hypoxylon, pero es relativamente fácil obsrevarla, también, siempre sobre madera muerta.

Ampliamente distribuida en zonas templadas del Hemisferio Norte (San Martin \& Rogers 1989). Georreferenciada para Europa occidental, India, Australia, México, Estados Unidos y Canadá (GBIF en línea, nº 5255093). Citada en casi toda Galicia excepto Ourense (Rodríguez-Vázquez \& Castro 2016). 


\subsubsection{Basidiomycota}

Abortiporus biennis (Bull.) Singer, Mycologia 36 (1): 68 (1944)

Material estudiado: Tui, Guillarei, Albelos, 29TNG3043, 13 m, sobre Quercus robur, 09/11/2015, O. Requejo, LOU-Fungi 20299.

Ecología y distribución: el material revisado fructificaba sobre la base de un Quercus robur vivo, si bien es una especie habitualmente observada sobre restos leñosos. Común, extendida por el Hemisferio Norte, mayoritariamente en Europa (GBIF en línea, $\mathrm{n}^{\circ}$ 2544114). Frecuente en la Península Ibérica, también en Galicia (Soliño et al. 2000).

Agaricus arvensis Schaeff., Fung. bavar. palat. nasc. (Ratisbonae) 4: 310 (1774)

Material estudiado: O Porriño, Budiño, Orbenlle, Os Eidos, 29TNG3022, 30 m, bajo Quercus robur, 29/11/2014, A. Prunell y A. Díaz, LOU-Fungi 19840.

Ecología y distribución: recolectado entre hojas, bajo Quercus robur en bosque mixto donde también había Pinus pinaster y sotobosque de matorral poblado de Rubus sp., la zona estaba alejada de los húmedales..

Referenciada en el Hemisferio Norte. También se conoce de Australia (GBIF en línea, $n^{\circ}$ 5243429). Común en la Península Ibérica, también frecuente en Galicia (Soliño et al. 1999).

Agaricus augustus Fr., Epicr. syst. mycol. (Upsaliae): 212 (1838)

Material estudiado: O Porriño, Budiño, Orbenlle, observatorio ornitológico, 29TNG3061, 22 m, bajo Quercus suber, 20/07/2013, O. Requejo, LOU-Fungi 19955.

Ecología y distribución: especie de aparicíon estival, ha sido recolectada entre hojas bajo Quercus suber, próximo a Quercus robur.

Común en el Hemisferio Norte, aunque también se conoce de Australia (GBIF en línea, $n^{\circ}$ 5243429). También ampliamente distribuido por toda Europa, en todo tipo de bosques (Nauta 2000, Parra 2013). Frecuente en Galicia, especialmente en el litoral (Soliño et al. 1999).

Agaricus campestris L. Sp. pl. 2: 1173 (1753)

Material estudiado: Tuy, Rebordanes, Ponte das Febres 29TNG2996, 21 m, entre hierbas y hojas, 02/10/2016, Marta Martínez, LOU-Fungi 20631.

Ecología y distribución: común a principios de otoño en zonas herbosas que habitualmente no se anegan y bordes de caminos. 
Georreferenciado principalmente en toda Europa y Norteamérica, escasas reseñas en América del sur y Oceanía (GBIF en línea, nº 8089803). Ampliamente distribuido en toda Europa (Parra 2008). Es la especie del género más recolectada en Galicia (Rodríguez-Vázquez \& Castro 2016)

Amanita citrina Pers., Tent. disp. meth. fung. (Lipsiae): 66 (1797)

Material estudiado: O Porriño, Budiño, Orbenlle, observatorio ornitológico, 29TNG3061, 22 m, bajo Quercus robur, 03/11/2013, O. Requejo, LOU-Fungi 19985.Tui, Guillarei, Albelos, 29TNG3043, 13 m, en bosque de Pinus pinaster, 09/11/2015, O. Requejo, LOU-Fungi 20506.

Ecología y distribución: fácil de observar en otoño, micorrizando en todos los bosques mixtos y riparios muestreados, no tan presente en bosques aluviales y zonas más húmedas.

Común en el Hemisferio Norte (GBIF en línea, nº 3328320), también en la Península Ibérica (Castro 1996); sin embargo, las citas de este taxón en Asia y Norteamérica pueden corresponderse en parte a otras especies próximas (Neville \& Poumarat 2004). Muy frecuente en Galicia (Soliño et al. 1999).

Amanita excelsa (Fr.) Bertill., in Dechambre, Dict. Encyclop. Sci. Médic. 1(3): 499 (1866)

Material estudiado: O Porriño, Budiño, Orbenlle, observatorio ornitológico, 29TNG3061, 22 m, bajo Pinus pinaster, 29/11/2014, O. Requejo, LOU-Fungi 19842. O Porriño, Pontellas, barreras de Centeáns, 29TNG3007, $20 \mathrm{~m}$, bajo Pinus pinaster y Quercus robur, 19/12/2015, J.Á. Gándara \& O. Requejo, LOU-Fungi 20560.

Ecología y distribución: común en los bosques mixtos donde está presente Pinus pinaster y Quercus robur, no se ha observado en los ambientes más húmedos.

Parece tratarse de una especie frecuente en Europa (GBIF en línea, $n^{\circ}$ 8340529), pero su distribución es difícil de establecer (Neville \& Poumarat 2004), en parte debido a la confusión con A. excelsa var. spissa (Fr.) Neville \& Poumarat y $A$. excelsa var. valida (Fr.) Wasser. Común en Galicia (Soliño et al. 1999).

Amanita fulva Fr., Observ. mycol. (Havniae) 1: 2 (1815)

Material estudiado: O Porriño, Budiño, Orbenlle, Barrera A Granxa Sur, 29TNG3153, bajo Pinus pinaster y Salix atrocinerea, 10/11/2015, O. Requejo, LOUFungi 20525. Tuy, Rebordanes, Ponte das Febres 29TNG2996, $21 \mathrm{~m}$, en bosque de Quercus robur y Pinus pinaster, 22/10/2016, O. Requejo, LOU-Fungi 20659. 
Observaciones: podría confundirse con A. crocea (Quél.) Singer. Presenta coloraciones predominantemente anaranjadas, la carne en contacto con fenol se vuelve de color rojo vino, las esporas son más estrechas (valores medios de 8,6-9,9 $\mu \mathrm{m})$ y los valores de Qm son mayores $(1,05-1,23)$.

Ecología y distribución: la colección LOU-Fungi 20525, se recolectó en braña colmatada y con suelo firme, estabilizado por la intrusión de Pinus pinaster. Común en el resto de bosques mixtos con humedad baja.

Ampliamente referenciada en el Hemisferio Norte (GBIF en línea, $\mathrm{n}^{\circ}$ 5240224), también en la Península Ibérica y Galicia (Castro 1996).

Amanita gemmata (Fr.) Bertill., Dict. Encyclop. Sci. Médic. (Paris) 1(3): 496 (1866)

Material estudiado: O Porriño, Pontellas, barreiras de Centeáns, 29TNG3007, 20 m, bajo Pinus pinaster, 22/12/2014, C. Ayres, LOU-Fungi 19873. O Porriño, Budiño, Orbenlle, Barrera A Granxa Sur, 29TNG3153, bajo Pinus pinaster, 10/11/2015, O. Requejo, LOU-Fungi 20296.

Ecología y distribución: muy común en toda la zona, en los bosques con baja humedad.

Ampliamente extendido en el Hemisferio Norte, en Norteamérica algunas citas pueden corresponder a otras especies próximas (Neville \& Poumarat 2004). También se conoce de Nueva Zelanda (GBIF en línea, $\mathrm{n}^{\circ}$ 5240292). Frecuente en Galicia (Soliño et al. 1999), así como en el resto de la Península (Castro 1996).

Amanita mairei Foley, Mém. Soc. Hist. nat. Afr. Nord., Hors.sér. 2: 117 (1949)

Material estudiado: O Porriño, Budiño, Orbenlle, observatorio ornitológico, 29TNG3061, 22 m, bajo Quercus robur y Alnus glutinosa, 22/10/2013, O. Requejo, LOUFungi 19986.

Observaciones: algunos autores como Tulloss (1994) y Contu (2000), han tratado de separar varias especies dentro del grupo de Amanita mairei, pero los caracteres utilizados para su diferenciación (color del píleo, morfología de la volva, hábitat y morfología esporal) varían de modo continuo y no correlacionado, por lo que no es posible separar morfológicamente las especies.

Ecología y distribución: puede ser, junto a la colección LOU-Fungi 20525 de A. fulva y A. vaginata (LOU-Fungi 20526), la especie del género más próxima a ambientes higrófilos con suelo inundable.

Georreferenciada únicamente de Europa central y meridional (GBIF en línea, ${ }^{\circ}$ 5240290). Frecuente en la Península Ibérica (Castro 1996), también en 
Galicia (Soliño et al. 1999), aunque resulta difícil de definir su distribución, ya que macroscópicamente puede ser confundida con otros taxones próximos.

Amanita pantherina (DC.) Krombh., Naturgetr. Abbild. Beschr. Schwämme (Prague): 29 (1846)

Material estudiado: O Porriño, Budiño, Orbenlle, observatorio ornitológico, 29TNG3061, 22 m, bajo Quercus robur y Alnus glutinosa, 22/10/2013, O. Requejo, LOUFungi 19987. Salceda de Caselas, desembocadura río Becerreira, 29TNG3019, 20 m, bajo Quercus robur y Alnus glutinosa, 26/09/2015, J.Á. Gándara y O. Requejo, LOU-Fungi 20273. Tui, Rebordanes, Ponte das Febres 29TNG2996, 21 m, bajo Alnus glutinosa y Quercus robur, 02/10/2016, Marta Martínez, LOU-Fungi 02634.

Ecología y distribución: muy común en la zona de estudio, en suelos no higroturbosos. Se efectuó alguna recolección en zona riparia con suelo que habitualmente no se inunda.

Frecuente en el Hemisferio Norte, aunque también se conoce de Australia (GBIF en línea, $\mathrm{n}^{\circ}$ 5240255); sin embargo, estudios moleculares realizados por Oda et al. (2004) han permitido diferenciar dos grupos: uno euroasiático y otro norteamericano. Ampliamente citada para la Península Ibérica (Castro 1996), también para Galicia (Soliño et al. 1999).

Amanita rubescens Pers., Tent.disp. meth. fung. (Lipsiae): 71 (1797)

Material estudiado: O Porriño, Budiño, Orbenlle, observatorio ornitológico, 29TNG3061, 22 m, bajo Quercus robur, 03/11/2013, O. Requejo, LOU-Fungi 19984. O Porriño, Pontellas, barreras de Centeáns, 29TNG3007, $20 \mathrm{~m}$, bajo Quercus robur, 26/12/2014, Alfredo Justo, LOU-Fungi 19889. Salceda de Caselas, desembocadura río Becerreira, 29TNG3019, 20 m, bajo Quercus robur y Alnus glutinosa, 26/09/2015, J.Á. Gándara y O. Requejo, LOU-Fungi 20274. Tui, Guillarei, Albelos, 29TNG3043, 13 m, en bosque de Pinus pinaster y Quercus robur, 09/11/2015, O. Requejo, LOU-Fungi 20505. Tuy, Rebordanes, Ponte das Febres 29TNG2996, 21 m, bajo Alnus glutinosa y Quercus robur, 02/10/2016, Marta Martínez, LOU-Fungi 02635.

Ecología y distribución: al igual que $A$. pantherina, se efectuó alguna recolección en zona riparia con suelo que habitualmente no se inunda, el resto fueron en bosques mixtos no húmedos, ni inundables. Muy frecuente durante el otoño en toda la ZEC.

Común en el Hemisferio Norte, aunque Tulloss (2005) indica que las menciones extra europeas probablemente se correspondan a otros taxones. También se conoce de Australia (GBIF en línea, $n^{\circ}$ 3329063). Muy frecuente en la Península Ibérica (Castro 1996), al igual que en Galicia (Soliño et al. 1999), en donde presenta morfotipos muy diversos. 
Amanita vaginata (Bull.) Lam., Encycl. Méth. Bot. (Paris) 1 (1): 109 (1783)

Material estudiado: O Porriño, Budiño, Orbenlle, Barrera A Granxa Sur, 29TNG3153, bajo Pinus pinaster y Salix atrocinerea, 10/11/2015, O. Requejo, LOUFungi 20526.

Ecología y distribución: como sucede en la colección LOU-Fungi 20525 de A. fulva, se recolectó en braña colmatada y con suelo firme, estabilizado por la intrusión de Pinus pinaster.

A pesar de la dificultad que ofrece la identificación macroscópica, se trata del taxón más citado de la sección Vaginatae, especialmente en el Hemisferio Norte (GBIF en línea, $n^{\circ}$ 5240306), al igual que en la Península Ibérica (Castro 1996) y Galicia (Soliño et al. 1999). Confundible con otros taxones del género de color gris como Amanita mairei, por lo que no es posible establecer su distribución con exactitud.

Antrodia albida (Fr.) Donk, Persoonia 4 (3): 339 (1966)

Material estudiado: O Porriño, Budiño, Orbenlle, observatorio ornitológico, 29TNG3061, 22 m, sobre madera sin identificar, 10/05/2015, C. Ayres, LOU-Fungi 20205.

Observaciones: este poliporoide resupinado, de color blanco, con himenóforo muy variable (poros angulosos, crestados o laminados), presenta una gran variabilidad esporal. Como indica Bernicchia (2005), probablemente se deba a la presencia de basidios bispóricos. En la colección estudiada las basidiosporas son cilíndricas, de 8-10 x 4-4,5 $\mu \mathrm{m}$ y los basidios bispóricos de 25$30 \times 6-8 \mu \mathrm{m}$.

Ecología y distribución: fructificaba en primavera, sobre madera sin identificar que yacía sobre turba muy húmeda en bosque de Quercus robur, Alnus glutinosa y Salix atrocinerea, que años muy lluviosos se anega largos periodods de tiempo.

Ampliamente distribuida por todo el mundo (GBIF en línea, $\mathrm{n}^{\circ}$ 2542528). En la Península Ibérica también se encuentran citas de norte a sur, País Vasco (Picón 2005); Castilla y León (García-Blanco 2012); Andalucía (Dueñas et al. 2009); lo que denota una amplia distribución. En Galicia ha sido mencionada para Lugo y Pontevedra (Lago-Alvarez 2008, Lago et al. 2002).

Armillaria gallica Marxm. \& Romagn., in Boidin, Gilles \& Lanquetin, Bull. trimest. Soc. mycol. Fr. 103 (2): 152 (1987)

Material estudiado: O Porriño, Budiño, Orbenlle, observatorio ornitológico, 29TNG3061, 22 m, sobre Salix atrocinerea, 27/11/2013, O. Requejo, LOU-Fungi 19898. 
Ecología y distribución: el material estudiado se encontró parasitando un viejo ejemplar de Salix atrocinerea que crecía al borde de la laguna y que en épocas lluviosas permanece dentro de ella.

Georreferenciada en Dinamarca, Eslovenia, Irlanda, Reino Unido, Japón (GBIF en línea, $\mathrm{n}^{0}$ 113539614). Se encontraron varias citas repartidas por la Península Ibérica (Picón 2005, Rubio-Domínguez et al. 2006, Moreno-Arroyo 2004, García-Bona 2000, Rubio \& Miranda 2008, Fernández-Vicente 2014), algunas de ellas como $A$. lutea ss. auct. o $A$. bulbosa ss. auct., por lo que se piensa que es un taxón común en la Península. Frecuente también en Galicia (Rodríguez-Vázquez \& Castro 2016).

Arrhenia velutipes (P.D. Orton) Redhead, Lutzoni, Moncalvo \& Vilgalys, Mycotaxon 83: 48 (2002)

Material estudiado: Tui, Guillarei, Albelos, 29TNG3043, 13 m, en camino de tierra entre musgos, 09/11/2015, O. Requejo, LOU-Fungi 20522.

Ecología y distribución: recolectada entre musgos a la orilla de un camino arenoso, relativamente lejos de los bosques más húmedos.

Georreferenciada especialmente para el Norte y Centro de Europa (GBIF en línea, $n^{\circ}$ 2532726). En Galicia es poco frecuente, aunque ya había sido mencionada en las provincias litorales (Castro 1995, Requejo 2010).

Asterophora parasitica (Bull.) Singer, Lilloa 22: 171 (1951) [1949]

Material estudiado: Tuy, Rebordanes, Ponte das Febres 29TNG2996, $21 \mathrm{~m}$, sobre Russula sp., 22/10/2016, O. Requejo, LOU-Fungi 20654.

Ecología y distribución: taxón solo observado sobre Russula sp. en bosque mixto de Pinus pinaster y Quercus robur con sotobosque de matorral, alejado de zonas higroturbosas.

Especie presente en los países escandinavos y con bastantes menciones dispersas por Centroeuropa, Reino Unido y Portugal. También se conoce en América Central (GBIF en línea, $\mathrm{n}^{\circ}$ 8689267). Se encontraron citas ibéricas repartidas por toda la geografía (Rubio-Domínguez et al. 2006, Picón 2004, García Blanco \& Alonso Ortega 2008, Moreno-Arroyo 2004). Para Galicia también es conocida de Lugo, A Coruña y Pontevedra, aunque es probable que su distribución sea más amplia (Rodríguez-Vázquez \& Castro 2016). 
Astraeus hygrometricus (Pers.) Morgan, J. Cincinnati Soc. Nat. Hist. 12: 20 (1889)

Material estudiado: O Porriño, Budiño, Orbenlle, Os Eidos, 29TNG3022, $30 \mathrm{~m}$, en bosque mixto de Quercus robur y Alnus glutinosa, 15/01/2015, O. Requejo, LOUFungi 20621.

Ecología y distribución: frecuente en bosque mixtos no higrófilos y taludes de tierra.

Común en el Hemisferio Norte (GBIF en línea, no 5239766). En Galicia se ha citado de las cuatro provincias gallegas (Rodríguez-Vázquez \& Castro 2016).

Boletus edulis Bull., Herb. Fr. 2: tab. 60 (1782) [1781-82]

Material estudiado: Salceda de Caselas, desembocadura del río Becerreira, 29TNG3019, 20 m, en bosque de Quercus robur y Alnus glutinosa, 26/09/2015, J.Á. Gándara, LOU-Fungi 20268.

Ecología y distribución: micorriza con un amplio número de especie arbóreas presentes en la ZEC, no obstante, parece preferir las zonas más secas para fructificar.

Común en el Hemisferio Norte (GBIF en línea, n 113926468), al igual que en Galicia (Soliño et al. 1999).

Boletus erythropus Pers., Ann. Botanik (Usteri) 15: 23 (1795)

Material estudiado: O Porriño, Budiño, Orbenlle, observatorio ornitológico, 29TNG3061, 22 m, bajo Quercus robur, 17/10/2013, O. Requejo, LOU-Fungi 20212. Tuy, Rebordanes, Ponte das Febres 29TNG2996, 21 m, bajo Quercus robur, 02/10/2016, M. Martínez, LOU-Fungi 20639.

Ecología y distribución: similar a B. edulis.

Abundante en Europa, también referenciada de América del Norte y de Australia (GBIF en línea, $n^{\circ}$ 5954924). Frecuente en Galicia (Soliño et al. 1999).

Boletus reticulatus Schaeff., Fung. bavar. palat. nasc. (Ratisbonae) 4: 78 (1774) = Boletus aestivalis (Paulet) Fr., Epicr. syst. mycol. (Upsaliae): 422 (1838)

Material estudiado: Tuy, Rebordanes, Ponte das Febres 29TNG2996, 21 m, bajo Quercus robur, 02/10/2016, M. Martínez, LOU-Fungi 20633.

Ecología y distribución: similar a $B$. edulis y B. erythropus, más estival, con fructificaciones incluso en primavera. 
Georreferenciada por toda Europa, centro, sur y países escandinavos, también mencionada en Japón y México (GBIFen línea $n^{\circ}$ 5954691), como Boletus aestivalis (Paulet) Fr. y GBIF (en línea ${ }^{\circ}$ 5954988), Especie frecuente y de amplia distribución en Galicia (Rodríguez-Vázquez \& Castro 2016)

Boletus subtomentosus L., Sp. pl. 2: 1178 (1753)

$\equiv$ Xerocomus subtomentosus (L.) Quél., Fl. mycol. France (Paris): 418 (1888)

Material estudiado: Salceda de Caselas, desembocadura del río Becerreira, 29TNG3019, 20 m, en bosque de Quercus robur y Alnus glutinosa, 08/08/2015, J. Valeiras, LOU-Fungi 20243.

Ecología y distribución: al igual que el resto de especies del género citadas, micorriza con un amplio abanico de especies arbóreas, pero no fructifica en zonas higroturbosas.

Especie ampliamente georreferenciada para Europa occidental, también en China, Estados Unidos y Canadá (GBIF en línea, nº 2519457). Mencionada para las cuatro provincias gallegas (Rodríguez-Vázquez \& Castro 2016).

Bulbillomyces farinosus (Bres.) Jülich, Persoonia 8 (1): 69.1974

Material estudiado: O Porriño, Budiño, Orbenlle, observatorio ornitológico, 29TNG3061, $22 \mathrm{~m}$, sobre madera sin identificar, 17/03/2012, O. Requejo, LOU-Fungi 20214.Tui, Guillarei, turbera de Albelos, 29TNG3036, $20 \mathrm{~m}$, sobre tallo de planta herbácea, 07/09/2015, O. Requejo, LOU-Fungi 20257.

Observaciones: taxón de ubicación incierta, recolectado en su forma imperfecta Aegerita candida Pers. (Breintenbach \& Kränzlin 1984).

Ecología y distribución: la forma imperfecta Aegerita candida es muy común, aspecto observado durante los muestreos, sobre madera o restos herbáceos leñosos en suelos constantemente húmedos o anegados.

Ampliamente citado para Europa (GBIF en línea, $\left.\mathrm{n}^{\mathrm{0}} 100527641\right)$. En la Península Ibérica muestra una amplia distribución (Tellería 1991); sin embargo, para Galicia apenas conocemos un registro, también como anamorfo (Requejo 2012).

Callistosporium luteo-olivaceum (Berk. \& M.A. Curtis) Singer, Lloydia 9: 117 (1946)

= Callistosporium xanthophyllum (Malenç. \& Bert.) Bon, Doc. mycol. 6(24): 52 (1976)

Material estudiado: O Porriño, Budiño, Orbenlle, observatorio ornitológico, 29TNG3061, 22 m bajo Quercus robur, sobre tocón sin identificar, 03/11/2013, LOUFungi 19899. 
Ecología y distribución: es una especie saprotrófica, poco común en las localidades muestreadas, se recolectó en bosque mixto sobre los restos de un tocón muy degradado.

Registrada en Europa, América (norte y sur), Japón y Australia, aunque no demasiado frecuente (GBIF en línea, $\mathrm{n}^{\circ}$ 2532068). En la Península Ibérica, aparece publicada por Rubio-Domínguez et al. (2005), Picón (2005) y Arrillaga et al. (2010) en el norte, a pesar de ello parece ser un taxón poco frecuente. En Galicia se conoce de A Coruña, Lugo y Pontevedra, más abundante en el litoral (Lago \& Castro 2002).

Calocera cornea (Batsch) Fr., Stirp. Agri. Femison. 5: 67 (1827)

Material estudiado: O Porriño, Budiño, Orbenlle, observatorio ornitológico, 29TNG3061, 22 m, sobre madera de Salix atrocinerea, 07/10/2013, O. Requejo, LOUFungi 19988. Salceda de Caselas, Cerquido, Ponte Carneiro 29TNG3164, 35 m, sobre madera de Alnus glutinosa, 25/01/2015, O. Requejo, LOU-Fungi 19933. Salceda de Caselas, desembocadura del río Becerreira, 29TNG3019, 20 m, sobre madera de Quercus robur, 12/05/2015, O. Requejo, LOU-Fungi 20265.

Ecología y distribución: especie observada sobre un amplio abanico de sustratos leñosos, muy común en la zona de estudio durante todo el año.

Ampliamente distribuida por Europa (GBIF en línea, no 113544992), también en la Península Ibérica (Dueñas 1997) y Galicia (Rodríguez-Vázquez \& Castro 2016).

Calocera viscosa (Pers.) Fr., Syst. mycol. (Lundae) 1: 486 (1821)

Material estudiado: O Porriño, Pontellas, barreras de Centeáns, 29TNG3007, 20 $\mathrm{m}$, sobre madera de Pinus pinaster, 22/12/2014, O. Requejo, LOU-Fungi 19880. O Porriño, Budiño, Orbenlle, observatorio ornitológico, 29TNG3061, $22 \mathrm{~m}$, en talud de tierra entre musgos, 01/12/2015, O. Requejo, LOU-Fungi 20546.

Ecología y distribución: recolectada bien sobre madera, de Pinus pinaster en la colección LOU-Fungi 19880 o directamente sobre tierra, posiblemente con madera enterrada, en bosque mixto de Pinus pinaster y Quercus robur (LOU-Fungi 20546).

Observada con frecuencia por casi toda Europa (GBIF en línea, $\mathrm{n}^{\circ}$ 108382178), también en la Península Ibérica (Dueñas 1997) y Galicia (Rodríguez-Vázquez \& Castro 2016). 
Calyptella campanula (Nees) W.B. Cooke, Beih. Sydowia 4: 32 (1961)

Material estudiado: Salceda de Caselas, Cerquido, Ponte Carneiro 29TNG3164, 35 m, sobre restos herbáceos, 27/09/2014, O. Requejo, LOU-Fungi 19793.

Ecología y distribución: el material estudiado se recolectó en un acúmulo de plantas herbáceas secas, no es una especie común en la ZEC.

Taxón poco frecuente, de preferencia septentrional en el Hemisferio Norte, aunque también ha sido localizado en Francia (GBIF en línea, $\mathrm{n}^{\mathrm{o}}$ 113243485). En Galicia sólo conocemos una cita anterior, también procedente de la zona de estudio (Requejo 2012).

Calyptella capula (Holmsk.) Quél., Fl. mycol. France (Paris): 25 (1888)

Material estudiado: O Porriño, Budiño, Orbenlle, observatorio ornitológico, 29TNG3061, 22 m, sobre tallo de planta herbácea, 01/10/2012, O. Requejo, LOU-Fungi 19989.

Ecología y distribución: similar a C. campánula.

Poco frecuente, aunque ya citada para Pontevedra (Rodríguez-Vázquez \& Castro 2016), con distribución de preferencia septentrional en Europa (GBIF en línea, $\left.\mathrm{n}^{\circ} 113243501\right)$. En la Península Ibérica parece ser más común que $C$. campanula (Nees.) W.B. Cooke, citada en el sur por Moreno-Arroyo (2004) y en el norte por Vidal \& Tabarés (1992), Rubio-Domínguez et al. (2005), GarcíaBlanco (2012). Debido a su pequeño tamaño probablemente sea más común de lo que refleja la bibliografía.

Cantharellus amethysteus (Quél.) Sacc., Syll. Fung. (Abellini) 5: 482 (1887)

Material estudiado: Salceda de Caselas, Cerquido, Ponte Carneiro 29TNG3164, 35 m, bajo Pinus pinaster y Quercus robur, 02/10/2014, O. Requejo, LOU-Fungi 19803.

Ecología y distribución: recolectado en bosque mixto de Quercus robur y Pinus pinaster con presencia de Alnus glutinosa, raro en la zona de estudio.

Ampliamente georreferenciado en el Centro Europa, Noruega y Suecia (GBIF en línea, $n^{\circ}$ 5249555). En la Península Ibérica, a pesar de ser un taxón poco frecuente, parece preferir el norte (García-Bona 2000, Picón 2005, RubioDomínguez et al. 2006, Fernández-Vicente \& Undagoitia 2010, Rubio-Roldán \& Rubio-Casas 2010). En Galicia se conoce de las provincias de A Coruña, Pontevedra y Lugo (Roca Romalde 2002, Marcote et al. 2003, Requejo 2011b, Blanco-Dios 2015). 
Cantharellus cibarius Fr., Syst. mycol.1: 318 (1821)

Material estudiado: O Porriño, Pontellas, barreras de Centeáns, 29TNG3007, 20 m, bajo Eucalyptus globulus, 26/12/2014, A. Justo \& O. Requejo, LOU-Fungi 19891. Salceda de Caselas, Cerquido, Ponte Carneiro 29TNG3164, 35 m, bajo Pinus pinaster, 02/10/2014, R. Requejo, LOU-Fungi 19804. Salceda de Caselas, Cerquido, Ponte Carneiro 29TNG3164, 35 m, bajo Quercus robur, 27/12/2014, O. Requejo, LOU-Fungi 19925. O Porriño, Budiño, Orbenlle, Os Eidos, 29TNG3022, 30 m, bajo Quercus robur, 10/11/2014, O. Requejo, LOU-Fungi 19833.

Observaciones: la colección LOU-Fungi 19804 se corresponde con Cantharellus cibarius var. pallidus R. Schulz. Olariaga et al (2016) confirman la sinonimia de estos taxones en una reciente revisión del género en Europa.

Ecología y distribución: muy común en la ZEC, aunque parece preferir zonas no higroturbosas, solamente la colección LOU-Fungi 19804, se encontró en un lugar donde hace poco tiempo había brañas y brezales higrófilos, a los que poblaciones de Pinus pinaster les retiró parte del terreno.

Ampliamente citado; aunque no se conoce su distribución precisa debido a la confusión entre las numerosas variedades y a la existencia de taxones próximos (GBIF en línea, $\mathrm{n}^{\circ}$ 5249504). La variedad citada sólo aparece georreferenciada de Centroeuropa (GBIF en línea, $\mathrm{n}^{\circ}$ 5249510), probablemente por la misma razón.

Cantharellus ferruginascens P.D. Orton, Notes R. Bot. Gdn. Edinb. 29 (1): 84 (1969)

Material estudiado: O Porriño, Budiño, Orbenlle, Os Eidos, 29TNG3022, 30 m, bajo Quercus robur, 18/11/2014, J. Valeiras \& O. Requejo, LOU-Fungi 19829.

Ecología y distribución: recolectado en bosque mixto de Quercus robur y Pinus pinaster con presencia de Alnus glutinosa, muy raro en la zona de estudio.

Sólo aparece referenciada de Centroeuropa (GBIF en línea, n 5249494), probablemente por haber sido confundido con ejemplares oscuros de Cantharellus cibarius Fr. En la Península Ibérica se encontraron escasas citas: País Vasco (Picón 2005), Cataluña (Carbó et al. 2012), Asturias (RubioDomínguez et al. 2015), Andalucía (Becerra et al. 2015). Para Galicia hay una reciente de la provincia de Ourense (Blanco-Dios 2015).

Cantharellus melanoxeros Desm., Bot. Gall., Edn 2 (Paris) 2: 799 (1830)

Material estudiado: O Porriño, Budiño, Orbenlle, Os Eidos, 29TNG3022, 30 m, bajo Quercus robur y Pinus pinaster, 13/08/2014, O. Requejo, LOU-Fungi 19935. 
Ecología y distribución: se encontró una pequeña fructificación estival, creciendo en bosque mixto de Quercus robur y Pinus pinaster con sotobosque de matorral.

Especie rara, observada con más frecuencia en el norte de Europa (GBIF en línea, $\left.\mathrm{n}^{\circ} 113927025\right)$, incluida en la lista de especies protegidas de hongos en el Convenio de Berna (1982). En la Península Ibérica la encontramos bien representada, con citas de norte (Rubio-Domínguez 2005, Fernández-Vicente \& Undagoitia 2010, Pérez de Gregorio 2011) a sur (Moreno-Arroyo 2004, Lara Ruiz 2014, Díaz -Fernández et al. 2007). En Galicia se ha mencionado de las provincias de Lugo, A Coruña y Pontevedra (Rodríguez-Vázquez \& Castro 2016).

Cantharellus romagnesianus Eyssart. \& Buyck, Cryptog. Mycol. 20 (2): 108 (1999)

Material estudiado: O Porriño, Budiño, Orbenlle, Os Eidos, 29TNG3022, 30 m, bajo Quercus robur y Pinus pinaster, en un talud de tierra, 04/06/2014, O. Requejo, LOUFungi 19936. O Porriño, Budiño, Orbenlle, Os Eidos, 29TNG3022, $30 \mathrm{~m}$, en talud de tierra con musgos bajo Quercus robur y Pinus pinaster, 29/11/2014, O. Requejo, LOU-Fungi 20249 .

Observaciones: recientes estudios moleculares indican que $C$. romagnerianus y C. pseudominimos son sinónimos, predominando el epíteto romagnesianus (Olariaga et al. 2016).

Ecología y distribución: común en bosques no higroturbosos de la zona de estudio, sobre todo en taludes de tierra muy umbríos.

No georreferenciado con exactitud (GBIF en línea, $\mathrm{n}^{\circ} 5467096$ y n $^{\circ}$ 119263903). Es un taxón poco frecuente en Europa, su distribución Ibérica indica preferencias septentrionales y litorales como la cornisa cantábrica (Pérez-Butrón et al. 2006, 2011, Cuesta et al. 2011) y Galicia, donde ha sido observado en A Coruña, Lugo y Pontevedra (Lago-Álvarez 2008, Blanco-Dios 2011, Requejo 2011b, De la Peña 2016).

Cerioporus meridionalis (A. David) Zmitr. \& Kovalenko, Int. J. Medic. Mushrooms (Redding) 18(1): 33 (2016)

$\equiv$ Polyporus meridionalis (A. David) H. Jahn, Westfälische Pilzbriefe 11 (7): 176 (1980)

Material estudiado: O Porriño, Budiño, Orbenlle, Os Eidos, 29TNG3022, $30 \mathrm{~m}$, sobre restos herbáceos, 21/03/2013, P. Veiga, LOU-Fungi 19938.

Observaciones: píleo de unos 2-2,5 cm de diámetro, parduzco, con el estipe central, algodonoso en la base. Poros alargados, dispuestos radialmente. Basidiosporas elipsoides, uni o plurigutuladas, de 7-9 x 3-4 mm. Los poros 
grandes, 1-3/mm con disposición radial, la anchura de las basidosporas y la ausencia de color negro en el estipe lo caracterizan perfectamente (Berniccia 2005).

Ecología y distribución: fructificaba sobre tallos secos de planta herbácea bastante dura, en bosque ripario muy umbrío. Muy raro en la zona de estudio.

Se encuentra en la región mediterránea europea en hábitats húmedos. No se conoce bien su distribución mundial; pero ha sido observado en Francia, Italia, Península Ibérica, Marruecos e Islas Canarias, (GBIF en línea, no 11076328). Raro en Galicia, únicamente citado para Ourense (Alonso Díaz 2016).

Cerioporus mollis (Sommerf.) Zmitr. \& Kovalenko, Int. J. Medic. Mushrooms (Redding) 18(1): 33 (2016)

$\equiv$ Datronia mollis (Sommerf.) Donk, Persoonia 4 (3): 338 (1966)

Material estudiado: O Porriño, Budiño, Orbenlle, observatorio ornitológico, 29TNG3061, 22 m, sobre madera sin identificar, 12/05/2013, O. Requejo, LOU-Fungi 20216.

Ecología y distribución: su resistencia a la descomposición, provoca que sea relativamente fácil ver algún ejemplar sobre troncos o ramas caídas de buen diámetro, sobre todo en bosques de caducifolios.

Común en Europa hasta la parte septentrional de la Península Ibérica, pero también mencionada de Asia, Norte y Sudamérica (GBIF en línea, $\mathrm{n}^{\circ}$ 2547204). No frecuente, pero extendida por toda Galicia (Rodríguez-Vázquez \& Castro 2016).

Ceriporiopsis subvermispora (Pilát) Gilb. \& Ryvarden, Mycotaxon 22 (2): 364 (1985)

झ Fibuloporia subvermispora (Pilát) Domanski, Acta Soc. Bot. Pol. 38 : 453 (1969)

$\equiv$ Tyromyces subvermisporus (Pilát) Ryvarden, Norw. Jl Bot. 20: 10 (1973)

Material estudiado: O Porriño, Budiño, Orbenlle, observatorio ornitológico, 29TNG3061, 22 m, sobre madera de Pinus pinaster, 13/08/2014, O. Requejo, LOU-Fungi 19941.

Observaciones: basidioma resupinado de color blanco y aspecto ceroso, himenio con poros angulosos de 2-4 por $\mathrm{mm}$. Sistema hifal monomítico con presencia de fíbulas. Basidiosporas cilíndricas o alantoides, de 4,5-5 x 1,5 $\mu \mathrm{m}$.

Ecología y distribución: recolectado en época estival sobre rama de Pinus pinaster en bosque mixto, en el que también había Quercus robur y Alnus glutinosa. 
Aparece referenciada para Nueva Zelanda, Brasil, Estados Unidos, Canadá y Europa septentrional, aunque también para Eslovenia (GBIF en línea, $\mathrm{n}^{\circ}$ 100527282). Apenas citado para la Península Ibérica (Rubio-Domínguez et al. 2006). No la conocemos mencionada para Galicia.

Chaetotyphula actiniceps (Petch) Corner, Monogr. Clavaria (Ann. Bot. Mem. 1): 209 (1950)

Material estudiado: Salceda de Caselas, Cerquido, Ponte Carneiro 29TNG3164, 35 m, sobre restos de planta herbácea, 25/11/2014, R. Requejo, LOU-Fungi 19921.

Observaciones: pequeños basidiomas claviformes o espatuliformes de color blanco translúcido, crema en exsiccata, totalmente recubiertos de prominentes pelos. Basidiosporas de anchamente elipsoides a subglobosas, de 15-11,5 x 9,3-11,5 $\mu \mathrm{m}$. Basidios tetra y bispóricos, de 30-37 × 8-10 $\mu \mathrm{m}$, con esterigmas hasta $8 \mu \mathrm{m}$ de largo. Cistidios claviformes que emergen del subhimenio, de hasta $230 \times 13 \mu \mathrm{m}$, con paredes anchas. No se observaron fíbulas.

Ecología y distribución: es una especie de la que hay muy pocos datos sobre su ecología, en parte debido a las escasas recolecciones. El material estudiado fructificaba en otoño, en una sauceda inundada, sobre tallo de planta herbácea bastante dura, aparentemente Phytolacca americana, asentada sobre la turba húmeda en una zona encharcada.

Escasa distribución mundial, descrita originariamente en Hakgala, Sri Lanka. Sólo conocemos otra cita en Chile (Cybertruffle en línea). Podría tratarse de una primera cita europea, tanto del género como de la especie.

Chalciporus piperatus (Bull.) Bataille, Bull. Soc. Hist. nat. Doubs 15: 39 (1908)

Material estudiado: Tui, Guillarei, Albelos, 29TNG3040, 13 m, bajo Pinus pinaster, 10/11/2015, O. Requejo, LOU-Fungi 20298.

Ecología y distribución: hábitat y época de aparición en el material estudiado es la habitual para este taxón (Muñoz 2005, Castro 1985).

Georreferenciada en Europa y América (norte y sur), pero también fue observada en Australia y Nueva Zelanda (GBIF en línea, $\mathrm{n}^{\circ}$ 2524878). Ampliamente distribuida en Galicia aunque no abundante (Rodríguez-Vázquez \& Castro 2016).

Chroogomphus helveticus (Singer) M.M. Moser, in Gams, Kl. Krypt.-Fl., Edn 3 (Stuttgart) 2b/2: 51 (1967)

Material estudiado: Salceda de Caselas, Cerquido, Ponte Carneiro 29TNG3164, 35 m, bajo Pinus pinaster, 02/10/2014, R. Requejo, LOU-Fungi 19801. 
Observaciones: se diferencia de la especie próxima Chroogomphus rutilus (Schaeff.) O.K. Mill. por el píleo más seco, ausencia de mamelón, color más rosado y las hifas cuticulares no amiloides (Breitenbach \& Kränzlin 1991).

Ecología y distribución: recolectado bajo Pinus pinaster, en zona de antiguas brañas, en la que los pinos han conseguido ganar terreno y solidificar el suelo.

Georreferenciada para el Centro y Sur de Europa (GBIF en línea, $\mathrm{n}^{\circ}$ 113304332). Especie escasamente citada en la Península Ibérica (Dueñas et al. 2001). No la conocemos mencionada para Galicia.

Chroogomphus rutilus (Schaeff.) O.K. Mill., Mycologia 56 (4): 543 (1964)

Material estudiado: O Porriño, Budiño, Orbenlle, Os Eidos, 29TNG3022, $30 \mathrm{~m}$, bajo Pinus pinaster, 30/11/2014, O. Requejo, LOU-Fungi 19835. O Porriño, Pontellas, barreras de Centeáns, 29TNG3007, 20 m, bajo Pinus pinaster, 26/12/2015, A. Justo, LOUFungi 19930.

Ecología y distribución: muy común en todos los bosques no húmedos, donde está presente Pinus pinaster.

Común en Europa occidental, conocida también en América del Norte (GBIF en línea, $n^{\circ}$ 2524996). Frecuente en Galicia, especialmente en la zona litoral (Rodríguez-Vázquez \& Castro 2016).

Clavulina cinerea (Bull.) J. Schröt., in Cohn, Krypt.-Fl. Schlesien (Breslau) 3.1 (25-32): 442 (1888) [1889]

Material estudiado: O Porriño, Budiño, Orbenlle, observatorio ornitológico, 29TNG3061, 22 m, bajo Pinus pinaster y Quercus robur, 29/11/2014, O. Requejo, LOUFungi 19857.

Ecología y distribución: abundante durante el otoño en todos los bosques mixtos muestreados.

Observada en el Hemisferio Norte, común en Europa, pero también se conoce de Australia y África (GBIF en línea, n 5249860). También frecuente en Galicia (Soliño et al. 2000).

Clavulina coralloides (L.) J. Schröt., in Cohn, Krypt.-Fl. Schlesien (Breslau) 3.1 (25-32): 443 (1888) [1889]

=Clavulina cristata (Holmsk.) J. Schröt., Kryptogamen-Flora von Schlesien 3-1 (4): 443 (1888)

Material estudiado: O Porriño, Budiño, Orbenlle, observatorio ornitológico, 29TNG3061, 22 m, entre Polytrichum sp. bajo Betula pubescens, 22/10/2013, O. Requejo, 
LOU-Fungi 19856. Salceda de Caselas, desembocadura del río Becerreira, 29TNG3019, 20 m, bajo Alnus glutinosa y Quercus robur, 26/09/2015, J.Á. Gándara y O. Requejo, LOU-Fungi 20279.

Ecología y distribución: muy común en bosque mixtos, incluso en bosques aluviales donde produce ejemplares muy pequeños, formando alfombras sobre el suelo turboso y desnudo especielmente en primavera y verano, fuera de épocas de inundación. Se ha observado conviviendo con Laccaria tortilis.

Georreferenciada en el Hemisferio Norte, especialmente Europa (GBIF en línea, $n^{\circ}$ 5249883). Frecuente en Galicia (Soliño et al. 2000)

Clavulina rugosa (Bull.) J. Schröt., Krypt.-Fl. Schlesien (Breslau) 3.1 (25-32): 442 (1888) [1889]

Material estudiado: O Porriño, Pontellas, barreras de Centeáns, 29TNG3007, 20 m, bajo Pinus pinaster, 26/12/2014, A. Justo, LOU-Fungi 19895. Salceda de Caselas, Cerquido, Ponte Carneiro 29TNG3164, 35 m, bajo Pinus pinaster, 27/12/2014, J.Á. Gándara, LOU-Fungi 19923. Tui, Guillarei, aliseda de Albelos, 29TNG3019, 20 m, bajo Salix atrocinerea y Alnus glutinosa, 22/12/2015, O. Requejo, LOU-Fungi 20554.

Ecología y distribución: frecuente en los bosques mixtos alejados de las zonas más húmedas, en la ZEC muestra una marcada preferencia por las épocas frías.

Frecuente en el Hemisferio Norte, especialmente Europa, incluida la Península Ibérica, también en Australia y Nueva Zelanda (GBIF en línea, $\mathrm{n}^{\circ}$ 5249808). En Galicia es común (Soliño et al. 2000)

Clitocybe nebularis (Batsch) P. Kumm., Führ. Pilzk. (Zerbst): 124 (1871)

Material estudiado: O Porriño, Budiño, Orbenlle, Os Eidos, 29TNG3022, 30 m, entre hojas en bosque de Quercus robur y Pinus pinaster, 15/12/2016, O. Requejo, LOUFungi 20599.

Ecología y distribución: los ejemplares observados fructificaban a finales de otoño entre la hojarasca, época y hábitat habituales (Breitenbach \& Kränzlin, 1991).

Georreferenciada en el Hemisferio Norte, especialmente Europa, también en Nueva Zelanda (GBIF en línea, $n^{\circ}$ 2531072). Frecuente en Galicia (Rodríguez-Vázquez \& Castro 2016). 
Clitocybe vibecina (Fr.) Quél., Mém. Soc. Émul. Montbéliard, Sér. 2 5: 318 (1872)

Material estudiado: O Porriño, Budiño, Orbenlle, Os Eidos, 29TNG3022, 30 m, bajo Pinus pinaster, 29/11/2014, O. Requejo, LOU-Fungi 19839. O Porriño, Pontellas, barreras de Centeáns, 29TNG3007, 20 m, bajo Pinus pinaster, 22/12/2014, C. Ayres y O. Requejo, LOU-Fungi 19877.

Ecología y distribución: común en otoño e invierno en bosques donde está presente Pinus pinaster, excepto en las antiguas brañas.

Ampliamente georreferenciada en Europa (GBIF en línea, $n^{\circ}$ 2531116), aunque debido a la fácil confusión con taxones próximos debería de revisarse esta distribución, al igual que ocurre con las menciones gallegas (Rodríguez-Vázquez \& Castro 2016).

Clitopilus cystidiatus Hauskn. \& Noordel., Öst. Z. Pilzk. 8: 200 (1999)

Material estudiado: Salceda de Caselas, Cerquido, Ponte Carneiro, 29TNG3164, 35 m, bajo Pinus pinaster y Quercus robur, 02/10/2014, R. Requejo, LOU-Fungi 20549. Salceda de Caselas, desembocadura del río Becerreira, 29TNG3019, 20 m, 12/09/2015, bajo Populus nigra, O. Requejo, LOU-Fungi 20548.

Observaciones: los ejemplares revisados corresponden con la descripción original del taxón (Hausknecht \& Noordeloos 1999), diferenciado de la especie más próxima C. prunulus (Scop.) P. Kumm. por las tonalidades grises en el píleo y la presencia de numerosos queilocistidios en el filo laminar.

Ecología y distribución: parece ser una especie común en los bosques mixtos de Pinus pinaster y Quercus robur de la ZEC. Destaca la colección LOUFungi 20548, recolectada bajo Populus nigra en zona higroturbosa.

Georreferenciada para Centro Europa, Noruega y Suecia (GBIF en línea, $\mathrm{n}^{\mathrm{o}}$ 113223034). En la Península Ibérica, debido a la histórica confusión con $C$. prunulus (Scop.) P. Kumm., seguramente está mejor distribuido de lo que aparece en la bibliografía, País Vasco (Picón 2005) e Islas Canarias (Fernández-Vicente et al 2012). No la conocemos citada de Galicia.

Clitopilus prunulus (Scop.) P. Kumm., Führ. Pilzk. (Zerbst): 96 (1871)

Material estudiado: Tuy, Rebordanes, Ponte das Febres 29TNG2996, 21 m, bajo Quercus robur, 20/10/2016, O. Requejo, LOU-Fungi 20652.

Ecología y distribución: no es tan común en la zona de estudio como C. cystidiatus, el material revisado ha sido recolectado bajo Quercus robur en bosque de ribera. 
Especie frecuente en Europa, sur de Estados Unidos y América Central, también con alguna reseña en Japón (GBIF en línea, nº 2539197). En Galicia es la especie del género más conocida, bien distribuida por las cuatro provincias (Rodríguez-Vázquez \& Castro 2016).

Collybia cirrhata (Schumach.) Quél., Mém. Soc. Émul. Montbéliard, Sér. 2 5: 96 (1872)

= Collybia amanitae (Batsch) Kreisel, Pilzflora Deutschen Demokratischen Republick, Basidiomycetes (Gaullert-, Hut- und Bauchplze) (Jena): 47 (1987)

Material estudiado: O Porriño, Pontellas, barreras de Centeáns, 29TNG3007, 20 m, sobre hongo sin identificar, 19/12/2015, J.Á. Gándara \& O. Requejo, LOU-Fungi 20562.

Observaciones: identificable a simple vista por su pequeño tamaño y la presencia de esclerocios amarillos.

Ecología y distribución: fructificaban numerosos ejemplares sobre un carpóforo muy deteriorado, posiblemente del género Lactarius, en zona mixta en la que predominaba Pinus pinaster.

Observada en Europa y América del Norte, también en la costa oriental rusa y Brasil (GBIF en línea, nº 2532440). Común en la Península Ibérica (LagoÁlvarez 2008). En Galicia se ha mencionado de Lugo, Ourense y Pontevedra (Rodríguez-Vázquez \& Castro 2016).

Coltricia cinnamomea (Jacq.) Murrill, Bull. Torrey bot. Club 31 (6): 343 (1904)

Material estudiado: O Porriño, Budiño, Orbenlle, Os Eidos, 29TNG3022, 30 m, bajo Quercus robur y Alnus glutinosa, 15/01/2016, O. Requejo, LOU-Fungi 20596.

Observaciones: fácilmente diferenciable de Coltricia perennis (L.) Murrill por las dimensiones esporales 7,5-8 x $5 \mu \mathrm{m}$ (Jülich, 1980, Breitenbach \& Kränzlin, 1986; Berniccia 2005).

Ecología y distribución: fructificaba en invierno sobre suelo desnudo, en bosque mixto de Quercus robur y Alnus glutinosa.

Georreferenciada en todos los continentes menos África (GBIF en línea $n^{\circ}$ 2519879). Para la Península Ibérica la encontramos citada para las comunidades de Asturias (Rubio-Domínguez et al. 2006), Castilla La Mancha (Campos et al. 2014), País Vasco (Picón 2005), Navarra (García-Bona 2000) y Andalucía (Moreno-Arroyo 2004). En Galicia se ha citado de las provincias litorales (Lago-Álvarez 2008, De la Peña 2016) 
Conocybe brachypodii (Velen.) Hauskn. \& Svrček, in Hausknecht, Czech Mycol.51 (1): 43 (1999)

Material estudiado: Salceda de Caselas, Cerquido, Ponte Carneiro 29TNG3164, 35 m, bajo Pinus pinaster y Quercus robur, 01/09/2014, O. Requejo, LOU-Fungi 19972.

Observaciones: es un taxón muy variable, de talla pequeña a mediana, con colores apagados, cistidios con un largo cuello y capitados. Basidiosporas de 7-9 x 4-5,5 $\mu \mathrm{m}$, elipsoides a oblongas y con paredes delgadas, lo que coincide con material estudiado en otras regiones europeas (Prydiuk 2007).

Ecología y distribución: recolectado en otoño bajo Quercus robur y Pinus pinaster, muy raro en la zona de estudio.

$\mathrm{Su}$ distribución no se conoce con seguridad en el continente europeo (Arnolds 2005), parece ser común en Centroeuropa (GBIF en línea, $\mathrm{n}^{\circ}$ 101578658). No se encontraron citas para la Península Ibérica.

Coprinellus disseminatus (Pers.) J.E. Lange [as 'disseminata'], Dansk bot. Ark. 9 (6): 93 (1938)

$\equiv$ Coprinus disseminatus (Pers.) Gray, Nat. Arr. Brit. Pl. (London) 1: 634 (1821)

Material estudiado: O Porriño, Budiño, Orbenlle, observatorio ornitológico, 29TNG3061, $22 \mathrm{~m}$, sobre madera sin identificar, 22/09/2014, O. Requejo, LOU-Fungi 20246.

Ecología y distribución: común en la zona de estudio, incluso en zonas aluviales.

Disperso por todo el mundo, también en la Península Ibérica (GBIF en línea, $\left.n^{\circ} 2534625\right)$ y común en Galicia (Rodríguez-Vázquez \& Castro 2016).

Coprinellus heptemerus (M.Lange \& A.H.Sm.) Vilgalys, Hopple \& Jacq. Johnson, in Redhead, Vilgalys, Moncalvo, Johnson \& Hopple, Taxon 50 (1): 234 (2001)

$\equiv$ Coprinus heptemerus M. Lange \& A.H.Sm., Mycologia 45(5): 751 (1953)

Material estudiado: Salceda de Caselas, desembocadura del río Becerreira, 29TNG3019, 20 m, sobre excrementos de Sus scofra, 26/06/2015, J.Á. Gándara \& O. Requejo, LOU-Fungi 20602.

Observaciones: el frágil y delicado porte de la fructificación, que nace sobre excrementos, el poro germinativo de las esporas y los píleocistidios en forma de espinas, grandes, hasta $120 \mu \mathrm{m}$, mezclados con elementos globosos lo caracterizan perfectamente. 
Ecología y distribución: la presencia de jabalí (Sus cofra) en la ZEC, provoca que sea una especie fácil de encontrar durante todo el año y en todo tipo de ambientes por donde se mueve este mamífero.

Especie bastante bien distribuida en Europa (Uljé 2005), georreferenciada de Suecia, Canadá y Australia (GBFI en línea nº 2534647). No parece ser un taxón demasiado observado en la Península Ibérica, ya que se encontraron pocas y dispersas menciones (Rubio-Domínguez et al. 2006, Picón 2005, Moreno-Arroyo 2004) y, a pesar de ser común en la zona de estudio, no lo conocemos citado para Galicia.

Coprinellus micaceus (Bull.) Vilgalys, Hopple \& Jacq. Johnson, in Redhead, Vilgalys, Moncalvo, Johnson \& Hopple, Taxon 50 (1): 234 (2001)

$\equiv$ Coprinus micaceus (Bull.) Fr., Epicr. syst. mycol. (Upsaliae): 248 (1838)

Material estudiado: Salceda de Caselas, desembocadura del río Becerreira, 29TNG3019, 20 m, sobre tocón de Alnus glutinosa, 19/12/2015, O. Requejo, LOU-Fungi 20578

Ecología y distribución: aparentemente es una especie muy común en la ZEC, sobre troncos caídos o cualquier tipo de resto leñoso, incluso en ocasiones directamente en el suelo. Destacamos la colección citada por fructificar sobre tocón de Alnus glutinosa en zona turbosa inundable.

Taxón ampliamente referenciado en el Hemisferio Norte, así como Australia y Nueva Zelanda (GBIF en línea, no 2534578). Común en la Península Ibérica, tanto en el norte (Iglesias \& Fernández-Vicente, 2015) como en Andalucía (Moreno-Arroyo 2004). Ampliamente distribuido por Galicia (Rodríguez-Vázquez \& Castro 2016).

Coprinellus pallidissimus (Romagn.) P.Roux, Guy García \& S.Roux, in Roux, Mille et un Champignons: 13 (2006)

三 Coprinus pallidissimus Romagn., Bull. trimest. Soc. mycol. Fr. 92(2): 203 (1976)

Material estudiado: O Porriño, Budiño, Orbenlle, observatorio ornitológico, 29TNG3061, 22 m, entre restos leñosos y herbáceos, 17/10/2013, O. Requejo, LOU-Fungi 19949.

Observaciones: según Kees \& Uljé (2005) pertenece a la sección Veliformes. Se trata de un taxón caracterizado por la presencia de caulocistidios. También presenta queilocictidios de 45-110 x 25-40 $\mu \mathrm{m}$, elipsoides, globosos o esferopedunculados con un corto estípite y elementos del velo globosos de 25-37 $\mu \mathrm{m}$ de diámetro, algunos también pedunculados. En la colección estudiada tienden a ser lageniformes, de 30-75 x 12-20 $\mu \mathrm{m}$, con el cuello en ocasiones 
tortuoso, lo que lo diferencia de C. truncorum (Scop.) Redhead, Vilgalys \& Moncalvo. Y, las basidiosporas varían de citriformes a elipsoides, de 6,5-8,5 $\mu \mathrm{m}$, con poro germinativo central y base redondeada, a diferencia de C. micaceus (Bull.) Vilgalys, Hopple \& Jacq. Johnson que las presenta con ápice cónico y base truncada. tan común.

Ecología y distribución: hábitat muy similar a C. micaceus, aunque no

Taxón muy raro, conocido de Holanda y Francia (Kees \& Uljé 2005) y georreferenciado también para Eslovenia (GBIF en línea, $n^{\circ}$ 3318996). Poco iconografiado en la Península Ibérica, apenas se encontraron referencias (RubioDomínguez et al. 2006, Tabarés \& Rocabruna 2007, Iglesias et al. 2011) y una en las islas Canarias (Fernández-Vicente et al. 2012). No lo encontramos citado para Galicia.

Coprinopsis pseudofriesii (Pilát \& Svrček) Redhead, Vilgalys \& Moncalvo, in Redhead, Vilgalys, Moncalvo, Johnson \& Hopple, Taxon 50 (1): 230 (2001)

三Coprinus pseudofriesii Pilát \& Svrček, Česká Mykol. 21: 140 (1967)

Material estudiado: O Porriño, Budiño, Orbenlle, observatorio ornitológico, 29TNG3061, 22 m, sobre restos herbáceos, 07/10/2013, Gonzalo Requejo, LOU-Fungi 19948.

Observaciones: píleo de $5 \mathrm{~mm}$ o menos, de color gris, más o menos pardo, con zonas ocre en el centro, de aspecto pruinoso por la presencia del velo blanco u ocre. Basidiosporas de 8-10 x 5,6-7 $\mu \mathrm{m}$, elipsoides, más raramente ovoides o mitriformes, y poro germinativo central. Queilocistidios cilíndricos o lageniformes, de 40-82 x 7,5-23 $\mu \mathrm{m}$, pleurocistidios similares, pero con algún pequeño mucrón. Velo formado por elementos filamentosos ramificados, de hasta $10 \mu \mathrm{m}$ de diámetro, con divertículos y paredes anchas de hasta 1,5 $\mu \mathrm{m}$. Presenta fíbulas.

Ecología y distribución: recolectado sobre restos de gramíneas muy próximo a la laguna, raro en la zona de estudio.

Conocido en Europa (Kees \& Uljé 2005), georreferenciado para Centroeuropa (GBIF en línea, $\mathrm{n}^{\circ}$ 5242726) y, desde antiguo también en la Península Ibérica (Moreno \& García-Bona 1976), la que parece ser que es la única referencia hasta el momento. No observado anteriormente en Galicia.

Coprinus comatus (O.F. Müll.) Pers., Tent. disp. meth. fung. (Lipsiae): 62 (1797)

Material estudiado: Salceda de Caselas, Cerquido, Ponte Carneiro, 29TNG3164, $35 \mathrm{~m}$, en camino entre hierbas, 02/10/2015, O. Requejo, LOU-Fungi 20593. 
Ecología y distribución: el material estudiado se recolectó, en su hábitah característico (Uljé 2005), entre las hierbas de un camino de tierra desnudo, donde habitualmente se arrojan escombros y tierra.

Ampliamente conocido en el Hemisferio Norte; pero también en Sudamérica y Australia (GBIF en línea, $n^{\circ}$ 2536654). Muy frecuente en Galicia (Rodríguez-Vázquez \& Castro 2016).

Cortinarius anomalus (Fr.) Fr., Epicr. syst. mycol. (Upsaliae): 286 (1838)

Material estudiado: O Porriño, Pontellas, barreiras de Centeáns, 29TNG3007, 20 m, bajo Pinus pinaster, 22/12/2014, O. Requejo, LOU-Fungi 19874.

Ecología y distribución: recolectado micorrizando con Pinus pinaster en antiguas brañas, ahora pobladas de coníferas con sotobosque herbáceo.

Ampliamente mencionado en el Hemisferio Norte, especialmente en Europa (GBIF en línea, n 2529421). No es un taxón frecuente en Galicia, aunque si fue mencionado hace tiempo para la provincia de Pontevedra (Losa Quintana \& Freire 1978) y, más tarde, para las provincias de A Coruña, Lugo y de nuevo. Pontevedra (Rodríguez-Vázquez \& Castro 2016).

Cortinarius bibulus Quél., Compt. Rend. Assoc. Franç. Avancem. Sci. 9: 666 (1881) [1880]

= Cortinarius pulchellus J.E. Lange, Meddr Foren. Svampekundsk. Fremme 1: 3 (1926)

Material estudiado: O Porriño, Budiño, Orbenlle, observatorio ornitológico, 29TNG3061, 22 m, bajo Salix atrocinerea y Alnus glutinosa, 01/10/2013, O. Requejo, LOU-Fungi 20550.

Ecología y distribución: especie ligada a Alnus glutinosa, aunque podría asociarse también a Salix atrocinerea, lo que se pudo comprobar con una recolección efectuada en la turbera de Albelos. Las especies arbóreas mas próximas eran Salix y Pinus pinaster muy endebles por falta de oxígeno en el suelo. El ejemplar no se pudo conservar en exsiccata debido a su diminuto tamaño y a que ha sido utilizado para el estudio microscópico.

Georreferenciada preferentemente para el centro de Europa, Noruega y Suecia (GBIF en línea, $\mathrm{n}^{\mathrm{o}}$ 2529150). Es una especie rara y poco citada en la Península Ibérica, muy cosmopolita ya que fructifica tanto en zonas montanas como en las bajas, a menos de $150 \mathrm{~m}$ de altitud (Ballarà et al. 2011). En Galicia está citado por Requejo \& Blanco-Dios (2012) sub. C. pulchellus. 
Cortinarius chrysolitus Kauffman, Ann. Rep. N.Y. St. Mus. 179: 101 (1915)

= Cortinarius huronensis var. olivaceus Ammirati \& A.H. Sm., Michigan Botl 11(1): 21 (1972)

Material estudiado: O Porriño, Budiño, Orbenlle, observatorio ornitológico, 29TNG3061, 22 m, entre Sphagnum sp, bajo Salix atrocinerea, 04/06/2014, O. Requejo, LOU-Fungi 19920.

Observaciones: la colección estudiada por la predominancia de tonos oliváceos en el basidioma parece corresponder con C. huronensis var. olivaceus (Breitenbach \& Kränzlin 2000). Se observaron gran cantidad de basidios bispóricos, por lo que aparecen tamaños esporales ligeramente mayores de los esperados (7-11 x 5-6 $\mu \mathrm{m})$; sin embargo, el resto de caracteres coinciden perfectamente con la descripción del taxón.

Ecología y distribución: recolectado en zona higroturbosa inundable con Salix atrocinerea y algún Alnus glutinosa con sotobosque formado por comunidades de Sphagnum sp.

Distribución septentrional en el Hemisferio Norte, tanto en Europa, incluida Península Ibérica, como América (GBIF en línea, $\mathrm{n}^{\circ}$ 3350308). No conocemos menciones anteriores para Galicia.

Cortinarius evernius (Fr.) Fr., Epicr. syst. mycol. (Upsaliae): 294 (1838)

Material estudiado: O Porriño, Budiño, Orbenlle, observatorio ornitológico, 29TNG3061, 22 m, bajo Betula pubescens, 21/12/2013, O. Requejo, LOU-Fungi 19900.

Ecología y distribución: observado bajo Betula pubescens, entre musgos al pie de la laguna en zona muy sombría.

No citado para Galicia, sin embargo, parece tratarse de una especie frecuente de norte a sur de la Península Ibérica (García-Bona 1994, Ortega et al. 2010). Georreferenciada en el Hemisferio Norte, preferentemente en Europa (GBIF en línea, $n^{\circ}$ 2528897).

Cortinarius mucosus (Bull.) J. Kickx f., Fl. Crypt. Flandres (Paris) 1: 191 (1867)

Material estudiado: O Porriño, Pontellas, barreras de Centeáns, 29TNG3007, 20 m, bajo Pinus pinaster, 22/12/2014, C. Ayres, LOU-Fungi 19875.

Observaciones: las características macro y microscópicas corresponden correctamente con las indicadas por Palazón (2001), incluída la presencia de alguna basidiospora aberrante, de $21 \times 10 \mu \mathrm{m}$, con forma y ornamentación características de la especie. 
Ecología y distribución: recolectado en su hábitat típico, bosque de Pinus pinaster.

Ampliamente georreferenciado en el Hemisferio norte (GBIF en línea, $\mathrm{n}^{\circ}$ 2529494). En Galicia sólo se encontró citado para Lugo (Castro 2013) y A Coruña (Marcote et al. 2011)

Cortinarius saturninus (Fr.) Fr., Epicr. syst. mycol. (Upsaliae): 306 (1838)

Material estudiado: Tui, Guillarei, aliseda de Albelos, 29TNG3019, $20 \mathrm{~m}$, bajo Quercus robur y Alnus glutinosa, 10/11/2015, O. Requejo, LOU-Fungi 20519.

Ecología y distribución: el material estudiado se recolectó, en bosque inundable de Alnus glutinosa con algunos ejemplares de Quercus robur.

Frecuente en Europa septentrional y central, también referenciada de EEUU y Nueva Zelanda (GBIF en línea, nº 2529066). En la Península Ibérica encontramos varias citas (Ortega et al. 2004, Rubio-Domínguez et al. 2006, Picón 2005, García-Blanco \& Sánchez-Rodríguez 2009, Moreno-Arroyo 2004). No conocemos menciones para Galicia.

Cortinarius semisanguineus (Fr.) Gillet, Hyménomycètes (Alençon): 484 (1876) [1878]

Material estudiado: O Porriño, Pontellas, barreras de Centeáns, 29TNG3007, 20 m, bajo Pinus pinaster, 26/12/2014, O. Requejo, LOU-Fungi 20251.

Ecología y distribución: la recolección estudiada se corresponde con su hábitat y época de aparición habitual, bajo coníferas (Breitenbach \& Kränzlin 2000, Castro 1985).

Común en Europa, también en EEUU (GBIF en línea, nº 2529327). Muy frecuente en Galicia, especialmente en pinares (Rodríguez-Vázquez \& Castro 2016).

Craterellus tubaeformis (Fr.) Quél., Fl. mycol. France (Paris): 36 (1888)

$\equiv$ Cantharellus tubaeformis Fr., Syst. mycol. (Lundae) 1: 319 (1821)

Material estudiado: O Porriño, Budiño, Orbenlle, Os Eidos, 29TNG3022, 30 m, bajo Pinus pinaster, 18/11/2014, J. Valeiras \& O. Requejo, LOU-Fungi 19830. O Porriño, Pontellas, barreras de Centeáns, 29TNG3007, 20 m, 22/12/2014, O. Requejo, LOU-Fungi 19865.

Ecología y distribución: común, con fructificaciones muy abundantes, en bosques de Pinus pinaster o incluso mixtos, no observado en ambientes higrófilos. 
Ampliamente georreferenciada tanto para las costas norteamericanas como para Europa (GBIF en línea, $n^{\circ}$ 2554536). Para el noroeste es frecuente en los bosques de caducifolios (Rodríguez-Vázquez \& Castro 2016).

Crepidotus calolepis (Fr.) P. Karst., Bidr.Känn. Finl. Nat. Folk 32: 414 (1879)

Material estudiado: O Porriño, Budiño, Orbenlle, observatorio ornitológico, 29TNG3061, 22 m, sobre Salix atrocinerea, 07/12/2013, O. Requejo, LOU-Fungi 19901.

Ecología y distribución: recolectado en bosque aluvial de Salix atrocinerea, sobre un tronco seco que no tocaba el suelo.

Georreferenciada de Europa septentrional y central, así como EEUU (GBIF en línea, $n^{\circ}$ 5240970). A pesar de ser un taxón poco frecuente (Senn-Irlet 1995) parece estar bien distribuida en la Península Ibérica (Vidal 1989a, LagoÁlvarez 2008, Moreno-Arroyo 2004, Picón 2005, Pérez-Butrón et al. 2006) con citas también en las islas Canarias (Bañares \& Beltrán 2009). En Galicia se ha bía observado en las provincias litorales gallegas (Lago-Álvarez 2008).

Crepidotus caspari Velen., Mykologia (Prague) 3 (5-6): 70 (1926)

= Crepidotus lundellii Pilát, Fungi Exsiccati Suecici 5-6: 10 (1936)

Material estudiado: O Porriño, Budiño, Orbenlle, observatorio ornitológico, 29TNG3061, 22 m, sobre corteza de Salix atrocinerea, 11/12/2014, O. Requejo, LOUFungi 20253.

Ecología y distribución: recolectado en bosque aluvial de Salix atrocinerea, sobre corteza de un viejo árbol vivo.

Taxón del que no se conoce bien su distribución (GBIF en línea, $\mathrm{n}^{\circ}$ 7244066). Poco común en la Península Ibérica (Dasairas \& Castro 2007). No la conocemos citada para Galicia.

Crepidotus cesatii (Rabenh.) Sacc., Michelia 1 (1): 2 (1877)

Material estudiado: O Porriño, Budiño, Orbenlle, observatorio ornitológico, 29TNG3061, 22 m, sobre ramas caídas de Alnus glutinosa, 21/03/2012, LOU-Fungi 19996. Tui, Guillarei, aliseda de Albelos, 29TNG3019, $20 \mathrm{~m}$, sobre tronco recubierto de musgos, 22/12/2015, O. Requejo, LOU-Fungi 20570.

Ecología y distribución: fue encontrado tanto sobre pequeñas ramas como en troncos. En la ZEC parece mostrar preferencia por la madera de Alnus glutinosa. 
Común en Europa, también conocido de América del Norte y del Sur y de Australia (GBIF en línea, $n^{\circ}$ 7243941). Mencionado para toda Galicia (Rodríguez-Vázquez \& Castro 2016).

Crepidotus crocophyllus (Berk.) Sacc., Syll. fung. (Abellini) 5: 886 (1887)

Material estudiado: O Porriño, Budiño, Orbenlle, observatorio ornitológico, 29TNG3061, 22 m, sobre ramas de Quercus robur, 04/06/2014, O. Requejo, LOU-Fungi 19902. Salceda de Caselas, desembocadura del río Becerreira, 29TNG3019, 20 m, sobre madera en bosque de Quercus robur y Alnus glutinosa, 12/09/2015, O. Requejo, LOUFungi 20266.

Ecología y distribución: común en bosques inundables de la zona de estudio, aunque en ellos muestra cierta preferencia por Quercus robur más que por otras especies más específicas de estos ambientes.

Parece tratarse de una especie relativamente frecuente en América del Norte y Asia Oriental, no así en Europa (Kasuya et al. 2014), no georreferenciado con precisión (GIBF en línea). Las observaciones ibéricas se centran en el noroeste (Rubio-Domínguez et al. 2006, Pérez-Butrón et al. 2006, Picón 2004). En Galicia sólo se conoce de las provincias litorales (Marcote et al. 2011, BlancoDios 2008, De la Peña 2016).

Crepidotus epibryus (Fr.) Quél., Fl. mycol. France (Paris): 107 (1888)

Material estudiado: Tui, Guillarei, aliseda de Albelos, 29TNG3019, $20 \mathrm{~m}$, sobre hojas y pequeñas ramas en bosque de Alnus glutinosa, 10/11/2015, O. Requejo, LOUFungi 20530. O Porriño, Pontellas, barreras de Centeáns, 29TNG3007, 20 m, sobre pequeña rama sin identificar, 19/12/2015, O. Requejo, LOU-Fungi 20571.

Ecología y distribución: las colecciones estudiadas se recolectaron en bosque aluviales, fructificando bien sobre ramas u hojas en suelo turboso.

Conocida de América del Norte y Sur, así como de Japón, ampliamente distribuida por Europa (GBIF en línea, $\mathrm{n}^{\circ}$ 5240973), también en la Península Ibérica (Lago-Álvarez 2008). En Galicia se conoce de todas las provincias menos Ourense (Rodríguez-Vázquez \& Castro 2016).

Crepidotus variabilis (Pers.) P. Kumm., Führ. Pilzk. (Zerbst): 74 (1871)

Material estudiado: Salceda de Caselas, Cerquido, Ponte Carneiro, 29TNG3164, 35 m, sobre rama de Salix atrocinerea, 27/11/2015, O. Requejo, LOU-Fungi 20542. 
Ecología y distribución: debido a la similitud macroscópica entre las especies del género, es imposible establecer si esta es la más común. La exsiccata estudiada se recolectó en bosque de ribera, sobre una pequeña rama de Salix atrocinerea.

Se trata de la especie del género que ha sido referenciada más veces, aunque no se sabe con exactitud cuál es su distribución (GBIF en línea), debido en buena medida a la confusión nomenclatural del propio género hasta que se realice la revisión molecular del mismo (Aime 2001). En Galicia aparece mencionada de las cuatro provincias (Rodríguez-Vázquez \& Castro 2016).

Crucibulum laeve (Huds.) Kambly, Gast. Iowa: 167 (1936)

Material estudiado: Salceda de Caselas, Cerquido, Ponte Carneiro 29TNG3164, 35 m, sobre Pteridium aquilinum seco, 02/10/2014, O. Requejo, LOU-Fungi 19799.

Observaciones: está por realizar el estudio molecular comparativo entre este taxón y Crucibulum crucibuliformis (Scop.) Hoffm., que en Mycobank (en línea $n^{\circ} 147133$ ) son considerados sinónimos, a diferencia de lo indicado en Index Fungorum (en línea). Probablemente la confusión se debe a que Peziza crucibuliformis Schaeff. ha sido considerada sinónimo heterotípico de $P$. laeve Huds., basiónimo del taxón estudiado (O’Reily 2015).

Ecología y distribución: muy común sobre todo tipo de restos herbáceos y leñosos (Calonge 1998), nuestra recolección sobre Pteridium aquilinum confirma la poca exigencia en cuanto al sustrato.

Parece ser una especie común en todo el mundo (GBIF en línea, $\mathrm{n}^{\circ}$ 5243575), también ampliamente extendida en Galicia (Soliño. 2000).

Cryptomarasmius minutus (Peck) T.S. Jenkinson \& Desjardin, Mycologia 106 (1): 92 (2014)

इMarasmius minutus Peck, Ann. Rep. N.Y. St. Mus. nat. Hist. 27: 97 (1875) [1874]

= Marasmius capillipes Sacc., Nuovo G. bot. Ital. 8(2): 162 (1876)

Material estudiado: Salceda de Caselas, desembocadura del río Becerreira, 29TNG3019, 20 m, sobre hojas de Salix atrocinerea, 26/09/2015, J.Á. Gándara \& O. Requejo, LOU-Fungi 20284.

Observaciones: presenta el aspecto macroscópico de una pequeña Mycena. Basidiosporas cilíndrico elipsoides de 7,5-8 (8,7) x 3-3,7 $\mu \mathrm{m}$, queilocistidios y pleurocistidios lageniformes de 15-35 x 5-6,5 $\mu \mathrm{m}$. Pelis formada por elementos esferopedunculados con excrecencias, entre los que sobresalen píleocistidios similares a los cistidios himeniales. 
Ecología y distribución: el material estudiado colonizaba hojas de Salix atrocinerea caídas sobre suelo turboso en zona inundable, durante la época estival, antes de las crecidas.

Distribución escasamente conocida, probablemente al pasar inadvertido por su pequeño tamaño (Noordeloos, 1995). Pocas referencias en Centroeuropa (GBIF en línea, $\mathrm{n}^{\circ}$ 8236276) y, un tanto dispersas para la Península Ibérica (Moreno-Arroyo 2004, Rubio-Domínguez et al. 2006). Para Galicia esta citada en Pontevedra (Fernández-Martínez \& Castro 1998).

Cyathus striatus (Huds.) Willd., Fl. berol. prodr.: 399 (1787)

Material estudiado: O Porriño, Budiño, Orbenlle, observatorio ornitológico, 29TNG3061, 22 m, sobre restos leñosos de Salix atrocinerea, 13/08/2014, O. Requejo, LOU-Fungi 19954. Salceda de Caselas, Cerquido, Ponte Carneiro 29TNG3164, 35 m, sobre restos de madera sin identificar, 27/09/2014, O. Requejo, LOU-Fungi 19792.Tui, Guillarei, Albelos, 29TNG3043, 13 m, sobre restos leñosos, 09/11/2015, O. Requejo, LOU-Fungi 20518.

Ecología y distribución: muy común sobre restos leñosos en toda la ZEC, incluso directamente en el suelo, sobre turba en zonas inundables antes de las crecidas.

Abundante en todo o mundo (GBIF en línea, $\mathrm{n}^{\circ}$ 5243151). Común en toda la Península Ibérica (Calonge 1996), al igual que en Galicia (Soliño et al. 2000).

Deconica horizontalis (Bull.) Noordel., Österr. Zeit. Pilzkunde 18: 209 (2009)

$\equiv$ Melanotus horizontalis (Bull.) P.D. Orton, Notes R. bot. Gdn. Edinb. 41(3): 595 (1984)

$\equiv$ Melanotus hepatochrous (Berk.) Singer, Sydowia 5(3-6): 472 (1951)

Material estudiado: O Porriño, Pontellas, barreras de Centeáns, 29TNG3007, 20 m, sobre restos de madera sin identificar, 26/12/2014, O. Requejo, LOU-Fungi 20206.

Ecología y distribución: recolectado sobre una pequeña rama sin corteza en camino al pie de la laguna, en bosque de Pinus pinaster con algún Quercus robur y Cytisus scoparius, por lo que no se consiguió concretar el sustrato.

No se indican referencias en GBIF (en línea). En la Península Ibérica parece preferir el tercio norte, aunque no es muy común (Rubio-Domínguez et al 2005, García-Blanco 2012, Rubio \& Miranda 2008). En Galicia ha sido mencionada por Lago (2008) y Marcote et al. (2011). 
Delicatula integrella (Pers.) Fayod, Annls Sci. Nat., Bot., sér. 7 9: 313 (1889)

$\equiv$ Mycena integrella (Pers.) Gray, Nat. Arr. Brit. Pl. (London) 1: 621 (1821)

Material estudiado: Salceda de Caselas, Cerquido, Ponte Carneiro 29TNG3164, 35 m, bajo Alnus glutinosa, 07/09/2014, M. Martínez Lago y O. Requejo, LOU-Fungi 19845.O Porriño, Pontellas, barreras de Centeáns, 29TNG3007, 20 m, bajo Salix atrocinerea, 15/06/2015, O. Requejo, LOU-Fungi 20208. Salceda de Caselas, desembocadura del río Becerreira, 29TNG3019, 20 m, bajo Alnus glutinosa y Salix atrocinerea, 26/09/2015, J.Á. Gándara \& O. Requejo, LOU-Fungi 20277. Tui, Guillarei, Albelos, 29TNG3040, 13 m, sobre madera en zona de inundación, 29/09/2015, J. Valeiras \& O. Requejo, LOU-Fungi 20288.

Ecología y distribución: muy común, fructificando desde época muy estival hasta bien pasado el otoño en suelos higroturbosos, tanto sobre restos leñosos como sobre turba.

Especie ampliamente citada en la Península Ibérica (Vila et al. 1997), al igual que en el resto de Europa (GBIF en línea, $n^{\circ}$ 2531735). En Galicia su distribución probablemente es más amplia de lo que refleja la bibliografía, ya que sólo ha sido publicada por Marcote et al. (2003), Requejo (2012), Blanco-Dios (2014b), De la Peña (2016).

Descolea maculata Bougher, Australian J. Bot. 33 (6): 620 (1986)

= Descolea maculata var. occidentalis Esteve-Rav., Sánchez Nieto, M. Villarreal \& Barrasa, Riv. Micol. 40(3): 252 (1997)

Material estudiado: O Porriño, Pontellas, barreiras de Centeáns, 29TNG3007, 20 m, bajo Eucalyptus globulus, 26/12/2014, O. Requejo, LOU-Fungi 20230.Tui, Guillarei, Albelos, 29TNG3043, 13 m, en bosque de Pinus pinaster con Eucalyptus globulus, 09/11/2015, O. Requejo, LOU-Fungi 20520.

Observaciones: D. maculata var. occidentalis no es aceptada como taxón diferente del tipo (Lago-Álvarez \& Castro 2004).

Las Gándaras.

Ecología y distribución: fácil de observar bajo Eucaliptus globulus en

Presenta distribución asociada al género Eucalyptus, por lo que sólo se referencia de Australia, Nueva Zelanda, Península Ibérica, incluida Galicia (GBIF en línea, ${ }^{\circ}$ 7244516), Tasmania (Lago-Álvarez \& Castro 2004) y Brasil (Giachini et al. 2000).

Entoloma cetratum (Fr.) M.M. Moser, in Gams, Kl. Krypt.-Fl., Bd II b/2, ed. 4 (Stuttgart) 2b/2: 206 (1978)

Material estudiado: O Porriño, Pontellas, barreras de Centeáns, 29TNG3007, 20 m, bajo Pinus pinaster, 22/12/2014, O. Requejo, LOU-Fungi 19878. 
Ecología y distribución: recolectado en una antigua braña, ahora inexistente por la intrusión del Pinus pinaster.

Común especialmente en Centro Europa, Noruega y Suecia, aunque se ha observado en Norte y Sudamérica (GBIF en línea, $\mathrm{n}^{\circ}$ 2539557). En la Península Ibérica parece estar mejor representado en el noroeste (Lago-Álvarez 2008), con alguna cita también en Andalucía (Moreno-Arroyo 2004). Ampliamente distribuida por el territorio gallego (Soliño et al. 1999).

Entoloma chalybeum (Pers.) Noordel. [as 'chalybaeum'], Nordic J. Bot. 2 (2): 162 (1982)

= Entoloma chalybeum var. lazulinum (Fr.) Noordel., Persoonia 12(3): 206 (1984)

Material estudiado: Salceda de Caselas, desembocadura del río Becerreira, 29TNG3019, 20 m, bajo Quercus robur y Alnus glutinosa, 22/12/2015, O. Requejo, LOUFungi 20614.

Observaciones: la colección estudiada con sombrero escamoso y estriado por transparencia parece pertenecer a E. chalybeum var. lazulinum (Noordeloos 2005).

Ecología y distribución: ha sido observado en bosque de ribera bajo Alnus glutinosa y Quercus robur, en suelo arenoso.

Este taxón ha sido observado en Centro Europa, Noruega y Suecia, así como Inglaterra (GBIF en línea, $\mathrm{n}^{\circ}$ 3346647), citado para Galicia de las provincias litorales (Rodríguez-Vázquez \& Castro 2016). Sin embargo, la variedad tipo parece ser común en Japón, Chile, Centro, Estados Unidos, Canadá y Europa, incluida la Península Ibérica, (GBIF en línea, $n^{\circ}$ 7244257). En el noroeste ibérico sólo se conocen dos citas, una antigua de la provincia de A Coruña (Losa Quintana \& Freire 1978) y otra reciente para Pontevedra (De la Peña 2016).

Entoloma conferendum (Britzelm.) Noordel., Persoonia 10 (4): 446 (1980) = Entoloma conferendum var. pusillum (Velen.) Noordel., Persoonia 10(4): 450 (1980)

Material estudiado: Tui, Guillarei, turbera de Albelos, 29TNG3036, $20 \mathrm{~m}$, sobre turba bajo Salix atrocinerea, Carex sp. y Schoenus nigricans, 07/09/2015, J. Valeiras y O. Requejo, LOU-Fungi 20260.

Observaciones: los caracteres macro y microscópicos corresponden con la descripción de Noordeloos (2005), sin embargo, podría tratarse de $E$. conferendum var. pusillum (Velen.) Noord., diferenciado principalmente por presentar un aspecto más grácil y desarrollarse sobre madera muy degradada. La colección estudiada ha sido recolectada turbera adentro, donde persisten gran cantidad de restos en descomposición, procedentes de la vegetación circundante. 
Ecología y distribución: interesante recolección, que junto con Cortinarius bibulus son las recolectadas mas al interior de la turbera, accesible solo en épocas en las que el nivel hídrico esta muy bajo. En el caso del C. bibulus, la estrategia trófica parecía ser micorrizógena, para E. conferendum saprotrófica. Fructificaba sobre suelo turboso, muy pobre en oxígeno y muy sombrío, debido a la bóveda formada por Carex sp. y Schoenus nigricans.

El tipo ha sido observado por todo el mundo, especialmente en Europa (GBIF en línea, $\mathrm{n}^{\circ}$ 3346023), sin embargo, la variedad sólo se ha georreferenciado en Centroeuropa, Noruega y Suecia, así como Irlanda (GBIF en línea, n 3346022). Para la Península Ibérica encontramos E. conferendum var. pusillum mencionado por Esteve-Raventós et al (1999). En Galicia se citó el tipo de A Coruña, Lugo y Pontevedra (Rodríguez-Vázquez \& Castro 2016), no así la variedad.

Entoloma rhodocylix (Lasch) M.M. Moser, in Gams, Kl. Krypt.-Fl., Bd II b/2, ed. 4 (Stuttgart) 2b/2: 210 (1978)

Material estudiado: O Porriño, Budiño, Orbenlle, observatorio ornitológico, 29TNG3061, 22 m, bajo Salix atrocinerea, 22/09/2014, O. Requejo, LOU-Fungi 19849.

Ecología y distribución: recolectado un único ejemplar, sobre restos de hojas en suelo con hierba bajo Salix atrocinerea al pie de la laguna.

No conocemos su distribución a nivel mundial con exactitud, pero parece estar bien distribuido y ser común en Europa (Noordeloos 1992). Poco frecuente en el N.O. Ibérico, aunque ha sido mencionado para Pontevedra por Rodríguez-Vázquez \& Castro (1996) y para Lugo por Castro (1985).

Entoloma sarcitum (Fr.) Noordel., Persoonia 11 (2): 150 (1981)

Material estudiado: O Porriño, Budiño, Orbenlle, observatorio ornitológico, 29TNG3061, 22 m, bajo Salix atrocinerea y Osmunda regalis, 12/05/2013, O. Requejo, LOU-Fungi 19992. Ibídem 12/05/2013, O. Requejo, LOU-Fungi 19991. Salceda de Caselas, Cerquido, Ponte Carneiro 29TNG3164, 35 m, bajo Salix atrocinerea, 02/10/2014, R. Requejo, LOU-Fungi 19852.

Observaciones: basidiosporas de 8,8-10 x 7- 8,7 $\mu \mathrm{m}$, límites ligeramente menores que los indicadas por Noordeloos (2005).

Ecología y distribución: muy frecuente todo el año en la zona de estudio, tanto en bosques aluviales como límites de turberas.

Referenciada en Centro Europa, Noruega y Suecia (GBIF en línea, $\mathrm{n}^{\circ}$ 2539361), también en Francia y Holanda (Noordeloos 1992). Para la Península Ibérica encontramos escasas citas en el norte (Moreno et al. 2002, Vila \& 
Caballero 2009) y en Andalucía (Moreno-Arroyo 2004). No conocemos menciones para Galicia.

Entoloma sordidulum (Kühner \& Romagn.) P.D.Orton, Trans. Br. mycol. Soc. 43 (2): 175 (1960)

Material estudiado: O Porriño, Budiño, Orbenlle, observatorio ornitológico, 29TNG3061, 22 m, bajo Salix atrocinerea pero sobre Osmunda regalis , 11/12/2014, O. Requejo, LOU-Fungi 20255.

Observaciones: las basidiosporas con 5-6 ángulos, de 9-10 x 6,8-7,5 $\mu \mathrm{m}$, los basidios con fíbulas y la pelis tipo cutis, con hifas de hasta $7,5 \mu \mathrm{m}$, con elementos incrustados indican claramente que se trata de este taxón.

Ecología y distribución: la colección estudiada fructificaba directamente sobre raquis de Osmunda regalis en la turbera. Este hábitat difiere del indicado por Noordeloos (2005), parques y jardines.

No conocemos con exactitud su distribución a nivel mundial (GBIF en línea), pero en Europa parece ser un taxón disperso y bien distribuido (Noordeloos 1992), al igual que en la Península Ibérica (Tabarés \& Rocabruna 1998, Moreno-Arroyo 2004, Rubio-Domínguez et al. 2006). No la conocemos mencionada para Galicia.

Exidia glandulosa (Bull.) Fr., Syst. mycol. (Lundae) 2 (1): 224 (1822)

Material estudiado: Tui, Guillarei, Albelos, 29TNG3043, 13 m, sobre rama de Quercus robur, 26/12/2015, J. Valeiras, LOU-Fungi 20576.

Ecología y distribución: muy común en la zona de estudio, sobre todo sobre ramas caídas de frondosas.

Bien distribuido en Galicia (Soliño et al. 2000), ampliamente referenciada en todo el mundo, aunque con mayor frecuencia en Europa y Nordeste americano (GBIF en línea, $\mathrm{n}^{\mathrm{0}}$ 2553607).

Fistulina hepatica (Schaeff.) With., Bot. Arr. Brit. Pl.3: 405 (1792)

Material estudiado: O Porriño, Budiño, Orbenlle, observatorio ornitológico, 29TNG3061, 22 m, sobre Quercus robur, 22/10/2013, G. Requejo, LOU-Fungi 19997.

Ecología y distribución: recolectado en su hábitat y época habitual Breitenbach \& Kränzlin 1986), un viejo Quercus robur.

Ampliamente extendida en la zona norte de la Península Ibérica sobre viejos árboles planifolios, también en Galicia (Soliño et al. 2000). Observada en el continente americano, Australia y Europa (GBIF en línea, $n^{\circ}$ 2531012). 
Fomitiporia punctata (P. Karst.) Murrill, Lloydia 10: 254 (1947)

$\equiv$ Phellinus punctatus Pilát, Atlas Champ. l'Europe, Polyporaceae (Praha) 3 (1): 530 (1942)

Material estudiado: O Porriño, Budiño, Orbenlle, observatorio ornitológico, 29TNG3061, 22 m, sobre Salix atrocinerea, 15/05/2013, O. Requejo, LOU-Fungi 19946.

Ecología y distribución: recolectado parasitando un Salix atrocinerea en bosque aluvial.

Observada con frecuencia en Europa occidental, Japón, Estados Unidos, Canadá, así como diversos países de Sudamérica (GBIF en línea, nº 2520671 sub. Phellinus). También se conoce en Galicia desde 1917 para la provincia de Pontevedra (Lázaro-Ibiza 1917) y, con posterioridad, para la de A Coruña (LópezPrada et al. 1993).

Galerina calyptrata P.D. Orton, Trans. Br. mycol. Soc. 43(2): 237 (1960)

Material estudiado: O Porriño, Orbenlle, 29TNG3022, $20 \mathrm{~m}$, sobre musgos en muro, 7/12/2016, O. Requejo. LOU-Fungi 20671.

Observaciones: se trata de una especie de pequeño tamaño, semejante a Galerina cerina A.H.Sm. \& Singer, de la que se diferencia macroscópicamente por la coloración del píleo, olor y sabor ligeramente harinoso y el pequeño hinchamiento hialino de la base del pie, de hecho, De Haan \& Walleyn (2002) consideran ambas especies como dos formas diferentes de G. cerina.

Presenta esporas de oval a amigdaliformes, con perisporio, de 11-12 x 6,5-7,5 mm y queilocistidios de cilíndricos-sinuosos a lageniformes, algunos capitados.

Ecología y distribución: los ejemplares estudiados fructificaban entre musgos en un talud de tierra en bosque mixto de Pinus pinaster y Quercus robur. Especie común en Centro y Norte de Europa, también en las Islas Británicas (GBIF en línea, no 2533889), en la Península Ibérica aparece escasamente mencionada, pero se la conoce desde Asturias (Rubio et al. 2006) hasta Andalucía (Pancorbo Maza 2009) y en Galicia ha sido citada por Requejo (2012).

Galerina marginata (Batsch) Kühner, Encyclop. Mycol. 7: 225 (1935)

Material estudiado: O Porriño, Orbenlle, 29TNG3022, $20 \mathrm{~m}$, sobre madera de Salix atrocinerea, 7/12/2016, O. Requejo. LOU-Fungi 20670.

Ecología y distribución: fructificaba sobre restos de un Salix atrocinerea que permanecía erguido en bosque aluvial sobre suelo turbosos al pie de la laguna. 
Se trata de una especie que ha sido interpretada de forma diversa por los investigadores a lo largo del tiempo, por lo que no resulta fácil conocer su distribución mundial (GBIF en línea, $\mathrm{n}^{\mathrm{o}}$ 26333668), aunque ha sido georreferenciada por todo el Hemisferio Norte, incluida la Península Ibérica, y continente austral (GBIF en línea, $\mathrm{n}^{\circ}$ 2533848). En Galicia se conoce de las provincias de A Coruña, Lugo y Pontevedra (Rodríguez-Vázquez \& Castro 2016).

Ganoderma australe (Fr.) Pat., Bull. Soc. mycol. Fr. 5 (2,3): 65 (1889)

Material estudiado: Tui, Guillarei, turbera de Albelos, 29TNG3036, $20 \mathrm{~m}$, sobre Salix atrocinerea, 26/03/2015, O. Requejo. LOU-Fungi 20008.

Ecología y distribución: es habitual ver en saucedas inundables viejos carpóforos de Ganoderma sobre Salix atrocinerea viejos o muertos y tumbados.

Georreferenciado en Sudamérica, Europa y Australia, incluida Nueva Zelanda (GBIF en línea, $n^{\circ}$ 2549779). Debido a la confusión que presenta con $G$. adspersum (Schulzer) Donk es complicado aproximar su distribución ibérica. De hecho, se ha observado que multitud de citas de Andalucía resultaron ser incorrectas (Moreno-Arroyo 2004). No obstante, parece estar bien distribuido en la parte norte Peninsular (Dueñas \& Tellería 1988, García-Bona 2000, Picón 2005). En Galicia aparece mencionado para las provincias de A Coruña, Pontevedra y Lugo (Rodríguez-Vázquez \& Castro 2016).

Ganoderma lucidum (Curtis) P.Karst., Revue mycol., Toulouse 3 (9): 17 (1881)

Material estudiado: O Porriño, Budiño, Orbenlle, observatorio ornitológico, 29TNG3061, 22 m, sobre Salix atrocinerea, 07/10/2013, O. Requejo, LOU-Fungi 20016.

Ecología y distribución: común en la zona de estudio, muestra preferencia por los sauces en zonas muy húmedas.

Común en todo el mundo (GBIF en línea, $\mathrm{n}^{\circ}$ 2549730). No es un taxón frecuente, pero está ampliamente distribuido por toda Galicia (RodríguezVázquez \& Castro 2016).

Ganoderma resinaceum Boud., in Patouillard, Bull. Soc. mycol. Fr. 5 (2, 3): 72 (1890)

Material estudiado: Tui, Ribadelouro, Puente de la Madalena, 29TNG2992, 26 m, sobre Alnus glutinosa, 09/08/2015, O. Requejo, LOU-Fungi 20239.

Ecología y distribución: es la especie del género menos observada en la zona de estudio y más alejada de suelos higroturbosos. La colección estudiada se recolectó sobre Alnus glutinosa en bosque ripario, al lado de un camino de tierra. 
Ampliamente referenciado en América (norte y sur), Europa, norte de África, Australia y Nueva Zelanda (GBIF en línea, n 2549683). Taxón común en la Península Ibérica (Lago-Álvarez 2008), no así en Galicia, aunque se conoce de las provincias de A Coruña, Lugo y Pontevedra con cierta tendencia a crecer sobre eucaliptos (Rodríguez-Vázquez \& Castro 2016).

Gomphidius roseus (Fr.) Fr., Epicr. syst. mycol. (Upsaliae): 319 (1838)

Material estudiado: O Porriño, Budiño, Orbenlle, Os Eidos, 29TNG3022, 30 m, bajo Pinus pinaster, 29/11/2014, O. Requejo, LOU-Fungi 19841.

Ecología y distribución: observado en bosque mixto de Pinus pinaster y Quercus robur con algún Eucaliptus globulus, próximo a Suillus bovinus, especie con la que habitualmente establece cierta relación mutualista.

Común en el continente europeo, incluida la Península Ibérica (GBIF en línea, no 2515048). Muy común en toda Galicia (Rodríguez-Vázquez \& Castro 2016).

Gymnopilus junonius (Fr.) P.D. Orton, Trans. Br. mycol. Soc. 43 (2): 176 (1960) $=$ Gymnopilus spectabilis $\mathrm{s}$. auct.

Material estudiado: O Porriño, Pontellas, barreiras de Centeáns, 29TNG3007, 20 m, sobre tocón de Pinus pinaster, 26/12/2014, A. Justo, LOU-Fungi 19896. O Porriño, Budiño, Orbenlle, Os Eidos, 29TNG3022, 30 m, sobre Eucaliptus globulus, 15/10/2016, Marta Martínez Lago, LOU-Fungi 20642.

Ecología y distribución: abundante en la zona de estudio, tanto sobre restos leñosos como sobre árboles vivos (LOU-Fungi 20642).

Común en Galicia durante todo el año y en diversos substratos (Soliño et al. 1999), así como en el resto de Europa (GBIF en línea, nº 2533674).

Gymnopilus penetrans (Fr.) Murrill, Mycologia 4 (5): 254 (1912)

Material estudiado: O Porriño, Budiño, Orbenlle, Os Eidos, 29TNG3022, 30 m, sobre madera de Pinus pinaster, 30/11/2014, O. Requejo, LOU-Fungi 19836. O Porriño, Pontellas, barreiras de Centeáns, 29TNG3007, 20 m, sobre madera degradada de Pinus pinaster, 22/12/2014, J. Valeiras, LOU-Fungi 19867.Tui, Guillarei, Albelos, 29TNG3043, $13 \mathrm{~m}$, en bosque de Pinus pinaster entre restos, 09/11/2015, O. Reuqejo, LOU-Fungi 20502 .

Observaciones: semejante a G. hybridus (Gillet) Maire del que se diferencia por el mayor tamaño y la ausencia de anillo y/o cortina. 
Ecología y distribución: fácil de observar en otoño sobre todo tipo de restos de Pinus pinaster.

Muy común en el Hemisferio Norte (GBIF en línea, $\mathrm{n}^{\circ}$ 2533692), ampliamente citada para el noroeste ibérico (Soliño et al. 1999)

Gymnopilus picreus (Pers.) P.Karst., Bidr.Känn. Finl. Nat. Folk 32: 400 (1879)

Material estudiado: Tui, Guillarei, Albelos, 29TNG3043, 13 m, sobre tocón Salix atrocinerea, 09/11/2015, O. Requejo, LOU-Fungi 20507.Salceda de Caselas, Cerquido, Ponte Carneiro, 29TNG3164, 35 m, sobre tocón sin identificar, 27/12/2015, Rafael Estévez, LOU-Fungi 20538.

Ecología y distribución: no tan común como las otras dos especies del género citadas anteriormente, pero más próxima a bosques húmdos.

Taxón georreferenciado en Australia, Nueva Zelanda y en el Hemisferio Norte, especialmente Países Escandinavos (GBIF en línea, $n^{\circ}$ 2533726). En Galicia ha sido mencionada de A Coruña, Lugo y Pontevedra (Freire 1982, Rodríguez-Vázquez \& Castro 2006, Blanco-Dios 2006).

Gymnopus androsaceus (L.) Della Maggiora \& Trassinelli, Index Fungorum 171: 1 (2014)

$\equiv$ Marasmius androsaceus (L.) Fr., Epicr. syst. mycol. (Upsaliae): 385 (1838)

$\equiv$ Setulipes androsaceus (L.) Antonín, Česká Mykol.41(2): 86 (1987)

Material estudiado: O Porriño, Pontellas, barreiras de Centeáns, 29TNG3007, 20 m, sobre acículas de Pinus pinaster y restos herbáceos, 22/12/2014, O. Requejo, LOUFungi 19876.

Observaciones: Las medidas esporales resultaron un poco más anchas que lo indicado por Antonín \& Noordeloos (1993); sin embargo, coinciden con el intervalo observado por Bon (1999).

Ecología y distribución: común y muy abundante sobre acículas de Pinus pinaster caídas, el material estudiado fructificaba al pie de la laguna.

Georreferenciado para Europa y costa occidental de Estados Unidos (GBIF en línea, no 2537276 como Marasmius), Japón, centro y sur de Europa, norte de Australia y dispersa por el continente americano (GBIF en línea, $\mathrm{n}^{\mathrm{o}}$ 7769302 como Gymnopus). Muy frecuente en Galicia, sobre acículas de pino (Soliño et al. 1999). 
Gymnopus dryophilus (Bull.) Murrill, N. Amer. Fl. (New York) 9 (5): 362 (1916)

Material estudiado: O Porriño, Budiño, Orbenlle, observatorio ornitológico, 29TNG3061, 22 m, bajo Pinus pinaster y Quercus robur, 13/08/2014, O. Requejo, LOUFungi 19961.

Ecología y distribución: recolectado en verano en bosque mixto de Pinus pinaster y Quercus robur, creciendo entre hojas caídas y restos herbáceos.

Georreferencia en todos los continentes, excepto África (GBIF en línea, $n^{\circ}$ 5243756). Ampliamente extendida tanto en Galicia (Soliño et al. 1999) como en el resto de la Península Ibérica (GBIF en línea).

Gymnopus erythropus (Pers.) Antonín, Halling \& Noordel., Mycotaxon 63: 364 (1997)

Material estudiado: Tui, Guillarei, Albelos, 29TNG3040, 13 m, entre hierbas y restos orgánicos, 09/11/2015, O. Requejo, LOU-Fungi 20300.

Ecología y distribución: fructificaba en una zona herbosa muy abierta, próxima a una comunidad de bambú, donde también había hojas de estos.

Muy frecuente en Europa (centro y sur), también observada en la costa occidental norteamericana (GBIF en línea, no 5243771). Frecuente en Galicia (Soliño et al. 1999).

Gymnopus foetidus (Sowerby) P.M. Kirk, Index Fungorum 120: 1 (2014)

इMarasmius foetidus (Sowerby) Fr., Epicr. syst. mycol. (Upsaliae): 380 (1838)

इ Micromphale foetidum (Sowerby) Singer, Lloydia 8(3): 182 (1945)

Material estudiado: Salceda de Caselas, Cerquido, Ponte Carneiro 29TNG3164, 35 m, sobre tronco caído de Alnus glutinosa, R. Requejo, LOU-Fungi 19855.

Ecología y distribución: encontrado sobre tronco de Alnus glutinosa caído, en bosque ripario conviviendo con Mycena algeriensis y carpóforos degradados de Xanthoporia radiata.

Escasas referencias, sólo para Centroeuropa (GBIF en línea, $\mathrm{n}^{\circ} 2538110$, como Marasmius). No parece un taxón muy frecuente en la Península Ibérica, a pesar de que estar presente en distintos medios (Picón 2004, Rubio-Domínguez 2005, García-Bona 2000, García-Blanco 2012, Merino-Alcántara en línea, Tabarés \& Pascual 1987, Fernández-Vicente 2014). En Galicia ha sido mencionado para las provincias de A Coruña (Losa Quintana \& Freire 1978), Lugo (Blanco-Dios et al. 1989) y Pontevedra (De la Peña 2016). 
Gyrodon lividus (Bull.) Sacc., Syll. fung. (Abellini) 6: 52 (1888)

Material estudiado: Salceda de Caselas, Cerquido, Ponte Carneiro 29TNG3164, 35 m, bajo Alnus glutinosa, 02/10/2014, M. Martínez, LOU-Fungi 19800.

Ecología y distribución: ha sido recolectado micorrizando con Alnus glutinosa en bosque ripário.

Ampliamente georreferenciada en Europa, pero también mencionada para la costa oriental norteamericana y Japón (GBIF en línea, no 2525619). En Galicia sólo ha sido mencionada de la provincia de A Coruña (Justo \& Castro 2002; Marcote et al. 2003).

Gyroporus castaneus (Bull.) Quél., Enchir. fung. (Paris): 161 (1886)

Material estudiado: Tuy, Rebordanes, Ponte das Febres 29TNG2996, 21 m, bajo Quercus robur, 22/10/2016, Oscar Requejo, LOU-Fungi 20651.

Ecología y distribución: : han sido observados pequeños ejemplares creciendo bajo Quercus robur en talud de tierra, en bosque de ribera que habitualmente se inunda,

Especie difusa en todo el mundo, con mayor concentración de citas en Centroamérica y Europa (GBIF en línea, $n^{\circ}$ 2524274). Muy citado en Galicia, excepto para la provincia de Ourense (Rodríguez-Vázquez \& Castro 2016).

Hebeloma mesophaeum (Pers.) Quél., Mém. Soc. Émul. Montbéliard, sér. 2 5: 128 (1872)

Material estudiado: Salceda de Caselas, desembocadura del río Becerreira, 29TNG3019, 20 m, bajo Salix atrocinerea y Quercus robur, 31/10/2016, O. Requejo, LOU-Fungi 20672.

Observaciones: abundante en la zona de fructificación, produciendo carpóforos muy esbeltos y con la zona anular del pie muy próxima a las láminas.

Ecología y distribución: recolectado en bosque aluvial muy umbrío bajo Salix atrocinerea y Quercus robur.

Es un taxón muy común en toda Europa, incluida la Península Ibérica, pero también aparece mencionado para América del Norte y del Sur, así como el continente austral (GBIF en línea, $n^{\circ}$ 2533062). Muy común también en Galicia (Rodríguez-Vázquez \& Castro 2016). 
Hebeloma salicicola Beker, Vesterh. \& U. Eberh., in Eberhardt, Beker \& Vesterholt, Persoonia 35: 143 (2015)

Material estudiado: Tuy, Rebordanes, Ponte das Febres 29TNG2996, 21 m, en turba bajo Salix atrocinerea, 02/10/2016, Marta Martínez, LOU-Fungi 20637.

Observaciones: basidiomas de pequeña talla, que apenas llegan a los 35 $\mathrm{mm}$, con píleo más o menos blanco, con la zona central ocre más oscura y olor rafanoide. Esporas anchamente fusiformes, amigdaliformes o citriformes de 11,2$12(12,5) \times 5-5,6 \mu \mathrm{m}$, con sutil ornamentación verrucosa y apéndice variable. Queilocitidios cilíndricos capitados o claviformes con ápice ensanchado hasta 8$9 \mu \mathrm{m}$ y de 40-70 $\mu \mathrm{m}$ de largo, pleurocistidios no observados y caulocistidios de medidas y formas similares a los queilocistidios. Con estas características sumadas al exclusivo hábitat se puede caracterizar bien la especie.

Ecología y distribución: fructifica de forma muy abundante formando micorrizas en suelo turboso y desnudo en saucedas inundables, justo antes de anegarse, habitualmente coincide con Inocybe ochroalba e Hypholoma ericaeoides.

No lo encontramos georreferenciado en GBIF (en línea), aunque parece estar bien distribuido por toda Europa (Beker et al 2016) quienes también han revisado material de la Península Ibérica. No conocemos menciones para Galicia.

Hebeloma sinapizans (Paulet) Gillet, Hyménomycètes (Alençon): 527 (1876) [1878]

Material estudiado: Salceda de Caselas, desembocadura del río Becerreira, 29TNG3019, 20 m, bajo Populus nigra, 22/12/2015, O. Requejo, LOU-Fungi 20594.

Ecología y distribución: el material estudiado se recolectó en bosque de ribera bajo Populus nigra, entre acúmulos de hojas de este.

Común en Europa, también observado en Estados Unidos y Canadá (GBIF en línea, $n^{\circ}$ 2533010). En Galicia sólo se ha mencionado de la provincia de Lugo (Comesaña \& Castro 1999, Marcote et al. 2003).

Hemimycena angustispora (P.D. Orton) Singer, Sydowia 15(1-6): 62 (1962) [1961]

Material estudiado: Tuy, Guillarei, aliseda de Albelos, 29TNG3019, $20 \mathrm{~m}$, sobre pequeña rama sin identificar, 25/06/2016, O. Requejo, Lou-Fungi 20628. 
Observaciones: pequeños basidiomas de color blanco y porte mycenoide. Esporas estrechamente fusiformes de 8-12 x 2,5-3,5(4) $\mu \mathrm{m}$ con prominente apéndice hifal. Pileipelis tipo cutis formada por hifas que rondan las $10 \mu \mathrm{m}$ donde observamos Píleocistidios aciculares de hasta $95 \mu \mathrm{m}$ de largo. Caulocistidios similares a los Píleocistidios. Fíbulas observadas en todas las estructuras.

Ecología y distribución: se ha recolectado sobre una pequeña rama caída sobre suelo turboso en bosque de Alnus glutinosa y Salix atrocinerea inundable.

Apenas georreferenciado de Dinamarca, Estonia y Noruega (GBIF en línea, $\left.n^{\circ} 2527485\right)$. Distribución poco conocida, aun así, está presente en Europa central y del este (Antonín \& Noordeloos 2004). No se encontraron citas para la Península Ibérica.

Hohenbuehelia unguicularis (Fr.) O.K. Mill., in Thorn, Mycotaxon 25 (1): 44 (1986)

Material estudiado: O Porriño, Budiño, Orbenlle, observatorio ornitológico, 29TNG3061, 22 m, sobre ramas caídas de Salix atrocinerea, 01/10/2013, O. Requejo, LOU-Fungi 19999.

Observaciones: basidiocarpo sésil o subsésil, en forma de concha o abanico, superficie pruinosa, color pardo grisáceo, estriado por transparencia, láminas algo más claras que el píleo. Basidios claviformes, con algunas constricciones, de 20-24 x 5-6 $\mu \mathrm{m}$ y basidiosporas de cilíndricas a faseoliformes, de 4,8-8,3 x 2,3-4,6- (5) $\mu \mathrm{m}, \mathrm{Qn}=1,9$ ( $\mathrm{n}=25)$.

Ecología y distribución: se recolectó sobre ramas caídas de Salix atrocinerea en bosque ripario.

Taxón poco frecuente (Elborne 1995). Preferentemente referenciada para Centroeuropa y Países Nórdicos (GBIF en línea, $n^{\circ}$ 2526377). Especie muy poco citada en la Península Ibérica (Rubio-Domínguez, 2005; Sanclemente \& Llimona, 1987). No conocemos citas para Galicia.

Hortiboletus rubellus (Krombh.) Simonini, Vizzini \& Gelardi, in Vizzini, Index Fungorum 244: 1 (2015)

三Xerocomellus rubellus (Krombh.) Šutara, Czech Mycol. 60(1): 50 (2008)

= Xerocomus versicolor E.-J.Gilbert, Livres Mycologue 3: Bolets: 138 (1931)

$\equiv$ Xerocomus rubellus Quél., Compt. Rend. Assoc. Franç. Avancem. Sci. 24(2): 620 (1896) [1895] 
Material estudiado: O Porriño, Budiño, Orbenlle, Os Eidos, 29TNG3022, $30 \mathrm{~m}$, bajo Quercus robur, 07/10/2013, O. Requejo, LOU-Fungi 20227.Tui, Ribadelouro, Puente de la Madalena, 29TNG2992, 26 m, bajo Quercus robur y Salix atrocinerea, 09/08/2015, O. Requejo, LOU-Fungi 20240.

Ecología y distribución: común en los bosques de ribera de la ZEC, asociándose a un amplio número de especies arbóreas desde épocas muy estivales.

Taxón frecuente en Europa, también conocido de Estados Unidos, Canadá, Japón, Australia y Nueva Zelanda (GBIF en línea, no 8060178). En Galicia es frecuente y está ampliamente extendido (Soliño et al. 1999).

Hydnellum scrobiculatum (Fr.) P.Karst., Meddn Soc. Fauna Flora fenn. 5: 41 (1879)

Material estudiado: O Porriño, Budiño, Orbenlle, observatorio ornitológico, 29TNG3061, 22 m, creciendo en la base de un Quercus robur, 03/11/2013, O. Requejo, LOU-Fungi 20600.

Observaciones: ejemplar muy joven en el que se podían apreciar apéndices del himenio blancos, que viraban a pardo. Píleo con zonas concéntricas de color pardo rojizo o rosado, olor harinoso y basidiosporas nodulosas, de 6-7 x 5-6,2 $\mu \mathrm{m}$, coincidente con Pegler et al. (1997).

Ecología y distribución: fructificaba estableciendo micorriza en la base de un Quercus robur.

Georreferenciado en Europa, Norte y Centroamérica y Australia (GBIF en línea, $n^{\circ}$ 2522326). En la Península Ibérica a pesar de que se encontraron varias citas de norte a sur (García-Bona 2000, Picón, 2004, Moreno-Arroyo 2004), no parece ser una especie muy conocida. Observada su presencia en Galicia, provincia de Pontevedra, desde Losa España (1943) y A Coruña (Marcote et al 2009).

Hydnum repandum L., Sp. Pl.: 1178 (1753)

Material estudiado: O Porriño, Budiño, Orbenlle, Os Eidos, 29TNG3022, $30 \mathrm{~m}$, bajo Pinus pinaster y Quercus robur, 10/11/2014, O. Requejo, LOU-Fungi 19828. O Porriño, Pontellas, barreras de Centeáns, 29TNG3007, $20 \mathrm{~m}$, bajo Pinus pinaster, 22/12/2014, O. Requejo, LOU-Fungi 19859.

Ecología y distribución: es una especie fácil de encontrar en todas formaciones en las que está presente Pinus pinaster, no así en zonas húmedas. 
Común, observada en el Hemisferio Norte, Sur de Australia y Nueva Zelanda (GBIF en línea, $\mathrm{n}^{\circ}$ 2554716). Muy frecuente en toda Galicia, especialmente bajo coníferas (Rodríguez-Vázquez \& Castro 2016).

Hygrocybe conica (Schaeff.) P.Kumm., Führ. Pilzk. (Zerbst): 111 (1871)

Material estudiado: Salceda de Caselas, Cerquido, Ponte Carneiro 29TNG3164, 35 m, bajo Salix atrocinerea y Pinus pinaster, 02/10/2014, R. Requejo, LOU-Fungi 19802.

Ecología y distribución: recolectada en una zona muy sombría, en bosque de Pinus pinaster con algún Salix atrocinerea, donde antes se hallaban unas brañas, ahora colmatadas y colonizadas por las coníferas.

Ampliamente georreferenciada para Europa, América, Australia y Nueva Zelanda (GBIF en línea, $n^{\circ}$ 2538524), extendida tanto en Galicia (Soliño et al. 1999).

Hygrocybe miniata (Fr.) P.Kumm., Führ. Pilzk. (Zerbst): 112 (1871)

Material estudiado: O Porriño, Budiño, Orbenlle, Os Eidos, 29TNG3022, 30 m, entre musgos y restos leñosos bajo Quercus robur y Pinus pinaster, 01/12/2014, M. Martínez Lago y O. Requejo, LOU-Fungi 19858.

Ecología y distribución: ha sido observada entre musgos en paseo de ribera bajo Quercus robur y Pinus pinaster.

Observada y georreferenciada para Europa, América, Australia y Nueva Zelanda (GBIF en línea, no 2538580). Frecuente en Galicia, a excepción de la provincia de Lugo (Soliño et al. 1999).

Hygrophoropsis aurantiaca (Wulfen) Maire, L'Empoisonnem.Champ.: 99 (1921)

Material estudiado: O Porriño, Budiño, Orbenlle, Os Eidos, 29TNG3022, 30 m, entre restos leñosos, 17/10/2013, O. Requejo, LOU-Fungi 19968.Tui, Guillarei, Albelos, 29TNG3043, 13 m, en bosque de Pinus pinaster entre restos, 09/11/2015, O. Requejo, LOU-Fungi 20513. pinaster.

Ecología y distribución: frecuente entre y sobre restos de Pinus

Común en el Hemisferio Norte, especialmente en Europa, también observada en América del Sur, Australia y Nueva Zelanda. En Península Ibérica predomina la distribución septentrional (GBIF en línea, nº 2525710). Frecuente en Galicia (Soliño et al. 1999). 
Hygrophorus hypothejus (Fr.) Fr., Epicr. syst. mycol. (Upsaliae): 324 (1838)

Material estudiado: O Porriño, Pontellas, barreras de Centeáns, 29TNG3007, 20 m, bajo Pinus pinaster, 22/12/2014, J. Valeiras, LOU-Fungi 19872. Salceda de Caselas, Cerquido, Ponte Carneiro 29TNG3164, 35 m, bajo Quercus robur y Pinus pinaster 27/12/2014, O. Requejo, LOU-Fungi 19929.

Ecología y distribución: común bajo Pinus pinaster en la ZEC, la colección LOU-Fungi 19872, se recolectó en unas antiguas brañas, ahora con pinos y sotobosque herbáceo.

Frecuente en Europa, incluyendo la zona septentrional de la Península Ibérica (GBIF en línea, $\mathrm{n}^{\circ}$ 2538748), también conocido de las cuatro provincias gallegas (Freire 1982, Blanco-Dios 2005, Domínguez-Borines 2006 y Marcote et al. 2009).

\section{Hymenochaete rubiginosa (Dicks.) Lév., Ann. Sc. Nat. Bot. 5: 151 (1846)}

Material estudiado: O Porriño, Budiño, Orbenlle, Os Eidos, 29TNG3022, 30 m, sobre Quercus robur, 10/05/2015, O. Requejo, LOU-Fungi 20204. Tui, Guillarei, Albelos, 29TNG3043, 13 m, Sobre tocón de Quercus robur, 26/12/2015, J. Valeiras \& O. Requejo, LOU-Fungi 20565.

Ecología y distribución: común sobre madera de Quercus robur.

Extendido por todo el mundo, especialmente observado en Europa (GBIF en línea, $\mathrm{n}^{\circ}$ 2519770). Amplia distribución, tanto en Galicia (Soliño et al. 2000) como en el resto de la Península Ibérica (Tellería, 1991).

Hypholoma elongatum (Pers.) Ricken, Die Blätterpilze: 250 (1915)

Material estudiado: Tui, Guillarei, barreiras de Albelos, 29TNG3028, $25 \mathrm{~m}$, entre Sphagnum sp, gramíneas y Erica ciliaris, 15/06/2012, O. Requejo, LOU-Fungi 19980.

Observaciones: taxón macroscópicamente semejante a Hypholoma ericaeoides P.D. Orton, con basidiosporas de tamaño similar; pero con el poro germinativo mayor y las láminas presentan tonos violáceos evidentes (Noordeloos, 2011).

Ecología y distribución: recolectado en su hábitat habitual (Noordeloos 2011), aunque en nuestro caso además con suelos arcillosos habitualmente anegados en este caso y poblados de Erica ciliaris, Drossera intermedia, gramíneas y Sphagnum sp.

Georreferenciada en Canadá, Inglaterra, Irlanda, Centro y Norte de Europa e Islas Falkland (GBIF en línea, no 2533491). Especie poco observada en 
la Península Ibérica (González et al. 1997), seguramente debido a la preferencia por ambientes higroturbosos. No conocemos menciones anteriores para Galicia.

Hypholoma ericaeoides P.D. Orton, Trans. Br. mycol. Soc. 43 (2): 273 (1960)

Material estudiado: Salceda de Caselas, desembocadura del río Becerreira, 29TNG3019, 20 m, sobre tronco con musgos, 26/09/2015, O. Requejo, LOU-Fungi 20281.Salceda de Caselas, Cerquido, Ponte Carneiro, 29TNG3164, 35 m, bajo Salix atrocinerea, 04/10/2015, O. Requejo, LOU-Fungi 20291. Tuy, Rebordanes, Ponte das Febres 29TNG2996, 21 m, bajo Salix atrocinerea entre turba, 02/10/2016, Marta Martínez, LOU-Fungi 20640.

Observaciones: en la colección LOU-Fungi 20281 se observaron algunas basidiosporas de pequeño tamaño $(7,5 \mu \mathrm{m})$, no obstante, la mayoría se sitúa entre los valores reseñados por Noordeloos (2011).

Ecología y distribución: Fructifica de forma muy abundante en el suelo turboso y desnudo de saucedas inundables, justo antes de anegarse, habitualmente con Hebeloma salicicola e Inocybe ochroalba.

Frecuente en Centro y Norte de Europa, incluida Islandia (GBIF en línea, $n^{\circ}$ 2533460). En la Península Ibérica aparece citada de norte a sur (RubioDomínguez et al. 2006, Picón 2005, Moreno-Arroyo 2004, Heykoop \& Moreno 2007). No mencionada anteriormente para Galicia.

Hypholoma ericaeum (Pers.) Kühner, Bull. trimest. Soc. mycol. Fr. 52: 23 (1936)

Material estudiado: O Porriño, Pontellas, barreras de Centeáns, 29TNG3007, 20 $\mathrm{m}$, en camino de tierra entre restos leñosos, 22/12/2014, O. Requejo, LOU-Fungi 19882.Salceda de Caselas, Cerquido, Ponte Carneiro, 29TNG3164, 35 m, entre restos orgánicos, 27/12/2015, O. Requejo, LOU-Fungi 20535.

Ecología y distribución: la colección LOU-Fungi 19882 fructificó en un camino de tierra, sobre acúmulo de restos leñosos de Pinus pinaster, procedentes de una tala. La otra exsiccata revisada, LOU-Fungi 20535, crecía también sobre restos leñosos, pero en un lugar más húmedo y sombrío con suelo turboso, bajo Salix atrocinerea, Alnus glutinosa y Quercus robur.

Taxón escasamente georreferenciado, pero existente en el Hemisferio Norte (Europa y América) y Australia (GBIF en línea, n 2533479). bien distribuido en la Península Ibérica (Aramendi \& Hidalgo 2012, RubioDomínguez 2005, Picón 2005, Moreno-Arroyo 2004, Heykoop \& Moreno 2007). En Galicia se ha mencionado de las provincias litorales (Losa España 1943, Marcote et al. 2011) 
Hypholoma fasciculare (Huds.) P. Kumm., Führ. Pilzk. (Zerbst): 72 (1871)

= Hypholoma fasciculare var. pusillum J.E. Lange, Dansk bot. Ark. 4(4): 4 (1923)

Material estudiado: Salceda de Caselas, Cerquido, Ponte Carneiro 29TNG3164, $35 \mathrm{~m}$, sobre madera en descomposición sin identificar, 02/10/2014, R. Requejo, LOUFungi 19853. O Porriño, Pontellas, barreras de Centeáns, 29TNG3007, 20 m, sobre tocón de Pinus pinaster en descomposición, 26/12/2014, O. Requejo, LOU-Fungi 19934.Tui, Guillarei, Albelos, 29TNG3043, 13 m, sobre tocón sin identificar, 09/11/2015, O. Requejo, LOU-Fungi 20504. O Porriño, Budiño, Orbenlle, observatorio ornitológico, 29TNG3061, $22 \mathrm{~m}$, sobre tronco sin identificar, 01/12/2015, O. Requejo, LOU-Fungi 20592.

Observaciones: la colección LOU-Fungi 20592 destaca por mostrar un solo ejemplar de pequeño tamaño, con tonalidades rojo-violáceas en el píleo, pero el sabor extremadamente amargo y los caracteres microscópicos coinciden con lo indicado para esta especie (Noordeloos 2011, Breitenbach \& Kränzlin 1995). Podría tratarse de H. fasciculare var. pusillum J.E. Lange (GBIF en línea, ${ }^{\circ}$ 3554284), ya que otra especie semejante con carpóforos pequeños, con tonalidades rojizas en el píleo es Bogbodia uda (Pers.) Redhead, pero presenta basidiosporas mucho mayores (Noordeloos 2011) que las de la colección estudiada.

Ecología y distribución: muy común en toda la ZEC, sobre restos leñosos u ocasionalmente sobre suelo turboso, durante todo el año en casi todos los ambientes de Las Gándaras.

No georreferenciado (GBIF en línea) debido a la existencia de diversos taxones infraespecíficos. El tipo es común en Europa, también en Galicia (Soliño et al. 1999). No conocemos la variedad citada de Galicia.

Hypholoma lateritium (Schaeff.) P. Kumm., Führ. Pilzk. (Zerbst): 72 (1871)

= Hypholoma sublateritium (Fr.) Quél., Mém. Soc. Émul. Montbéliard, Sér. 2 5: 113 (1872)

Material estudiado: O Porriño, Budiño, Orbenlle, Os Eidos, 29TNG3022, 30 m, en tocón de Quercus robur, 15/10/2016, Marta Martínez, LOU-Fungi 20647.

Ecología y distribución: recolectado sobre madera de Quercus robur en bosque mixto.

Citado del Hemisferio norte, con mayor concentración en los países escandinavos, también presente en Australia y Nueva Zelanda, para la Península se encuentran georreferenciadas reseñas en la mitad sur (GBIF en línea, $n^{\circ}$ 2533424), aunque parece ser más común en el norte, incluida Galicia (LagoÁlvarez 2008). 
Imleria badia (Fr.) Vizzini, Index Fungorum 147: 1 (2014)

三Xerocomus badius (Fr.) E.-J.Gilbert, Livres Mycologue: 3: Bolets: 92 (1931)

$\equiv$ Boletus badius (Fr.) Fr., Syst. mycol. (Lundae) 1: 515 (1821)

Material estudiado: Tui, Ribadelouro, Puente de la Madalena, 29TNG2992, 26 $\mathrm{m}$, bajo Pinus pinaster y Quercus robur, 09/08/2015, O. Requejo, LOU-Fungi 20242. Tui, Guillarei, aliseda de Albelos, 29TNG3019, 20 m, bajo Salix atrocinerea y Alnus glutinosa, 22/12/2015, O. Requejo, LOU-Fungi, 20556. Tuy, Rebordanes, Ponte das Febres 29TNG2996, 21 m, bajo Quercus robus y Pinus pinaster, 02/10/2016, Marta Martínez Lago, LOU-Fungi 20649.

Ecología y distribución: común en formaciones de Pinus pinaster de la zona de estudio.

Referenciado de Australia, muy común en el Hemisferio Norte, incluida la Península Ibéica (GBIF en línea, $n^{\circ}$ 7832732). En todo tipo de bosques, aunque en Galicia es uno de los boletales más frecuentes en pinares (Rodríguez-Vázquez \& Castro 2016).

Inocybe asterospora Quél., Bull. Soc. bot. Fr. 26: 50 (1880) [1879]

Material estudiado: O Porriño, Budiño, Orbenlle, observatorio ornitológico, 29TNG3061, 22 m, bajo Alnus glutinosa, 04/06/2014, O. Requejo, LOU-Fungi 19916.

Ecología y distribución: recolectado en bosque aluvial inundable bajo Alnus glutinosa, al pie de la laguna en zona muy sombría.

Común en Europa, también referenciado de la costa oriental norteamericana, Japón y Nueva Zelanda (GBIF en línea, nº 2527952). Común y bien distribuido en la Península Ibérica (Esteve Raventós \& Villareal 2003, Moreno-Arroyo 2004, Rubio-Domínguez et al. 2006, Picón 2004, García-Blanco 2012, García-Bona 2000). En Galicia ha sido mencionado de todas las provincias, menos Pontevedra (Rodríguez-Vázquez \& Castro 2016).

Inocybe calamistrata (Fr.) Gillet, Hyménomycètes (Alençon): 513 (1876) [1878]

Material estudiado: O Porriño, Pontellas, barreiras de Centeáns, 29TNG3007, 20 m, bajo Pinus pinaster, 22/12/2014, C. Ayres, LOU-Fungi 19881. O Porriño, Orbenlle, 29TNG3022, 20 m. , bajo Quercus robur, 7/12/2017, O. Requejo, LOU-Fungi 20673.

Observaciones: fácilmente identificable por el olor a sardina y la base del estipe verdosa.

Ecología y distribución: muy común en la zona en bosque mixtos de Pinus pinaster y Quercus robur, no observada en las zonas más húmedas.

Ampliamente georreferenciado en el Hemisferio Norte (GBIF en línea, no 2528141), incluida la Península Ibérica. Común en Galicia (Soliño et al. 1999). 
Inocybe lacera (Fr.) P.Kumm., Führ. Pilzk. (Zerbst): 79 (1871)

Material estudiado: Tui, Guillarei, barreras de Albelos, 29TNG3028, 25 m, entre briófitos, bajo Salix sp, 09/06/2014, O. Requejo, LOU-Fungi 19917.

Ecología y distribución: Fructifica de forma abundante en época seca, entre briófitos en suelo arcilloso con Salix atrocinerea.

Frecuente en el Hemisferio Norte, pero observado también en Nueva Zelanda (GBIF en línea, $n^{\circ}$ 3330718). En la Península Ibérica se encuentra de norte a sur (Moreno-Arroyo 2004, Rubio-Domínguez et al. 2006, Picón 2004, García-Blanco 2012, García-Bona 2000). Citado para Galicia de las cuatro provincias (Soliño et al. 2000).

Inocybe maculata Boud., Bull. Soc. bot. Fr. 32: 283 (1885)

Material estudiado: O Porriño, Budiño, 29TNG3061, $22 \mathrm{~m}$, bajo Betula pubescens y Salix atrocinerea, 22/10/2013, O. Requejo, LOU-Fungi 20007. Tuy, Rebordanes, Ponte das Febres 29TNG2996, 21 m, bajo Salix atrocinerea, 02/10/2016, Marta Martínez, LOU-Fungi 20661.

Observaciones: el tamaño esporal coincide con Kuyper (1986), pero es ligeramente más pequeño que el indicado por Heim (1931) y Stangl (1991); sin embargo, el resto de caracteres corresponden exactamente, incluido el color pardo de las láminas y la ausencia de tonalidades amarillas en el pie. Especies con basidiosporas de tamaño similar son I. cookei Bres. e I. chlorochroa Corriol \& Guinb.; pero ambas presentan marcado olor a miel. estudio.

Ecología y distribución: frecuente en diversos ambientes de la zona de

Es común en Europa, taambién se ha referenciado de Japón, Tailandia, Estados Unidos y Canadá (GBIF en línea, ${ }^{\circ}$ 2527903). En Galicia se conoce desde Losa España (1943) en las provincias de A Coruña y Pontevedra.

Inocybe napipes J.E. Lange, Dansk bot. Ark. 2 (7): 44 (1917)

Material estudiado: O Porriño, Pontellas, barreras de Centeáns, 29TNG3007, 20 m, bajo Pinus pinaster, 22/12/2014, O. Requejo, LOU-Fungi 19884.

Observaciones: macro y microscópicamente coincide con la descripción de Stangl (1991) y las basidiosporas de 7,5-10 x 5,5-7,5 $\mu \mathrm{m}$, con las descritas por Heim (1931) con 5 a 6 nódulos, aunque en la colección estudiada llegan a 8 , al igual que ocurre en la colección asturiana analizada por RubioDomínguez (en línea). 
Ecología y distribución: recolectada bajo Pinus pinaster con sotobosque herbáceo, en zona donde antiguamente se hallaban unas brañas, hoy en día desaparecidas por la intrusión de esta conífera.

No conocemos su distribución mundial, aunque ha sido referenciado en Bélgica, Alemania y Madeira, (GBIF en línea, $\mathrm{n}^{\mathrm{0}}$ en línea). En la Península Ibérica parece no ser un taxón muy extendido (Moreno-Arroyo 2004, RubioDomínguez et al. 2006, Picón 2004) y en Galicia sólo se conoce del Parque Natural de las Fragas do Eume, A Coruña (Bellón \& Castro 2008).

Inocybe ochroalba Bruyl., Bull. trimest. Soc. mycol. Fr. 85: 345 (1970) [1969]

Material estudiado: Tuy, Rebordanes, Ponte das Febres 29TNG2996, 21 m, bajo Salix atrocinerea, 15/10/2016, O. Requejo, LOU-Fungi 20662.

Observaciones: píleo cónico convexo, finalmente aplanado, que ronda los $20 \mathrm{~mm}$, de color ocre o pardo amarillento con fisuras radiales y restos de velo blanquecino. Láminas amarillas, ocres, más oscuras en la madurez con la arista más clara. Estipe cilíndrico, blanco amarillento, de $25 \times 4 \mathrm{~mm}$, con pruina en el ápice. Esporas de 7,5-9(9,5) x 4,5-5,2 $\mu \mathrm{m}$, elipsoidales o amigdalifomes, no ornamentadas. Cistidios claviformes o utriformes, el aspecto es corto ancho, hasta $60 \mu \mathrm{m}$ de largo con pared ancha de $2,5 \mu \mathrm{m}$, amarillos con hidróxido amónico $\left(\mathrm{NH}_{4} \mathrm{OH}\right)$ y coronados en el ápice con cristales, coincidentes con (Stangl 1991, Kuyper 1986 y Esteve Raventós \& Vila 1997).

Ecología y distribución: el material estudiado se recolectó en una sauceda inundable con suelo desnudo y turboso justo antes de anegarse, conviviendo con Hebeloma salicicola e Hypholoma ericaeoides.

Georreferenciado principalmente en Centroeuropa y países nórdicos. En América hay algunas menciones en el oeste y este de Estados Unidos (GBIF en línea, $\mathrm{n}^{\circ}$ en línea 2527986). Escasamente distribuido también en la Península Ibérica (Picón 2004, Esteve Raventós \& Vila 1997, Pancorbo \& Ribes 2011). Para Galicia ha sido citado recientemente en Pontevedra (De la Peña 2016).

Inocybe phaeodisca Kühner, Bull. Soc. nat. Oyonnax 9 Suppl., Mém. hors sér. 1: 5 (1955)

Material estudiado: O Porriño, Budiño, Orbenlle, observatorio ornitológico, 29TNG3061, 22 m, entre Polytrichum sp, bajo Osmunda regalis, 03/11/2013, O. Requejo, LOU-Fungi 20220.

Ecología y distribución: se recolectó al pie de Osmunda regalis entre Polytrichum sp., en bosque mixto de Quercus robur, Salix atrocinerea y Alnus glutinosa. 
Distribución preferentemente europea (GBIF en línea, n 2528088). Poco común en la Península Ibérica (Esteve Raventós \& Villareal 2003, MorenoArroyo 2004, Rubio-Domínguez et al. 2006, Picón 2004, Rubio \& Miranda 2008), al igual que en Galicia, aunque se conoce de las provincias de A Coruña, Lugo y Ourense (Rodríguez-Vázquez \& Castro 2016).

Inocybe praetervisa Quél., Fungi Tridentini 1 (3): 35 (1883)

Material estudiado: Tui, Guillarei, turbera de Albelos, 29TNG3036, $20 \mathrm{~m}$, en prado con Salix atrocinerea próximos, 03/07/2015, J. Valeiras, LOU-Fungi 20215.

Ecología y distribución: el material recolectado fructificaba en verano, sobre tierra turbosa entre hierbas, en un prado limítrofe con una sauceda inundable.

Observado en Estados Unidos, Canadá y Europa (GBIF en línea, $\mathrm{n}^{\circ}$ 2527971). En Galicia sólo se conoce de las provincias de A Coruña y Lugo (Castro 1985).

Inocybe salicis Kühner, Bull. trimest. Soc. mycol. Fr. 70 : 175 (1955) [1954]

Material estudiado: O Porriño, Budiño, Orbenlle, observatorio ornitológico, 29TNG3061, 22 m, bajo Salix atrocinerea y Alnus glutinosa, 18/02/2013, O. Requejo, LOU-Fungi 20221.

Observaciones: pequeño Inocybe con píleo de color pardo amarillento. Basidiosporas marcadamente nodulosas, casi angulosas, de 10-12 x 7,5-8,5 $\mu \mathrm{m}$, caulocistidios y queilocistidios similares, lageniformes metuloides, de 50-80 x 16-24 $\mu \mathrm{m}$. Revestimiento pileico formado por hifas de 7-11 $\mu \mathrm{m}$ de ancho fuertemente incrustadas.

Ecología y distribución: recolectada entre hojas de Salix atrocinerea, en sauceda inundable muy sombría.

Georreferenciada en Centroeuropa, Países Escandinavos, Islandia y Canadá (GBIF en línea, $n^{\circ}$ 2527909). No se encontraron citas para la Península Ibérica.

Inocybe splendens R. Heim, Encyclop. Mycol., 1. Le Genre Inocybe (Paris) 1: 328 (1932)

Material estudiado: Salceda de Caselas, Cerquido, Ponte Carneiro 29TNG3164, 35 m, bajo Quercus robur, 27/12/2014, O. Requejo, LOU-Fungi 20201.

Observaciones: parece tratarse de un taxón muy variable del que aparecen en la bibliografía descripciones con ligeras diferencias (Kuyper 1986, 
Stangl 1991 y Heim 1931). El material estudiado presenta basidiosporas de elípticas a subamigdaliformes, de 8-11 x 5-6 $\mu \mathrm{m}$, con depresión suprahilar pequeña. Queilocistidios lageniformes, ventrudos, mucronados, de hasta 75 x 12 $\mu \mathrm{m}$ con paredes anchas (hasta $2,5 \mu \mathrm{m}$ ).

Nuestra colección coincide con I. splendens var. splendens según Kuyper (1986), con basidiocarpos robustos y píleo de color pardo ocre, taxón bien caracterizado y bien diferenciado de I. splendens var. phaeoleuca (Kropp et al. 2010).

Ecología y distribución: el material estudiado ha sido recolectado bajo un pequeño rodal de Quercus robur, circunda un prado que en años muy lluviosos llega a inundarse.

No georreferenciado en GBIF (en línea), probablemente debido a la confusión entre ambas variedades hasta épocas recientes. Citado en la Península Ibérica (Esteve-Raventos, 1999), publicación en la que se incluye una reseña bibliográfica para Galicia, sin embargo, no conseguimos localizar dicha cita.

Laccaria amethystina Cooke, Grevillea 12 (63): 70 (1884)

Material estudiado: O Porriño, Budiño, Orbenlle, observatorio ornitológico, 29TNG3061, 22 m, bajo Quercus robur, 27/11/2013, O. Requejo, LOU-Fungi 19903. O Porriño, Pontellas, barreiras de Centeáns, 29TNG3007, $20 \mathrm{~m}$, bajo Quercus robur, 22/12/2014, O. Requejo, LOU-Fungi 19866.

Ecología y distribución: frecuente en otoño en los bosques mixtos de Quercus y Pinus pinaster de la zona de estudio, no así en las zonas húmedas.

Especie común en el Hemisferio Norte, incluida la Península Ibérica (GBIF en línea, $n^{\circ} 2530983$ ) y Galicia (Soliño et al. 1999).

Laccaria impolita Vellinga \& G.M. Muell., in Mueller \& Vellinga, Mycotaxon 37: 387 (1990)

Material estudiado: Salceda de Caselas, Cerquido, Ponte Carneiro 29TNG3164, 35 m, bajo Pinus pinaster y Quercus robur, 02/10/2014, R. Requejo, LOU-Fungi 19807.

Observaciones: el basidioma robusto y el píleo escamoso con ausencia de estrías la diferencia macroscópicamente de Laccaria fraterna (Sacc.) Pegler (Mueller, 1992), que también presenta basidios bispóricos. Presenta fíbulas en todas las estructuras, basidiosporas globosas, de 8-11,5 $\mu \mathrm{m}$ con espínulas hasta 1,5 $\mu \mathrm{m}$, buen carácter diagnóstico según Mueller (1992). La colección estudiada concuerda con esta descripción, no tanto con la de Vellinga (1995), que indica espínulas esporales menores.

Ecología y distribución: recolectada en otoño en bosque mixto de Pinus pinaster y Quercus robur, muy rara en la zona de estudio. Parece tratarse de una especie poco común. 
A nivel mundial sólo ha sido referenciada tres veces para Europa, dos en Alemania y una en Finlandia (GBIF en línea). No conocemos menciones en la Península Ibérica.

Laccaria laccata (Scop.) Cooke, Grevillea 12 (63): 70 (1884)

= Laccaria laccata var. pallidifolia (Peck) Peck, Bull. N.Y. St. Mus. 157: 92 (1912) [1911]

Material estudiado: O Porriño, Budiño, Orbenlle, observatorio ornitológico, 29TNG3061, 22 m, bajo Salix atrocinerea y Betula pubescens, 21/12/2013, O. Requejo, LOU-Fungi 19904.O Porriño, Budiño, Orbenlle, Os Eidos, 29TNG3022, 30 m, bajo Pinus pinaster y Salix atrocinerea, 29/11/2014, O. Requejo, LOU-Fungi 20254.

Observaciones: las colecciones revisadas se corresponden con $L$. laccata var. pallidifolia Peck., pero se incluyen en el tipo siguiendo el criterio de Index Fungorum (en línea).

Ecología y distribución: muy común y cosmopolita en las zonas más secas del área de estudio.

Se trata, probablemente, de la especie más referenciada del género en todo el mundo, aunque fácilmente confundible macroscópicamente con especies próximas (GBIF en línea, $n^{\circ} 2530926$ ). La variedad se menciona preferentemente del Hemisferio Norte (GBIF en línea, $n^{\circ}$ 2530932), incluida Galicia (RodríguezVázquez \& Castro 2016).

Laccaria proxima (Boud.) Pat., Hyménomyc. Eur. (Paris): 97 (1887)

Material estudiado: O Porriño, Pontellas, barreras de Centeáns, 29TNG3007, 20 m, bajo Pinus pinaster, 22/12/2014, O. Requejo, LOU-Fungi 19886.

Ecología y distribución: recolectado en una antigua braña, ahora inexistente por la intrusión de Pinus pinaster.

Muy frecuente en Europa, también referenciada del continente americano (norte y sur), de Australia y Nueva Zelanda (GBIF en línea, $\mathrm{n}^{\mathrm{o}}$ 2530966). Ampliamente extendida en Galicia (Soliño et al. 1999).

Laccaria pumila Fayod, Annals R. Accad. Agric. Torino 35: 91 (1893) [1892]

Material estudiado: O Porriño, Budiño, Orbenlle, observatorio ornitológico, 29TNG3061, 22 m, entre Sphagnum sp, 02/03/2013, O. Requejo, REQ-Fungi 348.

Observaciones: especie bispórica, semejante a L. fraterna (Sacc.) Pegler, pero con ejemplares de menor tamaño, píleo completamente translúcido y estriado, basidiosporas ligeramente ovoides y estipitipelis con hifas cilíndricas hasta $10 \mu \mathrm{m}$, lo que coincide con lo indicado por Bas et al. (1995). 
Ecología y distribución: el material estudiado ha sido recolectado en zona higroturbosa, anegada, al pie de la laguna, micorrizando con Sphagnum sp., fructificando incluso en el agua.

Especie conocida para Europa Central y Septentrional y, en menor medida, para Nueva Zelanda, Estados Unidos y Canadá (GBIF en línea, n ${ }^{\circ}$ 2530978). Está poco citada en la Península Ibérica, donde mayoría de las recolectas se centran en la mitad norte (Pérez de Gregorio \& Macau 2008), aunque también está citada en el sur (Ortega et al. 2004). En Galicia se conoce de las dos provincias litorales (Rodríguez-Vázquez \& Castro 2016).

Laccaria tortilis (Bolton) Cooke, Grevillea 12 (63): 70 (1884)

Material estudiado: O Porriño, Budiño, Orbenlle, observatorio ornitológico, 29TNG3061, 22 m, bajo Betula pubescens, 27/11/2013, O. Requejo, LOU-Fungi 19905. Salceda de Caselas, Cerquido, Ponte Carneiro 29TNG3164, 35 m, bajo Pinus pinaster y Quercus robur, 02/10/2014, O. Requejo, LOU-Fungi 19806.O Porriño, Pontellas, barreras de Centeáns, 29TNG3007, 20 m, bajo Salix atrocinerea, 15/06/2015, O. Requejo, LOUFungi 20207.Tui, Guillarei, Albelos, 29TNG3043, $13 \mathrm{~m}$, sobre tierra entre musgos, 10/11/215, O. Requejo, LOU-Fungi 20297.

Observaciones: El hábitat higrófilo y las basidiosporas esféricas con grandes espínulas permiten caracterizar fácilmente esta pequeña Laccaria (Bas et al. 1995).

Ecología y distribución: muy común todo el año en el suelo turboso de los bosques aluviales de la ZEC. En épocas estivales se le ha visto conviviendo con pequeños ejemplares de Clavulina coralloides.

A pesar de su tamaño está ampliamente georreferenciada en Europa (GBIF en línea, $n^{\circ} 2530991$ ), extendida por los suelos higroturbosos de Galicia, aunque no frecuente (Soliño et al. 1999).

Lacrymaria velutina (Pers.) Konrad \& Maubl., Rev. Hym. France: 90 (1925) =Lacrymaria lacrymabunda (Bull.) Pat., Hyménomyc. Eur. (Paris): 123 (1887)

Material estudiado: O Porriño, Budiño, Orbenlle, observatorio ornitológico, 29TNG3061, 22 m, bajo Salix atrocinerea y Alnus glutinosa, 20/07/2013, O. Requejo, LOU-Fungi 20588. Salceda de Caselas, desembocadura del río Becerreira, 29TNG3019, 20 m, bajo Quercus robur, 19/12/2015, O. Requejo, LOU-Fungi 20574.

Observaciones: el material revisado se corresponde con Lacrymaria velutina. Index Fungorum (en línea) considera sinónimos a $L$. velutina y $L$. lacrymabunda (Bull.) Pat., pero Han et al. (2010) demuestran mediante análisis molecular que son taxones diferentes, aunque próximos; además, se caracterizan 
microscópicamente porque $L$. velutina tiene basidiosporas de mayor tamaño. Nuestras colecciones parecen corresponder a este taxón, ya que las esporas miden de $12,5-11,5(13,7) \times 6,8-7,5 \mu \mathrm{m}$.

Ecología y distribución: parece mostrar preferencia por suelos arenosos en ambientes riparios.

Debido a la confusión entre los dos taxones, no se ha podido establecer con precisión su distribución a nivel mundial. En GBIF, a pesar de que también se consideran sinónimos, se puede encontrar georeferencias para $L$. velutina (GBIF en línea, $\mathrm{n}^{\circ}$ 5242805). Sería necesaria una revisión en herbarios para aclarar la distribución de esta especie.

Lactarius aspideus (Fr.) Fr., Epicr. syst. mycol. (Upsaliae): 336 (1838)

Material estudiado: O Porriño, Pontellas, barreras de Centeáns, 29TNG3007, 20 m, bajo Salix atrocinerea, 19/12/2015, O. Requejo, LOU-Fungi 20563.

Observaciones: sólo ha sido recolectado un ejemplar de pequeñas dimensiones, pero el color amarillento con tonalidades lilacinas en las zonas dañadas, el látex que vira a lila al secar, la asociación con Salix y las basidiosporas reticulado crestadas, de anchamente elipsoides a subglobosas, de $8,1-10 \times 6,8 \times 7,5 \mu \mathrm{m}$, caracterizan la especie y la diferencian de otros taxa próximos como $L$. salicis-reticulatae Kühner, asociado a Salix reticulata en ambientes alpinos, con basidiosporas mayores, de L. flavidus Boud., no asociado a Salix, con basidiomas más robustos, látex y carne que oxidan a lila con mayor intensidad y basidiosporas sin retículo completo (Basso 1999, Heilmann Clausen et al. 1998).

Ecología y distribución: el material estudiado se recolectó en una sauceda inundable con suelo turboso, limítrofe con la turbera en sentido estricto.

Se trata de un taxón preferentemente septentrional en el Hemisferio Norte (GBIF en línea, $\mathrm{n}^{\circ}$ 5248603). Se encontraron pocas referencias para la Península Ibérica, lo que indica que es una especie rara (García-Blanco \& Sánchez Rodríguez 2009). En Galicia también está escasamente citada (Marcote et al. 2011, Blanco-Dios, 2014).

Lactarius controversus Pers., Observ. mycol. (Lipsiae) 2: 39 (1800)

Material estudiado: O Porriño, Budiño, Orbenlle, observatorio ornitológico, 29TNG3061, 22 m, bajo Alnus glutinosa, 03/11/2013, O. Requejo, LOU-Fungi 19974. Salceda de Caselas, desembocadura del río Becerreira, 29TNG3019, 20 m, bajo Alnus glutinosa, 12/09/2015, O. Requejo, LOU-Fungi 20276. O Porriño, Budiño, Orbenlle, Barrera A Granxa Sur, 29TNG3153, bajo Salix atrocinerea y Pinus pinaster, 10/11/2015, O. Requejo, LOU-Fungi 20295. 
Ecología y distribución: muy común, creciendo en corros en zonas de alisos y sauces.

Especie común en el Hemisferio Norte, (GBIF en línea, $n^{\circ}$ 5248714), al igual que en Galicia (Rodríguez-Vázquez \& Castro 2016).

Lactarius cyathuliformis Bon, Doc. mycol. 8 (30-31): 69 (1978)

Material estudiado: O Porriño, Budiño, Orbenlle, observatorio ornitológico, 29TNG3061, 22 m, bajo Alnus glutinosa, 20/07/2013, O. Requejo, LOU-Fungi 19977. Tui, Guillarei, Albelos, 29TNG3043, 13 m, bajo Salix atrocinerea y Quercus robur, 26/12/2015, O. Requejo, LOU-Fungi 20568.

Observaciones: la colección LOU-Fungi 19977 guardaba similitud macroscópicamente a L. omphaliiformis Romag., tanto por el color anaranjado como por la ausencia de tonalidades oliváceas o isabelinas; pero presenta basidiosporas coincidentes con L. cyathuliformis (Basso 1999, Heilmann Clausen et al. 1998), de 8,5-11x 6-7,7 $\mu \mathrm{m}$. La otra colección responde macro y microscópicamente con este taxón.

Ecología y distribución: recolectado en época estival en bosque de ribera bajo Alnus glutinosa.

Georreferenciado en la mitad norte de Europa occidental (GBIF en línea, $n^{\circ}$ 5248757), también en la Península Ibérica (Ortega et al. 2004, RubioDomínguez et al. 2006, Picón 2004, Moreno-Arroyo 2004, Rubio \& Miranda 2008). En Galicia sólo se conoce de Lugo (Blanco-Dios 2014) y de Pontevedra (Requejo 2012).

Lactarius deliciosus (L.) Gray, Nat. Arr. Brit. Pl. (London) 1: 624 (1821)

Material estudiado: O Porriño, Pontellas, barreras de Centeáns, 29TNG3007, 20 m, bajo Pinus pinaster, 22/12/2014, C. Ayres, LOU-Fungi 19868. Salceda de Caselas, Cerquido, Ponte Carneiro, 29TNG3164, 35 m, bajo Pinus pinaster, 01/10/2015, O. Requejo, LOU-Fungi 20286.

Ecología y distribución: común bajo Pinus pinaster. La colección de Salceda de Caselas, LOU-Fungi 20286, crecía en una antigua braña, hoy colonizada por Pinus pinaster.

Taxón muy polimorfo, probablemente el más citado del género, tanto en Europa, como en América del Norte. También se ha mencionado para Japón, India, Australia, Brasil y Chile (GBIF en línea, no 5248629). Extremadamente común por todo el territorio gallego (Rodríguez-Vázquez \& Castro 2016). 
Lactarius lacunarum Romagn. ex Hora, Trans. Br. mycol. Soc. 43 (2): 444 (1960)

Material estudiado: O Porriño, Budiño, Orbenlle, observatorio ornitológico, 29TNG3061, 22 m, bajo Alnus glutinosa y Salix atrocinerea, 22/10/2013, O. Requejo, LOU-Fungi 19975.

Ecología y distribución: recolectado al pie de la laguna, en zona inundada durante las crecidas, fructificando casi sumergido bajo Alnus glutinosa y Salix atrocinerea con presencia de Sphagnum sp. Este hábitat húmedo y turboso parece característico según Idzerda \& Noordeloos (1997), sin embargo, Basso (1999) lo menciona como más común en la zona mediterránea relacionado con Quercus ilex o $Q$. suber.

Ha sido georreferenciado en el centro y Norte de Europa, lo que parece desmentir lo indicado por Basso (1999) sobre su hábitat, algo semejante a lo que ocurre en el norte ibérico. También se ha observado en Centroamérica (GBIF en línea, $n^{0}$ 5248592). En Galicia se ha recolectado en las dos provincias litorales (Bellón et al. 2004, Lorenzo \& Castro 2004).

Lactarius necator (Bull.) Pers., Observ. mycol. (Lipsiae) 1: 42 (1796)

Nombre mal aplicado: Lactarius turpis (Winm.) Fr. (Index Fungorum en línea).

Material estudiado: O Porriño, Budiño, Orbenlle, observatorio ornitológico, 29TNG3061, 22 m, bajo Betula pubescens, 22/10/2013, O. Requejo, LOU-Fungi 19976.

Ecología y distribución: el material estudiado se recolectó micorrizando con abedules, su género mutualista habitual (Heilmann-Clausen \& al. 1998, Basso 2000).

Referenciado preferentemente en el Hemisferio Norte, especialmente en los Países Escandinavos; también en Australia (GBIF en línea, $n^{\circ}$ 5248670). La confusión histórica entre Lactarius necator (Bull.) Pers., L. turpis (Winm.) Fr. y L. plumbeus (Bull.) Gray dificulta conocer con exactitud la distribución ibérica. Ampliamente extendido por Galicia (Soliño et al. 2000).

Lactarius quietus (Fr.) Fr., Epicr. syst. mycol. (Upsaliae): 343 (1838)

Material estudiado: O Porriño, Budiño, Orbenlle, observatorio ornitológico, 29TNG3061, 22 m, bajo Quercus robur, 07/10/2013, O. Requejo, LOU-Fungi 20586. Salceda de Caselas, desembocadura del río Becerreira, 29TNG3019, 20 m, bajo Quercus robur, 26/09/2015, O. Requejo, LOU-Fungi 20269.

Ecología y distribución: común en bosque mixto con presencia de Quercus robur y Pinus pinaster. 
Conocido preferentemente de Europa, también de Japón, costa oriental norteamericana y Nueva Zelanda (GBIF en línea, $\mathrm{n}^{\circ}$ 5248916). Frecuente en Galicia (Rodríguez-Vázquez \& Castro 2016).

Lactarius subumbonatus Lindgr., Bot. Notiser: 200 (1845)

Material estudiado: Tui, Guillarei, Albelos, 29TNG3043, 13 m, bajo Salix atrocinerea y Quercus robur, 26/12/2015, O. Requejo, LOU-Fungi 20569.

Observaciones: los ejemplares revisados presentaban píleo arrugado, de color pardo oscuro y, en ocasiones, una ligera papila central. Látex abundante y olor a chicoria. Estipe subcilíndrico, con ensanchamientos en la zona central. Esporas subglobosas de 6,5-8 x 6-7 $\mu \mathrm{m}$ con crestas que forman retículos parciales. Lo diferenciamos de L. atlanticus Bon y L. serifluus (DC.) Fr. por la coloración del píleo, más oscura en el material estudiado, y por el tamaño de los cistidios (Basso 1999, Heilmann Clausen et al. 1998).

Ecología y distribución: fructificaba bajo Quercus robur y Salix atrocinerea en una zona de prado higroturboso.

No se detalla su georreferenciación en GBIF (en línea). Para la Península Ibérica lo encontramos citado en Andalucía (Moreno-Arroyo 2004) y Cataluña (Tabarés \& Rocabruna 1991, Basso 1999), coincidiendo con la afirmación de Basso (1999) de que es una especie con preferencias climáticas mediterráneas. No conocemos citas en Galicia.

Laetiporus sulphureus (Bull.) Murrill, Annls mycol. 18 (1-3): 51 (1920)

Material estudiado: O Porriño, Budiño, Orbenlle, observatorio ornitológico, 29TNG3061, 22 m, sobre Quercus robur, 03/11/2013, O. Requejo, LOU-Fungi 20222.

Ecología y distribución: a pesar de ser una especie común y fácil de identificar no se realizaron más observaciones en la zona de estudio. La colección estudiada se recolectó sobre Alnus glutinosa.

Especie común y ampliamente observada en todo el mundo, a excepción del continente africano (GBIF en línea, $\mathrm{n}^{\circ}$ 2542178). Muy extendido en la Península Ibérica (Lago-Álvarez 2008) y en Galicia es un parásito frecuente de caducifolios y eucaliptos (Rodríguez-Vázquez \& Castro 2016).

Lanmaoa fragrans (Vittad.) Vizzini, Gelardi \& Simonini, Index Fungorum 235: 1 (2015)

= Boletus fragrans Vittad., Descr. fung. mang. Italia: 153 (1835)

Material estudiado: Tuy, Ribadelouro, 29TNG2992, 26 m, bajo Quercus robur y Castanea sativa, 02/10/2016, O. Requejo, LOU-Fungi 20630.

Ecología y distribución: recolectado en su hábitat más frecuente, bosquete de Quercus robur y Castanea sativa (Muñoz 2005). 
Escasamente georreferenciado en el mundo, con citas solo de Suecia, España, Dinamarca y Estados Unidos (GBIF en línea, no 5954912), ampliamente ditribuído en la Península Ibérica (Muñoz 2005, Moreno-Arroyo 2004), también en Galicia (Rodríguez-Vázquez \& Castro 2016).

Leccinum variicolor Watling, Notes R. bot. Gdn Edinb. 24: 268 (1969)

Material estudiado: O Porriño, Budiño, Orbenlle, observatorio ornitológico, 29TNG3061, 22 m, bajo Betula pubescens, 07/10/2013, G. Requejo, LOU-Fungi 20223.

Ecología y distribución: ha sido observado en zonas con Betula pubescens al borde de la laguna.

Georreferenciada únicamente de Europa y Japón (GBIF en línea, no 2524553). Extendido por toda Galicia bajo abedules (Rodríguez-Vázquez \& Castro 2016).

Lentinus tigrinus (Bull.) Fr., Syst. orb. veg. (Lundae) 1: 78 (1825)

Material estudiado: O Porriño, Budiño, Orbenlle, Os Eidos, 29TNG3022, 30 m, sobre tronco de Salix atrocinerea, 07/10/2013, O. Requejo, LOU-Fungi 20584. O Porriño, Budiño, Orbenlle, observatorio ornitológico, 29TNG3061, 22 m, sobre madera de Salix atrocinerea, 22/10/2013, O. Requejo, Lou-Fungi 20224. O Porriño, Pontellas, barreras de Centeáns, 29TNG3007, 20 m, sobre tocón de Salix atrocinerea, 15/06/2015, LOU-Fungi 20209.Tui, Guillarei, Albelos, 29TNG3040, 20 m, sobre Salix atrocinerea, 29/09/2015, Julio Valeiras \& O. Requejo, LOU-Fungi 20289.

Ecología y distribución: especie muy común todo el año en todo tipo de bosques, con preferencia en bosques aluviales y madera de Salix atrocinerea.

Observada en todo el mundo, excepto el continente africano (GBIF en línea, $n^{\circ} 2545431$ ). Se ha observado por toda Galicia (Soliño et al. 2000).

Lenzites betulina (L.) Fr., Epicr. syst. mycol. (Upsaliae): 405 (1838)

Material estudiado: O Porriño, Pontellas, barreras de Centeáns, 29TNG3007, 20 m, sobre tocón de Pinus pinaster, 26/12/2014, A. Justo y O. Requejo, LOU-Fungi 19894. Tui, Rebordanes, Ponte das Febres 29TNG2996, $21 \mathrm{~m}$, sobre rama de Quercus robur, 26/03/2015, O. Requejo, LOU-Fungi 20009.

Ecología y distribución: común sobre madera en todo tipo de bosques, sobre todo donde está presente Quercus robur. En la colección LOU-Fungi 20009 los basidiomas se recolectaron sobre una rama en el arbol vivo, posible parasitismo.

Frecuente tanto en el Hemisferio Norte como en el Sur, a excepción del continente africano (GBIF en línea, $n^{\circ} 5247313$ ). Muy común en todo el noroeste Ibérico (Rodríguez-Vázquez \& Castro 2016). 


\section{Lepiota cristata (Bolton) P.Kumm., Führ. Pilzk. (Zerbst): 137 (1871)}

Material estudiado: Salceda de Caselas, Cerquido, Ponte Carneiro, 29TNG3164, 35 m, entre restos orgánicos, 27/11/2015, O. Requejo, LOU-Fungi 20537.

Ecología y distribución: recolectado entre restos herbáceos.

Común en el Hemisferio Norte, también mencionado de Australia y Nueva Zelanda (GBIF en línea, $n^{\circ}$ 2535471). Extendida por toda Galicia (Soliño et al. 1999).

Lepiota echinella Quél. \& G.E. Bernard, Bull. Soc. mycol. Fr. 4: pl. 1, fig. 2 (1888)

Material estudiado: O Porriño, Budiño, Orbenlle, observatorio ornitológico, 29TNG3061, 22 m, entre hierbas y restos leñosos, 01/09/2014, O. Requejo, LOU-Fungi 19956.

Ecología y distribución: la exsiccata estudiada se recolectó entre acúmulos y restos leñosos, herbáceos y hojarasca, en borde de camino al lado de bosque mixto de Alnus glutinosa y Quercus robur.

Taxón no frecuente, pero ampliamente distribuido en Europa (GBIF en línea, $\left.n^{\circ} 3340356\right)$. En Galicia se conoce de Lugo (Peña \& Peña, 2014) y Ourense (Bellón et al. 2006).

Lepista nuda (Bull.) Cooke, Handb. Brit. Fungi 1: 192 (1871)

Material estudiado: O Porriño, Budiño, Orbenlle, observatorioornitológico, 29TNG3061, 22 m, bajo Alnus glutinosa, 21/12/2013, O. Requejo, LOU-Fungi 19906.

Ecología y distribución: muy común entre restos orgánicos y bordes de caminos en toda la zona de estudio.

Frecuente y abundante, tanto en el Hemisferio Norte como en el Sur (GBIF en línea, no 5242048) y común en Galicia (Soliño et al. 1999).

Leratiomyces ceres (Cooke \& Masee) Spooner \& Bridge, Mycotaxon 103: 116 (2008)

Nombre mal aplicado: Stropharia aurantiaca (Cooke) M. Imai (Index Fungorum, en línea).

Material estudiado: O Porriño, Budiño, Orbenlle, observatorio ornitológico, 29TNG3061, 22 m, entre restos herbáceos, 17/10/2013, O. Requejo, LOU-Fungi $19983 . O$ Porriño, Pontellas, barreras de Centeáns, 29TNG3007, 20 m, entre restos de Acacia melanoxylon, 23/04/2015, C. Ayres, LOU-Fungi 20202. Salceda de Caselas, 
desembocadura del río Becerreira, 29TNG3019, 20 m, entre hierbas y restos orgánicos, 10/11/2015, O. Requejo, LOU-Fungi 20293. Tui, Guillarei, Albelos, 29TNG3040, 20 m, entre hierbas, 10/11/2015, O. Requejo, LOU-Fungi 20294. Tui, Guillarei, aliseda de Albelos, 29TNG3019, 20 m, entre restos leñosos y herbáceos, 19/12/2015, O. Requejo, LOU-Fungi 20577.

Observaciones: el taxon es fácil de reconocer por su llamativo color rojo fuerte, tanto en el sombrero como en el pie, así como el anillo efímero que presenta. Sin embargo, nomenclaturalmente es confuso, ya que algunos investigadores (Fungipedia en línea) defienden que Leratiomyces ceres es una especie americana y Stropharia aurantiaca (Cooke) M. Imai su homónima europea; mientras que otros las consideran sinónimas de Stropharia aurantiaca sensu P.D.Orton, D.A. Reid, Pegler \& Legon (Noordeloos 2011). Se siguen las observaciones de este autor, corroboradas por Index Fungorum (en línea).

Ecología y distribución: Muy común durante todo el año entre restos orgánicos y bordes de caminos en toda la zona de estudio, especielmente en las más secas.

No se conoce su distribución mundial, en parte debido a las confusiones nomenclaturales y taxonómicas comentadas anteriormente. En Galicia es frecuente, ha sido ampliamente citada (Soliño et al. 1999) con el sub. Stropharia aurantiaca (Cooke) M. Imai.

Leucoagaricus leucothites (Vittad.) Wasser, Ukr. bot. Zh. 34 (3): 308 (1977)

Material estudiado: Salceda de Caselas, Cerquido, Ponte Carneiro 29TNG3164, 35 m, entre la hierba bajo Salix atrocinerea y Alnus glutinosa, 02/10/2014, O. Requejo, LOU-Fungi 20252.Tui, Guillarei, Albelos, 29TNG3043, 13 m, entre hierba, 09/11/2015, O. Requejo, LOU-Fungi 20517.

Ecología y distribución: muy común durante todo el año entre restos orgánicos, bordes de caminos y zonas herbosas en toda la zona de estudio sobre todo en las más secas.

Ampliamente distribuido por el mundo (GBIF en línea, n²535875), incluida la Península Ibérica (Breitenbach \& Kränzlin 1995, Vellinga 2001). También cuenta con una extensa distribución por Galicia (Rodríguez-Vázquez \& Castro 2016).

Leucoagaricus meleagris (Gray) Singer, Lilloa 22: 422 (1951) [1949]

Material estudiado: O Porriño, Budiño, Orbenlle, observatorio ornitológico, 29TNG3061, 22 m, entre la hierba, bajo Salix atrocinerea, 22/09/2014, O. Requejo, LOUFungi 19781. 
Observaciones: píleo hasta $60 \mathrm{~mm}$, ligeramente trapezoide, superficie granuloso escamosa, de color pardo grisáceo con reflejos rosados, sobre fondo blanco. Láminas de blancas a amarillentas. Estipe cilíndrico, con ensanchamiento en la mitad inferior, ornamentado con un anillo simple y frágil, blanco con el borde ligeramente parduzco. Todo el basidioma enrojece a la manipulación. Esporas subglobosas de 7,5-12 x 5,5-7,5 $\mu \mathrm{m}, \mathrm{Q}_{\mathrm{n}}=1,4(\mathrm{n}=35)$. Queilocistidios variables en forma y tamaño, mucronados con alguno claviforme. Epicutis formado por elementos de hasta $150 \mu \mathrm{m}$, muy variables en formas, fusiformes, claviformes, flexuosos pudiendo ser mucronados o no. Crecimiento cespitoso o gregario.

Ecología y distribución: el material recogido se disponía parcialmente cespitoso, aunque algunos ejemplares estaban solitarios, entre las hierbas y acúmulos de hojas de Salix atrocinerea al lado de la laguna, protegido por el observatorio ornitológico.

Especie extendida, pero no frecuente. Escasas referencias en Europa, América del Norte y del Sur y Australia (GBIF en línea, n 2535796), habitual en invernaderos (Vellinga 2001). También se encontró una cita para Gran Canaria (López Quintanilla et al. 2013). No se conoce para Galicia.

Leucoagaricus pilatianus (Demoulin) Bon \& Boiffard, Docum. mycol. 6 (24): 45 (1976)

Material estudiado: O Porriño, Budiño, Orbenlle, observatorio ornitológico, 29TNG3061, 22 m, entre hierba bajo Quercus robur, Salix atrocinerea y Alnus glutinosa, 07/10/2013, O. Requejo, LOU-Fungi 19957.

Observaciones: píleo hasta $50 \mathrm{~mm}$, con un leve umbón, blanco y finas escamas púrpura, casi negras en el centro. Láminas blancas, que enrojecen al rozarlas o cuando envejecen, verdes en contacto con amoníaco, finalmente oscurecen hasta rojo púrpura, casi negro. Estipe blanco amarillento en la mitad inferior, enrojece al roce, al igual que la trama y el anillo, situado en el tercio superior. Sabor no relevante y olor ligero a caucho. No se observaron fíbulas, ni pleurocistidios, pero si queilocistidios claviformes o anchamente fusiformes, hasta $45 \times 15 \mu \mathrm{m}$. Las basidiosporas son oblongas o anchamente elipsoides, de 6,6-8,5 x 4,0-5,4 $\mu \mathrm{m}, \mathrm{Q}_{\mathrm{n}}=1,6(\mathrm{n}=25)$.

Ecología y distribución: recolectado en bosque mixto de Quercus robur, Salix atrocinerea y Alnus glutinosa, entre musgos y acúmulos de hojas. 
Taxón confundido con otras especies (Candusso \& Lanzoni, 1990) como Leucocoprinus badhamii (Berk. \& Broome) Locq. y Leucoagaricus americanus (Peck) Vellinga, por ello su distribución mundial es mal conocida (GBIF en línea). Para la Península se encontraron varias citas que confirman su presencia en el norte y sur (Pérez-Butrón et al. 2011, Moreno-Arroyo 2004, Picón 2004, Rubio-Domínguez et al. 2006, García-Blanco 2012). En Galicia se conoce de la provincia de Pontevedra (Blanco-Dios 2014).

Leucocoprinus birnbaumii (Corda) Singer, Sydowia 15 (1-6): 67 (1962) [1961]

Material estudiado: O Porriño, Budiño, Orbenlle, observatorio ornitológico, 29TNG3061, 22 m, entre hierbas y Polytrichum sp, 07/10/2013, G. Requejo, LOU-Fungi 19958.

Ecología y distribución: fructifica al abrigo de Alnus glutinosa entre restos herbáceos al pie de la turbera.

Ampliamente distribuido por el mundo (GBIF en línea, n²535598). Para Galicia se ha observado en A Coruña, Lugo y Pontevedra (Rodríguez-Vázquez \& Castro 2016).

Leucocoprinus jubilaei (Joss.) Wasser, Nov. Sist. vjssh. niz. Rast., 1975 12: 191 (1976) [1975-1976]

Material estudiado: Salceda de Caselas, desembocadura del río Becerreira, 29TNG3019, 20 m, bajo Alnus glutinosa y Quercus robur, 12/09/2015, O. Requejo, LOUFungi 20622.

Observaciones: Se caracteriza porque al manipular el carpóforo blanco amarillea intensamente. Presenta basidiosporas de elípticas a ovales, de 6-7,5 x 3,7-5 $\mu \mathrm{m}$, queilocistidios claviformes o cortamente fusiformes, con el ápice redondeado, sin apéndices y elementos de la pelis cilíndricos, hasta $180 \times 17,5 \mu \mathrm{m}$, con ápices redondeados.

Ecología y distribución: el material estudiado fructificaba a principios de otoño en bosque de ribera bajo Alnus glutinosa y Quercus robur.

Parece tratarse de una especie muy rara, georreferenciada sólo en Centroeuropa (GBIF en línea, $n^{\circ}$ 3332103). En la Península Ibérica tampoco se encuentra extendido (Rubio-Domínguez et al. 2006, Picón 2004). Para Galicia solo se conoce de Pontevedra (De la Peña 2016). 
Loweomyces fractipes (Berk. \& M.A. Curtis) Jülich, Persoonia 11 (4): 424 (1982)

$\equiv$ Abortiporus fractipes (Berk. \& M.A. Curtis) Bondartsev, in Komarova, Notul.syst. Sect. cryptog. Inst. bot. Acad. Sci. U.S.S.R. 12: 251 (1959)

$\equiv$ Spongipellis fractipes (Berk. \& M.A. Curtis) Komarova, Opredelitel' trutovykh gribov Belorussii: 20 (1964)

Material estudiado: Salceda de Caselas, desembocadura del río Becerreira, 29TNG3019, 20 m, sobre madera sin precisar en bosque de Alnus glutinosa y Quercus robur, 12/09/2015, O. Requejo, LOU-Fungi 20263.

Observaciones: basidiomas estipitados, de color blanco cremoso en la totalidad del carpóforo, aunque puede adquirir tonalidades ocres, en la madurez oxidadas en zonas dañadas y pequeños puntos en la superficie. Píleo flaveliforme e himenio decurrente por casi todo el estipe, con largos poros laberínticos, que pueden parecer irpicoides. Basidiosporas de 5-7,5 x 3-4 $\mu \mathrm{m}$, con una gran gútula oleosa central. Cistidiolos claviformes de 15-22 x 4-5 $\mu \mathrm{m}$. Los caracteres corresponden con la descripción de Jülich (1989), excepto que en el material revisado se observaron medidas esporales ligeramente mayores 5-7,5 x 3-4 $\mu \mathrm{m}$.

Ecología y distribución: fructificaba en camino arenoso que bordea bosque de ribera sobre madera enterrada procedente de este.

Se trata de una especie poco frecuente de la que no se conoce con seguridad su distribución a nivel mundial, aunque aparece referenciada para Austria, Eslovenia, Alemania, Eslovaquia, Bielorrusia, Georgia, Irán, EEUU y Brasil (GBIF en línea 2544383). Para la Península Ibérica la encontramos citada para el País Vasco (Picón 2004) y Cataluña (Rocabruna \& Tabarés 2003). Novedad para el catálogo gallego.

\section{Lycoperdon perlatum Pers., Observ. mycol. (Lipsiae) 1: 4 (1796)}

Material estudiado: Salceda de Caselas, Cerquido, Ponte Carneiro 29TNG3164, 35 m, bajo Quercus robur entre Rubus sp., 02/10/2014, R. Requejo, LOU-Fungi 19797.

Ecología y distribución: común en los bosques mixtos no inundables de la zona de estudio.

Ampliamente georreferenciada, en todo el mundo, excepto en el continente africano (GBIF en línea, $n^{\circ}$ 45243258). En Galicia probablemente se trate de la especie más común del género (Rodríguez-Vázquez \& Castro 2016). 
Lycoperdon pratense Pers., Neues Mag. Bot. 1: 87 (1794)

Material estudiado: Salceda de Caselas, Cerquido, Ponte Carneiro 29TNG3164, 35 m, en camino herbáceo, 27/09/2014, O. Requejo, LOU-Fungi 20624.

Ecología y distribución: común en zonas herbosas y bordes de caminos no inundables.

Georreferenciado en todos los continentes excepto el africano, muy común en el norte de Europa, Reino Unido y Península Ibérica (GBIF en línea, ${ }^{\circ}$ 5243244). Ampliamente citado en Galicia (Rodríguez-Vázquez \& Castro 2016).

Lycoperdon umbrinum Pers., Tent. meth. Fungorum: 53 (1797)

Material estudiado: O Porriño, Budiño, Orbenlle, observatorio ornitológico, 29TNG3061, 22 m, en camino de tierra bajo Quercus robur, 03/11/2013, O. Requejo, LOUFungi 19959.

Ecología y distribución: la especie menos observada del género, ha sido recolectada en bosquete de Quercus robur con sotobosque de matorral, entre hojas y Rubus sp.

Común en el Hemisferio Norte (GBIF en línea, $n^{\circ}$ 5243243). También frecuente en Galicia (Rodríguez-Vázquez \& Castro 2016).

Macrocystidia cucumis (Pers.) Joss., Bull. trimest. Soc. mycol. Fr. 49 (3-4): 373 (1934) [1933]

Material estudiado: O Porriño, Budiño, Orbenlle, Os Eidos, 29TNG3022, 30 m, entre restos herbáceos y Rubus sp., 29/11/2015, O. Requejo, LOU-Fungi 20248.

Ecología y distribución: recolectada entre detritus vegetales en el borde de un camino herbáceo que acompaña a un bosque ripario.

Muy común en toda Europa, también mencionada de Estados Unidos, Canadá, Japón, Tasmania y Nueva Zelanda (GBIF en línea, $n^{\circ}$ 2537939). En Galicia sólo se conoce de A Coruña y Pontevedra (Marcote et al. 2003, Blanco-Dios, 2005).

Marasmiellus candidus (Fr.) Singer, Pap. Mich. Acad. Sci. 32: 129 (1948) [1946]

Material estudiado: O Porriño, Budiño, Orbenlle, Os Eidos, 29TNG3022, $30 \mathrm{~m}$, sobre Rubus sp., 07/10/2013, O. Requejo, LOU-Fungi 19962.Tui, Guillarei, Albelos, 29TNG3043, 13 m, sobre pequeñas ramas de Rubus sp., 09/11/2015, LOU-Fungi 20516. 
Ecología y distribución: muy común a principios de otoño, sobre todo tipo de pequeñas ramas, incluso en bosque higrófilos.

Referenciada en todo el mundo de forma dispersa, a excepción de Sudamérica (GIBF en línea n 2537876). Especie común en Galicia (RodríguezVázquez \& Castro 2016).

Marasmiellus tricolor (Alb. \& Schwein.) Singer, Pap. Mich. Acad. Sci. 32 (32): 128 (1948) [1946]

Material estudiado: Tui, Guillarei, barreras de Albelos, 29TNG3028, $25 \mathrm{~m}$, sobre raíz de gramíneas, 09/06/2014, O. Requejo, LOU-Fungi 20585.

Ecología y distribución: observada en zona turbosa, arcillosa, sin árboles, donde apenas había vegetación herbácea, sobre raíces de gramíneas.

Debido a la existencia de varios taxones supeditados a este nombre no se conoce su distribución con precisión (GBIF en línea). En la Península Ibérica se encontraron pocas citas (Picón 2004, Rocabruna \& Tabarés 2009). Para Galicia únicamente ha sido citado de Pontevedra (Requejo, 2014).

Marasmiellus vaillantii (Pers.) Singer, Beihefte zur Nova Hedwigia 44: 313 (1973)

Material estudiado: O Porriño, Budiño, Orbenlle, Observatorio ornitológico, 29TNG3061, 22 m, sobre restos herbáceos, 13/08/2014, O. Requejo, LOU-Fungi 19960.

Ecología y distribución: común en todo tipo de bosques, en los aluviales, es habitual encontrarlo en zonas donde el agua acumula las pequeñas ramas caídas.

No se conoce su distribución mundial, aunque si ha sido mencionada de Norte y Centroeuropa: Suecia, Noruega, Dinamarca, Alemania, Austria y República Checa (GBIF en línea, no 2537834). Para la Península Ibérica no se encontraron demasiadas citas y todas ellas en el norte (Alonso et al. 2012, RubioDomínguez et al. 2006, Picón 2004, Pérez-Butrón et al. 2011, Duñabeitia et al. 2004), pero seguro que está más extendido. En Galicia sólo se conoce de la provincia de Pontevedra (Blanco-Dios 2008, Requejo 2012, De la Peña 2016). 
Marasmius epodius Bres., Fung. trident. 1(1): 88 (1881)

=Marasmius anomalus Lasch, Herb.vivum mycol.1806: t. 17: 97 (1854)

Material estudiado: O Porriño, Budiño, Orbenlle, Os Eidos, 29TNG3022, 30 m, sobre restos herbáceos, 07/10/2013, O. Requejo, LOU-Fungi 19847.

Observaciones: esta colección tiene basidiosporas de (14)17-20 x 4,5$5 \mu \mathrm{m}$ (Noordeloos 1995) y se observó una reacción fuertemente dextrinoide en las hifas de todo el basidioma, no sólo en las del estipe.

Ecología y distribución: el material estudiado se recolectó sobre restos secos de hierbas, posiblemente Avena.

Georreferenciada únicamente de Centroeuropa y región mediterránea ibérica (GBIF en línea, $n^{\circ}$ 2537258). En Galicia solo fue citado de A Coruña (Blanco-Dios 2014) y Lugo (Comesaña \& Castro 1999).

Marasmius bulliardii Quél., Bull. Soc. Bot. France 24: 323, XXXI (1878)

Material estudiado: Salceda de Caselas, Cerquido, Ponte Carneiro, 29TNG3164, $35 \mathrm{~m}$, sobre pequeñas ramas sin identificar, 27/09/2014, O. Requejo, LOU-Fungi 20229. Salceda de Caselas, desembocadura del río Becerreira, 29TNG3019, $20 \mathrm{~m}$, sobre pequeñas ramas, 26/09/2015, O. Requejo, LOU-Fungi 20283.

Ecología y distribución: común sobre pequeñas ramas, en la zona de estudio, parece mostrar preferencia por ambientes húmedos.

Observado en toda Europa, incluida la Península Ibérica, también, aunque parece más escaso, en Estados Unidos (GBIF en línea, $n^{\circ}$ 2537315). En Galicia sólo se conoce de Lugo (Comesaña \& Castro 1999).

Marasmius epiphylloides (Rea) Sacc. \& Trotter, Syll. fung. (Abellini) 23: 145 (1925)

Material estudiado: Tui, Guillarei, Albelos, 29TNG3043, 13 m, sobre hojas de Hedera elix, 09/11/2015, O. Requejo, LOU-Fungi 20509.

Ecología y distribución: común en todos los bosques donde crecen hiedras (Hedera hibernica), crece sobre sus hojas secas.

Especie extendida por toda Europa (GBIF en línea, $n^{\circ}$ 2537151). Se ha citado para Galicia de A Coruña, Lugo y Pontevedra (Rodríguez-Vázquez \& Castro 2016). 
Marasmius graminum (Lib.) Berk., Outl. Brit. Fung. (London): 222 (1860)

Material estudiado: O Porriño, Budiño, Orbenlle, Observatorio ornitológico, 29TNG3061, 22 m, sobre restos herbáceos, 07/09/2013, O. Requejo, LOU-Fungi 19846. laguna.

Ecología y distribución: se recolectó sobre restos herbáceos al pie de la

Frecuente en el Hemisferio Norte (GBIF en línea, $n^{\circ}$ 2537202), muy común en la Península Ibérica, aunque poco citado por su pequeño tamaño (Moreno \& Manjón 2010). No se conocen referencias para Galicia.

Marasmius rotula (Scop.) Fr., Epicr. syst. mycol.: 385 (1838)

Material estudiado: Salceda de Caselas, desembocadura del río Becerreira, 29TNG3019, 20 m, sobre pequeñas ramas de Alnus glutinosa, 31/07/2015, J. Valeiras y O. Requejo, LOU-Fungi 20233.

Ecología y distribución: Muy frecuente, sobre todo en bosque ripario.

Extremadamente común en el Hemisferio Norte, también se extiende por el Hemisferio Sur, aunque parece menos frecuente (GBIF en línea, ${ }^{\circ}$ 2537293). Especie muy frecuente por toda Galicia (Rodríguez-Vázquez \& Castro 2016).

Mucronella calva (Alb. \& Schwein.) Fr., Hymenomyc. Eur. (Upsaliae): 629 (1874)

Material estudiado: O Porriño, Budiño, Orbenlle, observatorio ornitológico, 29TNG3061, $22 \mathrm{~m}$, sobre madera sin identificar con aphylloforal sin identificar, 17/03/2012, N.F. Andrés Rodríguez, REQ-Fungi 367.

Ecología y distribución: crecimiento geotrópico. Especie frecuente en ramas tumbadas o restos leñosos sobre suelos húmedos, en el caso del material recolectado también fructificaba sobre un hongo poroide resupinado no identificado, aunque no parecía demostrar parasitismo.

Común en el Hemisferio Norte, también en la Península Ibérica. Escasas referencias para Sudamérica y Australia (GBIF en línea, $n^{\circ}$ 3292343). No conocemos menciones para Galicia.

Muscinupta laevis (Fr.) Redhead, Lücking \& Lawrey, Mycol. Res. 113 (10): 1167 (2009)

= Arrhenia muscigena (Pers.) Quél., Fl. mycol. France (Paris): 33 (1888)

= Cyphellosterum laeve (Fr.) D.A. Reid, Beih. Nova Hedwigia 18: 337 (1965) 
Material estudiado: O Porriño, Budiño, Orbenlle, observatorio ornitológico, 29TNG3061, $22 \mathrm{~m}$, sobre musgos en talud de tierra, 01/12/2015, O. Requejo, LOU-Fungi 20544.

Ecología y distribución: normalmente sobre musgos en taludes de tierra en todas las zonas de muestreo.

Común en Centroeuropa, Noruega y Suecia, también referenciada para Península Ibérica, Canadá, Malasia y Nueva Zelanda (GBIF en línea, $\mathrm{n}^{\circ}$ 5955029). En Galicia se ha mencionado de A Coruña, Lugo y Pontevedra (Rodríguez-Vázquez \& Castro 2016).

Mutinus elegans (Mont.) E. Fisch., Syll. fung. (Abellini) 7: 13 (1888)

Material estudiado: Tui, Guillarei, Albelos, 29TNG3040, 20 m, entre bambú, 09/11/2015, O. Requejo, LOU-Fungi 20292.

Ecología y distribución: poco común en la zona de estudio. Ha sido recolectado en un bosque de Quercus robur y Alnus glutinosa entre bambú, al pie de una pradera higroturbosa.

Georreferenciada de Centroeuropa, Norte y Centroamérica y Brasil (GBIF en línea, ${ }^{\circ}$ 5239471). Poco frecuente en la Península Ibérica, común en Galicia, especialmente en la zona litoral (Rodríguez-Vázquez \& Castro 2016).

Mycena acicula (Schaeff.) P. Kumm., Führ. Pilzk. (Zerbst): 109 (1871)

Material estudiado: Salceda de Caselas, Cerquido, Ponte Carneiro 29TNG3164, $35 \mathrm{~m}$, sobre tronco caído de Salix atrocinerea, 02/10/2014, O. Requejo, LOU-Fungi 19791.

Ecología y distribución: frecuente sobre pequeñas ramas, cortezas o restos leñosos caídos, en todo tipo de bosques.

Común en el Hemisferio Norte, también observada en Australia y Nueva Zelanda (GBIF en línea, no 2526861). Frecuente en el NO Ibérico (RodríguezVázquez \& Castro 2016).

Mycena algeriensis Maire, Encyclop. Mycol. 10: 490 (1938)

Material estudiado: Salceda de Caselas, Cerquido, Ponte Carneiro 29TNG3164, $35 \mathrm{~m}$, sobre tronco caído de Alnus glutinosa, 02/10/2014, R. Requejo \& O. Requejo, LOUFungi 19844.

Ecología y distribución: fructificaba sobre tronco de Alnus glutinosa tumbado en barrizal, conviviendo con Gymnopus foetidus y Xanthoporia radiata. 
Georreferenciada para Europa, incluida Península Ibérica, Norte y Sudamérica y Australia (GBIF en línea, $n^{\circ}$ 7243548). No citada para Galicia.

Mycena amicta (Fr.) Quél., Mém. Soc. Émul. Montbéliard, Sér. 2 5: 243 (1872)

Material estudiado: O Porriño, Budiño, Orbenlle, Os Eidos, 29TNG3022, 30 m, sobre estróbilo de Pinus pinaster, 30/11/20114, O. Requejo, LOU-Fungi 19848.

Ecología y distribución: recolectada sobre piñas de Pinus pinaster su sustrato habitual (Robich 2003).

Común en el Hemisferio Norte, también referenciada de Nueva Zelanda (GBIF en línea, $\mathrm{n}^{\circ}$ 2527081). En Galicia se ha mencionado para A Coruña (Castro 1985) y Pontevedra (Lorenzo \& Castro 2011, De la Peña 2016).

Mycena atrovinosa Robich, Mycena d'Europa (Trento): 241 (2003)

Material estudiado: O Porriño, Budiño, Orbenlle, observatorio ornitológico, 29TNG3061, 22 m, bajo Quercus robur y Salix atrocinerea, 29/11/2014, O. Requejo, LOU-Fungi 20587.

Observaciones: se diferencia macroscópicamente de otras especies de la sección Fragilipedes por las fuertes tonalidades vinosas del carpóforo, más oscuras en el sombrero, contrastando con las láminas grises. Y, microscópicamente, por las basidiosporas que no sobrepasan las $6 \mathrm{~mm}$ de ancho, por los queilocistidios fusiformes, mazudos y lisos y las hifas del epicutis gruesas, hasta $6 \mathrm{~mm}$ de ancho, con escreciencias largas, hasta $22 \mathrm{~mm}$.

Ecología y distribución: recolectado en bosque mixto de Quercus robur y Salix atrocinerea, inundable en años muy lluviosos.

Taxón reciente (Robich 2013), del que no se conoce de forma precisa su distribución (GBIF en línea, 372962). No lo conocemos citado para la Península Ibérica.

Mycena capillaripes Peck, Rep. (Annual) Trustees State Mus. Nat. Hist., New York 41: 63 (1888)

Material estudiado: O Porriño, Budiño, Orbenlle, observatorio ornitológico, 29TNG3061, 22 m, bajo Quercus robur, 22/10/2013, O. Requejo, LOU-Fungi 19910.

Ecología y distribución: el material estudiado fructificaba bajo Quercus robur, entre musgos y restos de hojas, al borde de la laguna.

No se conoce su distribución mundial con precisión (GBIF en línea, $\mathrm{n}^{\circ}$ 38864), aunque en Italia es frecuente (Robich, 2013), al igual que ocurre en 
Galicia (Soliño et al. 1999). En la Península Ibérica también parece estar ampliamente distribuida (Rubio-Domínguez et al. 2006, Picón 2004, GarcíaBlanco 2012, Moreno-Arroyo 2004, Carbó 2001)

Mycena corynephora Maas Geest., Proc. K. Ned. Akad. Wet., Ser. C, Biol. Med. Sci. 86 (3): 407 (1983)

Material estudiado: O Porriño, Budiño, Orbenlle, observatorio ornitológico, 29TNG3061, 22 m, sobre rama de Salix atrocinerea, 26/06/2014, O. Requejo, LOU-Fungi 19918.

Ecología y distribución: fructifica en troncos de frondosas, donde convive con M. pseudocorticola y M. meliigena, sobre todo en bosque de ribera y aluviales.

Georreferenciada en Centroeuropa, Países Escandinavos, Inglaterra y Península Ibérica (GIBF, en línea $\mathrm{n}^{\circ}$ 2526960). En Galicia solo ha sido mencionada para Pontevedra en repetidas ocasiones (Rodríguez-Vázquez \& Castro 2016, De la Peña 2016).

Mycena epipterygia (Scop.) Gray, Nat. Arr. Brit. Pl. (London) 1: 619 (1821)

Material estudiado: Tui, Guillarei, Albelos, 29TNG3043, 13 m, en bosque de Pinus pinaster, 09/11/2015, O. Requejo, LOU-Fungi 20514.

Ecología y distribución: común en bosques mixtos, entre restos de los árboles presentes, no observada en bosques húmedos.

Común en el Hemisferio Norte, también referenciado en Australia y Nueva Zelanda (GIBF en línea $n^{\circ}$ 2527146). También es frecuente en Galicia (Soliño et al. 1999).

Mycena galericulata (Scop.) Gray, Nat. Arr. Brit. Pl. (London) 1: 619 (1821)

Material estudiado: O Porriño, Budiño, Orbenlle, observatorio ornitológico, 29TNG3061, 22 m, sobre Salix atrocinerea, 03/11/2013, LOU-Fungi 20000.

Ecología y distribución: fructificaba sobre Salix atrocinerea seco, que aún se mantenía en pie.

Referenciada en todo el mundo, excepto el continente africano (GBIF en línea, $n^{\circ}$ 2526880), común en Galicia (Soliño et al. 1999). 


\section{Mycena galopus (Pers.) P. Kumm., Führ. Pilzk. (Zerbst): 108 (1871)}

Material estudiado: O Porriño, Budiño, Orbenlle, Os Eidos, 29TNG3022, $30 \mathrm{~m}$, entre hojas de Quercus robur, 15/10/2016, M. Martínez, LOU-Fungi 20643; ibídem, bajo Salix atrocinerea, 07/12/2016, O. Requejo, LOU-Fungi 20669.

Observaciones: la colección LOU-Fungi 20669, se corresponde con Mycena leucogala (Cooke) Sacc., sinónimos según el Index Fungorum (en línea).

Ecología y distribución: común en bosque mixtos de caducifolios, entre hojarrasca, no observada en bosques inundables.

Amplia distribución en el Norte de Europa sobre todo en los países escandinavos, algo más dispersa en el sur del continente (GBIF en línea, $\mathrm{n}^{\circ}$ 3318620). En Galicia se conoce en las cuatro provincias con una vasta representación (Rodríguez-Vázquez \& Castro 2016).

Mycena leptocephala (Pers.) Gillet, Hyménomycètes (Alençon): 267 (1876) [1878]

Material estudiado: O Porriño, Budiño, Orbenlle, observatorio ornitológico, 29TNG3061, 22 m, sobre rama de Alnus glutinosa, 01/12/2015, O. Requejo, LOU-Fungi 20603.

Ecología y distribución: fructificaba en rama caída de Alnus glutinosa sobre suelo turboso en bosque inundable.

Se trata de una especie con estatus mal definido, por lo que no se conoce su distribución mundial, aunque ha sido observada con frecuencia en Centroeuropa, Noruega y Suecia (GBIF en línea, $n^{\circ} 179400$ ). Ampliamente citada en la Península Ibérica, se observa preferencia por las zonas mediterráneas (Rubio-Domínguez et al. 2006, Picón 2004, García-Blanco 2012, MorenoArroyo 2004, Pérez de Gregorio 2005), también se conoce en las Islas Canarias (Fernández-Vicente et al. 2012). Para Galicia se encuentra citada en A Coruña, Lugo y Pontevedra (Rodríguez-Vázquez \& Castro 2016)

Mycena meliigena (Berk. \& Cooke) Sacc., Syll. fung. (Abellini) 5: 302 (1887)

Material estudiado: O Porriño, Budiño, Orbenlle, observatorio ornitológico, 29TNG3061, 22 m, sobre Salix atrocinerea, 01/10/2013, O- Requejo, LOU-Fungi 20001. Tuy, Rebordanes, Ponte das Febres 29TNG2996, 21 m, sobre tronco de Alnus glutinosa, 22/10/2016, O. Requejo, LOU-Fungi 20655.

Ecología y distribución: fructifica en troncos de caducifolios donde convive con $M$. pseudocorticola y M. corynephora, sobre todo en bosque de ribera y aluviales. 
Georreferenciada de forma dispersa por Europa, incluida Península Ibérica, y Canadá (GBIF en línea, ${ }^{\circ}$ 2527253). En el territorio gallego se ha observado en A Coruña, Lugo y Pontevedra (Rodríguez-Vázquez \& Castro 2016).

Mycena metata (Secr. ex Fr.) P. Kumm., Führ. Pilzk. (Zerbst): 109 (1871)

Material estudiado: Tui, Guillarei, aliseda de Albelos, 29TNG3019, $20 \mathrm{~m}$, bajo Salix atrocinerea y Alnus glutinosa, 22/12/2015, O. Requejo, LOU-Fungi 20601.

Ecología y distribución: muy común en los suelos desnudos de saucedas y alisedas, donde fructifican con abundancia y donde también es común ver ejemplares atacados por Spinellus fusiger (Link) Tiegh (Zygomycota).

Es una especie frecuente en Europa, incluida Península Ibérica, pero también se ha observado en Estados Unidos, Canadá y Nueva Zelanda (GIBF en línea $\mathrm{n}^{\circ}$ 2527099). En Galicia se ha observado en las provincias litorales (Rodríguez-Vázquez \& Castro 2016).

Mycena mirata (Peck) Sacc., Syll. fung. (Abellini) 5: 290 (1887)

Material estudiado: O Porriño, Budiño, Orbenlle, observatorio ornitológico, 29TNG3061, $22 \mathrm{~m}$, entre Polytrichum, bajo Betula pubescens y Salix atrocinerea, 21/12/2013, O. Requejo, LOU-Fungi 19911.

Ecología y distribución: recolectada entre Polytrichum, bajo Betula pubescens y Salix atrocinerea a orillas de la laguna.

Observada en Centro y Norte de Europa, costa mediterránea ibérica, Canarias y Canadá. En Galicia únicamente se conoce de Pontevedra (Lorenzo \& Castro 2011).

Mycena mucor (Batsch) Quél., Mém. Soc. Émul. Montbéliard, Sér. 2 5: 436 (1875)

Material estudiado: O Porriño, Budiño, Orbenlle, observatorio ornitológico, 29TNG3061, 22 m, sobre hojas de Salix atrocinerea caídas, 20/07/2013, O. Requejo, LOU-Fungi 20002.

Observaciones: las basidiosporas en el material estudiado oscilan entre (7)7,8-10,9 x 4-5,5 $\mu \mathrm{m}$, ligeramente más anchas que lo indicado por Aronsen (2002-2015) y Robich (2016), probablemente debido a la presencia de bastantes basidios bispóricos, no obstante la forma y coeficiente esporal $\mathrm{Q}=2$ son coincidentes con lo indicado por dichos autores, así como los basidios ovoides, de 20-23 x 9-10 $\mu \mathrm{m}$ con largos esterigmas, los queilocistidios claviformes en 
forma de brocha, la pelis formada por hifas ornamentadas con excrecencias y ramificaciones de hasta $10 \mu \mathrm{m}$ y el estipe ornamentado con caulocistidios lageniformes, algunos septados de hasta $100 \mu \mathrm{m}$ de largo.

Ecología y distribución: común sobre hojas de Salix atrocinerea depositadas en el fondo de la turbera durante los perídos en los que desciende el nivel del agua.

Georreferenciada de Inglaterra, Irlanda y Centro y Norte de Europa (GBIF en línea, $\mathrm{n}^{\circ}$ 2527037). Podría ser el primer registro para la Península Ibérica.

Mycena pilosella Maas Geest., Proc. K. Ned. Akad. Wet., Ser. C, Biol. Med. Sci. 91(2): 149 (1988)

Material estudiado: Tuy, Guillarei, aliseda de Albelos, 29TNG3019, $20 \mathrm{~m}$, sobre tallo de Osmunda regalis, 09/11/2015, O. Requejo, LOU-Fungi 20663.

Observaciones: píleo hemisférico a cónico, que en algunos ejemplares deja intuir un ligero umbón. En ejemplares jóvenes es color crema, con la parte central más oscura, a medida que va madurando la zona oscura se extiende de forma degradada hasta el margen que adquiere tonalidades crema. Láminas blanco cremoso en número próximo a 15 , adnadas o ligeramente escotadas. Estipe cilíndrico, concolor con la parte central el píleo, pruinoso, base recubierta de pelosidades blanquecinas que lo unen al sustrato. Presenta esporas cilíndrico elipsoides, de 8,7-10(10,6)-4,5-5 $\mu \mathrm{m}$, queilocistidios muy variables morfológicamente (claviformes, lageniformes o utriformes), de 30-47 x 8-17 $\mu \mathrm{m}$, a veces con prolongaciones flexuosas apicales. Pleurocistidios no observados. Hifas del estipe con pequeñas excrecencias y caulocistidios claviformes, que superan las $150 \mu \mathrm{m}$ de largo con ápices de hasta $6 \mu \mathrm{m}$, a veces bifurcados y, en algunas ocasiones, con la base ensanchada. Fíbulas presentes en las estructuras observadas. Estas características coinciden con Robich (2003), a excepción del color del pie, que lo considera blanco. Este autor tampoco menciona los queilocistidios claviformes. Especies con microscopía similar como M. stipata Maas Geest. \& Schwöbel no presenta los caulocistidios mencionados y en $M$. villicaulis Maas Geest. las esporas son mayores y los pelos del estipe tienen paredes anchas.

Ecología y dsitribución: se recolectó sobre troncos de Osmunda regalis cuando este aún no ha brotado.

Especie no georreferenciada en GBIF (en línea). La única cita ibérica que se encontró es la de Villareal et al. (1998). 
Mycena pseudocorticola Kühner, Encyclop. Mycol. 10: 687 (1938)

Material estudiado: O Porriño, Budiño, Orbenlle, observatorio ornitológico, 29TNG3061, 22 m, sobre Alnus glutinosa, 21/03/2013, O. Requejo, LOU-Fungi 20003.

Ecología y distribución: fructifica en troncos de frondosas donde convive con M. corynephora y M. meliigena, sobre todo en bosquees de ribera y aluviales.

Frecuente en Europa, incluida la zona septentrional de la Península Ibérica (GBIF en línea, $\mathrm{n}^{\mathrm{0}}$ 2527066). En Galicia sólo se ha observado en Pontevedra (Requejo 2008, Requejo 2012, De la Peña 2016) y A Coruña (Marcote et al. 2011)

Mycena pura (Pers.) P.Kumm., Führ. Pilzk. (Zerbst): 107 (1871)

Material estudiado: Tui, Guillarei, aliseda de Albelos, 29TNG3019, 20 m, bajo Salix atrocinerea y Alnus glutinosa, 23/12/2015, O. Requejo, LOU-Fungi 20590.

Ecología y distribución: recolectada en zona herbosa con suelo turboso al borde de una aliseda inundable.

Durante un tiempo este taxón no se ha diferenciado de $M$. rosea Gramberg, por lo que las citas antiguas son confusas. Está georreferenciada por todo el mundo, excepto el continente africano (GBIF en línea, $\mathrm{n}^{\circ}$ 2527219). Común en Galicia (Soliño et al. 1999).

Mycena rubromarginata (Fr.) P.Kumm., Führ. Pilzk. (Zerbst): 109 (1871)

Material estudiado: O Porriño, Budiño, Orbenlle, observatorio ornitológico, 29TNG3061, 22 m, sobre Quercus robur, 03/11/2013, O. Requejo, LOU-Fungi 19912.

Ecología y distribución: observada sobre el tronco de un viejo Quercus robur musgoso, en bosque muy umbrío.

Frecuente en las Islas Británicas, Centro y Norte de Europa, también referenciada de Península Ibérica, Canadá y costa oriental rusa (GBIF en línea, $\mathrm{n}^{\circ}$ 2527041). En Galicia sólo se conoce de Pontevedra (Castro 1985, Lago \& Castro 2003).

Mycena sanguinolenta (Alb. \& Schwein.) P.Kumm., Führ. Pilzk. (Zerbst): 108 (1871)

Material estudiado: O Porriño, Budiño, Orbenlle, observatorio ornitológico, 29TNG3061, 22 m, bajo Quercus robur y Salix atrocinerea, 22/09/2014, O. Requejo, LOU-Fungi 19975. 
Ecología y distribución: el material estudiado ha sido recolectado próximo a la laguna, en zona de Quercus robur y Salix atrocinerea, entre hojarrasca.

Ampliamente georreferenciada para Europa, incluida la Península Ibérica y Canadá, también observada en Estados Unidos, Islas Canarias, Rusia, Japón, Australia y Nueva Zelanda (GBIF en línea, $\left.n^{\circ} 2527135\right)$. En Galicia se ha citado para A Coruña, Lugo y Pontevedra (Soliño et al. 1999, Requejo, 2012).

\section{Mycena scirpicola M. Villarreal, Heykoop, Esteve-Raventós \& Maas Geest.,} Persoonia 16 (4): 531 (1998)

Material estudiado: Tui, Guillarei, aliseda de Albelos, 29TNG3019, $20 \mathrm{~m}$, sobre tallo de Osmunda regalis, 26/12/2015, O. Requejo, LOU-Fungi 20607.

Observaciones: la colección estudiada presenta basidiosporas de 8-10 x 4-5 mm. Este ancho esporal es ligeramente menor que el indicado por Robich (2003), no así con el propuesto por Aronsen (2012-2015). Se observaron queilocistidios variables, de fusiformes o lageniformes, a subclaviformes y ventrudos, con protuberancias en el ápice, los caulocistidios son filiformes con la base ensanchada y las hifas de la estipitipelis, con excrecencias, diferencian este taxón de otros similares como Mycena pilosella Maas Geest., que tiene caulocistidios con ápices ensanchados y redondeados, o Mycena villicaulis Maas Geest. que presenta basidiosporas mayores.

Ecología y distribución: en la revisión bibliográfica no encontramos menciones de recolecciones sobre Osmunda regalis, hasta el momento se conoce sobre Scirpus holoschoenus (holotipo), Rubus sp., Abies alba, ramas enterradas y musgos (Robich, 2003; Aronsen, 2012-2015).

Parece tratarse de un taxón raro, no se conoce su distribución mundial con precisión, aunque si fue referenciada para la Península Ibérica, Italia y Noruega (GBIF en línea). No conocemos citas anteriores para Galicia.

Mycena seynii Quél., Bull. Soc. bot. Fr. 23: 351 (1877) [1876]

Material estudiado: O Porriño, Pontellas, barreras de Centeáns, 29TNG3007, 20 m, sobre piña de Pinus pinaster, 19/12/2015, J.Á. Gándara \& O. Requejo, LOU-Fungi 20558. Tuy, Rebordanes, Ponte das Febres 29TNG2996, 21 m, sobre piña de Pinus pinaster, 02/10/2016, O. Requejo, LOU-Fungi 20632.

Ecología y distribución: común sobre piñas en todos los pinares de la zona de estudio. 
Especie frecuente en el centro y sur de Europa, Marruecos, Sierra Leona, etc. sobre piñas, aunque únicamente aparece georreferenciada de la Península Ibérica (GBIF en línea, no 5447950). Común en Galicia (Soliño et al. 1999)

Mycena stylobates (Pers.) P. Kumm., Führ.Pilzk. (Zerbst): 108 (1871)

Material estudiado: O Porriño, Budiño, Orbenlle, observatorio ornitológico, 29TNG3061, 22 m, sobre hoja de Typha latifolia, 27/11/2013, O. Requejo, LOU-Fungi 19913.

Ecología y distribución: destacar en nuestra recolección que ha sido observada en turbera, sobre Typha latifolia.

Ampliamente referenciada de Europa, también de Estados Unidos, Canadá, Islas Canarias, Brasil y Australia (GBIF en línea, $n^{\circ}$ 2526866). En Galicia sólo se conoce de las provincias atlánticas (Rodríguez-Vázquez \& Castro 2016).

Mycena tenerrima (Berk.) Quél., Mém. Soc. Émul. Montbéliard, Sér. 2 5: 151 (1872)

= Mycena adscendens Maas Geest., Proc. K. Ned. Akad. Wet., Ser. C, Biol. Med. Sci. 84 (2): 211 (1981)

Material estudiado: O Porriño, Budiño, Orbenlle, observatorio ornitológico, 29TNG3061, 22 m, sobre Salix atrocinerea, 01/10/2013, LOU-Fungi 20006. Ibídem sobre Osmunda regalis, 03/11/2013, O. Requejo, LOU-Fungi 19908. O Porriño, Budiño, Orbenlle, Os Eidos, 29TNG3022, 30 m, sobre Salix atrocinerea, 07/10/2013, G. Requejo, LOU-Fungi 19909.

Observaciones: parece existir cierta confusión nomenclatural en esta especie. Por una parte, en Index Fungorum (en línea) se recomienda el uso de $M$. tenerrima (Berk.) Quél., en tanto algunos investigadores como Robich (2016) consideran como nombre prioritario M. adscendens Maas Geest.

Ecología y distribución: muy común sobre troncos de caducifolios, así como sobre la corteza de pequeñas ramas caídas en todo tipo de bosques de la zona de estudio.

En GIBF (en línea) no se indica su distribución mundial, se sugiere como binomen prioritario M. adscendens. En la Península Ibérica parece ser un taxón común en el norte (Pérez Butron et al. 2011, Picón 2004, Lago-Álvarez 2008, Rubio-Domínguez 2005). Frecuente en Galicia para A Coruña, Ourense y Pontevedra (Rodríguez-Vázquez \& Castro 2016). 
Mycena vitilis (Fr.) Quél., Mém. Soc. Émul. Montbéliard, Sér. 2 5: 106 (1872)

Material estudiado: O Porriño, Budiño, Orbenlle, observatorio ornitológico, 29TNG3061, 22 m, sobre Osmunda regalis, 21/12/2013, O. Requejo, LOU-Fungi 19914. Salceda de Caselas, Cerquido, Ponte Carneiro, 29TNG3164, 35 m, entre musgos y turba, 21/01/2015, O. Requejo, LOU-Fungi 20623.

Ecología y distribución: parece tratarse de una especie común en zonas húmedas. La colección LOU-Fungi 19914 se realizó sobre tallo de Osmunda regalis, en cambio para LOU-Fungi 20623, fué directamente sobre suelo turboso.

Ampliamente georreferenciada para Europa, también para Estados Unidos y Canadá (GBIF en línea, $n^{\circ}$ 2526842). En territorio gallego se conoce de A Coruña, Lugo y Pontevedra (Rodríguez-Vázquez \& Castro 2016).

Mycoacia uda (Fr.) Donk, Medded. Nedl.Mycol. Ver. 18-20: 151 (1931)

Material estudiado: Salceda de Caselas, desembocadura del río Becerreira, 29TNG3019, $20 \mathrm{~m}$, sobre rama en bosque de Quercus robur y Alnus glutinosa, 26/09/2015, LOU-Fungi 20275.

Ecología y distribución: fructificaba a finales de verano, sobre rama caída bastante degradada sin identificar en bosque no inundable de Quercus robur y Alnus glutinosa.

Frecuente en Europa, también mencionada para Estados Unidos, Canadá y Australia (GBIF en línea, ${ }^{\circ}$ 2544416). Mencionada en Galicia para Pontevedra (Tellería 1990), A Coruña (Marcote et al. 2011) y Lugo (López-Prada \& Castro 2002).

Naucoria escharioides (Fr.) P. Kumm., Der Führer in die Pilzkunde: 76, 1871 $\equiv$ Alnicola escharioides (Fr.) Romagn., Bull. trimest. Soc. mycol. Fr. 58: 126 (1944) [1942]

Material estudiado: O Porriño, Budiño, Orbenlle, observatorio ornitológico, 29TNG3061, 22 m, bajo Salix atrocinerea y Alnus glutinosa, 12/05/2013, O. Requejo, LOU-Fungi 19981. Ibídem, bajo Alnus glutinosa, 11/12/2016, O. Requejo, LOU-Fungi 20610. Salceda de Caselas, Cerquido, Ponte Carneiro, 29TNG3164, 35 m, bajo Alnus glutinosa, 29/09/2015, O. Requejo, LOU-Fungi 20616.

Observaciones: la colección LOU-Fungi 20610 presenta coloración semejante a Naucoria luteolofibrillosa (Kühner) Kühner \& Romagn., con píleo y láminas muy claras; no obstante, la ausencia de velo y queilocistidios con ápices engrosados diferencian ambas especies (Breitenbach \& Kränzlin 2000, Henrici 2008). 
Ecología y distribución: es la especie más común del género y una de las más habituales en las zonas húmedas de la zona de estudio. Fructifica durante todo el año micorrizando con Alnus glutinosa. También se recolectó bajo Salix atrocinerea, en este caso había alisos próximos, por lo que es complicado confirmar la relación con sauces.

Según la revisión de Fernandez-Sasia et Moreau (2011) es una especie común pero mal interpretada, a pesar de la revisión nomenclatural propuesta en ese trabajo, decidimos citarla como N. escharioides (Fr.) P. Kumm. siguiendo el criterio de Index Fungorum (en línea).

No se indica con precisión su distribución mundial, sin embargo, conocemos citas del norte y centro de Europa hasta Francia, Islas Británicas y también en Nueva Zelanda (GBIF en línea, 26339534). Para Galicia la encontramos citada como Alnicola escharioides (Requejo 2012) para la provincia de Pontevedra y sin precisar localidad por Marcote et al. (2009) sub. Naucoria escharioides.

Naucoria scolecina (Fr.) Quél., Mém. Soc. Émul. Montbéliard, Sér. 2 5: 438 (1875)

三Alnicola scolecina (Fr.) Romagn., Bull. trimest. Soc. mycol. Fr. 58: 121 (1944) [1942]

Material estudiado: O Porriño, Budiño, Orbenlle, observatorio ornitológico, 29TNG3061, $22 \mathrm{~m}$, en turbera bajo Salix atrocinerea y Alnus glutinosa, 01/12/2015, O. Requejo, LOUFungi 20608.

Observaciones: el píleo pardo rojizo, higrófano y estriado en húmedo, las basidiosporas finamente verrucosas, de 10-12,5 x 5-7 $\mu \mathrm{m}$ y la asociación con Alnus glutinosa nos indican que se trata de esta especie (Reid 1984, Henrici 2008, Breitenbach \& Kränzlin 2000).

Ecología y distribución: habitual en bosques aluviales y riparios micorrizando con Alnus glutinosa.

Parece ser común en las Islas Británicas, centro y norte de Europa. También mencionada para Australia y Chile (GBIF en línea, nº 2534062). Para la Península Ibérica encontramos varias citas distribuidas de norte a sur (Esteve Raventós \& Villareal 2003, Rubio-Domínguez et al. 2006, Picón 2004, Vila 1999, Moreno-Arroyo 2004). No la conocemos mencionada para Galicia. 
Naucoria subconspersa Kühner ex P.D. Orton, Trans. Br. mycol. Soc. 43 (2): 323 (1960)

三Alnicola subconspersa (Kühner ex P.D. Orton) Bon, Docums Mycol. 9(no. 35): 41 (1979)

Material estudiado: O Porriño, Budiño, Orbenlle, observatorio ornitológico, 29TNG3061, 22 m, en turbera bajo Salix atrocinerea y Alnus glutinosa, 01/12/2015, O. Requejo, LOU-Fungi 20609.

Observaciones: la presencia de velo blanco persistente en el borde del píleo, dejando restos a lo largo del estipe la diferencia macroscópicamente de $N$. scolecina (Fr.) Quél. El tamaño esporal de la colección estudiada se corresponde con los valores indicados por Breitenbach \& Kränzlin (2000), ligeramente mayores que los de Reid (1984). Fernández-Sasia \& Moreau (2011) descartan que la variabilidad esporal del taxón se deba a una posible bisporia y la consideran asociada a la climatología. También se han observado algunas basidiosporas aberrantes, que rondaban las $15 \times 6,5 \mu \mathrm{m}$, lo que podría hacer pensar en Alnicola dubis Métrod ex P.-A. Moreau \& J.-P. Vidonne, taxón complejo y difícil de separar de $N$. subconpersa (Moreau et al. 2006). Futuros estudios moleculares del grupo permitirán definir mejor cada uno de estos taxones.

Ecología y distribución: recolectado en bosque inundable con sotobosque turboso, bajo Salix atrocinerea y Alnus glutinosa, por lo que es complicado distinguir con cual establecía la micorriza.

Con todas estas dificultades para diferenciar macro y microscópicamente el taxón es difícil establecer su distribución con seguridad. Sólo se referencia de las Islas Británicas, Centroeuropa, Países Escandinavos y Canadá (GBIF en línea, 2534041). Es un taxón raro en la Península Ibérica (Fernandez Sasia \& Moreau 2011). Para Galicia solo se citó en A Coruña (Marcote et al. 2011).

Naucoria umbrina Bres., K. svenska Vetensk-Akad. Handl. 2: 313 (1900)

三Alnicola umbrina (R. Maire) Kühner, Bull. trimest. Soc. mycol. Fr. 47: 241 (1931)

Material estudiado: O Porriño, Budiño, Orbenlle, observatorio ornitológico, 29TNG3061, 22 m, bajo Salix atrocinerea, 12/05/2013, O. Requejo, LOU-Fungi 19982.

Observaciones: la determinación de la especie se llevó a cabo siguiendo los trabajos de Moreau (2006) y Reid (1984). En este último se corresponde con $N$. striatula P.D. Orton, que Moreau $(2004,2005)$ considera sinónima de $N$. umbrina Bres. 
Además de Naucoria umbrina Bres, Index Fungorum (en línea), recoge como aceptado el taxón Tubaria umbrina R. Maire, sinónimo de Alnicola umbrina (R. Maire) Kühner. No obstante, Moreau (2004) revisando el material de Maire indica que se trata de una especie perteneciente algénero Alnicola.

A pesar de estar de acuerdo con el criterio de Moreau al usar el género Alnicola en sus revisiones, tanto taxonómicas como nomenclaturales (2004, 2005), para ser fieles a la metodología adoptada para elaborar este catálogo, optamos por citar el material revisado como Naucoria siguiendo el criterio de Index Fungorum.

Ecología y distribución: el material estudiado se recolectó bajo Alnus glutinosa en bosque aluvial inundable.

No se conoce su distribución mundial (GIBF en línea $n^{\circ}$ 54288). Rara en la Península Ibérica y en Galicia sólo se ha citado de Pontevedra (Requejo 2012).

Neoboletus junquilleus (Quél.) Gelardi, Simonini \& Vizzini, Index Fungorum 192: 1 (2014)

= Boletus erythropus var. junquilleus (Quél.) Bon, Doc. mycol. 15(60): 38 (1985)

Material estudiado: O Porriño, Budiño, Orbenlle, observatorio ornitológico, 29TNG3061, 22 m, bajo Quercus robur, 17/10/2013, O. Requejo, LOU-Fungi 20213.

Ecología y distribución: Recolectado en bosque mixto de Pinus pinaster y Quercus robur.

Especie poco frecuente, georreferenciada únicamente de Centroeuropa, Dinamarca, Suecia y Península Ibérica (GBIF en línea n 7423577). En Galicia sólo ha sido mencionado para la provincia de Pontevedra (Blanco-Dios 2005)

Nidularia deformis (Willd.) Fr., in Fries \& Nordholm, Symb.gasteromyc. (Lund) 1: 3 (1817)

= Nidularia farcta (Roth.) Fr., Syst. mycol. (Lundae) 2(2): 301 (1823)

Material estudiado: O Porriño, Budiño, Orbenlle, observatorio ornitológico, 29TNG3061, 22 m, sobre pequeñas ramas caídas, 07/09/2013, O. Requejo, LOU-Fungi 20226.

Observaciones: el análisis de los caracteres macro y microscópicos permiten identificarla con seguridad (Calonge 1998, Breitenbach \& Kränzlin 1986). Las hifas de la capa superficial, altamente ramificadas, permiten separarla de N. pulvinata (Schwein.) Fr. 
Ecología y distribución: recolectada como saprotrófica sobre rama semienterrada en turba, en zona muy sombría.

Especie escasamente georreferenciada, aunque parece extendida en el Hemisferio Norte: Suecia, Noruega, Países Bajos y Canadá, también en Australia y Nueva Zelanda (GBIF en línea, no 5243099 sub. N. farcta). En la Península Ibérica sólo se la conoce de Madrid, Beira Litoral (Calonge 1996) y Bizkaia (Fernández-Vicente 2013). Para Galicia se encontró una reciente cita en Pontevedra (De la Peña 2016).

Oligoporus alni (Niemelä \& Vampola) Piątek, Polish Bot. J. 48 (1): 17 (2003) 三 Postia alni Niemelä \& Vampola, Karstenia 41(1): 7 (2001)

Material estudiado: Tui, Guillarei, aliseda de Albelos, 29TNG3019, 20 m, sobre madera de Salix atrocinerea, 19/11/2015, O. Requejo, LOU-Fungi 20575.

Observaciones: presenta carpóforos pequeños e intensamente azules, 56 poros/mm y basidiosporas de 4,4-6 x 1,1-1,3 $\mu \mathrm{m}$. Según Piątek (2003) y Bernicchia (2005) se trata de una especie bien caracterizada a pesar de la semejanza con $O$. subcaesius (A. David) Ryvarden \& Gilb., que tiene basidiomas carnosos, de más de $5 \times 2-3 \mathrm{~cm}$, con tonalidades azuladas muy tenues, 4-5 poros/mm y basidiosporas alantoides de 4-5 (6) x 1-1,2 $\mu \mathrm{m}$. Tampoco existe confusión con $O$. caesius (Schrad.) Gilb. \& Ryvarden que fructifica habitualmente sobre madera de coníferas y tiene basidiosporas más cortas (Bernicchia 2005).

Ecología y distribución: recolectada sobre rama de Salix atrocinerea en sauceda inundable.

A pesar de ser observada frecuentemente en los países nórdicos, también mencionada de Polonia, Francia y Canadá (GBIF en línea $n^{\circ}$ 5464370), como afirma Piątek (2003) su distribución sigue siendo incierta y requiere una revisión de los herbarios debido a la confusión con Postia subcaesia (A. David) Jülich. No se encontraron citas ibéricas y tampoco la conocemos mencionada para Galicia.

Panaeolus antillarum (Fr.) Dennis, Kew Bull. 15 (1): 124 (1961)

Material estudiado: O Porriño, Budiño, Orbenlle, observatorio ornitológico, 29TNG3061, 22 m, sobre excrementos de caballo, 22/09/2014, O. Requejo, LOU-Fungi 19778.

Ecología y distribución: hongo fimícola hallado en su hábitat habitual (Breitenbach \& Kränzlin 1995), cuya presencia en la zona de estudio se condiciona a los excrementos de caballo. 
Poco frecuente, pero extendido por casi todo el mundo (GBIF en línea, $\mathrm{n}^{\circ}$ 3317043). Para la Península Ibérica lo encontramos mencionado en Asturias (RubioDomínguez et al. 2006), Andalucía (Moreno-Arroyo 2004) e Islas Baleares (Mir \& Mellis 2008). En Galicia fue recolectada únicamente en las provincias de A Coruña y Pontevedra (Marcote et al. 2003, Rodríguez-Vázquez \& Castro, 2001).

Panaeolus papilionaceus (Bull.) Quél., Mém. Soc. Émul. Montbéliard, Sér. 2 5: 152 [122 repr.] (1872)

= Panaeolus sphinctrinus (Fr.) Quél., Mém. Soc. Émul. Montbéliard, sdér. 25 : 151 (1872)

Material estudiado: O Porriño, Budiño, Orbenlle, observatorio ornitológico, 29TNG3061, $22 \mathrm{~m}$, sobre excrementos de caballo, 22/09/2014, O. Requejo, LOU-Fungi 19779.

Ecología y distribución: hongo fimícola (Breitenbach \& Kränzlin 1995), en la zona de estudio se ha recolectado en excrementos de caballo.

Extremadamente frecuente en Europa, incluida la Península Ibérica, también georreferenciado del continente americano, Japón y Australia (GBIF en línea, $\mathrm{n}^{\mathrm{o}}$ 3317061). En Galicia ha sido mencionado para Lugo, Ourense y Pontevedra (Soliño et al. 2000).

Paralepista flaccida (Sowerby) Vizzini, in Vizzini \& Ercole, Mycotaxon 120: 262 (2012)

इLepista flaccida (Sowerby) Pat., Hyménomyc. Eur. (Paris): 96 (1887)

Material estudiado: Salceda de Caselas, Cerquido, Ponte Carneiro 29TNG3164, 35 m, bajo Salix atrocinerea y Rubus sp., 27/12/2014, J.Á. Gándara y O. Requejo, LOUFungi 19924.

Ecología y distribución: recolectado bajo Salix atrocinerea en camino que bordea un bosque inundable. Común en la zona de estudio sobre restos orgánicos.

Frecuente y abundante en Europa (GBIF en línea, $n^{\circ}$ 5242079), también en Galicia (Soliño et al. 1999).

Panus conchatus (Bull.) Fr., Epicr. syst. mycol. (Upsaliae): 396 (1838) [18361838]

Material estudiado: Tuy, Rebordanes, Ponte das Febres 29TNG2996, 21 m, sobre tocón sin identificar, 22/10/2016, O. Requejo, LOU-Fungi 20653.

Ecología y distribución: especie poco común en las zona, recolectada sobre tocón en bosque mixto no inundable. 
Georreferenciado en Europa, sobre todo países escandinavos hasta el norte de la Península Ibérica, Centroamérica y sur de los Estados Unidos, así como en el sudoeste asiático y Oceanía con citas en Japón, Papúa Nueva Guinea y Australia (GBIF en línea, $\mathrm{n}^{0}$ 5247111). También está citado en el sur de la Península Ibérica (Moreno-Arroyo 2004), por lo que no debe ser un taxón raro. En Galicia está presente en las cuatro provincias (Lago-Álvarez 2008).

Paxillus involutus (Batsch) Fr., Epicr. syst. mycol. (Upsaliae): 317 (1838)

Material estudiado: O Porriño, Budiño, Orbenlle, observatorio ornitológico, 29TNG3061, 22 m, bajo Betula pubescens, 07/10/2013, G. Requejo, LOU-Fungi 19969. Ibídem, sobre tronco de Quercus robur, 01/12/2015, O. Requejo, LOU-Fungi 20547.

Ecología y distribución: común en toda la zona, sobre todo bosques no inundables de frondosas y ambientes riparios. La colección LOU-Fungi 20547 se recolectó sobre madera de Quercus robur. A pesar de ser considerada una especie claramente micorrízogena (Rudawska \& Kieliszewska-Rokicka, 1997), parece comportarse, en este caso, como saprotrófico lignícola.

Ampliamente georrefrenciada para el Hemisferio Norte, pero también se observó en Chile, Australia y Nueva Zelanda (GBIF en línea, $n^{\circ}$ 5240002). Común en Galicia (Soliño et al. 1999).

Phaeolus schweinitzii (Fr.) Pat., Essai taxonomique sur les familles et les genres des Hyménomycètes: 86 (1900)

Material estudiado: O Porriño, Pontellas, barreras de Centeáns, 29TNG3007, 20 m, sobre tocón de Pinus pinaster, 22/12/214, O. Requejo, LOU-Fungi 19864.

Ecología y distribución: frecuente sobre los tocones y raíces de Pinus pinaster enterrados .

Especie lignícola muy común en el Hemisferio Norte. También observada en las Islas Canarias, Sudáfrica, Australia y Nueva Zelanda (GBIF en línea, $n^{\circ}$ 2542126). Común en Galicia (Soliño et al. 2000).

Phlebia tremellosa (Schrad.) Nakasone \& Burds. [as 'tremellosus']. Mycotaxon 21: 245 (1984)

इMerulius tremellosus Schrad., Spicil. fl. germ.1: 139 (1794)

Material estudiado: Salceda de Caselas, Cerquido, Ponte Carneiro 29TNG3164, 35 m, sobre tronco de Pinus pinaster, 21/01/201, O. Requejo, LOU-Fungi 20013. 
Ecología y distribución: fructificaba sobre tronco seco de Pinus pinaster que permanecía erguido a los pies de la braña.

Muy frecuente, especialmente en el Hemisferio Norte. Referencias escasas para Sudamérica y Australia (GBIF en línea, nº 3292343). Común en Galicia (Rodríguez-Vázquez \& Castro 2016).

Phlebia rufa (Pers.) M.P. Christ., Dansk bot. Ark. 19 (2): 164 (1960)

Material estudiado: Salceda de Caselas, Cerquido, Ponte Carneiro, 29TNG3164, 35 m, sobre tocón y hojas de Populus nigra, 27/12/2015, O. Requejo, LOU-Fungi 20541.

Populus nigra.

Ecología y distribución: recolectada en zona inundable, sobre restos de

Georreferenciada de toda Europa occidental, también de Japón, Canadá y Australia (GBIF en línea, $n^{\circ}$ 2545043). En Galicia se ha mencionado en las provincias de A Coruña, Pontevedra y Lugo (Rodríguez-Vázquez \& Castro, 2016).

Phlebiopsis crassa (Lév.) D. Floudas \& Hibbett, Fungal Biology 119: 710 (2015)

三Lopharia crassa (Lév.) Boidin, Bull. trimest. Soc. mycol. Fr. 74: 479 (1959)

三 Porostereum crassum (Lév.) Hjortstam \& Ryvarden, Syn. Fung. (Oslo) 4: 29 (1990)

Material estudiado: Tui, Guillarei, aliseda de Albelos, 29TNG3019, 20 m, 22/12/215, sobre pequeña rama sin identificar, O. Requejo, LOU-Fungi 20573.

Observaciones: basidioma resupinado con aspecto algodonoso, de intenso color lila, que oscurece al madurar, y con la zona de crecimiento blanca. Cistidios fusiformes con el ápice fuertemente incrustado, hifas con paredes anchas y sin fibulas y basidiosporas de cilíndricas a anchamente fusiformes, de $7-8 \times 4-5 \mu \mathrm{m}$.

Ecología y distribución: especie común en la zona de estudio, sobre ramas caídas en la turba en espacios inundables.

Especie rara, georreferenciada para Portugal, Estados Unidos, Canadá, Japón y ampliamente distribuida por Australia y Nueva Zelanda (GBIF en línea, $\mathrm{n}^{\mathrm{o}}$ 7898018). No la conocemos citada de Galicia

Phloeomana alba (Bres.) Redhead, Index Fungorum 289: 1 (2016)

三 Mycena alba (Bres.) Kühner, Encyclop. Mycol. 10: 594 (1938)

Material estudiado: O Porriño, Budiño, Orbenlle, observatorio ornitológico, 29TNG3061, 22 m, sobre tronco musgoso de Salix atrocinerea, 13/08/2014, O. Requejo, LOU-Fungi 19970. 
Observaciones: basidiosporas globosas, queilocistidios de claviformes a subfusiformes, hifas de la cutícula con excrecencias gruesas, digitaliformes y anchas, hasta $22-25 \mathrm{~mm}$, así como lamelas decurrentes o subdecurrentes, que permiten diferenciarla de especies semejantes como P. hiemalis (Osbeck) Redhead y P. speirea (Fr.) Redhead (Robich 2003). La colección estudiada es tetraspórica y con fíbulas, tiene basidiosporas globosas, de 5,6-7,7 $\mu \mathrm{m}$ como indica Robich (2003); pero ligeramente menores a lo indicado por Aronsen (2002-2015) y Breitenbach \& Kränzlin (1991).

Ecología y distribución: Especie cortícola, recolectada sobre Salix atrocinerea en verano.

Gerorrefernciada únicamente para países nórdicos, Centroeuropa y Península Ibérica (GBIF en línea, nº 8041067). No conocemos menciones para Galicia.

Phloeomana speirea (Fr.) Redhead, Index Fungorum 15: 2 (2013)

三 Mycena speirea (Fr.) Gillet, Hyménomycètes (Alençon): 428 (1876) [1878]

Material estudiado: O Porriño, Budiño, Orbenlle, observatorio ornitológico, 29TNG3061, 22 m, sobre rama de Salix atrocinerea, 26/06/2014, O. Requejo, LOU-Fungi 19919.

Observaciones: semejante a $P$. alba (Bres.) Redhead, de la que se diferencia por presentar basidiosporas elipsoides, no globosas, de 8-11 x 4-6 $\mu \mathrm{m}$ y las hifas de la cutícula ligeramente gelificadas, con pequeñas excrecencias y anchura no superior a $5 \mu \mathrm{m}$ (Robich 2003).

Ecología y distribución: muy abundante, con numerosos ejemplares sobre ramas y troncos de Salix atrocinerea secos, pero que no tocan el suelo.

Especie común en Europa occidental, incluida la Península Ibérica, pero también observada en Canadá, Australia y Nueva Zelanda (GBIF en línea, ${ }^{\circ}$ 8213692). Sin embargo, en Galicia sólo se conoce de Lugo (Campoamor 1996) y recientemente Pontevedra (De la Peña 2016).

Pholiota gummosa (Lasch) Singer, Lilloa 22: 517 (1951) [1949]

Material estudiado: Tui, Guillarei, Albelos, 29TNG3043, 13 m, sobre tierra con restos leñosos, 29/10/2015, J. Valeiras \& O. Requejo, LOU-Fungi 20290. Salceda de Caselas, desembocadura del río Becerreira, 29TNG3019, 20 m, sobre Quercus robur, 09/11/2015, J. Valeiras \& O. Requejo, LOU-Fungi 20527.

Ecología y distribución: común en bosques de ribera, bien sobre madera o directamente sobre la tierra cuando esta está enterrada. 
Especie de la que se desconoce con precisión su distribución mundial, aunque fue georreferenciada para Europa occidental, Islas Canarias, Canadá, Estados Unidos, Brasil y Nueva Zelanda (GBIF en línea, n 55265). Común en Galicia (Soliño et al. 1999).

Pholiota tuberculosa (Schaeff.) P. Kumm., Führ. Pilzk. (Zerbst): 83 (1871)

Material estudiado: O Porriño, Budiño, Orbenlle, observatorio ornitológico, 29TNG3061, 22 m, sobre Salix atrocinerea, 11/12/2014, O. Requejo, LOU-Fungi 19854.

Ecología y distribución: recolectada sobre rama seca de Salix atrocinerea vivo en zona higroturbosa inundable.

Ampliamente georreferenciada para Europa occidental, también para Canadá y Estados Unidos (GBIF en línea, $n^{\circ}$ 2534278). Frecuente en Galicia (Rodríguez-Vázquez \& Castro 2016).

Pisolithus arhizus (Scop.) Rauschert, Z. Pilzk. 25(2): 50 (1959)

Material estudiado: Tuy, Rebordanes, Ponte das Febres 29TNG2996, 21 m, en camino de tierra en bosque de Pinus pinaster y Quercus robur, 02/10/2016, Marta Martínez, LOU-Fungi 20636.

Ecología y distribución: común, estableciendo micorrizas en bosques mixtos, pero fructificando en claros como los caminos circundantes.

Ampliamente extendido en la Península Ibérica (Calonge 1998, LagoÁlvarez 2008). En Galicia también se ha citado en múltiples ocasiones (Rodríguez-Vázquez \& Castro 2016).

Pluteus hongoi Singer, Fieldiana, Bot. 21: 95 (1989)

=Pluteus nothopellitus Justo \& M.L. Castro, Mycotaxon 102: 222 (2007)

Material estudiado: O Porriño, Budiño, Orbenlle, Os Eidos, 29TNG3022, 30 m, sobre madera de frondosa, 15/10/2016, M. Martínez, LOU-Fungi 20660.

Observaciones: los ejemplares estudiados presentaban tonalidades gris muy claras, casi blancas, pudiendo confundirse con P. cervinus (Schaeff.) P. Kumm. A pesar de que diferenciar estas especies es muy complejo sin análisis moleculares (Justo et al. 2014), la caracterizamos basándonos en los apéndieces de los cistidios bifurcados y la ausencia de escamas o fibras pardas en el estipe.

En la revisión de Justo et al. (2014), se sinonimizan P. nothopellitus con $P$. hongoi, criterio no recogido todavía en Index Fungorum (en línea). 
Ecología y distribución: recolectado en zona muy sombría, bajo frondosas en bosque no inundable.

No lo encontramos georreferenciado, como $P$. hongoi apenas existen dos registros americanos (GBIF en línea, $n^{\circ}$ 5449616). Es un taxón muy raro en la Península Ibérica del que apenas se conoce de Galicia (Justo \& Castro 2007).

Pluteus phlebophorus (Ditmar) P.Kumm., Führ.Pilzk. (Zerbst): 98 (1871)

Material estudiado: Salceda de Caselas, desembocadura del río Becerreira, 29TNG3019, 20 m, entre restos orgánicos, 10/11/2015, O. Requejo, LOU-Fungi 20528.

Ecología y distribución: recolectado en bosque de ribera entre restos orgánicos bajo Alnus glutinosa y Quercus robur.

Georreferenciado en Europa occidental, también en Canadá (GBIF en línea, $n^{\circ} 7641695$ ). En Galicia sólo se conoce de la provincia de A Coruña (Lago $\&$ Castro 1997) y Pontevedra (De la Peña 2016).

Pluteus plautus (Weinm.) Gillet, Hyménomycètes (Alençon): 394 (1876) [1878]

Material estudiado: Salceda de Caselas, Cerquido, Ponte Carneiro 29TNG3164, 35 m, sobre restos de Salix atrocinerea, 02/10/2014, Roberto Requejo, LOU-Fungi 19808.

Observaciones: se trata de un complejo de especies aún mal conocidas y en fase de revisión (A. Justo, comunicación personal).

Ecología y distribución: recolectado en bosque de ribera entre restos de Salix atrocinerea.

Hasta el momento está georreferenciado para Europa occidental y Canadá (GBIF en línea, $n^{\circ}$ 5241290). En la Península Ibérica su distribución es amplia (Justo \& Castro 2007) y en Galicia aparece mencionado para Lugo (LagoÁlvarez 2008), Pontevedra y A Coruña (Rodríguez-Vázquez \& Castro 2001).

Pluteus podospileus Sacc. \& Cub., Syll. fung. (Abellini) 5: 672 (1887)

Material estudiado: O Porriño, Budiño, Orbenlle, observatorio ornitológico, 29TNG3061, 22 m, sobre restos de Salix atrocinerea, 16/08/2014, O. Requejo, LOUFungi 19971.

Ecología y distribución: recolectado en verano, próximo a la laguna sobre restos de Salix atrocinerea.

Georreferenciado para Europa occidental y Canadá (GBIF en línea, $n^{\circ}$ 5241244). Ampliamente extendido en Galicia (Rodríguez-Vázquez \& Castro 2001). 
Pluteus poliocnemis Kühner, in Kühner \& Romagnesi, Bull. trimest. Soc. mycol. Fr. 72 (3): 182 (1956)

Material estudiado: Salceda de Caselas, desembocadura del río Becerreira, 29TNG3019, 20 m, sobre restos orgánicos, 10/11/2015, O. Requejo, LOU-Fungi 20529.

Ecología y distribución: ha sido recolectado en bosque de ribera, entre restos de Salix atrocinerea.

Parece tratarse de una especie rara, georreferenciada en Centroeuropa sólo en 6 ocasiones (GBIF en línea, $\left.n^{\circ} 5449879\right)$, también rara en la Península Ibérica (Justo et al. 2005). No la conocemos citada para Galicia.

Lentinus arcularius (Batsch) Zmitr., International Journal of Medicinal Mushrooms (Redding) 12(1): 88 (2010)

$\equiv$ Polyporus arcularius (Batsch) Fr., Syst. mycol. (Lundae) 1: 342 (1821)

Material estudiado: O Porriño, Budiño, Orbenlle, observatorio ornitológico, 29TNG3061, 22 m, sobre rama de Quercus robur, 01/09/2014, O. Requejo, LOU-Fungi 19973.

Ecología y distribución: recolectado sobre rama caída de Quercus robur a finales de verano en bosque no inundable.

Taxón frecuente, referenciado tanto para el Hemisferio Norte como para el Sur, a excepción del continente africano. Común en la Península Ibérica (GBIF en línea, $n^{\circ}$ 5246898). Ampliamente distribuido por Galicia (Rodríguez-Vázquez \& Castro 2016).

Polyporus tuberaster (Jacq. ex Pers.) Fr., Syst. mycol. (Lundae) 1: 347 (1821)

Material estudiado: O Porriño, Budiño, Orbenlle, Os Eidos, 29TNG3022, 30 m, sobre madera sin identificar, 30/04/2014, O. Requejo, LOU-Fungi 19937.Tui, Guillarei, turbera de Albelos, 29TNG3036, $20 \mathrm{~m}$, sobre madera sin identificar, 28/08/2015, Cesar Ayres, LOU-Fungi 20259.

Ecología y distribución: muy común durante todo el año sobre ramas caídas en bosques mixtos de frondosa.

Especie georreferenciada para Europa occidental, Japón, Canadá y Australia (GBIF en línea, $\mathrm{n}^{\circ}$ 5246979). Extendido por Galicia (RodríguezVázquez \& Castro 2001). 
Porodaedalea pini (Brot.) Murrill, Bull. Torrey bot. Club 32(7): 367 (1905)

$\equiv$ Phellinus pini (Brot.) A. Ames, Annales Mycologici 11 (3): 246 (1913)

Material estudiado: O Porriño, Pontellas, barreras de Centeáns, 29TNG3007, 20 m, sobre Pinus pinaster, 22/12/2014, O. Requejo, LOU-Fungi 19861.Tui, Ribadelouro, Puente de la Madalena, 29TNG2992, 26 m, sobre Pinus pinaster, 09/08/2015, O. Requejo, LOU-Fungi 20241.

Ecología y distribución: especie parásita, muy frecuente sobre troncos de viejos Pinus pinaster.

Extensamente georreferenciada en el Hemisferio Norte (GBIF en línea, nos 2519825 y 2519833 como Phellinus). Común en Galicia (Soliño et al. 2000).

Postia subcaesia (A. David) Jülich, Persoonia 11 (4): 424 (1982)

三Tyromyces subcaesius A. David, Bull. mens. Soc. linn. Lyon 43: 120 (1974)

Material estudiado: Salceda de Caselas, Cerquido, Ponte Carneiro 29TNG3164, 35 m, sobre madera de Alnus glutinosa, 21/01/205, O. Requejo, LOU-Fungi 20012.

Ecología y distribución: ha sido encontrada en bosque inundable, sobre rama caída de Alnus glutinosa.

Su distribución no es muy concreta, ya que se consideraba la misma especie que $P$. caesia (Schrad.) P. Karst., aun así, la encontramos referenciada de Centroeuropa, países nórdicos, Islas Británicas, modificado mapa a 25/06/2016 (GBIF en línea, $n^{\circ}$ 109006). Ampliamente citado en Galicia (Rodríguez-Vázquez $\&$ Castro 2016) por lo que seguro que en la Península está más repartido de lo que reflejan las citas bibliográficas. De todas estas menciones se justifica una revisión por la posible confusión con Oligoporus alni (Niemelä \& Vampola) Piątek.

Psathyrella candolleana (Fr.) Maire, Bull. Soc. mycol. Fr.: 185 (1913)

Material estudiado: Salceda de Caselas, desembocadura del río Becerreira, 29TNG3019, 20 m, entre restos leñosos y herbáceos, 31/07/2015, O. Requejo, LOU-Fungi 20231.

Ecología y distribución: muy común descomponiendo restos herbáceos y detritus orgánicos después de lluvias estivales.

Especie frecuentemente observada en todo el Hemisferio Norte, incluida la Península Ibérica, también en la región macaronésica, Chile, Australia y Nueva Zelanda (GBIF en línea, no 2534852). Común en Galicia (Soliño et al. 1999). 
Psathyrella spadiceogrisea (Schaeff.) Maire, Mém. Soc. Sci. Nat. Maroc. 45: 113 (1937)

Material estudiado: O Porriño, Budiño, Orbenlle, observatorio ornitológico, 29TNG3061, 22 m, entre restos orgánicos bajo Salix atrocinerea y Osmunda regalis, 13/08/2014, O. Requejo, LOU-Fungi 19947.

Ecología y distribución: común entre restos de hojas y restos orgánicos en bosques mixtos muy sombríos, incluso inundables.

Taxón frecuente en Europa occidental, pero también referenciado para Brasil, Rusia, Japón y Australia (GBIF en línea, nº 23535021). En Galicia sólo se conoce de las provincias litorales (Rodríguez-Vázquez \& Castro 2001).

Pseudoboletus parasiticus (Bull.) Šutara, Česká Mykol.45 (1-2): 2 (1991)

三Xerocomus parasiticus (Bull.) Quél., Fl. mycol. France (Paris): 418 (1888)

Material estudiado: O Porriño, Budiño, Orbenlle, observatorio ornitológico, 29TNG3061, 22 m, sobre Scleroderma citrinum, 01/09/2014, R. Requejo, LOU-Fungi 19967. Salceda de Caselas, desembocadura del río Becerreira, 29TNG3019, 20 m, sobre Scleroderma citrinum, 26/09/2015, O. Requejo. LOU-Fungi 20270. Scleroderma.

Ecología y distribución: recolectada a finales de verano, sobre

Especie extendida, aunque no frecuente en Europa occidental y costa oriental de Canadá (GBIF en línea, ${ }^{\circ}$ 2524803). También en Galicia (RodríguezVázquez \& Castro 2001).

Pseudocraterellus undulatus (Pers.) Rauschert, Feddes Repertorium 98 (1112): 661 (1987)

= Pseudocraterellus sinuosus (Fr.) Corner, Beih. Sydowia 1: 268 (1958) [1956]

Material estudiado: O Porriño, Budiño, Orbenlle, Os Eidos, 29TNG3022, 30 m, en talud de tierra musgoso, bajo Pinus pinaster y Quercus robur, 29/11/2014, O. Requejo, LOU-Fungi 19838. Salceda de Caselas, desembocadura del río Becerreira, 29TNG3019, 20 m, bajo Quercus robur y Alnus glutinosa, 26/09/2015, O. Requejo, LOU-Fungi 20280.O Porriño, Budiño, Orbenlle, observatorio ornitológico, 29TNG3061, 22 m, bajo Quercus robur, 01/12/2015, O. Requejo, LOU-Fungi 20534.

Ecología y distribución: común en los bosques mixtos no inundables de la zona de estudio en lugares donde está presente Quercus robur.

Taxón ampliamente georreferenciado en Europa, incluida la Península Ibérica, también mencionada para Canadá, Centroamérica, Japón y Australia (GBIF en línea, $\mathrm{n}^{\circ}$ 2554613). Muy conocido en todo en Galicia (Rodríguez-Vázquez \& Castro 2016). 


\section{Psilocybe coprophila (Bull.) P. Kumm., Führ. Pilzk. (Zerbst): 71 (1871)}

Material estudiado: O Porriño, Budiño, Orbenlle, observatorio ornitológico, 29TNG3061, 22 m, sobre excrementos de cabalo, 22/09/2014, O. Requejo, LOU-Fungi 19782.

Ecología y distribución: hongo fimícola (Noordeloos 2011), hallado sobre excrementos de caballo.

Especie frecuente en la Galicia septentrional (Soliño et al. 1999) y ampliamente referenciada en el Hemisferio Norte, Australia y Nueva Zelanda (GBIF en línea, $n^{\circ}$ 45242467). Novedad provincial.

Ramariopsis pulchella (Boud.) Corner, Monograph of Clavaria and allied Genera (Ann. Bot. Memoirs 1): 645 (1950)

Material estudiado: O Porriño, Budiño, Orbenlle, observatorio ornitológico, 29TNG3061, 22 m, bajo Osmunda regalis, 07/10/2013, O. Requejo, LOU-Fungi 19990.

Observaciones: presenta basidiosporas verrucosas de 3-55 X 2,5-3,5 (4) $\mu \mathrm{m}$, fíbulas abundantes y basidios tetraspóricos de $20 \times 4 \mu \mathrm{m}$, coincidente con Breitenbach \& Kränzlin (1986).

Ecología y distribución: el material estudiado se recolectó directamente en el interior de la turbera, en una zona habitualmente inundada, bajo Salix atrocinerea y Alnus glutinosa.

Se trata de un taxón referenciado especialmente para Centroeuropa y países nórdicos, además de la Península Ibérica, También en Brasil y Australia (GBIF en línea, $n^{\circ}$ 2540204). No la conocemos mencionada para Galicia.

Resupinatus applicatus (Batsch) Gray, A natural arrangement of British plants 1: 617 (1821)

Material estudiado: O Porriño, Budiño, Orbenlle, observatorio ornitológico, 29TNG3061, 22 m, sobre rama de Salix atrocinerea, 30/04/2014, O. Requejo, LOU-Fungi 19942.

Ecología y distribución: recolectado en bosque mixto, sobre rama caída de Salix atrocinerea.

Está ampliamente citado del Hemisferio Norte y Australia, también se conoce de Brasil (GBIF en línea, $\mathrm{n}^{\circ}$ 2532215). Y para Galicia, ha sido mencionado en las provincias de A Coruña, Lugo y Pontevedra (RodríguezVázquez \& Castro 2016). 
Rhizopogon luteolus Fr., in Fries \& Nordholm, Symb. gasteromyc. (Lund) 1: 5 (1817)

Material estudiado: O Porriño, Budiño, Orbenlle, Os Eidos, 29TNG3022, $30 \mathrm{~m}$, en talud de tierra bajo Pinus pinaster, 15/01/2016, O. Requejo, LOU-Fungi 20597. Tuy, Rebordanes, Ponte das Febres 29TNG2996, 21 m, en muro de tierra con bosque de Quercus robur y Pinus pinaster, 15/10/2015, Marta Martínez, LOU-Fungi 20650.

Observaciones: la colección LOU-Fungi 20650, cuenta con un único ejemplar de dimensiones reducidas; pero que se identifica por el color amarillento del peridio que no enrojece al tacto, rizomas pardos, gleba parda olivácea y basidiosporas elípticas (Jülich, 1980).

Ecología y distribución: especie micorrizógena, común en taludes de tierra en bosques mixtos de Quercus robur y Pinus pinaster.

Ampliamente referenciada en Europa occidental, Australia y Nueva Zelanda (GBIF en línea, n 2524248). Común en Galicia (Soliño et al. 2000).

\section{Rhodocollybia butyracea (Bull.) Lennox, Mycotaxon 9 (1): 218 (1979)}

Material estudiado: O Porriño, Budiño, Orbenlle, Os Eidos, 29TNG3022, 30 m, bajo Quercus robur y Pinus pinaster, 07/10/2013, O. Requejo, LOU-Fungi 20228.

Ecología y distribución: especie humícola muy común en toda la zona de estudio, bajo frondosas en bosques no inundables.

Taxón extremadamente frecuente en Europa occidental, pero también ampliamente observada en América central y del norte y Australia (GBIF en línea, $\mathrm{n}^{\circ}$ 3321187). Muy frecuente en Galicia y ampliamente extendida (Rodríguez-Vázquez \& Castro 2016).

Rickenella fibula (Bull.) Raithelh., Metrodiana 4: 67 (1973)

Material estudiado: O Porriño, Budiño, Orbenlle, observatorio ornitológico, 29TNG3061, 22 m, entre musgos, 27/11/2013, O. Requejo, LOU-Fungi 19945. O Porriño, Pontellas, barreras de Centeáns, 29TNG3007, 20 m, entre musgos, 19/12/2015, O. Requejo, LOU-Fungi 20557. O Porriño, Pontellas, barreras de Centeáns, 29TNG3007, 20 m, entre musgos bajo Erica ciliaris, 22/12/2014, O. Requejo, LOU-Fungi 19885.

Observaciones: la colección 19885 presenta basidiocarpo blanco, excepto la base del estipe anaranjada, las basidiosporas son pequeñas, de 5,6-6 x 2,5 $\mu \mathrm{m}$ (Antonín \& Noordeloos 2004), parece tratarse de una forma albina.

Ecología y distribución: muy común entre briófitos en suelos sombreados o sobre árboles con troncos musgosos. 
Referenciada en el Hemisferio Norte, también observada en Sudamérica, Australia y Nueva Zelanda (GBIF en línea, $n^{\circ}$ 2523473). Ampliamente citada en Galicia (Rodríguez-Vázquez \& Castro 2016).

Rickenella mellea (Singer \& Clémençon) Lamoure, Beih. Sydowia, 8: 251, 1979

Material estudiado: O Porriño, Budiño, Orbenlle, observatorio ornitológico, 29TNG3061, 22 m, entre Sphagnum sp.07/09/2014, P. Veiga, LOU-Fungi 19944.

Observaciones: basidioma omfalinoide, hasta $10 \mathrm{~mm}$ de diámetro, de color pardo amarillento, algo más oscuro en el ombligo, con láminas subdecurrentes, separadas y escasas. Basidiosporas hialinas, cilíndricas, alguna con una estrangulación central, de 5-7 x 2,5-3 mm. Pleurocistidios semejantes a los queilocistidios, lageniformes, rara vez capitados.

Ecología y distribución: recolectada en turbera parasitando Sphagnum sp. en zona sombría. Rara.

Georreferenciada en Estados Unidos, Centroeuropa, países nórdicos y Nueva Zelanda (GBIF en línea, $\mathrm{n}^{\circ}$ 2523471), conocemos una cita ibérica en Asturias (Rubio-Domínguez en línea). No la conocemos mencionada para Galicia.

Roridomyces roridus (Fr.) Rexer, Die Gattung Mycena s.l., Studien zu Ihrer Anatomie, Morphologie und Systematik (Tübingen): 132 (1994)

इ Mycena rorida (Fr.) Quél., Mém. Soc. Émul. Montbéliard, Sér. 2 5: 108 (1872)

Material estudiado: O Porriño, Budiño, Orbenlle, Os Eidos, 29TNG3022, 30 m, sobre pequeñas ramas sin identificar, 07/10/2013, G. Requejo, LOU-Fungi 19943.Tui, Guillarei, Albelos, 29TNG3043, 13 m, sobre pequeñas ramas, 09/11/2015, LOU-Fungi 20503. Tui, Guillarei, aliseda de Albelos, 29TNG3019, 20 m, sobre ramas de Rubus sp., 22/12/2015, O. Requejo, LOU-Fungi 20555.

Ecología y distribución: muy común en bosques mixtos de todo tipo, sobre pequeñas ramas o restos herbáceos .

Frecuente y fácilmente identificable macroscópicamente. Georreferenciado del Hemisferio norte, también mencionada para Australia (GBIF en línea, $n^{\circ}$ 2527736). Común en la zona de estudio y ampliamente citada para Galicia (Soliño et al. 1999). 
Russula albonigra (Krombh.) Fr., Hymenomyc. Eur. (Upsaliae): 440 (1874)

Material estudiado: Salceda de Caselas, desembocadura del río Becerreira, 29TNG3019, 20 m, bajo Quercus robur y Alnus glutinosa, 26/09/2015, O. Requejo, LOUFungi 20272.

Ecología y distribución: el material estudiado se recolectó en bosque mixto muy sombrío, no inundable, de Quercus robur y Alnus glutinosa.

Referenciada para América del Norte y Europa occidental, también para las Islas Canarias, Japón, Australia y Tasmania (GBIF en línea, nº 2551443). Común en Galicia (Soliño et al. 2000).

Russula amoena Quél., Compt. Rend. Assoc. Franç. Avancem. Sci. 9: 668 (1881)

Material estudiado: O Porriño, Budiño, Orbenlle, Os Eidos, 29TNG3022, $30 \mathrm{~m}$, bajo Quercus robur, 29/11/2014, O. Requejo, LOU-Fungi 20234.

Ecología y distribución: fructificaba en bosque no inundable de Quercus robur.

Observada en el centro y sur de Europa, también en Japón (GBIF en línea, no 2551233). Común en Galicia (Soliño et al. 2000).

Russula amoenicolor Romagn., Bull. mens. Soc. linn. Lyon 31 (1): 175 (1962)

Material estudiado: O Porriño, Budiño, Orbenlle, observatorio ornitológico, 29TNG3061, 22 m, bajo Quercus robur y Alnus glutinosa, 03/11/2013, O. Requejo, LOUFungi 20612.

Ecología y distribución: recolectada bajo Quercus robur y Alnus glutinosa en zona no inundable, próxima a la laguna.

Georreferenciada en Suecia, Dinamarca, Centroeuropa, Austria y Andalucía (GBIF en línea, $n^{\circ}$ 2551477). Mencionada en Galicia sólo para las provincias de Lugo (Marcote et al. 2011) y Pontevedra (Requejo, 2012).

Russula amoenolens Romagn., Contribution a l'etude de quelques Aspergilles 21: 111 (1952)

Material estudiado: Salceda de Caselas, desembocadura del río Becerreira, 29TNG3019, 20 m, bajo Quercus robur y Alnus glutinosa, 12/09/2015, O. Requejo, LOUFungi 20532. 
Ecología y distribución: el material estudiado fructificaba a finales de verano en bosque de Quercus robur y Alnus glutinosa.

Observada con frecuencia en Europa occidental y Nueva Zelanda, también en Canadá (GBIF en línea, nº 2551439). Común en Galicia (Soliño et al. 2000).

Russula atropurpurea (Krombh.) Britzelm., Botan. Zbl. 54: 99 (1893)

Material estudiado: O Porriño, Budiño, Orbenlle, Os Eidos, 29TNG3022, 30 m, en bosque mixto de Pinus pinaster y Quercus robur, 15/10/2016, Marta Martínez, LOUFungi 20646.

Ecología y distribución: fructificaba bajo Quercus robur y Pinus pinaster en zona no inundable.

Taxón bien representado en el Hemisferio norte (GBIF en línea, ${ }^{\circ}$ 2551470) donde parece ser común en bosque de caducifolios. En Galicia se citó repetidas veces en las cuatro provincias (Rodríguez-Vázquez \& Castro 2016).

Russula caerulea Fr., Epicr. syst. mycol. (Upsaliae): 353 (1838) [1836-1838]

Material estudiado: O Porriño, Budiño, Orbenlle, Os Eidos, 29TNG3022, $30 \mathrm{~m}$, en bosque mixto de Pinus pinaster y Quercus robur, 15/10/2016, Marta Martínez, LOUFungi 20648.

Ecología y distribución: fructificaba bajo Quercus robur y Pinus pinaster en zona no inundable.

Muy común en el norte de Europa, especialmente en Suecia y Noruega, también en Reino Unido (GBIF en línea, n 7960831). En la Península Ibérica muestra una amplia distribución de norte a sur (Monedero 2011, Picón 2004, Rubio-Domínguez et al. 2006, Moreno-Arroyo 2004). Para Galicia está citada en las cuatro provincias (Rodríguez-Vázquez \& Castro 2016).

Russula chloroides (Krombh.) Bres., Fung. trident. 2 (14): 89 (1900)

Material estudiado: Tui, Guillarei, Albelos, 29TNG3036, 20 m, bajo Quercus robur, 29/08/2015, J. Valeiras \& O. Requejo, LOU-Fungi 20285.

Ecología y distribución: fructificaba bajo Quercus robur y Salix atrocinerea en una zona de prado higroturboso.

Intensamente referenciada para Europa occidental, incluidas las islas y la Península Ibérica, también observada en China, Japón, Estados Unidos y Canadá (GBIF en línea, $n^{\circ}$ 2551426). Común en Galicia (Soliño et al. 2000). 
Russula cyanoxantha (Schaeff.) Fr., Monogr. Hymenomyc. Suec. (Upsaliae) 2 (2): 194 (1863)

Material estudiado: O Porriño, Budiño, Orbenlle, observatorio ornitológico, 29TNG3061, 22 m, bajo Alnus glutinosa, 10/08/2013, O. Requejo, LOU-Fungi 19978.

Ecología y distribución: común en todo tipo de bosques de frondosas, no inundables, riparios e incluso en los bordes de los aluviales.

Al tratarse de una especie comestible se ha referenciado por todo el Hemisferio norte, así como Australia (GBIF en línea, nº 2331542). Común en Galicia (Soliño et al. 2000).

Russula densifolia Secr. ex Gillet, Hyménomycètes (Alençon): 231 (1876) [1878]

Material estudiado: O Porriño, Budiño, Orbenlle, observatorio ornitológico, 29TNG3061, 22 m, bajo Quercus robur, 03/11/2013, O. Requejo, LOU-Fungi 19783. Tuy, Rebordanes, Ponte das Febres 29TNG2996, 21 m, en bosque mixto de Pinus pinaster y Quercus robur, 22/10/2016, O. Requejo, LOU-Fungi 20656.

Ecología y distribución: relativamente común en bosques mixtos no anegados, aunque la colección LOU-Fungi 19783 fructificaba muy próxima a la laguna y zona inundable.

Taxón ampliamente georreferenciado en el Hemisferio norte (GBIF en línea, no 2551191). Común en Galicia (Soliño et al. 2000).

Russula emetica (Schaeff.) Pers., Observ. mycol. (Lipsiae) 1: 100 (1796)

Material estudiado: O Porriño, Budiño, Orbenlle, observatorio ornitológico, 29TNG3061, 22 m, en bosque mixto con Quercus robur, Pinus pinaster, Alnus glutinosa y Salix atrocinerea, 03/11/2013, O. Requejo, LOU-Fungi 20613.

Observaciones: este taxón se encuadra en un complejo grupo de especies de píleo rojo vivo, estipe y láminas blancos y sabor extremadamente picante. La cutícula de esta colección presenta coloración uniforme, con la subcutícula de color rosado y basidiosporas hasta $11 \mu \mathrm{m}$ de largo, lo que parece caracterizar a Russula emetica y diferenciarla de $R$. nobilis Velen. y R. silvestris (Singer) Reumax (Sarnari 1998, Monedero 2011, Kränzlin 2005). En este caso tampoco ayuda en la identificación el hábitat, ya que, ha aparecido en un bosque mixto con el suelo del muy húmedo, recubierto en algunas zonas por Sphagnum sp y Polytrichum sp. 
Ecología y distribución: varios ejemplares muy dispersos entre ellos en zona mixta con gran variedad arbórea, lo que dificulta saber con qué especie establecía simbiosis.

Se trata de una especie ampliamente referenciada en Europa occidental, incluida Península Ibérica, Japón, Estados Unidos, Canadá, Colombia, Chile y Australia (GBIF en línea, $n^{\circ}$ 2551213), pero debería de revisarse su distribución al tratarse de un grupo taxonómico complejo. Común en Galicia (Soliño et al. 2000).

Russula fragrans Romag., Bull. mens. Soc. linn. Soc. Bot. Lyon 23: 112 (1985)

Material estudiado: O Porriño, Budiño, Orbenlle, observatorio ornitológico, 29TNG3061, 22 m, bajo Quercus robur, 03/11/2013, O. Requejo, LOU-Fungi 19785.

Ecología y distribución: recolectada en bosque mixto no anegado, claramente bajo Quercus robur, aunque fructificaba muy próxima a la laguna y a una zona inundable.

Especie escasamente referenciada, sólo de Centroeuropa, Eslovenia y Península Ibérica (GBIF en línea, $\mathrm{n}^{\mathrm{0}}$ 3360500), aunque se trata de un taxón común, es fácilmente confundible con $R$. grata Britzelm. $(=R$. laurocerasi Melzer) con coloraciones idénticas y olor a laurel cerezo, no tan neto a almendras amargas. Común en Galicia (Soliño et al. 2000).

Russula fragrantissima Romagn., Russules d'Europe Afr. Nord: 350 (1967)

Material estudiado: Tuy, Rebordanes, Ponte das Febres 29TNG2996, 21 m, bajo Quercus robur y Castanea sativa, 22/10/2016, O. Requejo, LOU-Fungi 20658.

Observaciones: sombrero globoso e irregular, con tonalidades pardas, pardo rojizas, ocres y alguna zona blanquecina. El estipe se oxida al manipularla y la carne, al corte. Olor agradable con un cierto componente a almendras amargas. Esporas globosas a subglobosas de (7,5)8-10 x 7,5-8,5 $\mu \mathrm{m}$ con espinas que forman retículos parciales y epicutis compuesto por pelos de hasta $6 \mu \mathrm{m}$ de ancho la caracterizan (Monedero (2011).

Ecología y distribución: fructificaba bajo caducifolias en terreno no anegado. 
Aunque poco referenciada está presente en el Hemisferio norte, Europa y continente americano, donde hay una cita aislada en Alaska (GBIF en línea, $\mathrm{n}^{\circ}$ 2551289). En la Península Ibérica podría considerarse una especie rara (Picón 2004, Calonge \& Pérez de Gregorio 2002, Rubio et al. 2005, Monedero 2011). No encontramos citas para Galicia.

Russula medullata Romagn., Doc. mycol. 27 (106): 53 (1997)

Material estudiado: Salceda de Caselas, desembocadura del río Becerreira, 29TNG3019, 20 m, bajo Alnus glutinosa y Quercus robur, 31/07/2015, J. Valeiras, LOUFungi 20589.

Observaciones: resulta fácil su identificación por las láminas de color ocre amarillento al principio, después más oscuras e incluso ocre rosado, junto con las basidiosporas ornamentadas con verrugas aisladas (Sarnari 1998, Monedero 2011). Sin embargo, la longitud esporal de esta colección es ligeramente menor de lo esperado, 5,5-7,5 x 5-6,3 $\mu \mathrm{m}$.

Ecología y distribución: fructifican en zona mixta de Alnus glutinosa y Quercus robur, muy sombría y húmeda ya que limita con un bosquete aluvial.

Frecuentemente referenciada en los países nórdicos y Europa Central, así como en el País Vasco (Península Ibérica) y Canadá (GBIF en línea, $\mathrm{n}^{\circ}$ 2551339). En Galicia sólo la conocemos citada de Lugo (Castro et al. (1989).

Russula melzeri Zvára, De Schimmelgeslachten Monilia, Oidium, Oospora en Torula, Scheveningen 7 (3-4): 82 (1927)

Material estudiado: Tui, Guillarei, Albelos, 29TNG3043, 13 m, bajo Alnus glutinosa y Quercus robur, 09/11/2015, O. Requejo, LOU-Fungi 20508.

Observaciones: el pequeño tamaño, la cutícula aterciopelada y fisurada, de color carmín, la carne de sabor dulce, olor agradable y esporada ocre la identifican perfectamente (Monedero 2011, Kränzlin 2005, Sarnari 2005).

Ecología y distribución: el material estudiado ha sido recolectado en suelo desnudo y turboso de un bosque aluvial de Alnus glutinosa, en cuyos bordes crece algún Quercus robur.

Escasamente georreferenciado, sólo en Dinamarca, Suecia, Alemania, Polonia y Austria (GBIF en línea, $\mathrm{n}^{\circ}$ 2551175). En Galicia sólo había sido observada en A Coruña (Traba Velay 2013). 
Russula minutula Velen., České Houby 1: 133 (1920)

Material estudiado: O Porriño, Budiño, Orbenlle, observatorio ornitológico, 29TNG3061, 22 m, en turbera, zona inundada, bajo Salix atrocinerea y Alnus glutinosa, 01/12/2015, O. Requejo, LOU-Fungi 20545.

Observaciones: píleo de color rojo carmín, carne muy frágil, sabor dulce y esporada blanca, lo que la diferencia de otras pequeñas Russula de color rojo como $R$. melzeri Zvára. Microscópicamente presenta en el epicutis hifas primordiales septadas, de 2,5-4 $\mu \mathrm{m}$, ornamentadas con granulaciones (Sarnari 2005).

Ecología y distribución: fructificaba bajo el estrato arbóreo que rodea la turbera, en suelo muy húmedo e inundable.

Georreferenciada en Centroeuropa, países nórdicos, País Vasco (Península Ibérica) e India (GIBF en línea $n^{\circ}$ 2551176). No la conocemos citada de Galicia.

Russula nigricans Fr., Epicr. syst. mycol. (Upsaliae): 350 (1838)

Material estudiado: O Porriño, Budiño, Orbenlle, observatorio ornitológico, 29TNG3061, 22 m, bajo Quercus robur y Alnus glutinosa, 22/09/2014, O. Requejo, LOUFungi 19780.

Ecología y distribución: común en toda la zona de estudio, sobre todo en bosques mixtos de Quercus robur y Pinus pinaster no anegados, aunque la colección citada crecía en el borde de la laguna donde también había Alnus glutinosa.

Debido a la dificultad taxonómica que presenta este grupo se conoce mal su distribución mundial (GBIF en línea, $\mathrm{n}^{\circ}$ 11209426). Especie común en la Península Ibérica (Monedero 2011), también en Galicia (Soliño et al. 2000).

Russula ochroleuca Fr., Epicr. syst. mycol. (Upsaliae): 358 (1838)

Material estudiado: O Porriño, Budiño, Orbenlle, observatorio ornitológico, 29TNG3061, 22 m, bajo Quercus robur, 03/11/2013, O. Requejo, LOU-Fungi 19786.

Ecología y distribución: fructificaba en el claro de un bosque de Quercus robur con algún Alnus glutinosa próximo, al pie de la laguna.

Se trata de una especie común en Europa, pero también citada de Norteamérica y Japón (GBIF en línea, $n^{\circ}$ 2551419). Ampliamente citada en Galicia (Soliño et al. 2000). 
Russula praetervisa Sarnari, Monografia Illustrata del Genere Russula in Europa 1: 463 (1998)

Material estudiado: Salceda de Caselas, Cerquido, Ponte Carneiro, 29TNG3164, 35 m, bajo Quercus robur, 27/11/2015, O. Requejo, LOU-Fungi 20543.

Ecología y distribución: recolectada en el suelo herbáceo de un pequeño bosque ripario, bajo Quercus robur.

Se conoce de Centroeuropa, Inglaterra, Irlanda, Península Ibérica y Norteamérica, no georreferenciada (GBIF en línea). Para Galicia sólo aparece mencionada en A Coruña (Marcote et al. 2011).

Russula pseudoaeruginea (Romagn.) Kuyper \& Vuure, Persoonia 12 (4): 451 (1985)

Material estudiado: O Porriño, Budiño, Orbenlle, observatorio ornitológico, 29TNG3061, 22 m, bajo Quercus robur y Salix atrocinerea, 16/08/2014, O. Requejo, LOU-Fungi 19777.

Observaciones: según Monedero (2011) es una especie con preferencia por encinares calcáreos, sin embargo, Kränzlin (2005) la recoge como una especie relacionada con bosques de Quercus húmedos, de suelos neutros a ligeramente ácidos y Sarnari (1998) comenta una recolecta bajo abedules y chopos temblones en suelo paludoso y ácido. Sería necesario revisar más colecciones de diferentes procedencias para conocer bien su autoecología.

Ecología y distribución: recolectado en sauceda aluvial, bajo Salix atrocinerea y Quercus robur. Fructificaba en verano, en épocas que no está anegada, entre hojas caídas y briófitos, muy próxima a la colección LOU-Fungi 20604 de Russula sphagnophila.

Especie poco frecuente, que sólo aparece georreferenciada para Suecia, Dinamarca, Checoslovaquia y Península Ibérica (GBIF en línea, $n^{\circ} 2551555$ ). No la conocemos mencionada de Galicia.

Russula sardonia Fr., Epicr. syst. mycol. (Upsaliae): 353 (1838)

Material estudiado: O Porriño, Pontellas, barreras de Centeáns, 29TNG3007, 20 m, bajo Pinus pinaster, 22/12/2014, C. Ayres, LOU-Fungi 19879. Ibídem, 19/12/2015, O. Requejo, LOU-Fungi 20560.

Ecología y distribución: observada en su hábitat típico, coníferas (Monedero 2011), muy común bajo Pinus pinaster.

Extremadamente común en Europa, incluida Península Ibérica, pero también referenciada para Sudamérica y sur de África (GBIF en línea, $\mathrm{n}^{\circ}$ 2551274). Ampliamente extendida en Galicia (Soliño et al. 2000). 
Russula sphagnophila Kauffman, Report Mich. Acad. Sci. 11: 86 (1909)

Material estudiado: O Porriño, Budiño, Orbenlle, observatorio ornitológico, 29TNG3061, 22 m, bajo Quercus robur y Alnus glutinosa, 03/11/2013, O. Requejo, LOUFungi 20615. O Porriño, Budiño, Orbenlle, observatorio ornitológico, 29TNG3061, 22 m, bajo Quercus robur y Salix atrocinerea, 16/08/2014, O. Requejo, LOU-Fungi 20604.

Observaciones: los ejemplares de la colección LOU-Fungi 20604 destacan por el pequeño tamaño, ya que los píleos rondan los $10 \mathrm{~mm}$. La descripción macro y microscópica coincide con la de Kränzlin (2005), píleos con tonalidades rosadas, más oscuras en el centro, láminas blancas que viran a ocre, carne dulce, blanca que reacciona a rosa salmón o rosa pálido con sulfato ferroso. Basidiosporas de 7,5-10,5 x 6,5-8 $\mu \mathrm{m}$, con verrugas conectadas en retículo incompleto. Epicutis formado por pelos cilíndricos septados, de 2-5 $\mu \mathrm{m}$, pileocistidios septados, cilíndrico claviformes.

Algunas variedades de $R$. sphagnophila se han sinonimizado con $R$. nitida (Pers.) Fr. (Index Fungorum en línea, Sarnari, 2005), ya que esta cuando muestra color rosa intenso es semejante a $R$. sphagnophila, no obstante, tiene el estipe teñido de rosa, basidiosporas con verrugas escasamente conectadas, pileocistidios estrechos y es exclusiva de Betula (Moreno \& Lopéz, 1978; Monedero, 2011; Kränzlin, 2005).

Ecología y distribución: recolectada en sauceda aluvial, bajo Salix atrocinerea y Quercus robur. Fructificaba en verano, en épocas que no está anegada, entre hojas caídas y briófitos, la colección LOU-Fungi 20604 se encontraba muy próxima a $R$. pseudoaeruginea.

Debido a la confusión existente entre varios taxones próximos resulta imposible conocer su distribución mundial (GBIF en línea, $n^{\circ}$ 7240060). No encontramos referencias para la Península.

Russula subfoetens W.G. Sm., J. Bot., Lond. 11: 337 (1873)

Material estudiado: Salceda de Caselas, desembocadura del río Becerreira, 29TNG3019, 20 m, bajo Quercus robur y Alnus glutinosa, 12/09/2015, O. Requejo, LOUFungi 20531.

Observaciones: según Monedero (2011) la reacción rosa anaranjado al sulfato ferroso, las manchas ferruginosas en las láminas, el estipe grueso y cavernoso, el sabor ligeramente acre de las láminas, el olor desagradable, aunque ligero, así como las basidiosporas de 6,2-8,5 x 5-6,2 $\mu \mathrm{m}$, con pequeñas verrugas aisladas, y el epicutis formado por hifas septadas con pileocistidios fusiformes de hasta $8 \mu \mathrm{m}$ de ancho, algunos con un pequeño mucrón, permiten diferenciarla con precisión. 
Ecología y distribución: fructificaba en zona muy húmeda y sombría, aunque sin llegar a inundarse, bajo Quercus robur y Alnus glutinosa.

Ampliamente georreferenciada en Europa occidental, incluida Península Ibérica, pero también observada en Estados Unidos (GBIF en línea, no 8391773). En Galicia sólo se ha mencionado de Lugo (Marcote et al. 2011) y recientemente Pontevedra (De la Peña 2016).

Russula virescens (Schaeff.) Fr., Anteckn.Sver. Ätl. Svamp.: 50 (1836)

Material estudiado: O Porriño, Budiño, Orbenlle, Os Eidos, 29TNG3022, $30 \mathrm{~m}$, bajo Quercus robur, 07/09/2013, O. Requejo, LOU-Fungi 19979. Salceda de Caselas, desembocadura del río Becerreira, 29TNG3019, 20 m, bajo Quercus robur, 26/09/2015, O. Requejo, LOU-Fungi 20271.

Ecología y distribución: común bajo Quercus robur a finales de verano, principios de otoño. No se ha observado en zonas habitualmente anegadas.

Común en Europa occidental hasta Islandia, también en Estados Unidos y Asia oriental (GBIF en línea, no 2551423). Común en Galicia (Soliño et al. 2000).

Schizophyllum commune Fr. Observ. mycol. (Havniae) 1: 103 (1815)

Material estudiado: O Porriño, Pontellas, barreras de Centeáns, 29TNG3007, 20 m, sobre tronco de Pinus pinaster, 22/12/2014, J. Valeiras, LOU-Fungi 19860.Salceda de Caselas, Cerquido, Ponte Carneiro 29TNG3164, 35 m, sobre Pinus pinaster, 21/01/2015, O. Requejo, LOU-Fungi 20011. Salceda de Caselas, desembocadura del río Becerreira, 29TNG3019, $20 \mathrm{~m}$, sobre rama sin identificar, 10/11/2015, O. Requejo, LOU-Fungi 20510.

Ecología y distribución: frecuente, sobre ramas caídas y tocones de todo tipo de árboles, sobre todo en zonas no inundables.

Común en todo el mundo (GBIF en línea 5241128), también en Galicia (Soliño et al. 2000).

Scleroderma areolatum Ehrenb., Sylv. mycol. berol. (Berlin) 15: 27 (1818)

Material estudiado: O Porriño, Budiño, Orbenlle, observatorio ornitológico, 29TNG3061, 22 m, sobre Osmunda regalis, 07/10/2013, O. Requejo, LOU-Fungi 19964. Salceda de Caselas, desembocadura del río Becerreira, 29TNG3019, 20 m, bajo Alnus glutinosa, 31/07/2015, O. Requejo, LOU-Fungi 20237.Tui, Guillarei, Albelos, 29TNG3043, 13 m, bajo Quercus robur, 09/11/2015, O. Requejo, LOU-Fungi 20523. 
Observaciones: las basidiosporas de la colección LOU-Fungi 20237, alcanzan las 17,5 $\mu \mathrm{m}$, un poco más grandes que las indicadas por Calonge (1998), pero el pseudoestipe y la aureola amarilla alrededor de las escamas del peridio caracterizan la especie.

Ecología y distribución: común durante casi todo el año, aunque parece preferir ambientes riparios, la colección LOU-Fungi 19964, se recolectó en la turbera al pie de Osmunda regalis, posiblemente micorrizando con este.

Común en Europa occidental y Estados Unidos, también referenciada de Japón. Australia, Nueva Zelanda y Brasil (GBIF en línea, nº 5239963). Frecuente en la Península Ibérica (Calonge 1996) y Galicia (Soliño et al. 2000).

Scleroderma bovista Fr., Syst. Mycol. (Lundae) 3: 48 (1829)

Material estudiado: O Porriño, Budiño, Orbenlle, observatorio ornitológico, 29TNG3061, 22 m, bajo Quercus robur y Salix atrocinerea, 22/09/2014, O. Requejo, LOU-Fungi 19776. Salceda de Caselas, desembocadura del río Becerreira, bajo Quercus robur, 10/11/2015, O. Requejo, LOU-Fungi 20524.

Ecología y distribución: fácil de observar en zonas arenosas de bosques de frondosas y ripisilva, no así en bosques más húmedos.

Especie con amplia distribución mundial, también en la Península Ibérica (GBIF en línea, 5239977). Ampliamente extendido por Galicia (Soliño et al. 2000).

Scleroderma cepa Pers., Syn. meth. fung. (Göttingen) 1: 155 (1801)

Material estudiado: O Porriño, Budiño, Orbenlle, Os Eidos, 29TNG3022, 30 m, bajo Pinus pinaster y Quercus robur, 01/09/2014, O. Requejo, LOU-Fungi 19966.Salceda de Caselas, Cerquido, Ponte Carneiro, 29TNG3164, 35 m, en camino entre hierbas bajo Salix atrocinerea, 02/10/2014, O. Requejo, LOU-Fungi 20250. inundables.

Ecología y distribución: común en todo tipo de bosques, excepto en los

Muy frecuente en Europa, América del Norte, Australia y Nueva Zelanda, también referenciada de Japón y Sudamérica (GBIF en línea, ${ }^{\circ}$ 5239938). Común en Galicia (Soliño et al. 2000).

Scleroderma citrinum Pers., Syn. meth. fung. (Göttingen) 1: 153 (1801)

Material estudiado: O Porriño, Budiño, Orbenlle, observatorio ornitológico, 29TNG3061, 22 m, bajo Quercus robur y Pinus pinaster, 13/08/2014, O. Requejo, LOUFungi 19963. O Porriño, Budiño, Orbenlle, observatorio ornitológico, 29TNG3061, 22 m, bajo Quercus robur parasitado por Pseudoboletus parasiticus, 01/09/2014, R. Requejo, LOU-Fungi 19967. Salceda de Caselas, desembocadura del río Becerreira, 29TNG3019, $20 \mathrm{~m}$, en bosque de Quercus robur y Alnus glutinosa, parasitado por Pseudoboletus parasiticus, 26/09/2015, J.Á. Gándara y O. Requejo, LOU-Fungi 20270. 
Ecología y distribución: la especie más común del género en la zona de estudio, en ocasiones parasitada por Pseudoboletus parasiticus, sobre todo en épocas estivales.

Extremadamente abundante en Europa y Estados Unidos, también referenciada de Sudamérica, Canarias, Japón y Australia (GBIF en línea, $\mathrm{n}^{\circ}$ 5239982). Ampliamente extendido en Galicia (Soliño et al. 2000).

Scleroderma polyrhizum (J.F. Gmel.) Pers., Syn. meth. fung. (Göttingen) 1: 156 (1801)

Material estudiado: O Porriño, Pontellas, barreras de Centeáns, 29TNG3007, 20 m, en camino de tierra bajo Pinus pinaster, 22/12/2014, O. Requejo, LOU-Fungi 19862.

Ecología y distribución: la especie del género menos observada de la zona de estudio. Parece preferir los claros de los bosques más elevados de este espacio.

Muy frecuente en la Península Ibérica, pero también referenciada de Estados Unidos, Canarias, Japón, Australia y Nueva Zelanda (GBIF en línea, $\mathrm{n}^{\circ}$ 5239950). Se trata de la especie más común del género en Galicia (RodríguezVázquez \& Castro 2016).

Scleroderma verrucosum (Bull.) Pers., Syn. meth. fung. (Göttingen) 1: 154 (1801)

Material estudiado: O Porriño, Budiño, Orbenlle, observatorio ornitológico, 29TNG3061, 22 m, bajo Salix atrocinerea y Betula pubescens, 03/11/2013, O. Requejo, LOU-Fungi 19965.

Ecología y distribución: común, junto a $S$. areolatum, prefiere cualquier tipo de bosques y es la especie del género que más se acerca a zonas inundables.

Muy frecuente en Europa occidental, referenciada para Estados Unidos, Brasil, Japón, Tailandia, Australia y Nueva Zelanda (GBIF en línea, no 5239959). Común en Galicia (Soliño et al. 2000).

Sebacina epigaea (Berk. \& Broome) Bourdot \& Galzin, Hyménomyc.de France (Sceaux): 39 (1928) [1927]

Material estudiado: Salceda de Caselas, desembocadura del río Becerreira, 29TNG3019, 20 m, sobre tierra y musgos, 26/09/2015, J.Á. Gándara y O. Requejo, LOUFungi 20282.Tui, Guillarei, aliseda de Albelos, 29TNG3019, 20 m, sobre tierra y restos orgánicos, 10/11/2015, O. Requejo, LOU-Fungi 20521. 
Observaciones: basidioma de color blanco grisáceo, translúcido, con basidiosporas de 10-12 $\mu \mathrm{m}$ de largo, anchamente elípticas a subglobosas, en algunos casos amorfas y nodulosas. Basidios fragmentados longitudinalmente en cuatro epibasidios con largos esterigmas.

Ecología y distribución: ha sido recolectada sobre suelos muy húmedos y sombríos, pero no anegados, recubriendo todo tipo de superficies, tierra, musgos, madera, piedras, etc.

Georreferenciada de Europa occidental, incluida Península Ibérica, Estados Unidos, Caribe, China y Nueva Zelanda (GBIF en línea, $n^{\circ}$ 2522082). No conocemos menciones para Galicia.

Serpula himantioides (Fr.) P. Karst., Meddn Soc. Fauna Flora fenn. 11: 21 (1884)

Material estudiado: O Porriño, Budiño, Orbenlle, Os Eidos, 29TNG3022, $30 \mathrm{~m}$, sobre Pinus pinaster, 15/01/2015, O. Requejo, LOU-Fungi 20595.

Ecología y distribución: fructificaba sobre tronco y corteza de Pinus pinaster seco pero que aún se mantenía erguido.

Taxón del que es difícil conocer su distribución (GBIF en línea, $\mathrm{n}^{\mathrm{o}}$ 39383917), ya que se puede confundir con S. lacrymans (Wulfen) J. Schröt., más frecuente en interiores de edificaciones. Bien distribuido en la Península Ibérica (Lago-Álvarez 2008). En Galicia sólo se conoce de las provincias litorales (López-Prada \& Castro 1998, Lago-Álvarez 2008).

Sparassis crispa (Wulfen) Fr., Syst. mycol. (Lundae) 1: 465 (1821)

Material estudiado: Tui, Guillarei, Albelos, 29TNG3043, 13 m, bajo Pinus pinaster, 09/11/2015, O. Requejo, LOU-Fungi 20511.

Observaciones: fácilmente confundible con otros taxones del mismo género (Wang et al. 2004).

Ecología y distribución: a pesar de su ecología saprofita, se recolectó en la base de un Pinus pinaster vivo.

Frecuente en Europa occidental, también referenciado para Estados Unidos, Japón y Australia (GBIF en línea, n 2550247). Ampliamente extendida por Galicia (Soliño et al. 2000). 
Stereum gausapatum (Fr.) Fr., Hymen. europ.: 638 (1874)

Material estudiado: O Porriño, Budiño, Orbenlle, observatorio ornitológico, 29TNG3061, 22 m, sobre Quercus robur, 10/02/2014, O. Requejo, LOU-Fungi 19951. Salceda de Caselas, Cerquido, Ponte Carneiro, 29TNG3164, $35 \mathrm{~m}$, Sobre ramas de Quercus robur, 21/01/2015, O. Requejo, LOU-Fungi 20219.

Observaciones: en la colección LOU-Fungi 19951 se observaron basidiosporas de hasta $10 \mu \mathrm{m}$, pero los restantes caracteres coinciden con Benguria \& Martín (2008) y Breitenbach \& Kränzlin (1986). La trama delgada, que no llega a $1 \mathrm{~mm}$ y la ausencia de acantocistidios lo diferencian de $S$. rugosum Pers.

Ecología y distribución: común en bosque de Quercus robur, se observó como parásito y saprotrófico en diferentes ocasiones, sobre el tronco musgoso de roble o en ramas caídas de buén diámetro. La colección LOU-Fungi 19951 fructificaba al pie de la laguna.

Frecuente en Europa occidental y ampliamente distribuida por el resto del Hemisferio Norte, también referenciada para Brasil (GBIF en línea, $\mathrm{n}^{\circ}$ 2553078). En Galicia es conocido únicamente de la provincia de Pontevedra (Lago et al. 2003, De la Peña 2016).

Stereum hirsutum (Willd.) Pers., Observ. mycol. (Lipsiae) 2: 90 (1800) [1799]

Material estudiado: Salceda de Caselas, desembocadura del río Becerreira, 29TNG3019, $20 \mathrm{~m}$, sobre rama en bosque de Quercus robur y Alnus glutinosa, 12/09/2015, O. Requejo, LOU-Fungi 20267.Tui, Guillarei, Albelos, 29TNG3043, 13 m, sobre restos leñosos, 09/11/2015, O. Requejo, LOU-Fungi 20512. O Porriño, Pontellas, barreras de Centeáns, 29TNG3007, 20 m, sobre rama de Quercus robur, 19/12/2015, O. Requejo, LOU-Fungi 20559.

Observaciones: en la colección LOU-Fungi 20267 el espesor de los basidiomas rondaba $0,5 \mathrm{~mm}$, por lo que podría corresponder a Stereum ochraceoflavum (Schwein.) Sacc. (Benguria \& Martin 2008), pero el resto de los caracteres morfológicos y el tamaño de las basidiosporas (5-7 x 2-4 mm) conducen a S. hirsutum (Benguria \& Martin, 2008, Breitenbach \& Kranzlin 1986).

Ecología y distribución: ha sido recolectado como parásito y saprotrófico en diferentes ocasiones, siempre en bosques mixtos con caducifolios o ripisilvas. Muy frecuente en toda la zona de estudio, aunque no observado en zonas inundables.

Se trata probablemente de la especie más común y con mayor amplitud de distribución del género, ya que se referencia de todos los continentes, excepto África (GBIF en línea, $n^{\circ}$ 2553128). Muy abundante en Galicia (Soliño et al. 2000). 
Stereum ochraceoflavum (Schwein.) Sacc., Syll. fung. (Abellini) 6: 576 (1888)

Material estudiado: O Porriño, Budiño, Orbenlle, Os Eidos, 29TNG3022, 30 m, sobre pequeñas ramas sin identificar, 21/03/2013, O. Requejo, LOU-Fungi 19952. Tui, Rebordanes, Ponte das Febres 29TNG2996, 21 m, sobre ramas sin identificar, 03/07/2015, J. Valeiras, LOU-Fungi 20218.

Observaciones: basidioma resupinado, grueso, de color claro, basidiosporas elípticas, de 7-9 x 1,5-3 $\mathrm{mm}$ lo que permite diferenciarlo de Stereum hirsutum (Willd.) Pers. (Gibson 2012).

Ecología y distribución: es la especie del género que se muestra más estables en cuanto a apetencias tróficas, recolectado siempre como saprotrófico sobre pequeñas ramas caídas en bosques mixtos y riparios con frondosas. No observado en bosques aluviales.

No aparece georreferenciado en GBIF (en línea), aunque se conoce de la Península Ibérica, Eslovenia, Estonia, Alemania, Canarias, Estados Unidos, Australia. Extendido por casi toda Galicia, excepto Ourense (Rodríguez-Vázquez \& Castro 2016).

Suillus bovinus (L.) F. Roussel, Calvados: 34 (1796)

Material estudiado: O Porriño, Pontellas, barreras de Centeáns, 29TNG3007, 20m, bajo Pinus pinaster, 22/12/2014, J. Valeiras, Lou-Fungi 19863. O Porriño, Budiño, Orbenlle, Os Eidos, 29TNG3022, 30 m, bajo Pinus pinaster, 30/11/2014, O. Requejo, LOU-Fungi 19837.

Ecología y distribución: muy común en bosques donde está presente el Pinus pinaster, en ocasiones conviviendo con Gomphidius roseus.

Extremadamente frecuente en Europa occidental, desde Península Ibérica hasta Islandia, pero también se conoce de Estados Unidos, Japón y Australia (GBIF en línea, no 5239860). Común en Galicia (Soliño et al. 1999).

Tapinella atrotomentosa (Batsch) Šutara, Česká Mykol. 46(1-2): 50 (1992)

= Paxillus atrotomentosus (Batsch) Fr., Epicr. syst. mycol. (Upsaliae): 317 (1838)

Material estudiado: O Porriño, Budiño, Orbenlle, Os Eidos, 29TNG3022, 30 m, sobre tocón de Pinus pinaster, 15/10/2016, Marta Martínez, LOU-Fungi 20641.

Ecología y distribución: recolectado en su hábitat habitual, tocón de pino (Breitenbach \& Kränzlin 1991).

Ampliamente georreferenciada en Europa, también en América central y Estados Unidos, con alguna cita dispersa en Hawái y Japón (GBIF en línea, ${ }^{\circ}$ 5244304). Extendido en la Península, con mayor concentración de citas en el 
norte (Lago-Álvarez 2008). Común también en Galicia, citado en las cuatro provincias (Rodríguez-Vázquez \& Castro 2016).

Terana caerulea (Schrad. ex Lam.) Kuntze, Revisio generum plantarum 2: 872 (1891)

$\equiv$ Pulcherricium coeruleum (Lam.) Parmasto, Consp. System. Corticiac. (Tartu): 132 (1968)

Material estudiado: Salceda de Caselas, Cerquido, Ponte Carneiro, 29TNG3164, 35 m, sobre Quercus robur, 27/12/2014, O. Requejo, LOU-Fungi 19928. Tui, Guillarei, Albelos, 29TNG3043, 13 m, sobre madera de Quercus robur, 26/12/2015, J. Valeiras \& O. Requejo, LOU-Fungi 20566. O Porriño, Budiño, Orbenlle, Os Eidos, 29TNG3022, 30 m, sobre Vitis vinifera, 15/01/2015, O. Requejo, LOU-Fungi 20598.

Ecología y distribución: común, fructificando sobre una amplia variedad de especies, sobre madera muerta o incluso troncos de árboles vivos.

Especie ampliamente referenciada de forma dispersa por el Hemisferio Norte, también en Australia (GBIF en línea, $n^{\circ}$ 5244849). Frecuente en Galicia (Soliño et al. 2000).

Trametes hirsuta (Wulfen) Lloyd, Mycol. Writ. 7: 1319 (1924)

Material estudiado: O Porriño, Budiño, Orbenlle, observatorio ornitológico, 29TNG3061, $22 \mathrm{~m}$, sobre madera sin identificar, 12/05/2013, O. Requejo. LOU-Fungi 19939.

Ecología y distribución: recolectado sobre madera sin identificar en suelo muy húmedo, en bosque de Quercus robur, Alnus glutinosa y Salix atrocinerea próximo a la laguna y a una zona inundable.

Especie ampliamente georreferenciada en el continente americano, Europa occidental, Australia, Nueva Zelanda, Japón... (GBIF en línea, no 8032257). Ampliamente distribuido en la Península Ibérica (Lago-Álvarez 2008) y Galicia (Soliño et al. 2000).

Trametes ochracea (Pers.) Gilb. \& Ryvarden, N. Amer. Polyp., vol. 2 Megasporoporia - Wrightoporia (Oslo): 752 (1987)

Material estudiado: Salceda de Caselas, Cerquido, Ponte Carneiro, 29TNG3164, 35 m, sobre Salix atrocinerea, 25/01/2015, O. Requejo, LOU-Fungi 19922.

Ecología y distribución: recolectado sobre Salix atrocinerea tumbado en suelo higroturboso en zona inundable.

Taxón georreferenciado por todo el mundo, excepto África (GBIF en línea, no 2548374). Común en Galicia (Soliño et al. 2000). 
Trametes versicolor (L.) Lloyd, Mycol. Notes (Cincinnati) 65: 1045 (1921) [1920]

Material estudiado: O Porriño, Budiño, Orbenlle, observatorio ornitológico, 29TNG3061, 22 m, sobre Salix atrocinerea, 12/05/2013, O. Requejo, LOU-Fungi 19940. O Porriño, Pontellas, barreras de Centeáns, 29TNG3007, $20 \mathrm{~m}$, sobre tocón de Pinus pinaster, 26/12/2014, O. Requejo, LOU-Fungi 19890. Tui, Guillarei, turbera de Albelos, 29TNG3036, 20 m, sobre Salix atrocinerea 03/07/2015, O. Requejo, LOU-Fungi 20217. Salceda de Caselas, desembocadura del río Becerreira, 29TNG3019, $20 \mathrm{~m}$, sobre madera de Salix atrocinerea, 31/07/2015, J. Valeiras y O. Requejo, LOU-Fungi 20232. Tui, Ribadelouro, Puente de la Madalena, 29TNG2992, 26 m, sobre tocón sin identificar, 09/08/2015, O. Requejo, LOU-Fungi 20244.

Ecología y distribución: es la especie más común del género, fructifica sobre todo tipo de madera y todo tipo de bosques. En los aluviales, parece mostrar preferencia por Salix atrocinerea, en el que es capaz de recubrir grandes superficies de troncos caídos.

Probablemente uno de los taxa mejor conocidos y más extendidos por todo el mundo (GBIF en línea, no 2548311), también en la Península Ibérica y Galicia (Soliño et al. 2000).

Tremella mesenterica Retz., K. svenska Vetensk-Akad. Handl. 30: 249 (1769)

Material estudiado: Salceda de Caselas, Cerquido, Ponte Carneiro, 29TNG3164, 35 m, sobre ramas de Alnus glutinosa, 27/09/2014, O. Requejo, LOU-Fungi 19796. O Porriño, Pontellas, barreras de Centeáns, 29TNG3007, 20 m, sobre ramas sin identificar, 21/01/2015, O. Requejo, LOU-Fungi 20010.

Ecología y distribución: especie parásita de líquenes y de plantas leñosas. Común sobre todo en zonas inundables y bosques de ribera.

Frecuente en Europa, también en la Península Ibérica, Norte y Centroamérica, Australia, Nueva Zelanda, Japón... (GBIF en línea, n5237429). Ampliamente citada para Galicia (Rodríguez-Vázquez \& Castro 2016).

Tricholoma equestre (L.) P.Kumm., Führ. Pilzk. (Zerbst): 130 (1871)

Material estudiado: O Porriño, Budiño, Orbenlle, Os Eidos, 29TNG3022, $30 \mathrm{~m}$, bajo Pinus pinaster, 03/11/2013, O. Requejo, LOU-Fungi 20583. O Porriño, Pontellas, barreiras de Centeáns, 29TNG3007, 20 m, bajo Pinus pinaster, 22/12/2014, O. Requejo, LOU-Fungi 19870.

Ecología y distribución: especie micorrizógena de Pinus pinaster, encontrada en su hábitat habitual (Riva 1988). 
Ampliamente georreferenciada por Europa, incluida Península Ibérica, Estados Unidos y Canadá, también mencionada para Centroamérica, Brasil y Japón (GBIF en línea, $n^{\circ}$ 3324883). Frecuente en Galicia, especialmente bajo pinos (Soliño et al. 2000).

Tricholoma joachimii Bon \& A. Riva in Riva, Boll. Gruppo Micol. 'G.Bresadola' (Trento) 28(5-6): 270 (1985)

Material estudiado: Tui, Guillarei, Albelos, 29TNG3043, 13 m, bajo Pinus pinaster, 09/10/2015, O. Requejo, LOU-Fungi 20501.

Observaciones: este taxón fue confundido con T. fucatum (Fr.) P. Kumm. propio de zonas frías, como Pirineos, Centroeuropa y países nórdicos (GBIF en línea, $n^{\circ}$ 6014539); pero no existe en los países mediterráneos, donde es sustituido por T. joachimii Bon \& Riva, con preferencia por suelos ácidos y bajo coníferas.

Ecología y distribución: Recolectado en bosque mixto bajo Pinus pinaster, no es una especie frecuente.

Común, ampliamente extendida por la mitad norte de la Península Ibérica, también observada en Noruega, Suecia, Eslovaquia y Eslovenia (GIBF en línea no 540472). Ampliamente extendido en Galicia (Rodríguez-Vázquez \& Castro 2016).

Tricholoma portentosum (Fr.) Quél., Mém. Soc. Émul. Montbéliard, Sér. 2 5: 338 (1873)

Material estudiado: O Porriño, Pontellas, barreras de Centeáns, 29TNG3007, 20 m, bajo Pinus pinaster, 22/12/2014, O. Requejo, LOU-Fungi 19871.

Ecología y distribución: especie micorrizógena de Pinus pinaster, encontrada en su hábitat habitual (Riva 1988).

Georreferenciada por toda Europa, Estados Unidos y Canadá, también mencionada para Japón y Australia (GBIF en línea, no 5241860). Frecuente en Galicia, generalmente bajo pinos (Soliño et al. 2000).

Tricholoma saponaceum (Fr.) P.Kumm., Führ. Pilzk. (Zerbst): 133 (1871)

Material estudiado: O Porriño, Pontellas, barreras de Centeáns, 29TNG3007, 20 m, bajo Pinus pinaster, 22/12/2014, O. Requejo, LOU-Fungi 19871.

Ecología y distribución: es la especie más común del género en la zona de estudio. Frecuente en espacios mixtos no inundables con Pinus pinaster y Quercus robur. La colección estudiada se recolectó bajo Pinus pinaster en antiguas brañas, ahora pobladas de coníferas con sotobosque herbáceo. 
Georreferenciado en Europa, incluida la Península Ibérica, América del Norte, Japón, China, Australia y Nueva Zelanda (GBIF en línea, $n^{\circ}$ 3324249). Muy común en Galicia (Soliño et al. 1999).

Tricholomopsis rutilans (Schaeff.) Singer, Schweiz. Z. Pilzk. 17: 56 (1939)

Material estudiado: O Porriño, Budiño, Orbenlle, Os Eidos, 29TNG3022, $30 \mathrm{~m}$, sobre tocón de Pinus pinaster, 10/11/2014, O. Requejo, LOU-Fungi 19831. O Porriño, Pontellas, barreras de Centeáns, 29TNG3007, 20 m, sobre tocón de Pinus pinaster, 26/12/2014, A. Justo y O. Requejo, LOU-Fungi 19893.

Ecología y distribución: habitual sobre tocones o raíces enterradas de pinos, por toda la zona.

Distribución semejante a la especie anterior (GBIF en línea, $\mathrm{n}^{\circ}$ 2531814). Común sobre tocones de coníferas en Galicia (Soliño et al. 1999).

Tubaria conspersa (Pers.) Fayod, Annls Sci. Nat., Bot., sér. 7-9: 355 (1889)

Material estudiado: Salceda de Caselas, Cerquido, Ponte Carneiro 29TNG3164, 35 m, entre restos leñosos y herbáceos, 27/09/2014, O. Requejo, LOU-Fungi 19794.

Ecología y distribución: se recolectó en los bordes de un bosque aluvial, donde había acúmulos leñosos, pequeñas ramas y restos herbáceos almacenados por el agua de las crecidas.

Georreferenciada abundantemente en toda Europa desde la Península Ibérica hasta Islandia, también observada en Canadá, Japón y Australia (GBIF en línea, $\mathrm{n}^{\circ}$ 5240911). Mencionada en las cuatro provincias gallegas (RodríguezVázquez \& Castro 2016).

Tubaria furfuracea (Pers.) Gillet, Hyménomycètes (Alençon): 538 (1876) [1878]

= Tubaria hiemalis Romagn. ex Bon, Doc. mycol. 3 (8): 5 (1973)

Material estudiado: Salceda de Caselas, Cerquido, Ponte Carneiro 29TNG3164, 35 m, entre restos leñosos y herbáceos, J.Á. Gándara, LOU-Fungi 19915.

Ecología y distribución: recolectada en situación similar a la anterior, en esta ocasión al borde de un camino.

Es una especie ampliamente extendida por todo el planeta, excepto el continente africano. También georreferenciada para la Península Ibérica (GBIF en línea, $n^{\circ}$ 5240895). En Galicia solo fue citada en la provincia de Pontevedra (Rodríguez-Vázquez \& Castro 1996, De la Peña 2016). 
Typhula contorta (Holmsk.) Olariaga, Mycotaxon 121: 40 (2012)

= Macrotyphula fistulosa var. contorta (Holmsk.) Nannf. \& L. Holm, in Lundell, Nannfeldt \& Holm, Publications from the Herbarium, University of Uppsala, Sweden 17: 8 (1985)

Material estudiado: O Porriño, Budiño, Orbenlle, Observatorio ornitológico, 29TNG3061, 22 m, sobre rama de Alnus glutinosa, 21/12/2013, O. Requejo, LOU-Fungi 19907. Salceda de Caselas, Cerquido, Ponte Carneiro 29TNG3164, 35 m, 25/01/2015, O. Requejo, LOU-Fungi 19931.Tui, Guillarei, Albelos, 29TNG3043, 13 m, sobre ramas de Alnus glutinosa, 09/11/2015, O. Requejo, LOU-Fungi 20533.

Observaciones: se diferencia de T. fistulosa (Holmks.) Olariaga por las esporas hasta $17,5 \mu \mathrm{m}$, mientras que en $T$. contorta alcanzan las $20 \mu \mathrm{m}$ (Corner 1950).

Ecología y distribución: muy común sobre ramas caídas de Alnus glutinosa, en todo tipo de ambientes, sobre todo en los húmedos.

Georreferenciada de forma dispersa en Europa occidental, incluido el norte de Península Ibérica, y Estados Unidos (GBIF en línea, $\mathrm{n}^{\circ}$ 7461368). Escasamente citada para Galicia (Requejo 2012).

Typhula corallina Quél., Compt. Rend. Assoc. Franç. Avancem. Sci. 11: 505 (1883) [1882]

Material estudiado: O Porriño, Budiño, Orbenlle, Os Eidos, 29TNG3022, 30 m, sobre ramas de Rubus sp., 17/10/2013, O. Requejo, LOU-Fungi 19994; idem, sobre ramas de Salix viminalis, 17/10/2013, O. Requejo, LOU-Fungi 19995.

Observaciones: clávulas blancas, hasta $2 \mathrm{~mm}$, por lo que es difícil diferenciar la cabeza fértil del estípite, fructifican a partir de un esclerocio de 11,3 mm. Basidios claviformes, de $25 \times 7,5 \mu \mathrm{m}$, basidiosporas elípticas, de 5,2-7,5 x 3-3,7 (5) $\mu \mathrm{m}$. No presenta fíbulas, pero si ensanchamientos de hasta $5 \mu \mathrm{m}$ en los septos. Capa epidérmica con hifas anchas y sinuosas. En las colecciones estudiadas las medidas esporales son ligeramente mayores que las indicadas por Corner (1950) y menores que las de Olariaga \& Salcedo (2005).

Ecología y distribución: poco común en las zonas de muestreo. Los ejemplares estudiados se recolectaron en bosque de ribera sobre distintos substratos, pero siempre ramas con poco diámetro.

Especie poco frecuente, georreferenciada únicamente para el País Vasco (Península Ibérica) y Dinamarca (GBIF en línea 2539140). En Galicia fue citada sobre eucalipto por Lago-Álvarez (2008) para Ourense y Pontevedra. 
Typhula phacorrhiza (Reichard) Fr., Observ. mycol. (Havniae) 2: 298 (1818)

Material estudiado: O Porriño, Budiño, Orbenlle, Os Eidos, 29TNG3022, $30 \mathrm{~m}$, sobre hojas de Populus nigra, 29/11/2014, O. Requejo, LOU-Fungi 19850.

Observaciones: en la colección estudiada, se observaron en las medidas esporales (10-11,2 x 5-6,5 $\mu \mathrm{m})$ ligeras variaciones frente a lo indicado por Corner (1950), aunque este autor ya comenta la variabilidad en las basidiosporas del taxón. Presenta un aspecto muy parecido a Macrotyphula juncea (Alb. \& Schwein.) Berthier, pero tiene basidiosporas menores y nunca fructifica sobre esclerocios.

Ecología y distribución: común entre hojas caídas, bajo Populus nigra, aunque estas zonas suelen ser muy húmedas, parece preferir que no se aneguen.

Georreferenciado en una localidad de Estados Unidos y con mayor frecuencia en el Centro y Norte de Europa, incluida Islandia (GBIF en línea, ${ }^{\circ}$ 2539100). Para la Península Ibérica encontramos escasas citas (RubioDomínguez 2005, Moreno-Arroyo 2004). No la conocemos citada para Galicia.

Typhula quisquiliaris (Fr.) Henn., Bot. Jb. 23: 288 (1896)

Material estudiado: Tuy, Rebordanes, Ponte das Febres 29TNG2996, $21 \mathrm{~m}$, sobre Pteridium aquilinum, 22/10/2016, O. Requejo, LOU-Fungi 20657.

Ecología y distribución: recolectada sobre su sustrato habitual, helechos (Corner 1950).

Georreferenciada sólo en Europa, con escasas citas, pero dispersas por todo el continente (GBIF en línea, n 2539057). En la Península Ibérica parece ser un taxón poco frecuente con preferencia por el norte (Pérez-Butrón et al. 2011, Rubio-Domínguez et al. 2006, Lago-Álvarez 2008), posiblemente por la mayor concentración de Pteridium aquilinum en la zona norte y occidental ibérica (Moreno Saiz et al. 2015). Para Galicia solo se conoce de Lugo y Pontevedra (Rodríguez-Vázquez \& Castro 2016).

Typhrasa gossypina (Bull.) Örstadius \& E. Larss., in Örstadius, Ryberg \& Larsson, Mycol. Progr. 14 (25): 33 (2015)

$\equiv$ Psathyrella gossypina (Bull.) A. Pearson \& Dennis, Trans. Br. mycol. Soc. 31 (3-4): 184 (1948)

Material estudiado: O Porriño, Budiño, Orbenlle, observatorio ornitológico, 29TNG3061, 22 m, bajo Quercus robur, Salix atrocinerea y Alnus glutinosa, 12/05/2013, O. Requejo, LOU-Fungi 19950. 
Ecología y distribución: el material estudiado se recolectó en zona mixta de Quercus robur, Salix atrocinerea y Alnus glutinosa, muy húmeda y sombría entre restos orgánicos.

Resulta difícil establecer la distribución mundial precisa del taxón debido a la confusión entre Psathyrella gossypina (Bull.) A. Pearson \& Dennis con P. gossypina según Read, (Örstadius et al. 2015). Sin embargo, se georreferencia de Estados Unidos y Canadá una vez y de forma dispersa, en Europa occidental, incluido el norte de Península Ibérica (GBIF en línea, $\mathrm{n}^{\circ}$ 2534875). En Galicia fue mencionada para A Coruña y Lugo (Castro, 1985; Lago-Álvarez, 2008) y recientemente Pontevedra (De la Peña 2016).

Xanthoporia radiata (Sowerby) Tura, Zmitr., Wasser, Raats \& Nevo, Progress in Mycological Research (St. Helier) 2: 270 (2012)

$\equiv$ Mensularia radiata (Sowerby) Lázaro Ibiza, Rev. Real Acad. Cienc. Exact. Fís. Natur. Madrid 14: 736 (1916)

Material estudiado: O Porriño, Budiño, Orbenlle, observatorio ornitológico, 29TNG3061, 22 m, sobre Alnus glutinosa, 02/03/2012, O. Requejo, REQ-Fungi 353. Salceda de Caselas, Cerquido, Ponte Carneiro 29TNG3164, 35 m, sobre Alnus glutinosa, 27/09/2014, LOU-Fungi 19795.

Ecología y distribución: parásito específico que fructifica sobre ejemplares viejos de Alnus glutinosa, viviendo como saprofito una vez seco y caído el hospedante. Es una de las especies más fácil de observar en los bosques aluviales de la zona de estudio, debido a la abundancia y persistencia de los carpóforos.

Referenciada de Europa, costa oriental norteamericana y Australia (GBIF en línea, $n^{\circ} 2521199$ y n ${ }^{\circ}$ 7442237). Para Galicia se ha citado en A Coruña y Pontevedra (Rodríguez-Vázquez \& Castro 2016).

Xerocomellus chrysenteron (Bull.) Šutara, Czech Mycol. 60 (1): 49 (2008)

$\equiv$ Xerocomus chrysenteron (Bull.) Quél., Fl. mycol. France (Paris): 418 (1888)

Material estudiado: O Porriño, Budiño, Orbenlle, Os Eidos, 29TNG3022, $30 \mathrm{~m}$, bajo Quercus robur y Pinus pinaster, 17/10/2013, O. Requejo, LOU-Fungi 20227. O Porriño, Budiño, Orbenlle, observatorio ornitológico, 29TNG3061, 22 m, 29TNG3022, 30 m, en bosque mixto de Pinus pinaster y Quercus robur, 15/10/2016, Marta Martínez, LOU-Fungi 20645.

Ecología y distribución: muy común durante el otoño en los bosques no inundables de la zona de estudio.

Especie frecuente, ampliamente georreferenciada de Europa occidental, y también observado en Nueva Zelanda, Australia, China, Japón y Canadá y Estados Unidos (GBIF en línea, n 2519412). Muy común en Galicia (Soliño et al. 1999). 
Xerocomellus porosporus (Imler ex Bon) Šutara, Czech Mycol. 60(1): 50 (2008)

$\equiv$ Xerocomus porosporus Imler, Bull. trimest. Soc. mycol. Fr. 74(1): 97 (1958)

Material estudiado: O Porriño, Budiño, Orbenlle, Os Eidos, 29TNG3022, 30 m, en bosque mixto de Pinus pinaster y Quercus robur, 15/10/2016, Marta Martínez, LOUFungi 20644.

Ecología y distribución: a pesar de compartir hábitat con la especie anterior, no es tan común como ella. Recolectado en bosque mixto de Pinus pinaster y Quercus robur.

Muy común en Dinamarca, Suecia y Noruega y algo más disperso en el resto de Europa, incluida la Península Ibérica (GBIF en línea, $n^{\circ}$ 2519576). Se puede considerar un taxón bastante raro en Galicia, solo se conoce de Lugo (Marcote et al. 2011).

Xerocomellus ripariellus (Redeuilh) Šutara, Czech Mycol. 60 (1): 50 (2008) $\equiv$ Xerocomus ripariellus Redeuilh, Doc. mycol. 26(104): 30 (1997)

Material estudiado: Salceda de Caselas, desembocadura del río Becerreira, 29TNG3019, 20 m, bajo Populus nigra, 19/09/2015, O. Requejo, LOU-Fungi 20611. Tuy, Rebordanes, Ponte das Febres 29TNG2996, 21 m, bajo Salix atrocinerea y Populus nigra, Marta Martínez, Lou-Fungi 20638.

Observaciones: es una especie muy variable, macroscópicamente caracterizada por el píleo de color rojo sangre, que se cuartea desde el margen, y el estipe recubierto de granulaciones rojas (Muñoz et al. 2008). Pelis con elementos terminales globosos o piriformes, basidiosporas no truncadas con estrías longitudinales (Ladurner et al. 2001; Ladurner \& Simoni, 2003).

Ecología y distribución: los ejemplares revisados se recolectaron en su hábitat habitual, bajo caducifolios (Ladurner \& Simonini 2003). La zona donde se encontraban incluso se llega a inundar en años muy lluviosos.

No georreferenciado en GBIF (en línea); sin embargo, Ladurner \& Simoni (2003) han revisado material de Francia, Holanda, Italia y España. Según estos autores, en Cataluña se publicó como Boletellus catalaunicus Pöder, G. Moreno, Rocabruna \& Tabarés y, en el resto de la Península Ibérica se ha citado de norte a sur (Picón 2004, García-Blanco 2013, Moreno-Arroyo 2004, Gelpi 2006, Muñoz et al 2008). En Galicia lo encontramos referenciado para Lugo (Rodríguez-Vázquez \& Castro 2016). 


\subsubsection{Importancia corológica}

En resumen, la importancia de este catálogo se evidencia en el número de primeras y segundas citas de taxones, tanto para la Península Ibérica como para la Comunidad Gallega como se detalla a continuación distribuido por phylla.

Phyllum Ascomycota

\begin{tabular}{|c|c|}
\hline NOVEDAD PENINSULA IBERICA & RAROS O POCO CITADOS \\
\hline Arnium olerum & Cordyceps polyarthra \\
\hline Byssosphaeria schiedermayeriana & Torrubiella arachnophila \\
\hline Cordyceps polyarthra & \\
\hline Mollisia olivascens & \\
\hline Trichoderma piluliferum & \\
\hline
\end{tabular}

\begin{tabular}{|c|c|}
\hline NOVEDAD GALICIA & RAROS O POCO CITADOS \\
\hline Annulohypoxylon stygium & Beauveria bassiana \\
\hline Eutypella quaternata & Ciboria viridifusca \\
\hline Geopora tenuis & Hypomyces aurantius \\
\hline Gibellula pulchra & Isaria farinosa \\
\hline Helminthosphaeria clavariarum & Lasiosphaeris hirsuta \\
\hline Hymenoscyphus herbarum & Peroneutypa scoparia \\
\hline Lachnum tenuissimum & Peziza succosa \\
\hline Nemania aenea & Pyrenopeziza revincta \\
\hline Propolis farinosa & \\
\hline
\end{tabular}

\section{Phyllum Basidiomycota}

\begin{tabular}{|c|l|}
\hline NOVEDAD EUROPA & \\
\hline Chaetotyphula actiniceps & \\
\hline
\end{tabular}

\begin{tabular}{|c|c|}
\hline NOVEDAD PENINSULA IBERICA & RAROS O POCO CITADOS \\
\hline Conocybe brachypodii & Coprinopsis pseudofriesii \\
\hline Cordyceps polyarthra & Mycena pilosella \\
\hline Hemimycena angustispora & Nidularia deformis \\
\hline Inocybe salicis & Rickenella mellea \\
\hline Laccaria impolita & \\
\hline Mycena atrovinosa & \\
\hline Mycena mucor & \\
\hline Oligoporus alni & \\
\hline Russula sphagnophila & \\
\hline
\end{tabular}




\begin{tabular}{|c|c|}
\hline NOVEDAD GALICIA & RAROS O POCO CITADOS \\
\hline Ceriporiopsis subvermispora & Bulbillomyces farinosus \\
\hline Chroogomphus helveticus & Calyptella campanula \\
\hline Clitopilus cystidiatus & Cantharellus ferruginascens \\
\hline Coprinellus heptemerus & Cerioporus meridionalis \\
\hline Coprinellus pallidissimus & Cryptomarasmius minutus \\
\hline Cortinarius chrysolitus & Deconica horizontalis \\
\hline Cortinarius evernius & Galerina calyptrata \\
\hline Cortinarius saturninus & Inocybe ochroalba \\
\hline Crepidotus caspari & Leucoagaricus pilatianus \\
\hline Entoloma conferendum var. pusillum & Leucocoprinus jubilaei \\
\hline Entoloma sarcitum & Marasmiellus tricolor \\
\hline Entoloma sordidulum & Marasmiellus vaillantii \\
\hline Hebeloma salicicola & Marasmius bulliardii \\
\hline Hohenbuehelia unguicularis & Naucoria subconspersa \\
\hline Hypholoma elongatum & Naucoria umbrina \\
\hline Hypholoma ericaeoides & Neoboletus junquilleus \\
\hline Hypholoma fasciculare var. pusillum & Russula medullata \\
\hline Inocybe splendens & Russula melzeri \\
\hline Lactarius subumbonatus & Russula praetervisa \\
\hline Leucoagaricus meleagris & Typhula contorta \\
\hline Loweomyces fractipes & Xerocomellus porosporus \\
\hline Marasmius graminum & Xerocomellus ripariellus \\
\hline \multicolumn{2}{|l|}{ Mucronella calva } \\
\hline \multicolumn{2}{|l|}{ Mycena algeriensis } \\
\hline \multicolumn{2}{|l|}{ Mycena mirata } \\
\hline \multicolumn{2}{|l|}{ Mycena scirpicola } \\
\hline \multicolumn{2}{|l|}{ Naucoria scolecina } \\
\hline \multicolumn{2}{|l|}{ Phlebiopsis crassa } \\
\hline \multicolumn{2}{|l|}{ Phloeomana alba } \\
\hline \multicolumn{2}{|l|}{ Pluteus poliocnemis } \\
\hline \multicolumn{2}{|l|}{ Ramariopsis pulchella } \\
\hline \multicolumn{2}{|l|}{ Russula fragrantissima } \\
\hline \multicolumn{2}{|l|}{ Russula minutula } \\
\hline \multicolumn{2}{|l|}{ Russula pseudoaeruginea } \\
\hline \multicolumn{2}{|l|}{ Sebacina epigaea } \\
\hline Typhula phacorrhiza & \\
\hline
\end{tabular}




\subsection{Sinopsis taxonómica}

Esta sinopsis taxonómica se ha realizado en base a los datos obtenidos de la base de datos Index Fungorum (en línea, consultada 13/12/2016).

Como se aprecia con los datos anteriores el ratio género-orden es más elevado en la clase Basidiomycota que en Ascomycota (10,8 B::4,8 A), mientras que se aproxima el de género-familia (2,2 A::2,3 B), lo que indica que el número de géneros observados por familia es aproximadamente el mismo en ambos phylla.

\subsubsection{Ubicación taxonómica de los géneros del phyllum Ascomycota catalogados en las Gándaras de Budiño}

Orden Elaphomycetales

Familia Elaphomycetaceae

Elaphomyces Nees

Orden Helotiales

Familia Dermateaceae

Mollisia (Fr.) P. Karst.

Pyrenopeziza Fuckel

Familia Helotiaceae

Ascocoryne J.W. Groves \& D.E. Wilson

Bisporella Sacc.

Cudoniella Sacc.

Cyathicula De Not

Hymenoscyphus Gray

Ombrophila Fr.

Familia Hyaloscyphaceae

Pezizella Fuckel 
Familia Lachnaceae

Lachnum Retz.

Familia Leotiaceae

Leotia Pers.

Familia Rutstroemiaceae

Rutstroemia P. Karst.

Familia Sclerotiniaceae

Ciboria Fuckel

Orden Hypocreales

Familia Cordycipitaceae

Beauveria Vuill.

Cordyceps Fr.

Gibellula Cavara

Isaria Pers.

Torrubiella Boud.

Familia Hypocreaceae

Hypomyces (Fr.) Tul. \& C. Tul.

Trichoderma Pers.

Familia Ophiocordycipitaceae

Tolypocladium W. Gams

Orden Pezizales

Familia Helvellaceae

Helvella L.

Paxina Kuntze 
Familia Pezizaceae

Adelphella Pfister, Matocec \&I. Kusan

Peziza Fr.

Familia Pyronemataceae

Aleuria Fuckel

Geopora Harkn.

Scutellinia (Cooke) Lambotte

Tarzetta (Cooke) Lambotte

Orden Pleosporales

Familia Melanommataceae

Byssosphaeria Cooke

Orden Rhytismatales

Familia Marthamycetaceae

Propolis Fr.

Orden Sordariales

Familia Lasiosphaeriaceae

Arnium Nitschke ex G. Winter

Lasiosphaeris Clem.

Orden Trichosphaeriales

Familia Helminthosphaeriaceae

Helminthosphaeria Fuckel

Orden Xylariales

Familia Diatrypaceae

Diatrypella (Ces. \& De Not.) De Not. 
Eutypella (Nitschke) Sacc.

Peroneutypa Berl

Familia Xylariaceae

Annulohypoxylon Y.M. Ju, J.D. Rogers \& H.M. Hsieh

Hypoxylon Bull.

Nemania Gray

Rosellinia De Not

Xylaria Hill ex Schrank 
4.2.2. Ubicación taxonómica de los géneros del phyllum Basidiomycota catalogados en las Gándaras de Budiño.

Orden Agaricales

Familia Agaricaceae

Agaricus L.

Coprinus Pers.

Crucibulum Tul. \& C. Tul.

Cyathus Haller

Lepiota (Pers.) Gray

Leucoagaricus Locq. ex Singer

Leucocoprinus Pat.

Lycoperdon Pers.

Nidularia Fr. \& Nordholm

Familia Amanitaceae

Amanita Pers.

Familia Bolbitiaceae

Conocybe Fayod

Descolea Singer

Familia Cortinariaceae

Cortinarius (Pers.) Gray

Familia Clavariaceae

Mucronella Fr.

Ramariopsis (Donk) Corner

Familia Entolomateceae 
Clitopilus (Fr. ex Rabenh.) P. Kumm.

Entoloma Fr. ex P. Kumm.

Familia Fistulinaceae

Fistulina Bull.

Familia Hydnangiaceae

Laccaria Berk. \& Broome

Familia Hygrophoraceae

Hygrocybe (Fr.) P. Kumm.

Hygrophorus Fr.

Familia Hymenogastraceae

Galerina Earle

Gymnopilus P. Karst.

Hebeloma (Fr.) P. Kumm.

Naucoria (Fr.) P. Kumm.

Psilocybe (Fr.) P. Kumm.

Familia Inocybaceae

Crepidotus (Fr.) Staude.

Inocybe (Fr.) Fr.

Familia Lyophyllaceae

Asterophora Ditmar

Familia Marasmiaceae

Calyptella Quél.

Marasmius Fr.

Macrocystidia Joss. 
Familia Mycenaceae

Hemimycena Singer

Mycena (Pers.) Roussel

Roridomyces Rexer

Familia Omphalotaceae

Gymnopus (Pers.) Roussel

Marasmiellus Murrill

Rhodocollybia Singer

Familia Phallaceae

Mutinus Fr.

Familia Physalacriaceae

Armillaria (Fr.) Staude

Cryptomarasmius T.S. Jenkinson \& Desjardin

Familia Pleurotaceae

Hohenbuehelia Schulzer

Familia Pluteaceae

Pluteus Fr.

Familia Porotheleaceae

Phloeomana Redhead

Familia Psatyrellaceae

Coprinellus P.Karst.

Coprinopsis P.Karst.

Lacrymaria Pat.

Panaeolus (Fr.) Quél. 
Psathyrella Fr. ex Quél.

Typhrasa Örstadius \& E. Larss.

Familia Pterulaceae

Chaetotyphula Corner

Familia Repetobasidiaceae

Muscinupta Redhead, Lücking \& Lawrey

Rickenella Raithelh.

Familia Strophariaceae

Deconica (W.G. Sm.) P. Karst.

Hypholoma (Fr.) P. Kumm.

Leratiomyces Bresinsky \& Manfr. Binder ex Bridge, Spooner, Beever \& D.C. Park

Pholiota (Fr.) P. Kumm.

Familia Schizophyllaceae

Schizophyllum Fr.

Familia Tricholomataceae

Arrhenia Fr.

Callistosporium Singer

Clitocybe (Fr.) Staude

Collybia (Fr.) Staude

Delicatula Fayod

Lepista (Fr.) W.G. Sm

Resupinatus Gray

Tricholoma (Fr.) Staude 
Tricholomopsis Singer

Familia Tubariaceae

Tubaria (W.G. Sm.) Gillet

Familia Typhulaceae

Typhula (Pers.) Fr.

Orden Auriculariales

Familia Auriculariaceae

Exidia Fr.

Orden Boletales

Familia Boletaceae

Boletus L.

Chalciporus Bataille

Hortiboletus Simonini, Vizzini \& Gelardi

Imleria Vizzini

Lanmaoa G. Wu \& Zhu L. Yang

Leccinum Gray

Neoboletus Gelardi, Simonini \& Vizzini

Pseudoboletus Sutara

Xerocomellus Sutara

Familia Diplocystidiaceae

Astraeus Morgan

Familia Gomphidiaceae

Chroogomphus (Singer) O.K. Mill.

Gomphidius Fr. 
Familia Gyroporaceae

Gyroporus Quél.

Familia Hygrophoropsidaceae

Hygrophoropsis (J. Schröt.) Maire ex Martin-Sans

Familia Paxillaceae

Gyrodon Opat.

Paxillus Fr.

Familia Rhizopogonaceae

Rhizopogon Fr.

Familia Sclerodermataceae

Pisolithus Alb. \& Schwein

Scleroderma Pers.

Familia Serpulaceae

Serpula (Pers.) Gray

Familia Suillaceae

Suillus Gray

Familia Tapinellaceae

Tapinella E.-J. Gilbert

Orden Cantharellales

Familia Cantharellaceae

Cantharellus Juss.

Craterellus Pers.

Pseudocraterellus Corner

Familia Clavulinaceae 
Clavulina J. Schröt.

Familia Hydnaceae

Hydnum L.

Orden Dacrymycetales

Familia Dacrymycetaceae

Calocera (Fr.)

Orden Hymenochaetales

Familia Hymenochaetaceae

Coltricia Gray

Fomitiporia Murrill

Hymenochaete Lév.

Porodaedalea Murrill

Xanthoporia Murrill

Orden Polyporales

Familia Fomitopsidaceae

Antrodia P. Karst.

Laetiporus Murrill

Oligoporus Bref.

Phaeolus (Pat.) Pat.

Postia Fr.

Familia Ganodermataceae

Ganoderma P.Karst.

Familia Meruliaceae

Abortiporus Murrill 
Bulbillomyces Jülich.

Loweomyces (Kotl. \& Pouzar) Jülich

Mycoacia Donk

Phlebia Fr.

Familia Phanerochaetaceae

Ceriporiopsis Domański

Phlebiopsis Jülich

Terana Adans.

Familia Polyporaceae

Cerioporus Quél.

Lentinus Fr.

Lenzites Fr.

Panus Fr.

Polyporus P.Micheli ex Adans.

Trametes Fr.

Familia Sparassidaceae

Sparassis Fr.

Orden Russulales

Familia Russulaceae

Lactarius Pers.

Russula Pers.

Familia Stereaceae

Stereum Hill ex Pers.

Orden Sebacinales 
Familia Sebacinaceae

Sebacina Tul. \& C. Tul.

Orden Thelephorales

Familia Bankeraceae

Hydnellum P. Karst.

Orden Tremellales

Familia Tremellaceae

Tremella Pers.

En resumen, los 359 taxones que se mencionan pertenecen a 42 géneros de Ascomycota y 130 de Basidiomycota, incluidos en 20 y 56 familias, 9 y 11 órdenes, respectivamente. 


\section{AUTOECOLOGÍA, FENOLOGÍA Y MICOCENOSIS:}

\subsection{Autoecología y fenología}

Los hongos, ya desde antiguo, se consideran organismos muy importantes en el desarrollo de los diferentes procesos ecológicos que ocurren en los ecosistemas (Christensen 1989, Honrubia 2009). Como organismos heterótrofos que son, dependen para su supervivencia de la materia orgánica que diversos seres vivos les puedan suministrar, ya sean restos orgánicos en los hongos descomponedores o saprotróficos (García Auer et al. 2007) u organismos todavía vivos, en los necrotróficos y biotróficos mutualistas (líquenes y micorrizas) (Rodríguez-Tovar et al. 2004). Estos tres términos de uso habitual son meramente descriptivos, ya que un hongo no necesariamente presenta sólo uno de estos tipos. De hecho, existen especies que son siempre saprotróficas, algunas parásitas y otras mutualistas, pero también las hay que, dependiendo de las circunstancias, pueden cambiar su comportamiento (Hall et al. 2002, 2003) y sólo se puede confirmar con certeza su estrategia nutricional en el laboratorio (Honrubia et al. 1992). Un buen ejemplo es Armillaria mellea, con un comportamiento típico como parásita, pero puede sobrevivir como saprotrófica un tiempo hasta encontrar otro hospedador para sus micelios (Castro 1985) y, en este trabajo aparece Paxillus involutus recolectado en el suelo como micorrícico de Betula alba, pero también sobre un tronco de Quercus robur, sin aparente contacto con el suelo (saprotrófica?).

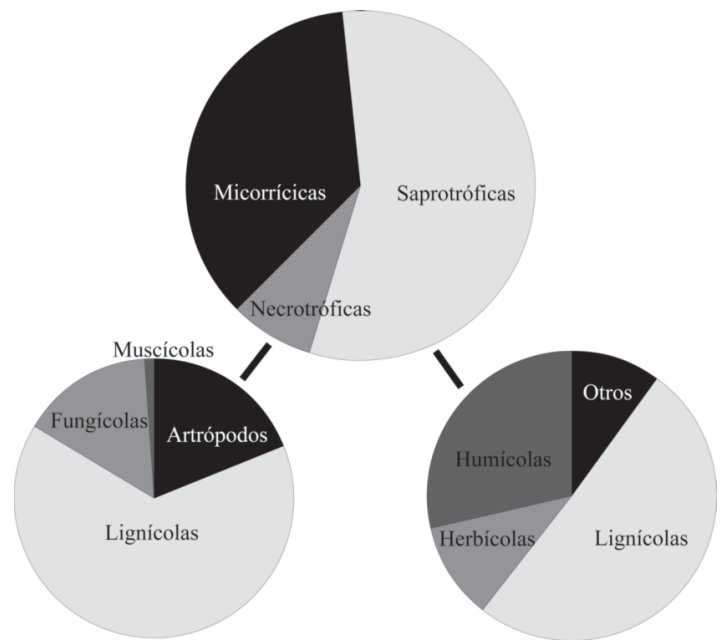

Fig. 5: Porcentaje de taxones según las estrategias tróficas que presentan: micorrícicos 36,2 \%, saprotróficos $57,1 \%$ y necrotróficos $7,7 \%$ 
Entre los taxones estudiados, siguiendo los datos aportados por la bibliografía utilizada para la identificación de especies, así como nuestras observaciones personales, consideramos que de los taxones recolectados 127 micorrícicos, 206 saprotróficos y 28 necrotróficos (figura 5).

Debido a la gran variedad de substratos sobre los que se han recolectado, los taxones saprotróficos se han subdividido en lignícolas (50,5\%), humícolas $(28,6 \%)$, herbícolas o sobre restos herbáceos $(10,7 \%)$ y el resto corresponden a 7 especies muscícolas, 4 folícolas, 5 frutícolas, 1 fungícolas y 4 fimícolas. Y, en el grupo de necrotróficos también se han diferenciado parásitas de artrópodos $(19,2 \%)$, lignícolas $(65,4 \%)$ y fungícolas $(15,4 \%)$.

La elevada humedad existente en los substratos se ve que favorece claramente la presencia de taxones lignícolas, al igual que ocurre en el grupo de las necrotróficas. También es de destacar la presencia de taxones parásitos de artrópodos (insectos y arácnidos) presente entre los musgos, lo que contrasta con el escaso número relacionado únicamente con briófitos, a pesar de la existencia de turberas de Sphagnum y numerosos muros de tierra recubiertos por una densa capa muscinal.

Como es sabido, la fructificación de los macromicetos (fenología) no es caprichosa, ni ocurre al azar (Cripss 2004), depende de diversos factores, entre los que destacan el tipo de vegetación circundante, la humedad edáfica y ambiental y la temperatura, así como diversas características biológicas propias de cada taxón (Pinna et al. 2010). Es, por tanto, el conjunto de estos parámetros ecológicos el que marca la distribución fenológica de las fructificaciones a lo largo del año, es decir, el ritmo de micetación (figura 6).

Los máximos de micetación ocurren durante los meses de setiembre a diciembre siguiendo una distribución unimodal, de forma semejante a lo que sucede en el resto de Galicia. El pico de primavera apenas destaca y se continúa durante el verano hasta el mes de septiembre en el que bajan ligeramente las temperaturas y aumentan las lluvias.

El comportamiento unimodal en este tipo de medios higroturbosos y forestales, como los de la ZEC Gándaras de Budiño, parece ser semejante al observado en el resto de la región noroccidental ibérica para otras formaciones vegetales, tanto de árboles caducifolios (Freire 1982, Pérez-Froiz 1990) como de coníferas (Castro 2015). La principal diferencia, probablemente debido a la proximidad con el océano que retrasa la llegada de las heladas y las temperaturas frías, la disminución de la micetación se refleja en el mes de enero, mientras que en los trabajos realizados contemplando toda Galicia, el bajón micetacional se refleja claramente a partir de diciembre, semejante a lo que ocurre en los terrenos dunares (Rodríguez-Vázquez, 2015). Esta distribución unimodal coincide con el resto del norte peninsular en bosques de caducifolios (Aiartzaguena et al. 2016). 


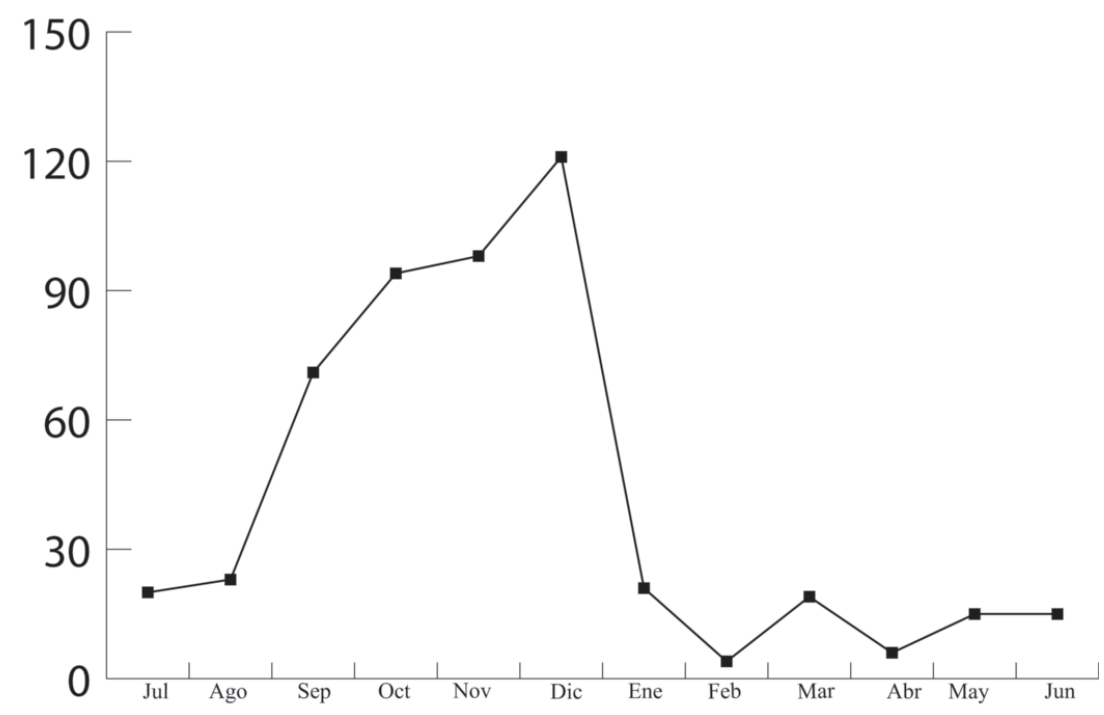

Fig. 6. Micetación anual considerando la totalidad de los muestreos

En la ZEC Gándaras de Budiño el pico de primavera es poco notable y la micetación no desaparece totalmente en la época veraniega debido a la cantidad de agua que retiene el suelo y la superficialidad constante de las capas freáticas, ya que como indican Pinna et al. (2010) esta humedad es muy importante para la aparición de los carpóforos en los períodos más secos. Esta es también una diferencia con las observaciones realizadas en el resto de Galicia (Freire, 1982, Pérez-Froiz, 1990 y Castro, 2015) que aprecian un fuerte repunte primaveral, más importante en primaveras frías y húmedas, en las que algunas especies de los géneros Amanita, Boletus, Xerocomus, etc. típicamente otoñales pueden fructificar en esta época, lo que no puede considerarse como una distribución bimodal de las especies.

Solamente en primavera se observa un pequeño repunte, que en nuestra consideración no permite asociarla con una distribución general bimodal, sin embargo, algunas especies han fructificado en primavera y otoño-invierno: Bulbillomyces farinosus, Helvella macropus, Entoloma sarcitum, Hymenochaete rubiginosa, Naucoria escharoides y Stropharia aurantiaca, entre las que presentan carpóforos carnosos. 
Parecen ser las bajas temperaturas y las breves heladas existentes en la zona las responsables de la desaparición de los carpóforos durante el invierno. Estas apreciaciones coinciden con las de Ohenoja (1988) en los bosques de Finlandia, con micetaciones obtenidas a partir de observaciones de más de una decena de años.

También se han recolectado en ambas estaciones hongos lignícolas, aunque la valoración de su fenología es más difícil debido a la longevidad de sus carpóforos y a la variedad de nichos que ocupan: Lenzites betulina, Xanthoporia radiata, Stereum ochraceoflavum y Trametes versicolor, por ello, no puede afirmarse taxativamente que se trate de brotes estacionales.

Otros taxones han manifestado un brote bastante alargado en el tiempo, sin llegar a ser anual. Es el caso de Crepidotus crocophyllus, Delicatula integrella y Lentinus tigrinus, que va desde junio a octubre y Lacyrmaria lacrymabunda y Porodaedalea pini, que se extienden de julio a diciembre.

Resulta curioso que especies como Cantharellus cibarius e Hypholoma fasciculare, frecuentes en el resto de Galicia durante todo el año (Freire 1982, Castro 2015, Pérez Froiz 1996) cuando están asociadas a caducifolios, en la ZEC Gándaras de Budiño únicamente han sido recolectados durante el otoño.

Como en las turberas las aguas suelen ser de tipo distrófico, pobres en nutrientes en suspensión, pero ricas en ácidos húmicos, fenólico y urónico, presentan un $\mathrm{pH}$ ácido. Esa acidez, escasez de nutrientes y ausencia de oxígeno crean un medio hostil, en el que sólo se encuentra vegetación especializada en zonas higroturbosas como briófitos (Sphagnum sp.pl.), juncáceas o plantas carnívoras del tipo de Drosera rotundifolia, que obtienen parte de su alimento capturando insectos, por ello el número de macromicetos observados también resultó ser escaso en estos medios hiperhúmedos. De hecho, en las épocas que se pudo penetrar en el interior de las turberas para muestrear, se han recolectado preferentemente hongos zoopatógenos: Torrubiella arachnophila, Cordyceps poliartha e Isaria farinosa.

La ausencia de árboles en el interior de las turberas es responsable también de la ausencia de hongos micorrícicos, o de que éstos tengan que buscar alternativas y adaptarse a la vegetación existente. No obstante, se recolectaron algunos, como Laccaria pumila y Cortinarius bibulus, que fructificaban posiblemente asociados a Sphagnum y Alnus glutinosa respectivamente, aunque en el segundo caso, el árbol más próximo se encontraba aproximadamente a 10 metros, lo que hace suponer que el micelio ocupaba un espacio relativamente grande.

Las comunidades arbóreas limítrofes con las turberas, saucedas y/o alisedas inundables, aportan interesantes hongos micorrícicos de pequeño tamaño, con píleo inferior a $1,5 \mathrm{~cm}$ de diámetro, pertenecientes a los géneros 
Autoecología, fenología y micocenosis

Lactarius, Naucoria, Laccaria o Scleroderma. Fuertemente relacionados con Osmunda regalis parecen estar las recolecciones de Inocybe phaeodisca, Ramariopsis pulchella y Scleroderma areolatum, ya que era la especie vegetal en la base de cuyo tronco (raquis) se encontraban.

Los hongos saprotróficos recolectados en estos medios han sido observados sobre restos orgánicos ajenos a la turbera, como hojas de Salix, en el caso de Mycena mucor, o madera alóctona en el de Bulbillomyces farinosus, o directamente sobre turba con esfagnos en el de Entoloma conferendum (E. conferendum var. pusillum) o el de Hypholoma ericaeoides.

Como es lógico, la colmatación de las turberas y lagunas de la ZEC Gándaras de Budiño, provoca pérdida de profundidad y la colonización por parte de Typha latifolia, planta acuática altamente competitiva y, algo más alejados, aparecen algunos ejemplares de Pinus pinaster creciendo, aunque mal por las condiciones anaeróbicas; sin embargo, si continúa dicha colmatación, podría llegar a compactarse el suelo y a estabilizarse la presencia de estos árboles foráneos. La aparición de la especie micorrícica Lactarius deliciosus, exclusiva de coníferas, al pie de las turberas en Rego da Lama (Salceda de Caselas), hace pensar que esta especie va ganando terreno en estos frágiles medios. Este caso ya se observa en Centeáns y en la barrera «A Granxa» Sur, donde bajo los pinos que ocupan las antiguas turberas ya es habitual encontrar micorrizas como Amanita vaginata o Cortinarius anomalus.

Al tratarse de un muestreo exhaustivo y continuado en el tiempo (4 años) se ha intentado ver si las variaciones climáticas manifestadas durante los últimos años se reflejaban reflejados en los patrones de fructificación, ya que el nivel de agua depende en gran medida de la distribución de las lluvias y las temperaturas anuales. Sin embargo, cuatro años consideramos que no es tiempo suficiente que permita extraer conclusiones fenológicas para las especies recolectadas, ya que los datos micológicos anteriores relativos a esta zona son muy escasos y fueron recogidos de forma azarosa (Rodríguez-Vázquez \& Castro 2016).

Los humedales son espacios en los que el agua, a pesar de estar estancada y permanecer en ellos la mayor parte del año, está en constante movimiento y realizando continuos trabajos de filtrado, decantación, depuración, drenajes etc... Por lo que, este movimiento provoca que los organismos de estas zonas húmedas tengan que estar también en continuo cambio para adaptarse y poder sobrevivir en condiciones tan inestables (Martínez Cortizas \& GarcíaRodeja 2001). Los hongos, que dependen de la vegetación circundante, no son una excepción y, por consiguiente el régimen anual de lluvias es importante, sin embargo, el funcionamiento de la distribución anual de las aguas freáticas y lacustres es muy diferente en turberas de zonas bajas, próximas al litoral, que de 
las turberas de montaña (Pontevedra Pombal \& Martínez Cortizas, 2004), así como la dureza de las temperaturas invernales en montaña que dificultan la aparición de carpóforos (Romero-Pedreira \& Sahuquillo-Balbuena, 2008).

Ha sido analizada la posible relación entre el patrón de fructificación y la pluviosidad anual mediante la distribución de la micetación para cada uno de los años prospectados (2013 a 2016) y confrontadas las observaciones con los datos suministrados por la Agencia Estatal de Meteorología para estos años. En todos ellos, los máximos de fructificación varían de agosto a diciembre, sin embargo, no se pone de manifiesto correlación alguna entre el aumento de la micetación y los meses más húmedos. Tampoco parecen afectar especialmente los veranos extremadamente secos de los últimos años. De hecho, el aumento de micetación veraniega observada durante los años 2014 y 2015 pueden estar más relacionados con los períodos frescos (veranos nubosos) que con la pluviosidad.

\subsection{Micocenosis}

Una micocenosis está constituida por un conjunto de especies de hongos (o de poblaciones de especies) que se desarrollan simultáneamente en el espacio y en el tiempo en un territorio determinado, es decir, interactúan en un mismo microambiente compartiendo y/o compitiendo por un mismo sustrato o recurso. (Begon et al. 1986, Villeneuve et al. 1991). De hecho, en un área como la ZEC Gándaras de Budiño se puede hablar de diferentes micocenosis, ya que la estructura de las comunidades de macromicetos depende esencialmente de la climatología y del tipo de substrato de los diferentes nichos que existan en el lugar, etc. (Lagàn et al. 1999, 2002, Richard et al. 2004, Tóth \& Feest 2007).

Excepto con técnicas moleculares resulta casi imposible poder abordar el estudio de las micocenosis de una determinada área utilizando únicamente la parte somática del organismo (Schmit \& Lodge 2005), ya que el organismo vegetativo, en general, está oculto en el interior del substrato y morfológicamente manifiestan gran uniformidad. Este problema es el responsable de que tradicionalmente, estos trabajos se hayan desarrollado mediante el estudio de fructificaciones (ascomas y basidiomas), la única parte visible.

La investigación sistematizada de micocenosis (micosociología) ha comenzado en Europa en la primera mitad del siglo XX, aunque los resultados no han sido publicados, por falta de aceptación por parte de la comunidad científica hasta bastante entrada la segunda mitad (Darimont 1973). De hecho, es evidente que el estudio de comunidades mediante fructificaciones presenta algunos problemas, que pueden resumirse en:

1. No existe correlación entre el número de carpóforos con el de individuos encontrados. Cuando se observan carpóforos diferentes no podemos 
Autoecología, fenología y micocenosis

afirmar de cuantos individuos se trata, es decir, cuantos micelios diferentes, activos o no, se encuentran en el lugar (Gardes \& Bruns 1996).

2. La identificación es compleja e imprecisa cuando se intenta realizarla de "visu", por lo que un inventario supone bastantes horas de laboratorio para certificar la identificación de los taxones observados, por ello, es siempre recomendable partir de un catálogo previo lo más exhaustivo posible.

3. Debido a que un mismo micelio no produce carpóforos anualmente, es necesario realizar inventarios durante varios años seguidos, de forma continuada durante todo el año, haciéndolo extensivo a un mínimo de 5 años (Castro 1985). En el caso particular de zonas higroturbosas, se agrava este problema porque resultan inaccesibles (inundadas) en ciertas épocas del año.

Sin embargo, el método de trabajo con fructificaciones tiene algunas ventajas para aplicar la metodología sociológica (Braun-Blanquet 1951, Darimont 1973) y desarrollar la micosintaxonomía:

1. Se trabaja únicamente con especies bien desarrolladas que poseen reproducción sexual.

2. Resulta práctico a la hora de monitorizar el funcionamiento de especies. Ya que ha sido el método más utilizado hasta el momento, permite comparar estudios y trabajos entre ecosistemas y/o lugares diferentes.

3. Permiten realizar análisis de la influencia de factores bióticos y abióticos que influyen en las micocenosis.

Aun así, se plantea otro problema a la hora de establecer y/o definir micocenosis en una localidad determinada. ¿Se puede considerar dentro de una misma comunidad especies saprotróficas, necrotróficas y micorrícicas o deberían analizarse por separado según el tipo de nutrición? Parece lógico que se separen, ya que el comportamiento espacio/temporal es muy diferente en una especie saprotrófica que en una biotrófica; sin embargo, no resulta fácil establecer en cada momento el tipo de nutrición que está utilizando el hongo para desarrollarse (Hall et al. 2003), por lo que sería casi imposible realizar esta diferenciación.

Además, no siempre resulta fácil saber la especie vegetal con la que se asocia un hongo. Por una parte, la presencia de zonas altamente higroturbosas (brañas, turberas) en las que se descompone fácilmente el substrato leñoso dificultando su identificación y, por otra, las formaciones arbóreas constituidas por diversas especies entremezcladas (Quercus robur, Alnus glutinosa y Salix atrocinerea, especialmente), también dificulta saber a quién/es se asocian. Y, un mismo taxón puede ser recolectado en micotopos diferentes, por ejemplo Mucronella calva que ha sido recolectada sobre ramillas de caducifolio y sobre el carpóforo de un poliporáceo, tan degradado que no ha sido posible identificarlo. 
De las colecciones estudiadas, 213 se relacionan con bosques de caducifolios y 56 con plantaciones de perennifolios (Acacia melanoxylon, Eucalyptus globulus y Pinus pinaster), en tanto en formaciones mixtas, es decir con árboles de hoja caduca y algún que otro pino y/o eucalipto intercalados, se recolectaron 28 .

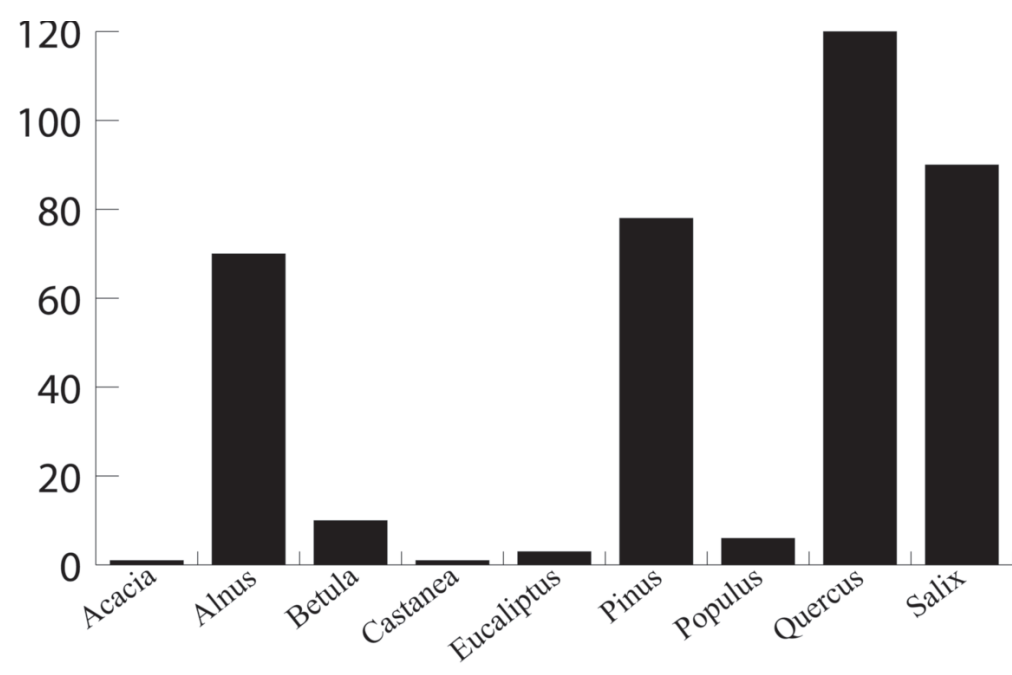

Fig. 7. Número de taxones distribuidos por especie arbórea: Acacia, Alnus, Betula, Castanea, Eucalyptus, Pinus, Populus, Quercus y Salix.

Como era de esperar la mayor parte de las especies recolectadas se asocian con Alnus glutinosa, Salix atrocinerea y Quercus robur, aunque también es de resaltar el importante aporte que hacen al catálogo las plantaciones forestales con Pinus pinaster (fig. 7).

En formaciones herbáceas y briofíticas, situadas a veces en bordes de caminos, turberas o prados brañosos, taludes, muros, etc. se han recolectado $4 \mathrm{y}$ 9 taxones, respectivamente. En tanto, 10 especies se asocian con helechos (Osmunda regalis y Pteridium aquilinum) y otras 8 con diversas especies vegetales (Arundo donax, Brassica oleracea, Hedera hibernica, Rubus sp., Typha latifolia y Vitis vinifera). Por último, aparecen algunos taxones no relacionadas directamente con la vegetación, ya que el substrato corresponde a excrementos, por ejemplo Coprinellus heptemerus (jabalí) o Deconica coprophila (caballo), hongos como Asterophora parasitica o Collybia cirrhata o artrópodos (dípteros, 
lepidópteros y arácnidos) representados por Beauveria bassiana (sobre Tipula), Gibellula pulchra (sobre araña) o Isaria farinosa (sobre pupas de insectos).

A la hora de realizar los muestreos no han sido diseñadas previamente parcelas, sino que se ha considerado en su totalidad un área ecológica higroturbosa con diferentes micotopos, y como tampoco se han recolectado, ni contabilizado la totalidad de los ejemplares observados para cada taxón, no se ha podido realizar un tratamiento estadístico de los datos (Álvarez et al. 2004). Sin embargo, al estar la mayor parte de las especies asociadas a alisos, robles, sauces y pinos hemos considerado presencia/ausencia del taxón y se le ha aplicado el índice de semejanza de Jaccard $\left(\mathrm{IJ}=\mathrm{n} / \mathrm{N}\right.$, donde $\mathrm{n}=\mathrm{n}^{\circ}$ especies comunes entre los hábitats a comparar y $\mathrm{N}=\mathrm{n}^{\circ}$ total recolectado en ambos hábitats). La similitud es bajísima en todos los casos varía entre 0,1 entre pinos y alisos y 0,34 entre robles y alisos. 


\section{CONCLUSIONES}

De los 359 taxones identificados destacan 62 novedades para Galicia, de los cuales 14 los son para la Península Ibérica: Arnium olerum, Byssosphaeria schiedermayeriana, Conocybe brachypodii, Cordyceps polyarthra, Hemimycena angustispora, Inocybe salicis, Laccaria impolita, Mollisia olivascens, Mycena atrovinosa, Mycena mucor, Oligoporus alni, Russula sphagnophila, Trichoderma piluliferum y Chaetotyphula actinipes. Este último además es nuevo para Europa, tanto a nivel género como de especie.

Los 359 taxones que se mencionan pertenecen a 42 géneros de Ascomycota y 130 de Basidiomycota, incluidos en 20 y 56 familias, 9 y 11 órdenes, respectivamente.

Entre los taxones estudiados se han recolectado 127 micorrícicos, 206 saprotróficos, mayoritariamente lignícolas y humícolas; 28 necrotróficos, en su mayoría lignícolas, pero destaca el aporte de entomopatógenos: Beauveria bassiana, Cordyceps polyarthra, Gibellula pulchra, Isaria farinosa, Torrubiella arachnophila.

La vegetación muestreada corresponde especialmente a árboles caducifolios, por lo que la distribución de la micetación anual es semejante a la observada en otros bosques de árboles caducifolios del resto de Galicia.

El 75,1\% del material ha sido recolectado en formaciones arbóreas y arbustivas, mayoritariamente relacionadas con Alnus glutinosa y Salix atrocinerea, y apenas el $24,1 \%$ en turberas y brañas. 


\section{REFERENCIAS BIBLIOGRÁFICAS}

Aiartzaguena, L., Picón, R., Sarrionandia, E. \& Salcedo, I. 2016. Patrones fenológicos de fructificaciones de los macromicetos del País Vasco. Zizak 12:9-21.

Aime, M.C. 2001. Byosystematic Studies in Crepidotus and the Crepidotaceae (Basidiomycetes, Agaricales). Blacksburg. Virginia.

Alonso DíAz, J. 2016. Algunas especies de macromicetos presentes en un jaral de Cistus ladanifer L. en el municipio de A Rúa de Valdeorras (Ourense, NO Península Ibérica) III. Micolucus 3:7-20.

Alonso, J.L., Fernández, J., Pérez-Butrón, J.L. \& Pérez-Puente, J.L. 2002. Setas de los eucaliptales de la cornisa cantábrica (IV) y catálogo micológico de los eucaliptales (III). Yesca 14: 18-41.

Álvarez, M., Córdoba, S., Escobar, F., Fagua, G., Gast, F., Mendoza, H., Ospina, M., UmaÇA, A.M. \& Villareal, H. 2004. Manual de métodos para el desarrollo de inventarios de biodiversidad. Instituto de Investigación de Recursos Ecológicos Alexander von Humboldt. Bogotá.

Antonín, V.A., \& Noordeloos, M.E. 1993. A monograph of Marasmius, Collybia and related genera in Europe. Part 1: Marasmius, Setulipes and Maramiellus. Libri Botanici, 8. IHW-Verlag. Eching.

Antonín, V.A. \& Noordeloos, M.E. 2004. A monograph of the genera Hemimycena, Delicatula, Fayodia, Gamundia, Myxomphalia, Resinomycena, Rickenella and Xeromphalina (tribus Mycenae sensu Singer, Mycena excluded) in Europe. IHW Verlag. Eching.

ArAmENDI, R. \& HidALgo, F. 2012. Stropharia albonitens y otras especies en abedulares relictos de la provincia de Ávila. Bol. Mic. Famcal 7: 19-36.

Arnolds, E. 2005. Conocybe Fayod in Noordeloos M.E. Kuyper TH.W. \& Vellinga C. (eds.). Flora Agaricina Neerlandica vol 6:120-179.

ARNOLDS, E.J.M. 2007. Biogeography and Conservation. In: Kubicek C.P. \& Druzhinina I.S. (eds.). Environmental and Microbial Relationships, 2nd Edition. The Mycota 4: 105-124. Springer- Verlag Berlin Heidelberg.

Aronsen, A. 2002-2015. http://www.mycena.no [Consultado el 19-12-2013]

Arrillaga, P., Ferreño, J. \& Iturrioz, J.I. 2010. Especies raras o poco conocidas de hongos macromicetos IV. Bol. Mic. Famcal 5:65-76.

Baldrian, P., Větrovský, T., Cajthaml, T., Dobiášová, P., Petránková, M., ŠnAJDR, J. \& EICHLEROVÁ, I. 2013. Estimation of fungal biomass in forest litter and soil. Fungal Ecol. 6 (1): 1-11.

Ballarà, J., Cadiñanos Aguirre, J.A., Calzada, A., Campos, J.C., Esteve-Raventós, F., Fernández Sasia, R., Gutiérrez, C., Macau, N., Mahiques, R., Mateos, A., Moreno, G., Ortega, A., Pérez, A., Pérez-De-Gregorio, M.À, Reyes, J.D., Santamaría, N., SuÁrez, E. \& VILA, J. 2011. Cortinarius ibero-insulares-3. Fungi non Delineati. Pars LVIII-LIX. Edizioni Candusso. Alassio. 
Bañares, Á. \& Beltrán, E. 2009. Estudio micológico del Parque Nacional de Garajonay (La Gomera, Islas Canarias). Agaricales s.1. I. Anales Jard. Bot. Madrid 66: 47-61.

Bas, C., Kuyper, Th.W., Noordeloos, M.E. \& Vellinga, E.C. (eds.). 1988. Flora Agaricina Neerlandica. Critical monographs on families of agarics and boleti occurring in the Netherlands, vol. 1. Ed. A.A. Balkema. Rotterdam.

Bas, C., Kuyper, Th.W., Noordeloos, M.E. \& Vellinga, E.C. (eds.). 1990. Flora Agaricina Neerlandica. Critical monographs on families of agarics and boleti occurring in the Netherlands, vol. 2. Ed. A.A. Balkema. Rotterdam.

Bas, C., Kuyper, Th.W., Noordeloos, M.E. \& Vellinga, E.C. (eds.). 1995. Flora Agaricina Neerlandica. Critical monographs on families of agarics and boleti occurring in the Netherlands, vol. 3. Ed. A.A. Balkema. Rotterdam.

Bas, C., Kuyper, Th.W., Noordeloos, M.E. \& Vellinga, E.C. (eds.). 1999. Flora Agaricina Neerlandica. Critical monographs on families of agarics and boleti occurring in the Netherlands, vol. 4. Ed. A.A. Balkema. Rotterdam.

Basso, M.T. 2000. Fungi Europaei vol. 7. Lactarius Pers. Mykoflora. Alassio.

Basso, M.T. 2005. Manual di Microscopia dei Funghi. Libreria Mykoflora. Alassio.

BAsso, M.T. 2012. Manual di Microscopia dei Funghi, vol. 2. Libreria Mykoflora. Vilanova d'Albenga.

Becerra, M., Robles, E. \& GaOna, J.M. 2015. Cantharellus ferruginascens, P.D. Orton, nueva especie para el catálogo micológico de Andalucía. Rev. Soc. Gad. Hist. Nat. 9: $19-20$.

Beggon, M., Harper, J.L. \& Townsend, C.R. 1986. Ecology: Individuals, Populations and Communities. Blackwell, Oxford.

Beker, J.H., Eberhart, U. \& Verterholt, J. 2016. Fungi Europaei vol. 14. Hebeloma (Fr.) P. Kumm. Edizioni tecnográfica. Lomazzo.

Bellón, X. \& CAstro, M.L. 2008. El género Inocybe (Fr.) Fr. En el Parque Natural "As Fragas do Eume" (A Coruña) In Annales Confederationis Europaea Mycologiae Mediterraneensis 2005: 81-87.

Bellón, X. Justo, A. \& Castro, M.L. 2004. Primeiro catálogo micolóxico do Parque Natural "As Fragas do Eume": aspectos ecolóxicos. Mykes 7: 19-28.

Bellón, X. Justo, A. \& Castro, M.L. 2006. Aportación ao coñecemento dos macromicetos de Chandrexa de Queixa (Ourense) (I). Mykes 9: 33-41.

Bellot, F. \& Casaseca, B. 1960 [1959]. Adiciones y correcciones a la Flora de Galicia. Anales Inst. Bot. Cavanilles 17(1): 233-248.

Benguria, E. \& Martín, J.L. 2008. Stereum Pers. ex S.F. Gray 1821. Butll. Assoc. Micol. Font $i$ Quer 6: 37-46.

Berniccia, A. 2005. Fungi Europaei vol. 10. Polyporaceae s.l. Edizioni Candusso. Alassio. 
Berniccia, A. \& GorJón, S.P. 2010. Corticiaceae s.l. Fungi Europaei vol. 12. Edizione Candusso. Alassio.

Bezerra, J.L., Costa, J.C.B., Bastos, C.N. \& Faleiro, F.G. 2003. Hypocrea stromatica sp. nov. teleomorfo de Trichoderma stromaticum. Fitopatol. Bras. 28(4): 408-412.

Blanco-Dios, J.B. 2005. Novedades corolóxicas de macromicetos do noroeste da Península Ibérica. Tarrelos 9: 38-41.

Blanco-Dios, J.B. 2005b. Novedades corolóxicas de macromicetos do noroeste da Península Ibérica. Mykes 8: 51-54.

Blanco-Dios, J.B. 2006. Novedades corolóxicas de macromicetos do noroeste da Península Ibérica (II). Mykes 9: 57-63.

Blanco-Dios, J.B. 2008 [2007]. Fragmenta Chorologica Gallaecica, Fungi 38-51. Mykes 10: 64-66.

Blanco-Dios, J.B. 2014 [2013]. Fragmenta Chorologica Gallaecica, Fungi 184-244. Mykes 16: 41-53.

Blanco-Dios, J.B. 2014b. Fragmenta Chorologica Gallaecica, Fungi 245-267. Mykes 17: 65-72.

Blanco-Dios, J.B. 2015. Notas sobre la familia Cantharellaceae en el Noroeste de la Península Ibérica (V): Aportaciones al conocimiento del subgénero Cantharellus. Micolucus 2: 36-42.

Blanco-Dios, J.B. 2011. Notas sobre la familia Cantharellaceae en el Noroeste de la Península Ibérica (III): Cantharellus lourizarianus y C. romagnesianus var. parvisporus, dos nuevos taxones del subgénero Parvocantharellus y Craterellus lutescens $f$. citrinosulphureus, f. nov. Tarrelos 13:7-15.

Blanco-Dios, J.B. 2014. Fragmenta Chorologica Gallaecica, Fungi 184-244. Mykes 16: 41-53. [2013].

Blanco-Dios, J.B., Salgado Fuentes, E. \& Zaera Landeira, E. 1989. Aportación ao estudio micolóxico do bosque de Quercus robur L. no concello de Lugo. Braña monogr. 1: 53-66.

Boertmann, D. 1995. The genus Hygrocybe. Funghi of Northem Europe, vol. 1. Danish Mycological Society. Svampetryk.

Bon, M. 1997. Clé monographique du genre Inocybe (Fr.) Fr. (1ère partie: généralités et espèces acystidiées $=$ Ss.-g. Inosperma Kühner) Doc. Mycol. 27(105): 1-75.

Bon, M. (1999) Flore Mycologique d'Europe 6. Les Collybio-Marasmïoïdes et ressemblants. Doc. mycol., mem. hors série 5: 1-171.

Breintenbach, J. \& Kränzlin, F. 1984. Champignons de Suisse. Tome I. Ascomycetes. Ed. Mykologia. Lucerne.

Breitenbach, J. \& Kränzlin, F. 1986. Champignons de Suisse. Tome II. Champignons sans lames. Ed. Mykologia. Lucerne. 
Breitenbach, J. \& Kränzlin, F. 1991. Champignons de Suisse. Tome III. Champignons à lames, lème partie. Ed. Mykologia. Lucerne.

Breitenbach, J. \& Kränzlin, F. 1995. Champignons de Suisse. Tome IV. Champignons á lames 2éme partie. Ed. Mykologia. Lucerne.

Breitenbach, J. \& Kränzlin, F. 2000. Champignons de Suisse. Tome V. Cortinariaceae. Ed. Mykologia. Lucerne.

BuEno, M.N. \& Illana, C. 2004. Bases corológicas de Flora Micológica Ibérica. Números 2224-2238. Cuad. Trab. Flora Micol. Ibérica 20: 56-91.

CALVo-PÉrEz, J. en linea. Fungipedia: Pachyella babingtonii. in www.fungipedia.org/clasificacionorden/ascomycota/pezizales/4 [consultado 1-10-2014].

CALonge, F.D. 1996. Bases corológicas de Flora Micológica Ibérica, $n^{\text {OS }} 693-894$ in Cuadernos de Trabajo de Flora Micológica Ibérica 9. Real Jardín Botánico - CSIC. Madrid.

Calonge, F.D. 1998. Gasteromycetes I. Lycoperdales, Nidulariales, Phallales, Sclerodermatales, Tulostomatales. Flora Mycologica iberica 3: 1-271. Real Jardín Botànico $\mathrm{y} \mathrm{J}$. Cramer, Madrid.

CAlonge, F.D. \& Pérez De Gregorio, M.A. 2002. Russula fragrantissima Romagnesi, una especie rara en España. Bol Soc Micol. Madrid 26: 233-234.

CAMAChO, A. (coord.). 2009a. Hábitat 3110. Aguas oligotróficas con un contenido de minerales muy bajo (Littorelletalia uniflorae). Ministerio Medio Ambiente y Medio Rural y Marino. Madrid.

CAmacho, A. (coord.). 2009b. Hábitat 3150. Lagos y lagunas eutróficos naturales, con vegetación Magnopotamion o Hydrocharition. Ministerio Medio Ambiente y Medio Rural y Marino. Madrid.

CAmpoAmor, J.N. 1996. Estudios sobre Tricholomataceae ibéricos. IV. Especies de la Sierra de Ancares (Noroeste de España). Bol. Soc. Micol. Madrid 21: 333-343.

Campos, J.C., Pancorbo, F., Ribes, M.A., Sánchez, G., Rodríguez, B., Cuesta, J. \& Vila J. 2014. Contribución al conocimiento de la micobiota del Parque Natural de la Sierra Norte de Guadalajara. Catálogo y especies más interesantes, I. Bol. Soc. Micol. Madrid 38:163-181.

Candusso, M. \& Lanzoni, G. 1990. Lepiota s.l. Fungi Europaei 4. Libreria editriche Giovanna Biella. Saronno.

Candusso, M. 1997. Hygrophorus s.l. Fungi Europaei 6. Libreria Basso. Alassio.

CANnon, P.F. \& KIRK, P.M. 2007. Fungal Families of the World. CABI Publishing. Wallingford.

CARbó, J. 2001. Bolets de Catalunya. Sociedad Catalana de Micologia. Lámina 938 Collecció 20.

Carbó, J. Macau, N. \& Pérez-De-Gregorio M.A. 2012. Bolets de Catalunya. Sociedad Catalana de Micologia. Lámina 1506 Collecció 31. 
Cardoso, J. \& Melo, I. 1992. Informação bibliográfica II. Portugal. Cuad. Trab. Flora Micol. Ibérica 5: 1-93.

Castillo, J. \& Guillén, A. en línea. Adelphella babingtonii. Mundo microscópico: biodiversidad virtual. In http://www.biodiversidadvirtual.org/micro/Adelphellababingtonii-8207-img1256.html [consultado 23-9-2014].

Castro, M.L. 1985. Macromicetos de pinares gallegos. Universidad de Santiago de Compostela.

Castro, M.L. 1995. Fragmenta chorologica occidentalia, Fungi, 5323-5370. Ann. Jard. Bot. Madrid 53(1): 103-105.

Castro, M.L. 1996. Catálogo del género Amanita Pers. ex Hook. (Agaricales) en Galicia (Península Ibérica). Ann. Jard. Bot. Madrid 54 (1): 61-67

CAstro, M.L. 2013. Nota breve-Comentarios e corrección de tres exsiccata do xénero Cortinarius da micoteca LOU-Fungi (Pontevedra), revisadas por José Antonio Cadiñanos Agruirre. Mykes 16: 33-34.

CAStro, M.L. 2015. Micobiota autóctona e alóctona: micocenosis, micosocioloxía. Mykes 18: $51-71$.

Castro, M.L., Checa, J. \& Pando, F. 1997. Bases corológicas de Flora Micológica Ibérica. Adiciones y números 1224-1411. Cuad. Trab. Flora Micol. Ibérica 12: 23 180.

Castro, M.L., Freire, L. \& Pérez Froiz, M. 1989. Nuevas aportaciones a la micoflora gallega in: II reunión del Grupo Botánico Gallego. Sobre flora y vegetación de Galicia. Xunta de Galicia. Santiago de Compostela: 35-39

Castro, M.L., Soliño, A. \& Freire, L. 1997. Fragmenta chorologica occidentalia, Fungi, 6128-6160. Ann. Jard. Bot. Madrid 55(2): 445-446.

Castro, M.L., González-DíAz, R. \& Gómez-Viso, D. 1995. Fragmenta Chorologica Occidentalia, Fungi, 5193-5227 Ann. Jard. Bot. Madrid 52(2): 200-201.

CAStroviejo, S. (coord. gen.) 1986-2012. Flora Ibérica 1-8, 10-15, 17-18, 21. Real Jardín Botánico, CSIC, Madrid.

Cereijo, D. 2001. O xénero Cordyceps (Fr.) Link en Galicia. Mykes 4: 29-36.

Charbonnel, J. 1995. Les reactifs mycologiques. Tome 1. Les reactifs macrochimiques. Edité Jacques Charbonnel. Ajain.

Charbonnel, J. 2004. Les reactifs mycologiques. Tome 2. Les reactifs microchimiques. Edité Jean-Claude David-Rogeat. Langeas. Ajain.

Christensen, M. 1989. A view of fungal ecology, Mycologia 81: 1-19.

CoBos-SuÁRez, P. 1989. Fitopatología del castaño (Castanea sativa Miller). Bol. Sanidad Vegetal 16: 11-19.

Comesaña, P. \& CAstro, M.L. 1999. Nuevas aportaciones al conocimiento de los Agaricales (Basidiomycotina) de la sierra de los Ancares (Lugo-España). Bol. Soc. 
Micol. Madrid 24: 81-93.

Cordero Rivera, A. (coord.) 2007. Plan de recuperación del galápago europeo (Emys orbicularis) en Galicia. Xunta de Galicia. Santiago de Compostela.

CORNER, E.J.H. 1950. A monograph of Clavaria and allied genera. Oxford University Press.

Cortés, C. \& Montón, J. 2004. Fongs nous o poc citats de la comarca del Segriá (Lleida). II Boscos de ribera. Rev. Catal. Micol. 26: 141-154.

Cortés, C. 2001. Hypoxylon howeianum in Bolets de Calatunya. Colleció 20: $\mathrm{n}^{\circ} 964$. Societat Catalana de Micologia. Barcelona.

CoRTÉs, C. 2009. Peroneutypa scoparia in Bolets de Calatunya. Colleció 28: nº 1390. Societat Catalana de Micologia. Barcelona.

CRIPPS, G.L. (ed.) 2004. Fungi in forest ecosistems: Systematics, diversity and ecology. New York Botanical Garden. New York.

Cuesta, J., Santamaría, N. \& Serrano, S. 2011. Cantharellus romagnesianus, Cantharellus gallaecicus, Mycenella rubropunctata y Pholliotina striipes, cuatro especies poco frecuentes encontradas en Candás (Asturias). Bol. Mic. Famcal 6:8396.

CYBERTRUFFL ON LINE. http://www.cybertruffle.org.uk/cgibin/robimaps.pl? organism $=300196 \&$ location $=U N \& g l o=e s p \&$ assoge $=\&$ link $=\&$ asso rg [Consultado el 20-02-2016]

DANIËLS, P.P. 2003. Bases corológicas de Flora Micológica Ibérica. Números 2124-2178. Cuad. Trab. Flora Micol. Ibérica 19: 104-165.

DARIMONT, F. 1973. Recherches mycosociologiques dans les fórets du Haute Belgique. Inst. Royal des Sciences Nat. Belgique.

Dasairas, A. \& CASTRo ,M.L. 2007. Micobiota do Parque Natural do Douro Internacional e Áreas adjacentes. Anais da Associação Micológica "A Pantorra" 7:7-137.

De HaAn, A. \& Walleyn, R. 2002. Studies in Galerina - Galerinae Flandriae (1). Fungi non Delineati 23: 1-66.

De La Peña, S. \& De La Peña, F. 2014. Contribución al conocimiento de la familia Agaricaceae en Galicia (I) (NO de la Península Ibérica). Tarrrelos 16: 20-26.

De La Peña, S. 2016. Guía Micológica de la Isla de Cortegada. Xunta de Galicia. Vilagarcia de Arousa.

Dennis, R.W.G. 1981. British Ascomycetes. J. Cramer. Vaduz.

Díaz-Fernández, M., Pancorbo, F., Cuesta, J. \& Santamaría, S. 2007. Cantharellus melanoxeros Desm., Bot. Gall.2: 799 (1830), primera cita para Extremadura. Boletín informativo Sociedad Micológica Extremeña 7:19-21.

Domínguez-Borines, V. 2006. Estudo da diversidade fúnxica de Camba (Ourense). Mykes 9: 27-31. 
DruZhinINA, I. \& KUBICEK, C.P. 2005 Species concepts and biodiversity in Trichoderma and Hypocrea: from aggregate species to species clusters? J. Zhejiang Univ. Sci. B. 6(2): 100-112.

DuEÑAS, M. 1997. Bases corológicas de Flora Micológica Ibérica, $\mathrm{n}^{\text {OS }} 1114-1223$ in Cuadernos de Trabajo de Flora Micológica Ibérica 11. Real Jardín Botánico - CSIC. Madrid.

Dueñas, M. 2001. Bases corológicas de Flora Micológica Ibérica. Adiciones. Cuad. Trab. Flora Micol. Ibérica 15: 25-36.

Dueñas, M. \& Tellería, M.T. 1988. Catálogo de los corticiáceos y poliporáceos, s.l. (Aphyllophorales, Basidiomycotina), de la micoflora cántabro-astur. Ruizia 5. Madrid.

Dueñas, M. TelleríA, M.T. \& Melo, I. 2009. The aphyllophorales (Basidiomycota) of a Mediterranean biodiversity "hotspot" - "Cazorla, Segura \& Las Villas" Natural Park (Spain). Mycotaxon 109: 465-468.

Dueñas, M., Illana, C., Blanco, N., Pando, F., Galán, R., Heykoop, M., \& Moreno, G. 2001. Bases corológicas de Flora Micológica Ibérica, $\mathrm{n}^{\mathrm{OS}} 1572-1767$ in Cuadernos de Trabajo de Flora Micológica Ibérica 15. Real Jardín Botánico - CSIC. Madrid

Duñabeitia ,M., Olariaga, I., Picón, R., Robredo, A., Rodríguez, N., Salcedo, I. \& SARRIONANDiA, E. 2012. Nuevas aportaciones al catálogo micológico de la Reserva de la Biosfera de Urdaibai (Bizkaia). Zizak 2:7-26.

Elborne, S.A. 1995. Hohenbuehelia S.Schulz. In Bas C. Kuyper TH.W. Noordeloos M.E. \& Vellinga C. (eds.). Flora Agaricina Neerlandica 3: 158-166.

Esteve-Raventós, F. 1991. Bases corológicas de Flora Micológica Ibérica, nos $1412-1571$ in Cuadernos de Trabajo de Flora Micológica Ibérica 13: 1-135.

Esteve-Raventós, F. 1999. Bases corológicas de Flora Micológica Ibérica. Números 1412-1571. Cuad. Trab. Flora Micol. Ibérica 1: 1-135.

Esteve-Raventós, F. \& Vila, J. 1997. Algunos Inocybe de la zona alpina de los Pirineos de Catalunya I. Rev. Catal. Micol. 20:177-186.

Esteve-Raventós, F., SÁnchez, C., Villarreal, M., \& Barrasa, J.M., 1997. Il genere Descolea nella Peninsula Ibérica. Riv. Micol. 40 (3): 251-260.

Esteve-Raventós, F., Villa, J. \& Listorella, J. 1999. Algunos Entoloma interesantes o poco conocidos de los Pirineos de Catalunya. Rev. Catal. Micol. 22:135-143.

EsteVe-Raventós, F. \& Villareal, M. 2003. Notas corológicas sobre algunos agaricales recogidos en el Parque Natural de Sanabria (Zamora), Valle del Bibei (Zamora, Orense) y Parque Natural de Montesinho (Tras-os-Montes, Portugal). Bol. Soc. Micol. Madrid 27:167-179.

FAVRE, J. 1948 Les associations fongiques des hauts-marais jurassiens. Beitr. Kryptogamenfl. Schweiz 10 (3):1-228.

Fernández-Martínez, M.A \& CAstro, M. (1998). Fragmenta Chorologica Occidentalia 
Fungi 6713-6749. Ann. Jard. Bot. Madrid 56(2): 352-353.

Fernández-Sasia, R. \& Moreau, P.A. 2011. Tres especies interesantes del género Alnicola Kühner, recogidas en Bizkaia. Errotari 8:123-134.

FernándeZ-Vicente J. 2013. Aportación al Catálogo de Macromicetos del Parque Natural del Gorbea y aledaños. Errotari 10:82-128.

FernándeZ-Vicente J. 2014. Aportación al Catálogo de Macromicetos del Parque Natural del Gorbea y aledaños y listado de especies de la familia Physalacriaceae, Marasmiaceae y Niaceae (Basidiomycota). Errotari 11:36-96.

Fernández-Vicente J. \& Undagoitia J. 2009. Aportación al Catálogo de Macromicetos del Parque Natural del Gorbea y aledaños, y listado de Ascomycetos (Ascomycota)(III). Errotari 6:118-149.

FernándeZ-Vicente J. \& Undagoitia J. 2010. Aportación al Catálogo de Macromicetos del Parque Natural del Gorbea y aledaños, Agaricales Cantharellaceae, Clavulinaceae, Hydnaceae, Tulasnellaceae (Basidiomycota). Errotari 7:69-83.

Fernández-Vicente, J., Iglesisas, P. \& Oyarzabal, M. 2012. Aportaciones al conocimiento micológicode la Gomera (Islas Canarias). Errotari 9:143-205.

FoURNIER J. \& MAGNI J.F. en línea. Pyrenomycetesfree. http://pyrenomycetes.free.fr/index.htm [Consultado el 03-03-2016]

Freire L. 1982. Macromycetes de la "Selva Negra" (Santiago). Universidad de Santiago

FUNGIPEDIA. en línea, Stropholoma aurantiacum (Cooke) Ryman in http://www.fungipedia.org/hongos/stropholoma-aurantiacum.html_[Consultado el 0303-2016]

GaLÁn R. 2001. Bases corológicas de Flora Micológica Ibérica. Números 1624-1676. Cuad. Trab. Flora Micol. Ibérica 15: 101-139.

García Auer, C., Michelato Ghizelini, A. \& Chapaval Pimentel, I. 2007. Decomposição fúngica de acículas en plantíos de pinos. Pesq. Flor. Bras., Colombo 54: $127-138$.

García, X.R. 2008. Guía das plantas de Galicia. Edicións Xerais. Vigo.

GARCía-Blanco, A. 2012. Adicciones al catálogo de las setas de la provincia de Valladolid (I) In http://asociacionvallisoletanademicologia.com/wordpress/catalogomicologico-de-valladolid [Consultado el 29-11-2016]

García-BlanCO, A. 2013. Adicciones al catálogo de las setas de la provincia de Valladolid (II) In http://asociacionvallisoletanademicologia.com/wordpress/catalogomicologico-de-valladolid [Consultado el 27-11-2016]

García Blanco A. \& Alonso Ortega J. L. 2008. Asterohpora parasitica, Xerocomus parasiticus y Laurobasidium lauri, tres formas curiosas de parasitismo. Boletín Asociación Micológica Zamorana 10:7-12.

García-Blanco, A. \& Sánchez-Rodríguez, J.A. 2009. Setas de la Península Ibérica y Europa. Everest. León. 
García-Bobadilla Prósper, F., Lago García, J.M., Juliani Aguado, C., Callejo Rey, A., Ramil Rego, P. \& Izco Sevillano, J. 2002. Humedales de Galicia. Xunta de Galicia.

GarcíA-Bona, L.M. 1994. El género Cortinarius en Euskalerria. Cuad. Secc. Ci. Nat. 10: $9-225$.

García-Bona, L.M. 2000. Catálogo micológico de Navarra. Gorosti. Pamplona.

GBIF en línea. Global Biodiversity Information Facility In www.gbif.org/species/ [consultada 30-12-2016].

GARDES, M. \& BRUnS, T.D. 1996. Community structure of ecto-mycorrhizal fungi in a Pinus muricata forest: above and below ground views. Canadian Journal of Botany 74: $1572-1583$.

Giachini, A.J., Oliveira, V.L., Castellano, M.A. \& Trappe, J.M. 2000. Ectomycorrhizal fungi in Eucalyptus and Pinus plantations in southern Brazil. Mycologia 92: 11661177.

Gibson, I. 2012. Trial key to Stereum in the Pacific Northwest in www.swims.ca/council/Stereu.htm [consultado el 11-10-2016]

GelPI, C. 2006. Dos Xerocomus poco frecuentes en Extremadura. Boletín informativo Sociedad Micológica Extremeña 6:20-21.

Gerhardt, E., Vila, J. \& Llimona X. 2000. Hongos de España y de Europa. Omega. Barcelona.

Gómez-Orellana, L., Rubinos Román, M., Cillero Castro, C., Hinojo Sánchez, B., Ramil-Rego, P. \& Ferreiro da Costa, P. 2014. Los humedales de Galicia como sumidero de carbono: evaluación, distribución y estado de conservación. Bol. R. Soc. Esp. Hist. Nat. Sec. Geol. 108: 19-26

Gómez-Reyes, V.M., Hernández Salmerón, I.R., Terrón-Alfonso, A. \& GuevaraGuerrero, G. 2012. Estudio taxonómico de Elaphomyces spp. (Ascomycota, Eurotiales, Elaphomycetaceae) de Michoacán, México. Rev. Mex. Micol. 36: 57-62.

GonzÁlez, V., Esteve-Raventós, F., Arenal, F. \& Villareal, M. 1997. Contribución al estudio taxonómico de los macromicetos de zonas higroturbosas alpinas y subalpinas del Pirineo Central. Lucas Mallada. 9: 71-90.

Hall, J.R., Yun, W. \& AMicucCI, A. 2002. Edible Mycorrhizal Mushrooms and their Cultivation, Proceedings of the Second International Conference on Edible Mycorrhizal Mushrooms. New Zealand Institute for Crop \& Food Research Limited.

HALl, J.R., Yun, W. \& AMicucCI, A. 2003. Cultivation of edible ectomycorrhizal mushrooms. Trends in Biotecnology 21(10): 433-438.

HAN, K.S., VolK, T.J. \& KIM, H.K. 2010. Identification of Lacrymaria velutina (Pers. Ex Fr.) Konrad \& Maubl. from Micheon-myeon, Jinju-city, Korea. Mycobiology 38(4): 249-255.

Hanlin, R.T.H. 1999. Combined keys to illustrated genera of Ascomycetes. Vol. 1 \& 2. 
APS Press. Minnesota.

Hausknecht, A. 2009. Conocybe Fayod, Pholiotina Fayod. Fungi Europaei 11. Edizione Candusso. Alassio.

Hausknecht, A. \& Noordeloos, M.E. 1999. Neue oder seltene Arten der Entolomataceae (Agaricales) in Mittel- und Südeuropa. Österr. Z. Pilzk. 8:199-221.

Heilmann-Clausen, J., Verbeken, A. \& Vesterholt, J. 1998. Fungi of Northern Europe vol. II. The genus Lactarius. The Danish Myclogical Society. Copenhagen.

HeIM, R. 1931. Le Genre Inocybe, Encyclopedie Mycologique 1. Paul Lechevalier \& Fils. Paris.

Henrici, A. 2008. Keys to Naucoria in Britain. Fiel Mycology 9(2):55-62.

Hernández, M.E. 2010. Suelos de humedales como sumideros de carbono y fuentes de metano. Terra latinoamericana 28(2):139-147.

Hernández-Crespo, J.C. en línea. Sistema de Información Micológica Ibérica. Real Jardín Botánico de Madrid, C.S.I.C. Proyecto Flora Micológica Ibérica I-VI (19992008) in http://www.rjb.csic.es/fmi/ sim/php [consultado 20/12/2015].

Heykoop, M. 2001. Bases corológicas de Flora Micológica Ibérica. Números 1677-1744. Cuad. Trab. Flora Micol. Ibérica 15: 139-187.

Heykoop, M. \& Moreno, G. 2001. Bases corológicas de Flora Micológica Ibérica. Números 1745-1765. Cuad. Trab. Flora Micol. Ibérica 15: 187-235.

Heykoop, M. \& Moreno, G. 2007. Catálogo de la microbiota agaricológica de la provincia de Guadalajara(España). Bol. Soc. Micol. Madrid 31:35-76.

Hodge, K.T., Gams, W., Samson, R.A., Korf, R.P. \& Seifert, K.A. 2005. Lectotypification and status of Isaria Pers.: Fr. Taxon 54(2): 485-489.

Hsieh, H.M., Ju, Y.M. \& Rogers, J.D. 2005. Molecular phylogeny of Hypoxylon and closely related genera. Mycologia 97: 844-865.

IDZERdA, S. \& Noordeloos, M.E. 1997. Studies in Lactarius sect. Tabidi. Österreichische Zeitschrift für Pilzkunde. 6:71-89.

Iglesias, P., Fernández-Vicente, J. \& Oyarzabal M. 2011. Aportaciones al conocimiento micológico de la isla de La Palma III. Errotari 8:159-199.

IGLESIAs, P. \& FERnÁNDEZ-ViCEnTE, J. 2015. Introducción al estudio del género Coprinus S. str. en España. Errotari 12:52-207

Illana, C. \& Blanco, M.N. 2001. Bases corológicas de Flora Micológica Ibérica. Números 1572-1614. Cuad. Trab. Flora Micol. Ibérica 15: 37-99.

INDEX FUNGORUM en línea. Bases de datos. In www.indexfungorum.org [consultada 30-122016].

IzCO, J. \& SÁnchez, J.M. 1995. Revisión crítica del listado de flora endémica gallega. Bot. Macaronesica 21: 75-84. 
JeAnNerot, B. 2010. Notes on Scutillinoid fungi collections of the Vienna University herbarium (Wu). Österr. Z. Pilzk 19:19-29.

Ju, Y.M. \& Rogers, J. 2013. Xylariaceae: Home of the Xylariaceae (versión 9.0, Sep 2010). In Roskoy Y. \& al. Species 2000 \& ITIS Catalogue of Life, 11th March 2013. UK.

Julich, W. 1980. Guida alla determinazione dei funghi vol 2. Aphyllophorales, Heterobasidiomycetes, Gasteromycetes. Saturina. Trento.

Justo, A. \& CASTRO, M.L. 2002. Revisión da micoteca LOU-Fungi: novas aportacións ó catálogo macromicolóxico galego. Mykes 5: 21-26.

Justo, A. \& CASTRO, M.L. 2007. An annotated checklist of Pluteus in the Iberian Peninsula and Balearic Islands. Mycotaxon (102): 231-234.

Justo, A. Castro, M.L. \& Caballero, A. 2005. Los géneros Pluteus y Volvariella (Basidiomycota, Fungi) en La Rioja (España). Rev. Cat. Micol. 27: 75-84.

Justo, A., Malysheva, E., Bulyonkova, T., Vellinga, E.C., Cobian, G., Nguyen, N., MinNIS, A.M. \& HiBBETT, D. 2014. Molecular phylogeny and phylogeography of Holarctic species of Pluteus section Pluteus (Agaricales: Pluteaceae), with description of twelve new species. Phytotaxa 180:1-85.

Kasuya, T., Uno, K. \& HosaKa, K. 2014. Reexamination of Crepidotus crocophyllus (Basidiomycota, Fungi) in Japan, with reference to tis phylogenetic placement. Univ. Bull. Chiba Inst. Sci. 7: 159-166.

Kees, C. \& UlJé, B. 2005. Coprinus Pers. In M.E. Noordeloos, TH.W. Kuyper \& Vellinga C. (eds.). Flora Agaricina Neerlandica 6: 22-109.

Kränzlin, F. 2005. Champignons de Suisse. Tome VI. Russulaceae. Ed. Mykologia. Lucerne.

Kropp, B.R., Matheny, P.B. \& Nanagyulyan, S.G. 2010. Phylogenetic taxonomy of the Inocybe splendens group and evolution of supersection "Marginatae". Mycología 102(3):560-573.

Krug, J.C \& Cain, R.F. 1972. Additions to the genus Arnium. Can, J. Bot. 50: 367-373

Kruys, A., Huhndorf, S. \& Miller, A. 2014. Coprophilous contributions to the phylogeny of Lasiosphaeriaceae and allied taxa within Sordariales (Ascomycota, Fungi). Fungal diversity 10(1): 101-113.

KUYPER, T.W. 1986. A revision of the Genus Inocybe in Europe. I. Subgenus Inosperma and the smooth-spored species of Subgenus Inocybe. Persoonia Sup.3:1-247.

Ladurner, H \& Simonini, G. 2003. Fungi Europaei vol. 8. Xerocomus s.l. Edizioni Canduso. Alassio.

Ladurner, H., Pöder, R., Rocabruna, A. \& Tabarés, M. 2001. Boletellus cataiaunicus Pöder, Moreno, Rocabruna et Tabarés: A synonym of Xerocomus ripariellus Redeuilh. Rev. Cat. Micol. 23: 121-125.

Lagàn, A., Angiolini, C., Loppi, S., Salerni, E., Perini, C., Barluzzi C. \& De Dominicis, 
V. 2002. Periodicity, fluctuations and successions of macrofungi in fir forest (Abies alba Miller) in Tuscany, Italy. Forest Ecology and Management 169: 187-202.

LagÀn, A., LoppiÀ, S. \& De Dominicis, V. 1999. Relationship between environmental factors and the proportions of fungal trophic groups in forest ecosystems of the central Mediterranean area. Forest Ecology and Management 124: 145-151.

Lago, M. \& Castro, M.L. 1997. Agaricales lignícolas sobre Eucalyptus en el N.W. de España. Cryptog. Mycol. 18(4): 291-298.

Lago, M. \& CASTro, M.L. 2002. Fragmenta chrologica occidentalia, Fungi 8392-8440. Ann. Jard. Bot. Madrid 60(1): 190-202.

LAGO, M. 2003. Fragmenta chorologica occidentalia, Fungi 8796-8822. Anales Jard. Bot. Madrid 60(2): 419-421.

LAGo, M., LóPez-Prada, M.I. \& CASTRO, M.L. 2002. Fragmenta chorologica occidentalia, Fungi, 8441-8481. Ann. Jard. Bot. Madrid 60(1): 202-205.

Lago-Álvarez, M. \& CAStro, M.L. (2004. Macrobasidiomicetos asociados a Eucalyptus en la Península Ibérica. Fungi non Delineati 27: 1-84.

Lago-Alvarez, M. 2008. Micoflora (Basidiomycota) de los eucaliptales del NO de la Península Ibérica. Guineana 14: 1-502.

LARA-Ruíz J. 2012. Contribución al conocimiento corológico de Cantharellaceae en el macizo Cazorla-Segura (SE península ibérica). Micobotánica-Jaén Año IX, No 4. http://www.micobotanicajaen.com/Revista/Articulos/JLaraR/Contribucion/ Cantharellaceae.html [consultado el 20-11-2016]

LÁzAro-IBizA, B. 1917. Los poliporáceos de la flora española. Rev. Real Acad. Ci. exact. nat. Madrid 15: 369-384

LANDerós, F. \& Guzmán-Dávalos, L. 2012. Revisión del género Helvella (Ascomycota, Fungi) en México. Rev. Mex. Micología 39:13-19

Le Gal, M. \& Mangenot, F. 1960. Contribution à l'étude des Mollisioides III. Revue de Mycologie 25: 134-214.

Llamas, B. \& Terrón, A. 2003. Atlas fotográfico de los hongos de la Península Ibérica. Ed. Celarayn. León.

Llistosella Vidal, J. 2008. Bases corológicas de Flora Micológica Ibérica. Números 2239-2324. Cuad. Trab. Flora Micol. Ibérica 22: 17-141.

López-Prada, M.I. \& CASTRO, M.L. 1996. Aportación al conocimiento de las especies del orden Aphyllophorales S.L. (Basidimycotina) en Galicia. Ann. Jard. Bot. Madrid 54: 68-73.

López-Prada, M.I. \& CAStro, M. 2002 [2001]. Fragmenta chorologica occidentalia, Fungi, 8019-8088. Ann. Jard. Bot. Madrid 59(2): 304-308.

López-Prada, M.I. Castro, M.L. \& Freire, L. 1993. El género Phellinus Quél. (Aphyllophorales, Basidiomycotina) en el N.W. de la Península Ibérica In Congreso Forestal Español Lourizán 1993. Sociedad Española de Ciencias forestales, Xunta de 
Galicia 3: 379-383.

López Quintanilla, J.F., Veláz Vergara, J.I., Vivoras, M.L. \& Escobio García, V.J. 2013. Contribución al conocimiento de los hongos del Jardín botánico Viera y Clavijo (Gran Canaria, Islas Canarias). Botánica Macaronésica 28: 51-62.

Lorenzo, P. \& CAstro, M.L. 2004. Aportación ó coñecemento do xénero Lactarius Pers. no Parque Natural do Monte Aloia (Pontevedra, N.O. Península Ibérica). Mykes 7: $37-$ 44

Lorenzo, P. \& Castro, M.L. 2011. Micetación do Parque Natural "Monte Aloia" (Pontevedra): diversidade e autoecoloxía. Mykes 12: 29-36 [2009].

Losa España, T.M. 1943. Datos para el estudio de la Flora Micológica gallega. Ann. Inst. Bot. Cavanilles 3: 134-257 [1942].

Losa Quintana, J.M. \& Freire, L. 1978. Macromicetos de Galicia: otoño 1975-invierno 1976. Brã̃a 1: 50-79

Lu, B., Druzhinina, I.S., Fallah, P., Chaverri, P., Gradinger, C., Kubicek, C.P. \& SAmuels, G.J. 2004. Hypocrea/Trichoderma species with pachybasium-like conidiophores: teleomorphs for T. minutisporum and T. polysporum and their newly discovered relatives. Mycologia 96(2): 310-342.

Makornwattana, M., Suwannasai, N., Phosri, C. \& Whalley, A.J.S. 2013. Problem species in the genus Annulohypoxylon (Xylariaceae). Proceedins International Graduate Research In http://www.grand.cmu.ac.th/igrc2013/proceedings/cfile/T15\%20MANLIKA\%20 (p.71-76).pdf [consultado 18-07-2016]

Marcote, J.M.C., Pose, M. \& Traba, J.M. 2003. Setas de Galicia. Xunta de Galicia.

Marcote, J.M.C., Pose, M. \& Traba, J.M. 2005. Cogomelos de Galicia. Xunta de Galicia. Santiago.

Marcote, J.M.C., Pose, M. \& Traba, J.M. 2009. Cogomelos de Galicia. Xunta de Galicia.

Marcote, J.M.C., Pose, M. \& Traba, J.M. 2011. 500 Setas del litoral atlántico y noroeste peninsular. Ed. Cumio. Pontevedra.

Marcote, J.M.C. \& Requejo, O. 2012. Aportación al conocimiento de los hongos entomopatógenos en Galicia (N.O. de la Península Ibérica). Tarrelos 14: 4-6.

Martínez Cortizas, A. \& Pérez Alberti, A. 1999. Atlas Climático de Galicia. Xunta de Galicia

Martínez Cortizas, A. (coord.) 2009a. Hábitat 7150. Depresiones en substratos turbosos del Rhynchosporium. Ministerio Medio Ambiente y Medio Rural y Marino. Madrid.

Martínez Cortizas, A. (coord.). 2009b. Hábitat 7130. Turberas de cobertor (* para las turberas activas). Ministerio Medio Ambiente y Medio Rural y Marino. Madrid.

Medard, G. 2006. Atlante fotografico degli Ascomiceti d'Italia. A.M.B. Trento. Italia. 
Merino Alcántara, D. en línea. Cudoniella clavus In http://www.micobota nicajaen.com /Revista/Articulos/DMerinoA/Galicia001/CudoniellaClavus.pdf [consultado el 2411-2016]

Merino Alcántara, D. en línea. Gymnopus foetidus (Sowerby) P.M. Kirk in http://www.micobotanicajaen.com/Revista/Articulos/DMerinoA/Aportaciones021/Gy mnopusFoetidus.pdf [consultado el 18/11/2016]

MiLleR, J.H. 1961. A monograph of the world species of Hypoxylon. University of Georgia Press.

Mir, G. \& Mellis, J.LL. 2008. Aportació al coneixement micológic de les Illes Balears. Menorca I. Rev. Catal. Micol. 30: 79-92

Monedero, C. 2011. El género Russula en la Península Ibérica.Centro de estudios micológicos de Euskadi. Bilbao.

Montecchi, A. \& Sarasini, M. 2000. Funghi ipogei d'Europa. A.M.B. Trento.

Moreau, P.A. 1992. Analyse écologique et patrimoniale des champignons supérieurs dans les tourbières des Alpes du Nord. Laboratoire Dynamique des Ecosystèmes d'Altitude-C. I. S. M. Université de Savoie [Tesis doctoral]

Moreau, P.A. 2004. Qu'est ce que Tubaria umbrina?. Bulletin semestriel de la Fédération des Associations mycologiques méditerranéennes 25 (1): 3-18.

Moreau, P.A. 2005. A nomenclatural revisión of the genus Alnicola (Cortinariaceae). Fungal Diversity 20:121-155.

Moreau P.A. 2006. Le genre Alnicola (Cortinariaceae), de la classification traditionnelle aux analyses moléculaires (avec clé expérimentale des Alnicola européens). Jaarboek van de Vlaamse-Mycologen-Vereniging 11: 5-14.

Moreno-Arroyo, B. 2004. Inventario Micológico Básico de Andalucía (IMBA) $1^{a}$ edición. Consejería de Medio Ambiente. Junta de Andalucía.

Moreau, P.A., Peintner, U. \& Gardes, M. 2006. Phylogeny of the ectomycorrhizal mushroom genus Alnicola (Basidiomycota, Cortinariaceae) based on rDNA sequences with special emphasis on host specificity and morphological characters. Molecular Phylogenetics and Evolution 38:794-807.

Moreno, G. \& García-BonA, L.M. 1976. Macromycetos interesantes de Navarra. I. Anal. Inst. Bot. Cavanilles 33: 125-133.

Moreno, G., García Manjón, J. L. \& Zugaza, A. 1986. Guía de los hongos de la Península Ibérica. Tomos I y II. Incafo. Madrid.

Moreno, G. \& López, G. 1987. Sobre la sociología de Macromycetes. Las comunidades de los abedulares de la sierra del Guadarrama (Melico-Betuletum Celtibericae). Anal. Inst. Bot. Cavanilles 34 (2): 439-465.

Moreno, G. \& Manjón, J.L. 2010. Guía de Hongos de la Península Ibérica. Omega. Barcelona.

Moreno, G., Galán, R., Llarandi, E. \& RitvirR, A. 2004. Estudio de los hongos en el 
parque nacional de Cabañeros (Ciudad Real) I. Bol. Soc. Micol. Madrid 28:229-269.

Moreno, G., Prieto, F. \& Heykoop, M. 2002. Adiciones al catálogo micológico de la zona centro Peninsular I. Bol. Soc. Mic. Madrid 26:131-145.

Moreno-GÁmez, J.F. en línea. Gibellula puchra Cavara in http://www.micobotanicajaen.com/Revista/Articulos/FMorenoG/ Artropodos/Gibellula\%20pulchra\%20(1).pdf [consultado el 18/11/2016]

Moreno Saiz, J.C., Pataro, L. \& Pajarón Sotomayor, S. 2015. Atlas de los pteridófitos de la Península Ibérica e Islas Baleares. Acta Botánica Malacitana 40:5-55.

Moser, M.M. 1986. Guida alla determinazione de funghi, vol. 1: Polyporales, Boletales, Agaricales, Russulales. Saturnia. Trento.

Mũ̃oz, J.A. 2005. Boletus s.l. Fungi Europaei 2. Edizione Candusso. Alassio.

Muñoz, J.A. Cadiñanos Aguirre J.A. \& Fidalgo E. 2008. Contribución al catálogo corológico del género Xerocomus en la Península Ibérica. Bol. Soc. Micol. Madrid 32:39-67.

MycoBAnK en línea. Nomenclatural Database of Funghi in http://www.mycobank.org/ [consultado por última vez 10-05-2016]

NautA, M.M. 2000. Agaricus L. in Noordeloos, M.E. Kuyper, Th.W. \& Vellinga, E.C. (ed.) Flora Agaricina Neerlandica 5. A.A. Balkema. Rotterdam.

Neville, P. \& Poumarat, S. 2004. Amanitaea. Amanita, Limacella \& Torrendia. Fungi Europaei 9. Edizione Candusso. Alassio.

Noordeloos, M.E. 1995. In Bas, C., Kuyper, T., Noordeloos, M. \& Vellinga, E. 1995. Flora Agaricina Neerlandica, vol. 3. Ed. A.A. Balkema. Rotterdam.

Noordeloos, M.E. 1992. Entoloma s.l. Fungi Europaei 5. Libreria Editriche Giovanna Biella. Saronno.

Noordeloos, M.E. 2004. Entoloma s.l. Fungi Europaei 5A. Edizione Candusso. Alassio.

Noordeloos, M.E. 2011. Strophariaceae s.l. Fungi Europaei 13. Edizione Candusso. Alassio

Noordeloos M.E., Kuyper Th.W. \& Vellinga E.C. (eds.). 2001. Flora Agaricina Neerlandica. Critical monographs on families of agarics and boleti occurring in the Netherlands, vol. 5. Ed. A.A. Balkema. Rotterdam.

Noordeloos M.E. Kuyper Th.W. \& Vellinga E.C. (eds.). 2005. Flora Agaricina Neerlandica. Critical monographs on families of agarics and boleti occurring in the Netherlands, vol. 6. Ed. A.A. Balkema. Rotterdam.

O'Reilly, P. 2015. Crucibulum laeve (Huds.) Kambly - Common bird's-nest Fungus In www.first-nature.com/fungi/crucibulum-laeve.php [consultado el 30/08/2016]

OdA, T., TANAKA, C \& TsudA, M. 2004. Molecular phylogeny of the widely distributed Amanita species, A. muscaria and A. pantherina. Mycol. Res. 108(8): 885-896. 
OJEDA, F. 2009. Hábitat 4020. Brezales húmedos atlánticos de Erica ciliaris (*). Ministerio Medio Ambiente y Medio Rural y Marino. Madrid.

Olariaga, I., Pérez Butrón, J., Fernandez, J. \& Alonso, J.L. 2006. Cantharellus pseudominimus especie poco citada en Europa. Yesca 18: 55-58.

Olariaga, I. \& Salcedo, I. 2005. Contribución al género Typhula Fr. (Fungi) en la Península Ibérica. Anales Biología 27: 39-51.

Olariaga, I., Moreno, G., Manjón, J.L., Salcedo, I., Hofstetter, V., Rodríguez, D. \& BuYCK, B. 2016. Cantharellus (Cantharellales, Basidiomycota) revisited in Europe through a multigene phylogeny. Fungal Diversity 83:263-292.

Örstadius, L., RyBerg, M. \& LARSSON, E. 2015. Molecular phylog enetics and taxonomy in Psathyrellaceae (Agaricales) with focus on psathyrelloid species: ingroduction of three new genera and 18 new species. Mycol. Progress 14(25): 1-42.

Ortega, A., Lorite, J. \& VAlle, F. 2010. Mycorrhizal macrofungi diversity (Agaricomycetes) from Mediterranean Quercus forests; a compilation for the Iberian Peninsula (Spain and Portugal). Nova Hedwigia 9(1-2): 1-31.

Ortega, A., Esteve-Raventós, F. \& Capilla, A. 2004. Contribución al Catálogo micológico de Sierra Nevada (Andalucía) II. Estudio de las comunidades riparias de media montaña. Bol. Soc. Micol. Madrid 28:197-206.

Palazón, A. 2001. Setas para todos. Ed. Pirineo. Huesca.

Palla Costa, P. 2014. Gibellula spp. asociadas a aranhas da mata do Paraíso, Viçosa-MG (Brasil) in http://locus.ufv.br/bitstream/handle/123456789/5370/texto\% 20comple to.pdf? sequence $=1 \&$ is Allowed $=y$ [consultado 31-08-2016].

PAlm, M.E. \& Chapela, I.H. (eds.) 1997. Mycology in sustainable development: Expandin concepts, vainishing bordel. Parkway Publeshers, Inc. Boone. North Carolina.

PAnCorbo MaZA, F. 2009. Aportaciones micológicas 9. Revista Micobotánica Jaén 4(3) in http://www.micobotanicajaen.com/Revista/Articulos/FPancorboM/Aportaciones009/ Aportaciones009.html [consultada 27/12/2016]

PANDo F. (ed.) 1996. Información bibliográfica III. Adiciones, correcciones e índices. Cuad. Trab. Flora Micol. Ibérica 8: 1-326.

PANDo F. (ed.) 1999. Bases corológicas de Flora Micológica Ibérica. Cuad. Trab. Fl.Micol. Ibérica. 13: 1412-1571. Madrid.

PAndo F. 2001. Bases corológicas de Flora Micológica Ibérica. Números 1615-1623. Cuad. Trab. Flora Micol. Ibérica 15: 99-101.

PANDo F. 2002. Bases de datos en línea de las colecciones de criptógamas del Herbario MA. http://www.rjb.csic.es/herbario/crypto/crydbe.htm.

Pando, F., Blanco, M., Calonge, F., Cardoso, J., Castro Cerceda, M.I., Checa, J., Daniëls, P.P., Descals, E., Dueñas, M. Esteve-Raventós, F., Heykoop, M., Illana, C., Lado, C., Melo, I., Moreno, G., Parra, L.A., Rodríquez Pérez, J., Salcedo, I., Santamaria, S. \& Tellería M.T. 2016. Flora Mycologica Iberica Project database. 
v1.3. Real Jardín Botánico de Madrid (CSIC). Dataset/Occurrence in http://www.gbif.es/ipt/resource? $r=$ floramicologicaiberica $\& v=1.3 \quad$ [consultado 10/12/2016]

Pando, F., Dueñas, M., Lado C. \& Tellería, M.T. (eds.) 1990. Información bibliográfica.I. España peninsular e Islas Baleares. Cuad. Trab. Flora Micol. Ibérica 1: 1-67.

Pando, F., Muñoz-Garmendia, F. \& Aedo, C. 1999. Manual de las bases de datos nomenclaturales de Flora Micológica Ibérica y Flora Ibérica. Cuad. Trab. Flora Micol. Ibérica 14: 1-64.

PAncorbo, F. \& RiBes, M.A. 2011. Contribución al conocimiento de la micobiota del Pirineo I. Errotari 8:104-118.

PARrA, L.A. 2003. Bases corológicas de Flora Micológica Ibérica. Números 2070-2123. Cuad. Trab. Flora Micol. Ibérica 19: 19-104.

Parra, L.A. 2013. Agaricus s.l. Fungi Europaei 1A. Edizione Candusso. Alassio.

Pegler, D.N., Roberts, P.J. \& Spooner, B.M. 1997. British Chanterelles and tooth fungi. Royal Botanic Gardens. Kew.

PÉreZ-BilbaO, A. \& GARrido, J. 2009. Evaluación del estado de conservación de una zona LIC (Gándaras de Budiño, Red Natura 2000) usando los coleópteros acuáticos como indicadores. Limnetica 28(1): 11-22.

PÉrez-Bilbao, A. 2010. Coleópteros acuáticos (Adephaga y Polyphaga) de las Gándaras de Budiño, Zona LIC (Red Natura 2000): Faunística, Ecología y Fenología. Bol. Biga 7: 7-69.

Pérez Butrón, J.L., Fernández-Vicente, J. \& Alonso, J.L. 2006. Setas de los Eucaliptales de la Cornisa Cantábrica (VIII). Catálogo micológico de los Eucaliptales (VII). Yesca 18:33-49.

Pérez Butrón, J.L., Alonso, J.L. \& Fernández-Vicente, J. 2011. Estudio y catalogación de la micoflora de los eucaliptales de Cantabria y Bizkaia. Ed. Sociedad Micológica Cántabra. Maliaño (Cantabria).

Pérez de Gregorio, M.À. 2005. Mycena leptocephala in Bolets de Calatunya. Colleció 24: $\mathrm{n}^{\circ}$ 1181. Societat Catalana de Micologia. Barcelona.

PÉrez de Gregorio, M.À. 2011.Craterellus melanoxeros in Bolets de Calatunya. Colleció 30: $\mathrm{n}^{\mathrm{o}}$ 1465. Societat Catalana de Micologia. Barcelona.

Pérez de Gregorio, M.Á. \& Macau, N. 2008. Dues Laccaria interessants trobades a Girona. Rev. Cat. Micol. 30: 45-49.

PiĄteK, M. 2003. Notes on Polish polypores 1. Oligoporus alni, comb. nov. Polish Botanical Journal 48(1): 17-20.

PICón, R. (coord.). 2005. Catalogación de la micoflora (macromicetos) de la CAPV. Sociedad micológica de Portugalete / Laboratorio de Botánica, Dep. Biología Vegetal y Ecología. UPV [In http://micologiaportugalete.com, PDF online [consultado el 11-7-2014]. 
PinNA, S., GÉvry, M., Côté, M. \& Sirois L. 2010. Factors influencing fructification phenology of edible mushrooms in a boreal mixed forest of Eastern Canada. For. Ecol. Manage. 260: 294-301.

PRYDIUK, M.P. 2007. New record of Concocybe species from Ukraine. II. The section Conocybe. Czech mycol. 59(1): 39-50.

REID, D.A. 1984. A revision of the British species of Naucoria sensu lato. Trans. Br. Mycol. Soc. 82(2):191-237.

ReQuejo, O. 2008. Mycena pseudocorticola Kühner en Galicia. Tarrelos 10: 20-21.

Requejo, O. 2010. Algúns fungos interesantes para Galicia. Tarrelos 12:20-24.

RequeJo, O. 2011. Fragmenta Chorologica Gallaecica, Fungi 139-146. Mykes 14: 81-83.

REQUEJO, O. 2011b. Una interesante recolecta de varias especies del género Cantharellus durante las XXI Xeiras Micolóxicas del Grupo Ecologista Adenco. Tarrelos 13: 1621.

RequeJo, O. 2012. Catálogo micolóxico (Ascomycota, Basidiomycota) das ribeiras do río Caselas (Pontevedra). Mykes 15:9-90.

RequeJo, O. 2014. Marasmiellus tricolor (Alb. et Schwein.:Fr) Singer, unha especie pouco frecuente recollida en Galicia. Mykes 16:19-24.

RequeJo, O. \& Blanco-Dios J.B. 2012. Notas sobre Cortinarius pulchellus J.E. Lange, nuevo taxón para la micoflora gallega (N.O. Península Ibérica). Yesca 24: 79-82.

Requejo, O. \& Castro, M.L. 2015a. Micobiota de las Gándaras de Budiño (Pontevedra, N.O. Península Ibérica), Ascomycota. Bol. Soc. Micol. Madrid 39: 37-44.

Requejo, O. \& Castro, M.L. 2015b. Micobiota nas Gándaras de Budiño (Pontevedra, N.O. Península Ibérica) II: Agaricales. Micolucus 2: 43-59.

RequeJo, O. \& PARAdA-Miniño, J. 2011. Algunos hongos interesantes encontrados sobre amentos de Alnus glutinosa (L.) Gaertn. Yesca 23:40-44.

RequeJo, O. \& PAis, M. 2012 [2011]. Fragmenta Chorologica Gallaecica, Fungi 156-166, Mykes 14: 87-89.

Requejo Martínez, O. 2010. Guía micolóxica do río Caselas. Concello de Salceda de Caselas (Pontevedra).

Ribes Ripoll, M.A. 2009. Setas de Tenerife 3. Micobotánica-Jaén Año 4, $\mathrm{N}^{\mathrm{o}} 4$, http://www.micobotanicajaen.com/Revista/Articulos/MARibes $R$ /Tenerife003/Tenerife003.html [consultado el 20-11-2016

RiBes Ripoll, M.A. en línea. Lachnum virgineum (Batsch) P. Karst. In http://www.micobotanicajaen.com/Revista/Articulos/MARibesR/Aportaciones008/La chnum\%20virgineum\%20010308\%20115.pdf [Consultado el 15/11/2016]

Ribes Ripoll, M.A. en línea. Lasiosphaeris hirsuta (Fr.) A.N. Mill. \& Huhndorf http://www.micobotanicajaen.com/Revista/Articulos/MARibesR/PirineoAragones001 /Lasiosphaeris\%20hirsuta\%20111009\%2037.pdf [Consultado el 27/02/2016] 
Richard, F., Moreau, P.A., Selosse, M.A. \& Gardes, M. 2004. Diversity and fruiting patterns of ectomycorrhizal and saprobic fungi in an old-growth Mediterranean forest dominated by Quercus ilex L. Canadian Journal of Botany 82: 1711-1729.

RIFAI, M.A. 1969. A revision of the genus Trichoderma. Mycol Pap. 116: 1-116.

RIVA, A. 2004. Tricholoma (Fr.) Staude. Fungi Europaei 3. Libreria editriche Giovanna Biella. Trento.

RoBICH, G. 2013. Mycena d'Europa. AMB. Trento.

RoBICH, G. 2016. Mycena d'Europa 2. AMB. Trento

Roca Romalde, J.C. 2002. Parque micolóxico do río Belelle. Deputación da Coruña.

Rocabruna, A. \& TABArÉs, M. 2003. Hongos nuevos o poco citados en Cataluña V. Rev. Cat. Micol.25:49-64.

RocabrunA, A. \& TABARÉs, M. 2011. Marasmiellus tricolor in Bolets de Calatunya. Colleció 28: $\mathrm{n}^{\circ}$ 1382. Societat Catalana de Micologia. Barcelona.

Rodríguez Guitián, M.A. \& Ramil-Rego, P. 2008. Fitogeografía de Galicia (NW Ibérico): análisis histórico y nueva propuesta corológica. Recursos Rurais 1(4): 19-50

Rodríguez-Tovar, A., Xocoostle-Cásarez, B. \& VAldÉs, M. 2004. Ecología molecular de los hongos ectomicorrízicos. Rev. Fitotec. Mex. 27(3): 267-278.

Rodríguez-VÁzquez, J. \& CAStro, M.L. 1996. Cogumelos dos piñeirais dunares do Baixo Miño. Monografías da Asociación Naturalista “Baixo Miño” 6: 1-42.

Rodríguez-VÁzQuez, J. \& CASTRO, M.L. 2001. Fragmenta chorologica occidentalia. Fungi 7700-7727. Ann. Jard. Bot. Madrid 59(1): 139-141.

Rodríguez-VÁzquez, J. \& CAStro, M.L. 2006. Algunhas novedades corolóxicas de macromicetos recolectados en Galicia (N.O. da Península Ibérica) (II). Mykes 9: 93 99.

Rodríguez-VÁzquez, J. \& CAStro, M.L. 2012. Algunhas novedades corolóxicas de macromicetos recolectados en Galicia (NO da Península Ibérica). Mykes 9: 93-99.

Rodríguez-VÁzquez, J. \& CAstro, M.L. 2016. Micobiota galega, 1867-2015 (Ascomycota, Basidiomycota). Documento preliminar para a base de datos micolóxica galega MICOBIOTAGALICIA.MDB. Ed. Grupo Micolóxico Galego in www.mykes.es/.../micobiotagalega 18672015.pdf [consultado 10/12/2016]

Romero PedreirA, D. 2015. Caracterización florística y fitoecológica de las turberas de las Sierras de Xistral y Ancares (NO de la Península Ibérica). Tesis Doctoral. Universidade da Coruña

Rubio Roldán, L. \& Rubio CASAs, L. 2010. Algunos Cantharellus interesantes de la Península Ibérica. Boletín informativo Sociedad Micológica Extremeña 10:31-40.

Rubio Domínguez, E. en línea. Annulohypoxylon stygium var. annulatum (Rehm) Y.M. Ju, J.D. Rogers \& H.M. Hsieh in http://www.asturnatura.com/especie/annulohypoxylonstygium-var-annulatum.html [consultado el 15-11-2016]. 
Rubio Domínguez, E. en línea. Coprinellus pallidissimus (Romagn.) P.Roux. in http://www.asturnatura.com/fotografia/setas-hongos/coprinellus pallidissimusromagn-1/24822.html [consultado 15-11-2016].

Rubio Domínguez, E. en línea. Gibellula pulchra Cavara in http://www.asturnatura.com/especie/gibellula-pulchra.html [consultado el $18 / 11 / 2016]$

Rubio Domínguez, E. en línea. Gibellula leiopus in http://www.asturnatura.com/fotografia/setas-hongos/gibellula-leiopus-vuill-exmaubl-mains-2/11727.html [consultado el 21-11-2016]

Rubio Domínguez, E. en línea. Inocybe napipes J.E.Lange in http:// www.asturnatura.com/fotografia/setas-hongos/inocybe-napipes-j-e-lange1/16448.html [consultado 28-08-2016].

Rubio Domínguez, E. En línea. in http://www.asturnatura.com/especie/nemaniaaureolutea.html [consultado el 20-11-2016]

Rubio Domínguez, E. (en línea) Rickenella mellea (Singer \& Clem.) Lamoure in http://www.asturnatura.com/especie/rickenella-mellea.html [consultado el 2-092016]

Rubio, E. \& Miranda, A. 2008. Exploración micológica en el Parque Natural de Somiedo (Asturias). 2a campaña. Basidiomycota (Agaricales s.1.). Bol. Soc. Mic. Madrid 32:157-211.

Rubio, E., Miranda, M.A., Linde, J., SÁnchez, J.A., Román, A., Menéndez, J.L., Delpont, M., Hairaud, M. \& Capoen, B. 2015. Adiciones al catálogo micológico del Parque Natural De Somiedo II. Bol. Soc. Mic. Madrid 39:163-194.

Rubio-Domínguez, E., SuÁrez, A., Miranda, M.A. \& Linde, J. 2006. Catálogo provisional de los macromicetos (setas) de Asturias. Real Instituto de Estudios Asturianos. Oviedo.

RudAWSKA, M. \& KieliszewSKA-RoKICKA, B. 1997. Mycorrhizal formation by Paxillus involutus in relation to their IAA-synthesizing activity. New Phytologist, 137:509517.

Samson, R.A. 1974. Paecilomyces and some allied Hyphomycetes. Studies in Mycology. 6:1-119.

Sanclemente, M.S. \& Llimona, X. 1987. Aportación al conocimiento de las tricolomatáceas de Cataluña. Rev. Soc. Cat. Micol.11:29-72.

Santamaría, A., Costa-Comelles, J., Alonso, A., Rodríguez, J.M. \& Ferrer, J. 1998. Ensayo del hongo entomopatógeno Beauveria bassiana (Balsamo) Vuillemin para el control de la mosca blanca de los cítricos Aleurothrixus floccosus (Maskell) (Homoptera: Aleyrodidae) y su acción sobre el parásito Cales noacki (Howard) (Hymenoptera: Aphelinidae). Bol. San. Veg. Plagas 24: 695-706

Salcedo, I., Melo, I. \& TelleríA, M.T. 2004. Bases corológicas de Flora Micológica Ibérica. Números 2179-2224. Cuad. Trab. Flora Micol. Ibérica 20: 17-54. 
SARNARI, M. 1998. Monografia illustrata del genere Russula in Europa I. AMB. Trento

SARNARI, M. 2005. Monografia illustrata del genere Russula in Europa II. AMB. Trento

Schmit, J.P. \& Lodge, D.J. 2005. Classical Methods and Modern Analysis for Studying Fungal Diversity. In Dighton J. White F.J. \& Oudemans P. (eds.). The Fungal Community: its organization and role in the ecosystem. CRC Press. Boca Raton (Florida): 193-214.

SeCRetaría de La CONVEnción De RAmSAR 2006. Manual de la Convención de Ramsar: Guía a la Convención sobre los Humedales (Ramsar, Irán, 1971), 4a. edición. Secretaría de la Convención de Ramsar, Gland (Suiza).

Senn-Irlet, B. 1995. The genus Crepidotus (Fr.) Staude in Europe. Persoonia 16(1):1-80.

SHIVA, M.P. \& VERMA, S.K. (eds.). 2002. Approaches to sustainable forest management and biodiversity conservation. International Books Distributors. Uttaranchal (India).

Silva-Pando, F.J., García Martínez, X.R. \& Valdés-Bermejo, E. 1987. Vegetación de las Gándaras de Budiño. Diputación de Pontevedra.

Sobrado Maestro, C. 1909. Datos para la flora micológica gallega. Bol. Real Soc. Esp. Hist. Nat. 9: 345-348.

Soliño, A., Justo, A. \& CAStro, M.L. 1999. Recopilación bibliográfica (1850-1997) de citas macromicolóxicas de Galicia I: ordes Agaricales, Auriculariales, Boletales e Cantharellales. Mykes 2: 3-73

SoliÑo, A., Justo, A. \& CASTRO, M.L. 2000. Recopilación bibliográfica (1850-1997) de citas macromicolóxicas de Galicia II: Basidiomycota (non Agaricales, Auriculariales, Boletales e Cantharellales) e Ascomycota. Mykes 3: 3-72.

StANGL, J. 1991. Guida alla determinazione dei fungi Vol. 3. Inocybe. Saturina. Trento.

SuÁrez, E. \& SuÁrez Gracia, D. 2012. Adiciones al catálogo corológico de los macromycetos de la provincia de Teruel IV. Bol. Soc. Mic. Madrid 36:143-162.

Tabarés, M. \& Pascual, R. 1987. Bolets de Catalunya. Sociedad Catalana de Micologia. Lámina 286 Collecció 06.

TABARÉs, M. \& Rocabruna, A. 1998. Aportación al conocimiento de los hongos de la sierra de la Collserola (III). Rev. Cat. Mic. 21:171-183.

Tabarés, M. \& Rocabruna, A. 1991. Aportación al conocimiento de los hongos de la sierra de la Collserola (II). Rev. Cat. Micol. 14.15:87-98.

Tabarés, M. \& Rocabruna, A. 2007. Fongs nous o poc citats a Catalunya IX. Rev. Cat. Micol. 29: 35-44.

TelleríA, M.T. 1990 [1989]. Fragmenta chorologica occidentalia, Fungi, 2450-2472. Ann. Jard. Bot. Madrid 47(2): 461-463.

TelleríA, M.T. (ed.) (1991) Bases corológicas de Flora Micológica Ibérica, $\mathrm{n}^{\mathrm{OS}}$ 1-132 in Cuadernos de Trabajo de Flora Micológica Ibérica 3: 1-188. 
Tellería, M.T. (ed.) 1992. Bases corológicas de Flora Micológica Ibérica. Números 133249. Cuad. Trab. Flora Micol. Ibérica 4: 1-208.

Tellería, M.T. (ed.) 1993. Bases corológicas de Flora Micológica Ibérica. Números 250375. Cuad. Trab. Flora Micol. Ibérica 6: 1-180.

Tellería, M.T. Melo, I. \& Salcedo, I. 1991. Bases corológicas de Flora Micológica Ibérica. Números 1-132. Cuad. Trab. Flora Micol. Ibérica 3: 1-188.

Tóth, B.B. \& FEEST, A. 2007. A simple method to assess macrofungal sporocarp biomass for investigating ecological change. Canadian Journal of Botany 85(7): 652-658.

Traba Velay, J.M. 2013. Algunas especies interesantes del género Russula recolectadas en el entorno del río Lambre, A Coruña. Tarrelos 15: 22-28.

TulLoss, R.E. 2005. Amanita distribution in the Americas with comparison to eastern and southern Asia and notes on spore character variation with latitude and ecology. Mycotaxon 93: 189-231.

Tzean, S.S., Hsien, L.S. \& Wu, W.J. 1997. The genus Gibellula on spiders in Taiwan. Mycologia 89 (2): 309-318.

UlJÉ, C. B. 2005. Coprinus Pers. In: Noordeloos M. E., Kuyper T. W. and Vellinga E. C. Flora Agaricina Neerlandica, Vol. 6. Taylor \& Francis Group. Boca Raton.

Vellinga, E.C. 2001. Leucoagaricus (Locq. Ex) Sing. in Noordeloos, M.E. Kuyper, Th.W. \& Vellinga, E.C. (ed.) Flora Agaricina Neerlandica 5. A.A. Balkema. Rotterdam.

VIDAL, J.M. 1989a. Crepidotus mollis var. calolepis in Bolets de Calatunya. Colleció 8: $\mathrm{n}^{\circ}$ 363. Societat Catalana de Micologia. Barcelona.

VIDAL, J.M. 1989b. Lachnum virgineum in Bolets de Calatunya. Colleció 8: no 373. Societat Catalana de Micologia. Barcelona.

VIDAL, J.M. \& Tabarés M. 1992. Calyptella capula in Bolets de Calatunya. Colleció 11: $\mathrm{n}^{\circ}$ 504. Societat Catalana de Micologia. Barcelona.

VILA, J. 1999. Alnicola scolecina in Bolets de Calatunya. Colleció 18: $\mathrm{n}^{\circ} 851$. Societat Catalana de Micologia. Barcelona.

VILA, J. \& Caballero F. 2009. Entoloma nuevos o interesantes de la Península Ibérica (2). Fungi non delineati Pars XLV. Edizioni Candusso. Alassio.

Vila, J., Rocabruna, A., Llistosella, J., Tabarés, M., Llimona, X \& Hoyo, P. 1997. Fongs nous o poc citats de Catalunya I. Andorra II. Rev. Cat. Micol. 20: 105-24.

Villareal, M., Heykoop, M., Esteve-Raventós, F. \& Maas Geesteranus, R.A. 1998. Further new species of Mycena and a new section from Spain. Persoonia 16(4):527535 .

Villeneuve, N., Grandtner, M.M. \& Fortin, J.A. 1991. The study of macrofungal communities: defining adequate sampling units by means of cluster analysis. Vegetatio 94: 125-132. 
WANG, B. \& QIU, Y.L. 2006. Phylogenetic distribution and evolution of mycorrhizas in land plants. Mycorrhiza 16: 299-363

WANG, Z., DAi, Y.C. \& HibBett, D.S. 2004. Phylogenetic relationships of Sparassis inferred from nuclear and mitochondrial ribosomal DNA and RNA polymerase sequences. Mycologia 96 (3): 1015-1029.

Webster, J. \& Rifai, M.A. 1968. Culture studies on Hypocrea and Trichoderma. Trans. Brit. Mycol. Soc. 51: 511-514 


\section{AGRADECIMIENTOS}

Los autores agradecen a todas aquellas personas que acompañaron en los muestreos de campo y/o aportaron material a este trabajo, N. Floro Andrés, Cesar Ayres, Rafael Estévez, José Álvarez Gándara, Marta Martínez Lago, Gonzalo Requejo, Roberto Requejo y Pablo Veiga Mínguez.

Por su ayuda en la recopilación bibliográfica e identificación de algunos taxones, a los Dres. A. Justo, con el género Pluteus, P.A. Moreau con el género Naucoria, a N. Heine con Arnium olerum, a J. Rodríguez Vázquez con las citas de la micobiota gallega y, a Manuel Domínguez Rey por sus comentarios y compartir sus conocimientos sobre los humedales. A Carlos Sanchidrián Gracía por la foto aérea de la ZEC.

También agradecer el apoyo y ayudas prestadas a los miembros del Grupo Micológico Gallego, Sociedade Galega de Historia Natural, Asociación Herpetológica Española, Verdegaia y ACDE Trezecatorze.

Por último, agradecer a Julio Valeiras, Ester Abad Casas y a todo el equipo de Valoranatura (Proyecto Valoranatura, Gándaras de Budiño) por su desinteresada colaboración en todo momento y por el excelente trabajo que permite poner en valor esta ZEC. 


\section{INDICE DE ESPECIES}

acicula Mycena 114 actiniceps Chaetotyphula 61 adscendens Mycena 122 aenea Nemania 39 aenea var. aureolutea Nemania 39 aenea var. macrospora Nemania 39 aeneum Hypoxylon 39

Boletus aestivalis 54 alba Mycena 130 alba Phloeomana 101 albida Antrodia 52 albonigra Russula 140 algeriensis Mycena 114 alni Oligoporus 127 alni Postia 127 alniella Pezizella 42 amanitae Collybia 65 amenti Cyathicula 31 amenti Peziza 31 amenti Pezizella 31 amethysteus Cantharellus 57 amethystina Laccaria 97 amicta Mycena 115 amoena Russula 140 amoenicolor Russula 140 amoenolens Russula 140 androsaceus Gymnopus 83 androsaceus Marasmius 83 androsaceus Setulipes 83 angustispora Hemimycena 86 anomalus Cortinarius 69 anomalus Marasmius 112 antillarum Panaeolus 127 applicatus Resupinatus 137 arachnophila Cordyceps 45 arachnophila Torrubiella 45 aranicida Torrubiella 45 arcularius Lentinus 133 arcularius Polyporus 133

areolatum Scleroderma 148

arhizus Pisolithus 132

arvensis Agaricus 48

aspideus Lactarius 100

asterospora Inocybe 93

atra Helvella 34

atropurpurea Russula 141

atrotomentosa Tapinella 153

atrotomentosus Paxillus 153

atrovinosa Mycena 115

augustus Agaricus 48

aurantia Aleuria 26

aurantiaca Hygrophoropsis 89

aurantiaca Stropharia 105

aurantius Hypomyces 35

australe Ganoderma 81

babingtonii Adelphella 26

babingtonii Pachyella 26

badia Imleria 93

badius Boletus 93

badius Xerocomus 93

bassiana Beauveria 28

betulina Lenzites 104

bibulus Cortinarius 69

biennis Abortiporus 48

birnbaumii Leucocoprinus 108

bovinus Suillus 153

bovista Scleroderma 149

brachypodii Conocybe 66 bulliardii Marasmius 112 butyracea Rhodocollybia 138 caerulea Russula 141 caerulea Terana 154 calamistrata Inocybe 93 calolepis Crepidotus 72 calva Mucronella 113 calyptrata Galerina 80 
campanula Calyptella 57

campestris Agaricus 48

candida Aegerita 55

candidus Marasmiellus 110

candolleana Psathyrella 135

capillaripes Mycena 115

capillipes Marasmius 74

capula Calyptella 57

caspari Crepidotus 72

castaneus Gyroporus 85

catinus Tarzetta 44

cejpii Scutellinia 43

cepa Scleroderma 149

ceres Leratiomyces 105

cesatii Crepidotus 72

cetratum Entoloma 76

chalybeum Entoloma 77

chalybeum var. lazulinum Entoloma 77

chloroides Russula 141

chrysenteron Xerocomellus 160

chrysenteron Xerocomus 160

chrysolitus Cortinarius 70

cibarius Cantharellus 58

cibarius var. pallidus Cantharellus 58

cinerea Clavulina 62

cinnamomea Coltricia 65

cirrhata Collybia 65

citrina Amanita 49

citrina Bisporella 29

citrinum Scleroderma 149

clavariarum Helminthosphaeria 33

clavus Cudoniella 30

coeruleum Pulcherricium 154

comatus Coprinus 68

commune Schizophyllum 148

conchatus Panus 128

conferendum Entoloma 77

conferendum var. pusillum Entoloma 77

conica Hygrocybe 88

conspersa Tubaria 157 contorta Typhula 158

controversus Lactarius 100

coprophila Psilocybe 137

corallina Typhula 158

coralloides Clavulina 62

cornea Calocera 56

corynephora Mycena 116

crassa Lopharia 130

crassa Phlebiopsis 130

crassum Porostereum 130

crispa Sparassis 151

cristata Clavulina 62

cristata Lepiota 105

crocophyllus Crepidotus 73

cucumis Macrocystidia 110

cyanoxantha Russula 142

cyathuliformis Lactarius 101

cystidiatus Clitopilus 64

deformis Nidularia 126

deliciosus Lactarius 101

densifolia Russula 142

disseminatus Coprinellus 66

disseminatus Coprinus 66

domiciliana Peziza 41

dryophilus Gymnopus 84

echinella Lepiota 105

edulis Boletus 54

elegans Mutinus 114

elongatum Hypholoma 90

emetica Russula 142

epibryus Crepidotus 73

epigaea Sebacina 150

epiphylloides Marasmius 112

epipterygia Mycena 116

epodius Marasmius 112

equestre Tricholoma 155

ericaeoides Hypholoma 91

ericaeum Hypholoma 92

erythropus Boletus 54

erythropus Gymnopus 84 
erythropus var. junquilleus Boletus 126 gra escharioides Alnicola 123

escharioides Naucoria 123

evernius Cortinarius 70

excelsa Amanita 49

farcta Nidularia 126

farinosa Isaria 36

farinosa Propolis 42

farinosus Bulbillomyces 55

farinosus Paecilomyces 36

fasciculare Hypholoma 92

fasciculare var. pusillum Hypholoma 92

ferruginascens Cantharellus 58

fibula Rickenella 138

firma Rutstroemia 43

fistulosa var. contorta Macrotyphula 158

flaccida Paralepista 128

flaccida Lepista 128

foetidum Micromphale 84

foetidus Gymnopus 84

foetidus Marasmius 84

fractipes Abortiporus 109

fractipes Loweomyces 109

fractipes Spongipellis 109

fragrans Lanmaoa 103

fragrans Russula 143

fragrans Boletus 103

fragrantissima Russula 143

fulva Amanita 49

furfuracea Tubaria 157

fuscum Hypoxylon 35

galericulata Mycena 116

gallica Armillaria 53

galopus Mycena 117

gausapatum Stereum 151

gemmata Amanita 50

glandulosa Exidia 79

gossypina Psathyrella 159

gossypina Typhrasa 159

graminum Marasmius 113 granulatus Elaphomyces 31

gummosa Pholiota 131

helveticus Chroogomphus 61

hepatica Fistulina 79

hepatochrous Melanotus 75

heptemerus Coprinellus 67

heptemerus Coprinus 67

herbarum Hymenoscyphus 35

hiemalis Tubaria 157

himantioides Serpula 151

hirsuta Lasiosphaeris 38

hirsuta Trametes 154

hirsutum Stereum 152

hongoi Pluteus 132

horizontalis Deconica 75

horizontalis Melanotus 75

howeanum Hypoxylon 36

huronensis var. olivaceus Cortinarius 70

hygrometricus Astraeus 54

hypothejus Hygrophorus 90

hypoxylon Xylaria 46

impolita Laccaria 97

integrella Delicatula 76

integrella Mycena 76

involutus Paxillus 129

joachimii Tricholoma 156

jubilaei Leucocoprinus 108

junonius Gymnopilus 82

junquilleus Neoboletus 126

laccata Laccaria 98

laccata var. pallidifolia Laccaria 98

lacera Inocybe 94

lacrymabunda Lacrymaria 99

lacunarum Lactarius 102

lacunosa Helvella 34

laeve Crucibulum 74

laeve Cyphellosterum 113

laevis Muscinupta 113

lateritium Hypholoma 92

leptocephala Mycena 117 
leucothites Leucoagaricus 106

lividus Gyrodon 85

longipes Xylaria 47

lubrica Leotia 38

lucidum Ganoderma 81

luteolus Rhizopogon 138

luteo-olivaceum Callistosporium 56

lundellii Crepidotus 72

macropus Helvella 34

maculata Descolea 76

maculata var. occidentalis Descolea 76

maculata Inocybe 94

mairei Amanita 50

mammiforme Hypoxylon 43

mammiformis Rosellinia 43

marginata Galerina 80

medullata Russula 144

melanoxeros Cantharellus 59

meleagris Leucoagaricus 106

meliigena Mycena 117

mellea Rickenella 139

melzeri Russula 144

meridionalis Cerioporus 60

meridionalis Polyporus 60

mesenterica Tremella 155

mesophaeum Hebeloma 85

metata Mycena 118

micaceus Coprinellus 67

micaceus Coprinus 67

miniata Hygrocybe 89

minutula Russula 144

minutus Cryptomarasmius 74

minutus Marasmius 74

mirata Mycena 118

mollis Cerioporus 60

mollis Datronia 60

mucor Mycena 118

mucosus Cortinarius 70

muscigena Arrhenia 113

napipes Inocybe 94 nebularis Clitocybe 63

necator Lactarius 102

nigricans Russula 145

nothopellitus Pluteus 132

nuda Lepista 105

ochracea Trametes 154

ochraceoflavum Stereum 152

ochroalba Inocybe 95

ochroleuca Russula 145

olerum Arnium 28

olivascens Mollisia 38

ophioglossoides Cordyceps 45

ophioglossoides Elaphocordyceps 45

ophioglossoides Tolypocladium 45

pallidissimus Coprinellus 67

pallidissimus Coprinus 67

pantherina Amanita 51

papilionaceus Panaeolus 128

parasitica Asterophora 53

parasiticus Pseudoboletus 136

parasiticus Xerocomus 136

penetrans Gymnopilus 82

perelegans Haglundia 38

perlatum Lycoperdon 109

phacorrhiza Typhula 159

phaeodisca Inocybe 95

phlebophorus Pluteus 133

picreus Gymnopilus 83

pilatianus Leucoagaricus 107

pilosella Mycena 119

pilulifera Hypocrea 46

piluliferum Trichoderma 46

pini Phellinus 135

pini Porodaedalea 135

piperatus Chalciporus 61

plautus Pluteus 133

podospileus Pluteus 133

poliocnemis Pluteus 134

polyarthra Cordyceps 30

polyrhizum Scleroderma 150 
porosporus Xerocomellus 161 porosporus Xerocomus 161 portentosum Tricholoma 156 praetervisa Inocybe 96 praetervisa Russula 145 pratense Lycoperdon 110 proxima Laccaria 98 prunulus Clitopilus 64 pseudoaeruginea Russula 146 pseudocorticola Mycena 120 pseudofriesii Coprinopsis 68 pseudofriesii Coprinus 68 pseudominimus Cantharellus 59 pulchella Ramariopsis 137 pulchellus Cortinarius 69 pulchra Gibellula 33 pumila Laccaria 98 punctata Fomitiporia 80 punctatus Phellinus 80 pura Mycena 120 quaternata Eutypella 32 quaternata Quaternaria 32 queletii Paxina 40 queletii Helvella 40 quercina Diatrypella 31 quietus Lactarius 102 quisquiliaris Typhula 159 radiata Mensularia 160 radiata Xanthoporia 160 repandum Hydnum 88 resinaceum Ganoderma 81 reticulatus Boletus 54 revincta Mollisia 42 revincta Pyrenopeziza 42 rhodocylix Entoloma 78 ripariellus Xerocomellus 160 ripariellus Xerocomus 160 romagnesianus Cantharellus 59 rorida Mycena 139 roridus Roridomyces 139 roseus Gomphidius 82

rotula Marasmius 113

rubellus Hortiboletus 88

rubellus Xerocomellus 88

rubellus Xerocomus 88

rubescens Amanita 51

rubiginosa Hymenochaete 90

rubromarginata Mycena 120

rufa Phlebia 130

rugosa Clavulina 63

rutilans Tricholomopsis 157

rutilus Chroogomphus 62

salicicola Hebeloma 86

salicis Inocybe 96

sanguinolenta Mycena 120

saponaceum Tricholoma 156

sarcitum Entoloma 78

sarcoides Ascocoryne 28

sardonia Russula 146

saturninus Cortinarius 71

schiedermayeriana Byssosphaeria 29

schweinitzii Phaeolus 129

scirpicola Mycena 121

scolecina Alnicola 124

scolecina Naucoria 124

scoparia Peroneutypa 40

scrobiculatum Hydnellum 88

scutellata Scutellinia 44

semisanguineus Cortinarius 71

seynii Mycena 121

sinapizans Hebeloma 87

sinuosus Pseudocraterellus 136

sordidulum Entoloma 79

spadiceogrisea Psathyrella 136

spectabilis Gymnopilus 82

speirea Mycena 131

speirea Phloeomana 131

sphagnophila Russula 146

sphinctrinus Panaeolus 128

splendens Inocybe 96 
striatus Cyathus 75

stygium Annulohypoxylon 27

stygium Hypoxylon 27

stylobates Mycena 122

subcaesia Postia 135

subcaesius Tyromyces 135

subconspersa Alnicola 125

subconspersa Naucoria 125

subfoetens Russula 147

sublateritium Hypholoma 92

subtomentosus Boletus 55

subtomentosus Xerocomus 55

subumbonatus Lactarius 103

subvermispora Ceriporiopsis 60

subvermispora Fibuloporia 60

subvermisporus Tyromyces 60

succosa Peziza 41

sulphureus Laetiporus 103

tenerrima Mycena 122

tenuipes Isaria 30

tenuis Geopora 32

tenuissimum Lachnum 37

tenuissimus Dasyscyphus 37

tigrinus Lentinus 104

tortilis Laccaria 99

tremellosa Phlebia 129

tremellosus Merulius 129

tricolor Marasmiellus 111

tubaeformis Cantharellus 71

tubaeformis Craterellus 71

tuberaster Polyporus 134

tuberculosa Pholiota 132

turpis Lactarius 102

uda Mycoacia 123

umbrina Alnicola 125

umbrina Naucoria 125

umbrinum Lycoperdon 110

undulatus Pseudocraterellus 136

unguicularis Hohenbuehelia 87

vaginata Amanita 52 vaillantii Marasmiellus 111

variabilis Crepidotus 73

variicolor Leccinum 104

velutina Lacrymaria 99

velutipes Arrhenia 53

verrucosum Scleroderma 150

versicolor Propolis 42

versicolor Trametes 155

versicolor Xerocomus 88

vibecina Clitocybe 64

violacea Ombrophila 40

virescens Russula 148

virgineum Lachnum 37

viridifusca Ciboria 29

viscosa Calocera 56

vitilis Mycena 123

xanthophyllum Callistosporium 56 
La Zona de Especial Conservación (ZEC) Gándaras de Budiño está situada en el suroeste de la provincia de Pontevedra (Galicia, Península Ibérica). A pesar de las agresiones sufridas a lo largo de la historia, aún se conservan zonas muy representativas de esta con fauna y flora propia de estos lugares y poco frecuente en el resto del N.O. peninsular.

Ocupa una extensión de aproximadamente 800 ha, en las que destacan un amplio complejo de humedales, conformados por turberas, brañas, bosques aluviales y lagunas, así como brezales atlánticos, bosques de ribera y amplias extensiones más secas, constituidas básicamente por bosques mixtos de robles y pinos.

En este espacio se realiza un estudio micológico con recolecciones periódicas durante 4 años, de las cuales resulta un catálogo con 359 taxa, con una aportación al catálogo gallego de 62 especies.

Entre ellas destaca Chaetotyphula actinipes, que se menciona por primeravez para Europa, además de Arnium olerum, Byssosphaeria schiedermayeriana, Conocybe brachypodii, Cordyceps polyarthra, Hemimycena angustispora, Inocybe salicis, Laccaria impolita, Mollisia olivascens, Mycena atrovinosa, Mycena mucor, Oligoporus alni, Russula sphagnophila y Trichoderma piluliferum, no mencionados anteriormente para la Península Ibérica.

Desde el punto de vista de la estrategia trófica destacan las especies entomapatógenas: Beauveria bassiana, Cordyceps polyarthra, Gibellula pulchra, Isaria farinosa y Torrubiella arachnophila. De las restantes 125 son micorrícicas, 211 son saprotróficas y 38 necrotróficas, en ambos casos, mayoritariamente lignícolas, justificado porque las 3/4 partes del material ha sido recolectado en formaciones arbóreas de Alnus glutinosa y Salix atrocinerea.

Además, se analiza la autoecología de las especies, los patrones de fructificación y su aportación corológica, tanto ibérica como mundial.

ISSN: 1135-7924

elSSN: 2444-359X
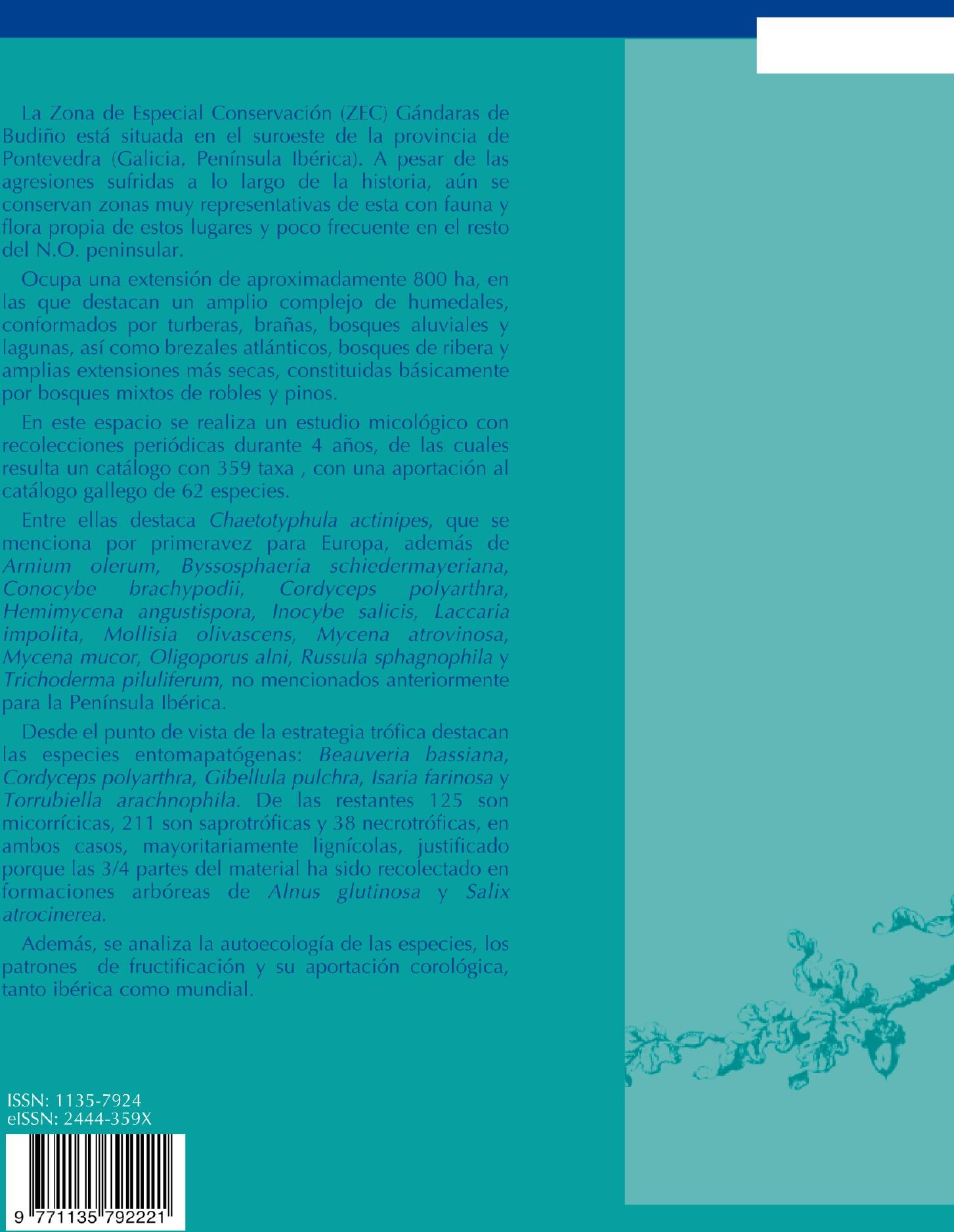